\title{
Tensions and Possibilities
}

The Interplay of 'Traditional' Cultural Elements and the Creation of 'Contemporary' Rapanui, Māori and Samoan diasporic Theatre

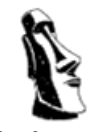

He Moto, He Koa

Te Hakapiri o te Haka Ara e te Api ki te Ana o te A'amu Api ki Rapanui, Māori e ko Sāmoa

\author{
as \\ Tensiones y Posibilidades \\ La Integración de Elementos Culturales 'Tradicionales' en la Creación \\ 'Contemporánea' de Teatro Rapanui, Māori y diasporico Samoano
}

Moira Sofia Fortin Cornejo

\begin{abstract}
A thesis
submitted to the Victoria University of Wellington

in fulfilment of the requirements for the degree of

Doctor of Philosophy
\end{abstract}

Victoria University of Wellington

2016 


\section{Abstract}

This thesis focuses on notions of 'traditional' and 'contemporary' theatre in two Pacific Island contexts, Aotearoa and Rapa Nui. It explores how notions of 'tradition' are imagined, recreated, and performed through the 'contemporary' creative arts, with a particular focus on theatre. It offers insight about culturally-situated understandings of 'tradition', and seeks to acknowledge diverse meanings and perceptions of theatre that exist across diverse Pacific Island cultures, languages, and epistemologies.

Ideas about what constitutes 'tradition' have been significantly impacted by colonial histories, and that these culturally and historically situated ideas have wide-ranging implications for creative possibilities in the 'contemporary' performing arts. 'Traditional' performances are often seen as acceptable and relevant to Indigenous communities in Aotearoa and Rapa Nui, contributing to processes of cultural reclaiming and revitalisation. Although cultural continuity is a significant theme in Indigenous theatre in Aotearoa and Rapa Nui, the different emphasis placed upon notions of 'tradition' across these comparative contexts has led to very different artistic possibilities being available. In Rapa Nui there is a general reluctance in the performing arts to deviate from 'tradition' or to declare work as 'contemporary.' The reproduction of 'traditional' styles and stories is one response to ongoing colonialism in Rapa Nui, and to the ever present demands of the tourist industry.

Māori and Samoan theatre practitioners in Aotearoa have developed theatre forms and processes that are based in cultural values and epistemologies while also being integrated with European theatre techniques, creating innovative approaches to 'contemporary' themes and understandings. These developments in the creative arts are supported by the availability of a wide range of theatre education opportunities. Culturally reflective and situated approaches to theatre education have enabled Indigenous theatre practitioners in Aotearoa to use theatre as a forum to express ideas and issues to the community weaving in a variety of different cultural influences, and techniques.

This thesis utilised a case-study methodology and open-ended interviews, framed under the research methodology of talanoa, to interact with Māori, Samoan diasporic and Rapanui theatre practitioners, in order to explore their perceptions towards 'traditional' and 'contemporary' practices. This research focuses on the positives of cultural dialogue, and it emerges from a desire to support intercultural theatre practices in Aotearoa and Rapa Nui. 


\section{Acknowledgments}

To my parents Juan Fortin and Sylvia Cornejo for their support

To A. Prof. David O’Donnell and Dr. April Henderson, my supervisors

To the Victoria University Research Support Grant Committee

To Michele Fontana, Sally Richards, and the fellow PhD candidates from the 310 office

To Dr. Tui Nicola Clery for both inspiration and reading the manuscript

To all the interviewees: Iaheto Ah Hi, Marlene Alfaro, Magdalena Amenábar, Tiare Iti Araki, Marisol Araki, Ana Maria Arredondo, Barbara Barriga, Sean Coyle, Pablo Fortin, Victoria Fuentealba, Miria George, Hilary Halba, Virginia Haoa, Puaru Hotus, Julio Hotus, Marta Hotus, Karlo Huke, Pamela Huke, Nicola Hyland, Patricia Iturbe, Hone Kouka, Carlos Lillo, Tupe Lualua, Cristian Paoa, Vela Manusaute, Rua McCallum, Vai Tiare Merino, Cristian Moreno, Mishelle Muagututi‘a, Tanya Muagututi‘a, Macarena Oñate, Felipe Pakarati, Miriam Pakarati, Tuvalu Pate, Taofia Peleasa, Anapela Polataivao, Angie Pont, Claudia Quiroga, Vai a Heva Rapu, Lynn Rapu, Katherine Ringeling, Rangimoana Taylor, Kereama Te Ua, Mahani Teave, Barbara Tramon, Gabriel Tramon, Bendicto Tuki, Andrea Ubal, Makerita Urale, Alexei Vergara, Isabel Vilches, Mario Villanueva, Annette Zamora.

\section{Mauru'uru}

Ki to'oku matua tane Juan Fortin e to'oku matua vahine Sylvia Cornejo

Kia A. Prof. David O’Donnell e ko Dr. April Henderson to‘oku maori rara

Ki te tayata ta'ato'a o te Victoria University Research Support Grant

Kia Michele Fontana, Sally Richards e korua ta'ato'a ki te piha 310

Kia Dr. Tui Nicola Clery o te vanayanaya, ki tai`o te papa'i rae

Kia korua ta'ato'a i ha'u'u mai i te ana papa'i nuinui nei: Iaheto Ah Hi, Marlene Alfaro, Magdalena Amenábar, Tiare Iti Araki, Marisol Araki, Ana Maria Arredondo, Barbara Barriga, Sean Coyle, Pablo Fortin, Victoria Fuentealba, Miria George, Hilary Halba, Virginia Haoa, Puaru Hotus, Julio Hotus, Marta Hotus, Karlo Huke, Pamela Huke, Nicola Hyland, Patricia Iturbe, Hone Kouka, Carlos Lillo, Tupe Lualua, Cristian Paoa, Vela Manusaute, Rua McCallum, Vai Tiare Merino, Cristian Moreno, Mishelle Muagututi ‘a, Tanya Muagututi'a, Macarena Oñate, Felipe Pakarati, Miriam Pakarati, Tuvalu Pate, Taofia Peleasa, Anapela Polataivao, Angie Pont, Claudia Quiroga, Vai a Heva Rapu, Lynn Rapu, Katherine Ringeling, Rangimoana Taylor, Kereama Te Ua, 
Mahani Teave, Barbara Tramon, Gabriel Tramon, Bendicto Tuki, Andrea Ubal, Makerita Urale, Alexei Vergara, Isabel Vilches, Mario Villanueva, Annette Zamora.

\section{Agradecimientos}

A mis padres Juan Fortin y Sylvia Cornejo por su constante apoyo

A A. prof. David O’Donnell y a Dr. April Henderson mis supervisores

Al comite del Victoria University Research Support Grant

A Michele Fontana, Sally Richards y a todos los candidatos a Doctor de la oficina 310

A Dr. Tui Nicola Clery por sus comentarios inspiradores y por leer el borrador de esta tesis

A todo los que de una u otra forma participaron y colaboraron en esta investigación:

Iaheto Ah Hi, Marlene Alfaro, Magdalena Amenábar, Tiare Iti Araki, Marisol Araki, Ana Maria Arredondo, Barbara Barriga, Sean Coyle, Pablo Fortin, Victoria Fuentealba, Miria George, Hilary Halba, Virginia Haoa, Puaru Hotus, Julio Hotus, Marta Hotus, Karlo Huke, Pamela Huke, Nicola Hyland, Patricia Iturbe, Hone Kouka, Carlos Lillo, Tupe Lualua, Cristian Paoa, Vela Manusaute, Rua McCallum, Vai Tiare Merino, Cristian Moreno, Mishelle Muagututi'a, Tanya Muagututi'a, Macarena Oñate, Felipe Pakarati, Miriam Pakarati, Tuvalu Pate, Taofia Peleasa, Anapela Polataivao, Angie Pont, Claudia Quiroga, Vai a Heva Rapu, Lynn Rapu, Katherine Ringeling, Rangimoana Taylor, Kereama Te Ua, Mahani Teave, Barbara Tramon, Gabriel Tramon, Bendicto Tuki, Andrea Ubal, Makerita Urale, Alexei Vergara, Isabel Vilches, Mario Villanueva, Annette Zamora. 


\section{Table of Contents}

Abstract...................................................................................2

Acknowledgments - Mauru'uru -Agradecimientos................................3

Table of Contents....................................................................................... 5

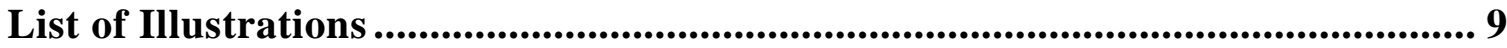

Seed - Karu - La Semilla ........................................................................ 10

Chapter One: Introduction - He Ha'a Mata - Vamos Viendo Dijo el Ciego.........11

1.1 Introduction ............................................................................................ 11

1.1.1 Exploring the Construction of the 'Traditional' and the 'Contemporary:' Implications and Consequences for Cultural Creativity .................................... 18

1.1.2 Research Background ................................................................................... 19

1.1.3 Locating the Researcher: Place, Voice and Positionality ......................... 22

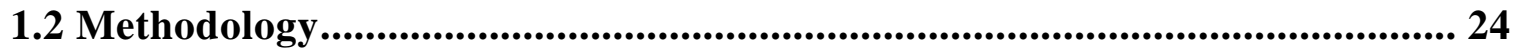

1.2.1 Combining Research Methods ................................................................ 24

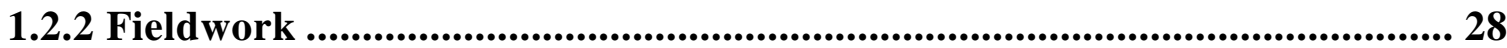

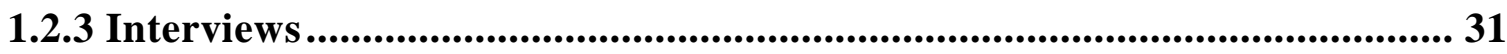

1.2.4 The Use of Three Languages ....................................................................... 32

1.3 Chapter Outline ............................................................................................... 33

Chapter Two: Histories and Relationships - He A'amu o te Hakapiri - De a dos se Baila el Tango ..................................................................36

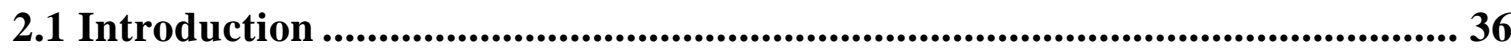

2.2 The Relationship between Rapa Nui and Chile............................................... 38

2.2.1 The Influence of Oral Narratives on Rapanui Theatre ............................... 39

2.2.2 Rapa Nui, Social Change, and the ongoing impacts of Encounters with European Explores ......................................................................................... 40

2.2.3 Isla de Pascua, a Chilean Colony in the Pacific .......................................... 42

2.2.4 The Modernisation of Rapa Nui and Influences on Rapanui Performing Arts ......................................................................................................................... 45

2.3 Relationship between Māori Peoples and New Zealand ............................... 49

2.3.1 The influence of Oral Narratives in Contemporary Māori Theatre

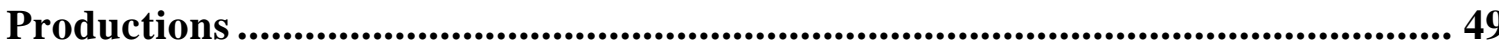


2.3.2 Historical Influences on the Production of Contemporary Māori

Theatre..

2.3.3 Institutional and Structural Support for the Performing Arts in Aotearoa:

Developing Māori Methodologies for Theatre Training and Practice................. 54

2.4 Samoan Migration to Aotearoa ................................................................... 56

2.4.1 Oral Tradition and Samoan Theatre in Aotearoa........................................ 56

2.4.2 The Influence of Christian Missionaries on Samoan Theatre

Productions 57

2.4.3 The Samoan Colonial Era: Inspiring Theatre Productions in Aotearoa ... 58

2.4.4 Samoan Migration to Aotearoa 60

2.4.5 Tertiary Education and the Samoan Community in Aotearoa. 62

2.5 Comparing Histories and Theatre Productions from Three Different Pacific Cultures in Two Different Contexts 63

2.5.1 The Influence of History on Contemporary Theatre Production ............... 63

2.5.2 Governmental Support for the Development of the Creative Arts 65

2.5.3 Cultural Encounters with Polynesian Peoples and their Influence on the Rapanui Creative Arts 67

2. 5.4 Cultural Encounters in Aotearoa and their Influence on the Creative Arts 69

2.5.5 Theatre Training in Two Different Contexts ......................................... 71

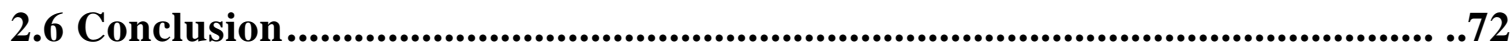

Chapter Three: Theoretical Framework - Hai Aha He Anga Te Me'e Nei - Al Pan Pan y al Vino Vino ............................................................74

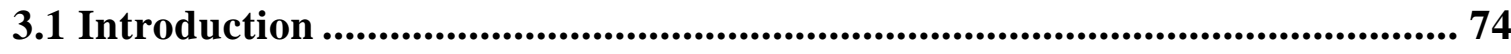

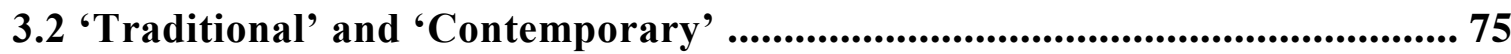

3.3 Intercultural exchanges within Theatre Practice .......................................... 86

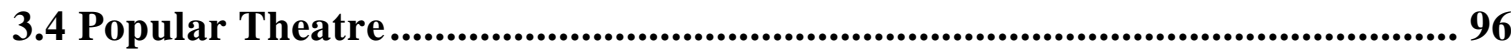

3.5 Community Theatre .................................................................................103

3.6 Touristic Performances ......................................................................110

3.7 Conclusion .....................................................................................................117

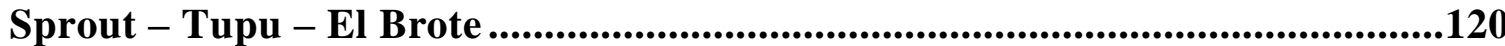

Chapter Four: Historical Development of Rapanui, Māori_and Samoan Diasporic Theatre - Hakaara o te a'amu o Rapa Nui, Māori_e Sāmoa - De Tal Palo Tal Astilla 
4.1 Introduction 121

4.2 Historical Development of Rapanui Theatre ..............................................122

4.2.1 Rapanui Theatre: Case Studies............................................................140

4.2.2 Hetereki A Rau Nui ..............................................................................141

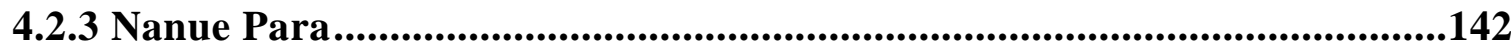

4.3 Historical Development of Māori Theatre.......................................................146

4.3.1 Māori Theatre: Case Studies.......................................................................1632

4.3.2 Maui: One Man against the Gods ....................................................1632

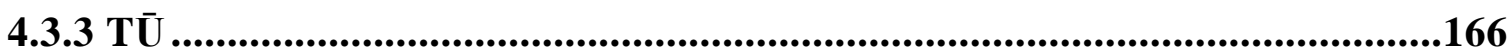

4.4 The Historical Development of Samoan Theatre in Aotearoa .....................1698

4.4.1 Samoan Diasporic Theatre: Case Studies...........................................1843

4.4.2 Fresh Off the Boat .....................................................................................1843

4.4.3 Frangipani Perfume.......................................................................1876

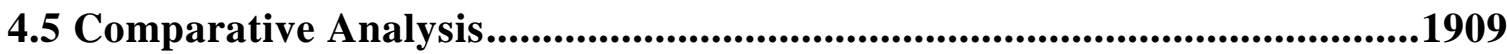

4.5.1 Comparing the Contexts where Theatre is Performed in Aotearoa and Rapa Nui .....................................................................................................................191

4.5.2 Community Theatre practice in Aotearoa: Intercultural Encounters and Collaborations through Theatre Practice.

4.5.3 The Use of Indigenous Languages in the Production of Māori, Samoan diasporic and Rapanui Theatre ......................................................................1965

4.5.4 The Role of the Storyteller in Māori, Samoan diasporic and Rapanui Theatre 1987

4.5.5 The Influence of Shakespeare in Māori and Samoan Theatre in

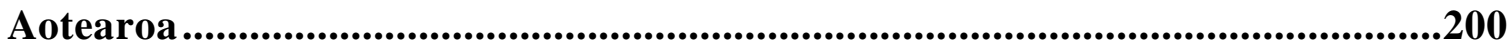

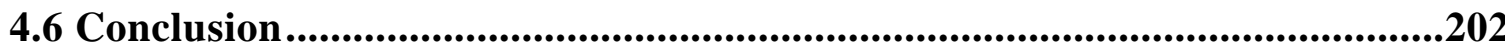

Chapter Five: Theatre Training in Aotearoa and Rapa Nui - Pehe Ana Hapi ki Hakararama i te A'amu - Tugar Tugar... Salir a Jugar .2043

5.1 Introduction .2043

5.2 Theatre Training at different Tertiary Institutions in Chile and Aotearoa .2065

5.2.1 Theatre Training in Tertiary Institutions in Chile ...................................2076

5.2.2 Te Kura Toi Whakaari: New Zealand Drama School ............................2109

5.2.3 Pacific Institute for Performing Arts (PIPA) and Whitireia ..................2176 
5.2.3.1 Pacific Institute for Performing Arts (PIPA) ..................................2187

5.2.3.2 Whitireia Community Polytechnic......................................................221

5.2.4 Bicultural Theatre Course at Otago University .....................................2243

5.2.5 Indigenous Theatre Education: Synergies and Possibilities across

Contexts .2287

5.3 Theatre Training Outside Tertiary Institutions.......................................2309

5.3.1 Mata Tu'u Hotu Iti ...............................................................................231

5.3.2 Te Rakau Hua O Te Wao Tapu .........................................................2343

5.3.3 Pacific Underground.......................................................................................2398

5.3.4 Theatre Training: Learning on the Job ......................................................241

5.4 Writers Training..........................................................................2432

5.4.1 Writers Workshop in Rapa Nui ........................................................2443

5.4.2 Writer's Block Workshop ......................................................................2476

5.4.3 Creative Writing Approaches across Contexts ....................................2509

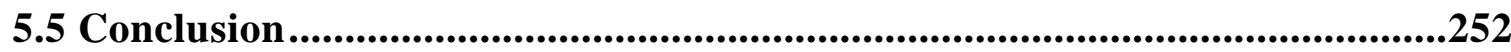

Harvest - 'Ahune - La Cosecha .......................................................................2543

Chapter Six: Findings and Conclusion - Ko Mau A - Atender y Entender para Aprender

6.1 Introduction

6.2 Different Approaches and Conceptualisations: 'Traditional' and

'Contemporary' Theatre .2587

6.3 Intercultural Collaborations through Theatre .........................................2609

6.4 Community Theatre and the Development of Māori and Samoan Diasporic

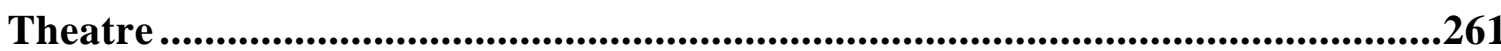

6.5 Self-determination through Indigenous Theatre .2632

6.6 Intercultural Theatre Training: The Integration of 'Traditional' Cultural Elements with European Theatre Techniques ..............................................2643

6.7 Theatre: A Liminal Space ..............................................................2676

6.8 Policy Implications and Possibilities for Theatre Practice in Rapa Nui ....2687

6.9 Original Contribution to Knowledge and Conclusion ................................2689

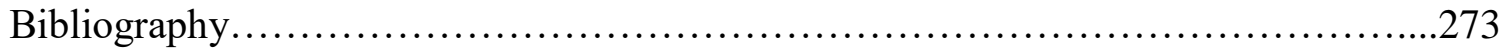

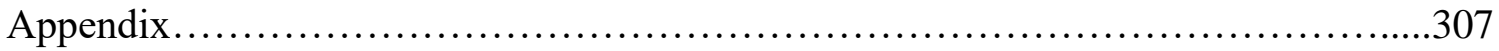




\section{List of Illustrations}

Figure 1. Paina site in front of Ahu Hana Te'e. Photo by Moira Fortin ..................................... 124

Figure 2. An artist's impression of a paina ceremony, by Te Pou Huke ..................................... 124

Figure 3. Chronology of the development of Rapanui theatre .............................................. 126

Figure 4. Rapa Nui group performing a Miro O'one (1934). Photo courtesy MAPSE ............... 127

Figure 5. Mata Tu'u Hotu Iti performing at Orono. Photo courtesy of MAPSE .......................... 129

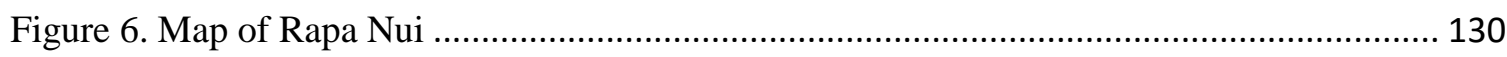

Figure 7. Use of space in Kaiga (1993). Photo by Moira Fortin................................................ 131

Figure 8. Uho, Te Uka. Tapati Rapa Nui 2009. Photo by Moira Fortin....................................... 135

Figure 9. Ure A Oho Vehi during Tapati Rapa Nui 2009. Photo by Moira Fortin ...................... 135

Figure 10. Koro Pate Tuki as Hetereki (2008). Photo courtesy of Aldea Educativa ................... 141

Figure 11. Stage background under construction for Tapati 2014. Photo courtesy of Juliet Hotus,

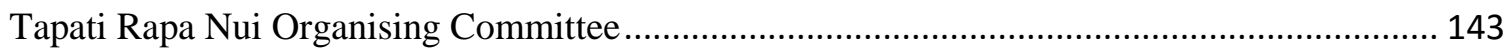

Figure 12. Nanue Para (2014). Photo courtesy of Juliet Hotus, Tapati Rapa Nui Organising

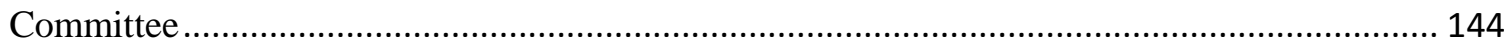

Figure 13. Whatungarongaro (1990) directed by Roma Potiki and John Anderson ................... 154

Figure 14. The Ragged (2015) by Helen Pearse-Otene........................................................... 159

Figure 15. Chronology of the development of Māori theatre..................................................... 162

Figure 16. Maui: One Man against the Gods (2007) directed by Tanemahuta Gray ................. 165

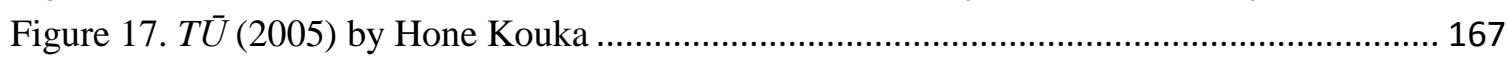

Figure 18. Romeo and Tusi (2013) by Erolia Ifopo and Oscar Kightley .................................. 174

Figure 19. Rangi \& Mau's Amazing Race (2015) by Tanya Muagututi ‘a and Joy Vaele........... 176

Figure 20. Tatau-Rites of Passage (1996) by Zeal Theatre and Pacific Underground ................ 178

Figure 21. The Factory (2011) by Kila Kokonut Krew ........................................................ 180

Figure 22. Black Faggot (2014) by Victor Rodger ............................................................. 181

Figure 23. The Eel and Sina (2015) by Jono Soo-Choon......................................................... 182

Figure 24. Chronology of the development of Samoan theatre in Aotearoa................................ 183

Figure 25. Fresh Off the Boat (1993) by Oscar Kightley and Simon Small ............................... 185

Figure 26. Frangipani Perfume (1998) by Makerita Urale......................................................... 188 
䆖 Seed

1 Karu

La Semilla 


\title{
Chapter One
}

\author{
Introduction
}

\author{
He Ha'a Mata
}

\section{Lamos Viendo Dijo el Ciego}

\subsection{Introduction}

In 2008 I watched the DVD of Tanemahuta Gray's Maui: One Man against the Gods (2007). ${ }^{1}$ The work of this Māori director excited and inspired me as an example of a 'traditional' Māori story which had been staged in a totally 'contemporary' style, without losing the sense that a Māori worldview was at the core of this performance. The play opens with a stage in darkness; a man and a woman chant the Māori creation oral narrative about the separation of Ranginui (Sky-father) and Papatuanuku (Earth-mother). Māori musical instruments resembling the sound of wind play, while four artists engage in an aerial performance. From the centre stage, which is covered with fabric, we hear voices naming the eight sons of Ranginui and Papatuanuku, using different tones and intonations, but the same rhythm. Chants begin to crescendo while the fabric begins to rise. Eight actors are revealed; moving forward they repeat a set of movements from a haka, until everyone performs a haka in unison, marking the birth of Ranginui and Papatuanuku's children, and filling the stage with light.

In Rapa Nui I observed and been involved in a variety of storytelling practices which are performed not only orally, but also visually; using takona (body painting), and kaikai

\footnotetext{
${ }^{1}$ At that time I was doing my MA in Pacific Island Studies at Otago University. I borrowed the DVD of this performance from Martyn Roberts who was the lighting designer for this production.
} 
(storytelling using string figures as illustration throughout the recitation of the narration) (M. Fortin, 2010, p. 102). Rapanui performing arts have a long history which is embedded in the culture, however theatre as it is understood in a Western framework ${ }^{2}$ began in Rapa Nui in 1975, with the work of the theatre group Mata Tu'u Hotu Iti (MTHI). This group was composed of local actors who performed 'traditional' Rapanui stories in different natural open air settings on the island (Paloma Huke, 1995, p. 52). Usually MTHI performances depicted the arrival of the Rapanui high chief, ariki Hotu Matu'a which were enacted in the same place where it is believed that ariki first arrived on the island. Their last performance was in 1999; however the work of MTHI continues to have a strong influence on the style and content of theatre in Rapa Nui. Although representations of 'traditional' stories were very important to the group, there have been significant changes in the way theatre is practised on Rapa Nui since this time.

The inclusion of theatre performances in the summer cultural Festival Tapati Rapa Nui in 2000 has led to many changes. These 'traditional' theatre productions in Rapa Nui were very slow, relying heavily on the character of the storyteller who was both the narrator and director. During these performances the storyteller told everybody on stage during the performance what they had to do, so there was little need for a script, or rehearsals prior to performances. In time 'contemporary' performances of 'traditional' stories have become more choreographed, including for example rehearsed battle and travelling sequences, which give more dynamism and rhythm to performances. As a performer and actress of Chilean heritage who has lived and performed in Rapa Nui for more than ten years, and a student of Pacific cultures and epistemologies, Maui struck me as very different from the theatrical presentation of 'traditional' Indigenous stories that I had become familiar with while resident in Rapa Nui.

When I first watched Maui, and as I subsequently watched a wide range of Māori and diasporic Samoan theatre productions, it struck me that the blend of 'traditional' and 'contemporary' cultural elements in contemporary theatre appears to be a smooth process in Aotearoa, while in Rapanui theatre this blending of styles is not so apparent. This difference initiated this research journey considering the ways in which Indigenous epistemologies are being integrated and explored through the performing arts in

\footnotetext{
${ }^{2}$ I argue that Western theatre can be defined as a collaborative art in which different elements such as script, lights, stage, set, sound, costume, music, and choreography are combined to produce a performance that is presented to an audience in a specific place, at a specific time.
} 
contemporary Aotearoa ${ }^{3}$ and Rapa Nui. I am interested in how 'traditional' stories are being transformed and mixed with European theatrical elements, and in the cultural and community processes that underpin these performances.

This thesis aims firstly, to comparatively examine the different ways in which notions of 'traditional' and 'contemporary' theatre are conceptualised by artists and performers in contemporary Aotearoa and Rapa Nui. Secondly, to investigate how these different attitudes shaped and influenced the production of culturally reflective 'contemporary' theatre practices in these comparative contexts. Thirdly, to discover how Indigenous theatre practice in Aotearoa could become a source of inspiration for the production of theatre works in Rapa Nui. In order to achieve these aims, this thesis focuses on how Indigenous theatre practitioners in Aotearoa and Rapa Nui have integrated different 'traditional' cultural elements with European theatre techniques in their contemporary work.

During the talanoa sessions I conducted with Rapanui artists and members of the community, I discovered that Rapanui theatre practice is perceived with critical eyes. For example, Rapanui musician Mario Villanueva Tuki said that Rapanui theatre "could be a lot better if they rehearsed and prepared way in advance for each performance, not just one day before the presentation" (Villanueva Tuki, 2014). Similarly, Rapanui dancer and choreographer Marisol Araki stated “it can be very boring because they don't rehearse, and also because they repeat and repeat and repeat the same thing all over again without adding or creating anything new" (Araki, 2014). Theatre practitioner and singer Puaru Hotus expressed her disappointment in Rapanui theatre because "in the end, you don't understand what is going on on-stage... if you don't know the story beforehand there is no way you, as a visitor, may understand what the story is it about... and it's really sad because this is happening during Tapati, the most important festival for the Rapa Nui culture!” (P. Hotus, 2014). Julio Hotus, Rapanui Regional Cultural Adviser at the National Council for Culture and the Arts even stated that "if theatre occurs in the encounter with the audience, where a message or story is transmitted from the actors to the audience, then I would say that in Rapa Nui theatre does not exist, because the message or story of the play does not reach the audience!"' (J. Hotus, 2014). These

\footnotetext{
${ }^{3}$ In 1986 the Māori language became officially the second language changing the name of the country from New Zealand to Aotearoa/New Zealand. To show my respect to the tangata whenua (people of the land) I will use Aotearoa in the majority of this thesis when referring to this country.
} 
statements demonstrate the concern that these Rapanui artists have about the ad hoc nature of Rapanui theatre. Rapanui dancers Tuvalu Pate Tuki and Miriam Pakarati Gula agree that it would be necessary to further develop the way in which theatre is practiced in Rapa Nui today, because it is an important source of information and of transmission of knowledge for the Rapanui community. All this concerns support the third research question, which aims to determine what Rapanui theatre practitioners can learn from the Indigenous theatre practice in Aotearoa. Some similarities between Indigenous cultures in the Pacific have been traced by scholars of different disciplines such as historians, anthropologists, linguists, and archaeologists. However Pacific cultures are also incredibly diverse. Based on some cultural similarities between Rapa Nui and Aotearoa, I will argue that Rapanui theatre production could draw examples from the culturally embedded theatre practices that have been developed in Aotearoa.

This research analyses how different histories and discourses related to ideas of 'traditional' and 'contemporary' theatre in these two cultural contexts have shaped and influenced the production of 'contemporary' performances that are seen as culturally relevant, reflective, and respectful. Māori theatre in Aotearoa has combined elements of tikanga Māori with aspects and techniques from European theatre, creating unique blends of 'traditional'/Indigenous and 'contemporary' theatrical elements. Tikanga Māori can be understood as referring to "Māori practice or protocol" (S. Turner, 2002, p. 71) where behaviours, worldviews, and ways of addressing others are strongly linked together. Practicing tikanga Māori defines and produces values and behaviours that Māori communities believe are "ideal, appropriate, [and] correct" (S. Turner, 2002, p. 75).

Māori theatre and the use of Māori epistemologies in processes of creating theatre has been a strong cultural influence on the theatre created by Samoan communities in Aotearoa. This thesis will also explore the theatre practice of the Samoan diaspora in Aotearoa as an example of culturally-situated contemporary theatre practice, but more importantly as an example of how an indigenous group can learn theatre practice from another indigenous group, by collaborating in different theatre productions. Samoan theatre has been influenced by Māori theatre in many different ways. Since the 1980s, Samoan theatre practitioners have worked and experienced the work itself by collaborating with Māori on various Māori productions, such as Wellington's Taki Rua Theatre. Samoan practitioners have been inspired by the success of the development of Māori theatre, particularly in the early 1990s where the work was critically acclaimed. In 
view of the success of Māori theatre, Samoan practitioners have learned theatre in substantial ways, for example seeking professional training at Toi Whakaari, Whitireia, and PIPA, as well as engaging in community-based theatre practices connecting with local communities and performing Samoan stories. In recent years Māori theatre practitioners have also mentored Samoan theatre practitioners through incentives such as the Matariki Development Festival encouraging Samoan practitioners to write their own plays. If Samoan practitioners can be influenced and inspired by Māori theatre, then the same might be possible for Rapanui theatre.

I consciously chose not to use the term Pasifika because, the term Pasifika is broadly used and understood in contemporary Aotearoa. I am aware that people of Pacific Island heritage call themselves 'Pasifika' in Aotearoa, but when they are among other Pacific Islanders, especially outside Aotearoa, the term 'Pasifika' is no longer used. There is a history of this debate whether to acknowledge the place of origin or to group Pacific Islanders under the umbrella term 'Pasifika'. The term emerged from the New Zealand education system and can be understood as:

[A] collective term used to refer to people of Pacific heritage or ancestry who have migrated or been born in Aotearoa New Zealand. Pasifika includes, recent migrants or first, second and subsequent generations of New Zealand born Pasifika men, women and children of single or mixed heritages. They identify themselves with their indigenous Pacific countries of origin because of family and cultural connections with Sāmoa, Cook Islands, Tonga, Niue, Tokelau, Fiji, Solomon Islands, Tuvalu and other Pacific countries. Pasifika people are not homogenous and Pasifika does not refer to a single ethnicity, nationality, gender, language or culture (Education Review Office, 2012, p. 6).

I acknowledge that theatre practitioners from Fiji, Tonga, the Cook Islands, and Tokelau have performed and created different theatre productions around the country. An in-depth analysis and discussion of theatre productions created by the different Pacific Islands communities living in Aotearoa is outside of the scope of this thesis. But I have chosen Samoan theatre as a case study because Samoans are the largest Pacific Island population (apart from the Indigenous Māori) living in Aotearoa ${ }^{4}$, and because the development of

\footnotetext{
${ }^{4}$ According to the Census of the 5th March 2013 the population of the Samoan ethnic group comprised 144,138 people comprising $3.3 \%$ of the total population in New Zealand and $49 \%$ of the Pacific Island
} 
Pacific Island theatre in Aotearoa has been dominated by Samoan diasporic theatre practitioners.

Samoan peoples have migrated in significant numbers to urban centres such as Auckland, Wellington, and Christchurch. Aotearoa has become a key site for Samoan diasporic theatre (Balme and Cartensen, 2001, p. 35). The term diaspora is understood in this thesis as referring to "the mental and emotional links between people from the same cultural background but living in [a] different part of the world" (Balme \& Carstensen, 2001, p. 36). Diasporic theatre productions in Aotearoa's urban centres create new spaces in which to share and explore these mental and emotional ties to new places and communities within Samoan and Pasifika diasporic communities, and with the wider community in Aotearoa. Furthermore, Samoan plays explore diverse staging and styles of representation, combining different representational "codes" (Balme and Cartensen, 2001, p. 42), resulting in performances that are not only part of their place of origin, but also part of the place where they have been created and shown.

Samoan diasporic theatre to date has integrated European theatre techniques with elements of popular culture, and with Samoan 'traditional' customs to create unique 'contemporary' works. Popular culture refers to "a set of generally available artefacts: films, records, clothes, TV programmes, modes of transport, etc." (Hebdige, 1988, p. 47) which are part of a shared cultural heritage for all peoples living in the new context of Aotearoa. The use of elements of popular culture in examples of Samoan theatre is reflective of the diverse cultural influences in the New Zealand context.

This thesis will focus on theatrical works created by Māori and Samoan theatre practitioners in Aotearoa, and Indigenous theatre in Rapa Nui, between 1970 and 2015. It will use a case-study methodology to examine the integration of 'traditional' cultural elements into ‘contemporary’ works. Open-ended interviews with Māori, Samoan and Rapanui theatre practitioners explore attitudes towards 'traditional' and 'contemporary' practices in and through theatre. These open-ended conversations drew on talanoa (Violeti, 2006) as a culturally-situated Pacific research method which is "context specific and responsive to the needs of people in a given situation" (Clery, 2014, p. 108).

Histories of colonisation in Aotearoa and Rapa Nui undoubtedly influence both historical

population living in Aotearoa (Statistics New Zealand, 2014), where many Samoans are second and third generation in Aotearoa. 
and current relationships to theatre in these different cultural contexts. Colonial discourses and understandings continue to inform current theatre practices, and this includes influencing how creativity is valued, and what forms of creativity are seen as possible and acceptable in the present. In the book Post-Colonial Transformation (2001) Ashcroft describes the impacts of colonialism. He points to the loss of "language," the way in which "history" is explained and understood by the dominant culture, and the ways in which Indigenous culture has been transformed into an "allegory" (Ashcroft, 2001, pp. 14-15) for the tourist industry, and argues that these factors have all had an effect on the creativity of Indigenous communities. In the wake of the collapse of many of the industries and trade agreements established during colonialism, the economies of Pacific Island countries are increasingly dependant on the tourist industry. To meet the demands of the tourist market, and this includes the commodification of cultural forms and Indigenous peoples and communities, especially in the case of Rapa Nui, performing arts have been transformed, to some extent, in an allegory for the tourist industry. However, narrations of Indigenous stories in Indigenous languages have enabled Indigenous theatre in Aotearoa and Rapa Nui to reclaim and acknowledge their particular ways of knowing and being.

This research consciously focuses on the positives of cultural dialogue, with a desire to better understand and support intercultural theatre practices in Aotearoa and Rapa Nui. It is important to move past fixed ideas of 'tradition' because the notion of 'tradition' is itself of colonial origin. By moving away from these colonial concerns, a decolonisation of creativity may be possible. However, despite any perceived colonial overtones, notions of 'tradition' are meaningful to practitioners and perpetuated for this reason. Cultural heritage, identity, and creativity should continue to be celebrated and explored through theatre and the arts. I argue that the creative arts can support processes of reflection generating discussions and dialogue not only about past issues, but also about how societies chose to face the future.

This thesis assumes that theatre is based in dialogue and intercultural collaboration. I understand dialogue and collaboration as the willingness to overcome differences, but not as the absence of conflict, and this is reflected in the Spanish proverb that is the title of this introductory chapter. Proverbs are well-known sayings that state a generally accepted 'truth' or offer a piece of advice: 
A proverb is a short, generally known sentence of the folk which contains wisdom, truth, morals and traditional views in a metaphorical, fixed and memorizable form and which is handed down from generation to generation (Mieder, 1990, p. 24).

The proverb "Vamos Viendo Dijo el Ciego" translates into English as "Let's see, said the blind man." This saying can be found in Chilean culture as well as in the English language. It highlights the notion that vision extends beyond what is seen. The verb 'to see' refers to the ability to understand many ways of knowing, and acknowledging these differences. In Chile 'traditional' proverbs are widely used in contemporary society, linking popular culture and 'traditional' understandings of life in the present. This multilayered approach is reflected in each title throughout this thesis, which through language seeks to point towards different layers of seeing and understanding. This conceptual framework is part of the purpose and positionality of this thesis, and reflects original contribution I am hoping to make with and through my work.

\subsubsection{Exploring the Construction of the 'Traditional' and the 'Contemporary:' Implications and Consequences for Cultural Creativity}

The term 'tradition' is of relatively recent historic origin. Its contemporary use suggests a continuity with the historic past, which is not always accurate (Hobsbawm \& Ranger, 2012). 'Tradition' is always constructed through the lens and values of the present. Pacific anthropologists have debated how much weight should be given to the colonial meaning of 'tradition' ( Jolly \& Thomas, 1992). Their work has acknowledged the diverse meanings of 'tradition' found across Pacific Island languages and worldviews, thus initiating processes of interrogating the term 'tradition.' This research presents several examples of Māori, Samoan diasporic, and Rapanui theatre that demonstrate different perceptions of what constitutes 'tradition.'

In present day Rapa Nui, the colonially inherited idea of preserving 'traditional' aspects of culture is very powerful. Theatre productions which deal with 'traditional' themes in a 'traditional' style are highly valued among the Indigenous community. In contrast 'contemporary' theatre and the arts are often seen as betraying 'tradition' and culture. While the reproduction of 'traditional' styles and stories has been a way of celebrating 
the survival of Indigenous cultures in the face of colonial hegemony and domination, these polarised understandings significantly restrict creative possibilities, and could themselves be understood as extensions of colonial dialogues which perceived Indigenous cultures as "dying" (Urry, 1979, p. 15), focussing on the preservation of 'tradition.'

This thesis seeks to better understand the general reticence towards creating 'contemporary' theatre in Rapa Nui, in order to propose a set of recommendations for the further development of Rapanui theatre inspired and informed by Indigenous theatre in Aotearoa. Therefore, it will explore how 'tradition' is understood and reproduced by artists and actors in Rapa Nui, and in Aotearoa. Hobsbawm and Ranger define the term 'tradition' as a set of activities that seeks to instruct values and norms of behaviour by repeating them over time, implying a continuity with the past (Hobsbawm \& Ranger, 2012, p. 1). The terms 'tradition' and 'traditional' are conceptualised within this thesis as ideational and cultural platforms which are inextricably connected to the creation of 'contemporary' works. 'Traditional' practices necessarily and paradoxically always involve 'contemporary' cultural elements; they are constantly re-created and reinterpreted in and through perspectives and values from the present.

\subsubsection{Research Background}

I became a permanent resident in Rapa Nui in 1999. I started working as a drama teacher at the only existing school on the island at that time, Liceo Lorenzo Baeza Vega, where I worked until 2004. In this role I attempted to introduce students to theatre pieces written by authors such as Shakespeare, Moliere, Pirandello, and to the work of well-known contemporary Chilean playwrights, such as Radrigán and Griffero. My idea, as a naïve and recent graduate from drama school in Chile, was to use these authors as tools to encourage different forms of expression in the students. Living on such a tiny island I thought that it could be beneficial for the students and the audiences to know and understand different realities and ways of living and speaking through theatre. I hoped that culturally diverse and different performances might help audiences to reflect on their own understandings and behaviours through reading or performing different types of drama pieces. 
However, these workshops generally failed to engage students' interest or imagination, mainly due to the fact that foreign material did not seem at all relevant to their lives. Since the creation of Mata Tu'u Hotu Iti, Rapanui peoples have continued to perform theatre in almost the same way that this group performed it. Their work has become a blueprint for creativity. Other art forms in Rapa Nui have developed more contemporary styles and techniques; for example incorporating new musical instruments and rhythms and using different artistic techniques and materials in painting and sculpting. However when it comes to theatre, Rapanui contemporary artistic expressions are generally looked down on. Blending cultural influences through performances is regarded as something that is really difficult to achieve, and is generally considered undesirable.

It is relevant to think about Indigenous theatre in Aotearoa in relationship to Rapanui peoples and theatre, because there are cultural values and understandings that people from these two different regions hold in common. These common values support the creation of theatrical works that not only honour and celebrate culture and traditions, but also reflect upon issues connected with life in the contemporary Pacific and how these impact upon identities. Pacific cultures and histories have commonalities that are meaningful, but that they are also incredibly diverse. Although we can make arguments for broad commonalities in terms of cultural values, family, people, land, and language there are also many significant differences. Aotearoa and Rapa Nui are radically different in many respects. Areas of difference includes population, geographic size, the proximity of major metropolitan areas and other Polynesian islands, and the existence of a national arts funding board with dedicated funding for theatre, as well as differences in support for Polynesian arts more generally. These are all aspects that will be taken into account when comparing Māori and Samoan theatre practices in Aotearoa, and approaches to theatre practice in contemporary Rapa Nui.

Māori culture has had a significant influence on people in Rapa Nui, and there is an established cultural connection between these two Polynesian cultures. During talanoa it became clear that for Rapanui peoples, the Indigenous people of Aotearoa are seen as culturally connected (Araki Pont, 2014; Lillo Haoa, 2014) and not seen as a colonial entity. This allows a different relationship to develop, leading to a perception that Māori culture is less 'foreign' than cultural influences from Chilean peoples (Pont Chamorro, 2014). A cultural restoration process which involved historical and cultural connections between Polynesian people started in Rapa Nui in the 1960s with the election of the first 
Rapanui Mayor, Alfonso Rapu (Fuentes, 2013a, p. 54). Since then Rapanui people have been consciously looking at the responses of other Pacific Island peoples to social and cultural issues facing them; for example Marquesans, Tahitians, and particularly Māori. This thesis will show that the influence of Māori people is evident in the development of the Rapanui language education programme and in the renewal of Rapanui dance performances. Both of these cultural developments mirror strategies of cultural decolonisation adopted by Māori as a response to histories of colonisation which had decimated their language and demonised Māori forms of cultural expression and identity.

The Indigenous Language Seminar (ILS) held in Rapa Nui in July 2004, invited Māori teachers who were involved in the creation and development of Kura Kaupapa and Kohanga Reo Indigenous language immersion schools in Aotearoa. ILS had a significant and enduring influence on language education in Rapa Nui, helping in the creation of the Rapanui Language Academy in December 2004. During talanoa with Virginia Haoa Cardinali member of the Rapanui Language Academy, she explained that this academy operates under similar principals to those framing the Kura Kaupapa practice in Aotearoa, and with similar intentions for the revitalisation of language and culture (Haoa Cardinali, 2014).

With regards to the influence of Māori on the performing arts in Rapa Nui, the Indigenous dance form called hoko has many components in common with the Māori haka. The term hoko is used to refer to gestures and movements, especially from the upper body, which are performed while singing in a seated position (Englert, 2007, p. 300). In 1976 Rapanui performers travelled to Aotearoa, and saw the Māori haka for the first time. The hoko style they created on their return in Rapa Nui was strengthened and inspired by the movement vocabulary of the haka, and included sharp movements and facial expressions. This version of the hoko has become an important and enduring feature in the Rapanui contemporary performing arts scene (Bendrups, 2006, p. 28).

Following the historical development of Māori and Samoan diasporic theatre in Aotearoa, I argue that Rapanui practitioners could use theatre as a vehicle for reflecting upon and sharing both old and new stories, exploring and negotiating their cultural identities, as well as for expressing their desires, frustrations, sense of humour, politics, social issues, and self-determination. At its best, theatre can be used as a tool for initiating communication about culture and identity locally. This dialogue can extend to 
other Polynesian peoples, as well as stimulating dialogue and reflection with the Chilean community in Rapa Nui and in Chile.

\subsubsection{Locating the Researcher: Place, Voice and Positionality}

My name is Moira Sofia Fortin Cornejo. I have Indigenous Chilean, French, and Spanish heritage. I was born in Santiago, Chile, and I have lived, studied, worked, and performed in Chile, Germany, Rapa Nui, and Aotearoa. I come from a country which is classified as a 'third world country'. My country of birth was colonised a long time ago by the Spanish who destroyed almost everything that was there. During my childhood I studied at a bicultural German school. At the age of eighteen I spoke fluent German and knew more about German history and geography than Chilean, despite the fact that the school celebrated both cultures. Now in my adulthood I speak fluent English. If we take my life as an example, and see it from the angle of post-colonialism, it can be said that I have been colonised three times in my life. I am aware that:

[i]t is virtually impossible, in the present day to ignore the interpretative climate of post-colonial-angst, despite the fact that there is a danger in viewing everything to do with cultural relations in this light (Watson, 2002, p. 109).

I understand cultural relations as an exchange, where both sides can contribute and learn. I am not interested in the appropriation of knowledge, language, or cultural practices. It is not my goal or concern to put the professional creative development of any seemingly

'superior' or more 'developed' culture on a higher level than another. Cultural encounters can be seen from a more positive perspective. They create necessary spaces for intercultural interactions where cultural forms interact with and inform one another without any single culture dominating the interaction creating new cultural forms which better "reflects the complex realities of an increasingly globalized and transnational world" (Clery, Cochise, \& Metcalfe, 2015, p. 307).

The ability to speak three languages has enabled me to communicate with people from different cultures; allowing me to share my experiences as a "local" (Selasi, 2015) from Santiago and Rapa Nui with other Rapanui locals, who in return they have shared with me their stories, their protocols, their dances and songs, as well as their language. I have enduring family connections in Rapa Nui. My grandmother Berta Alfaro chose to 
develop relationships with people from Rapa Nui in the early 1970s. Since then my family has been connected to the Rapanui culture and its people. My interest in Rapanui culture was passed on to me from her daughter, my aunt, Eliana Cornejo, who is married to a Rapanui man, Juan Hey, and lives in Rapa Nui until the present day.

Although I am not yet fully fluent in Te Re'o Rapanui, the Rapanui language, I understand and regularly participate in conversations held in Te Re'o Rapanui. Indeed, during my fieldwork for my MA in 2008 some people answered my enquiries entirely in Te Re'o Rapanui (M. Fortin, 2010). Language is of great importance to cultural understanding, and to conducting successful research with Indigenous communities.

Living and performing in Rapa Nui for more than ten years I have been working with artists who share a common creative passion for the performing arts. Cultural encounters through the creative arts can be characterised as a collaboration, in which both parties work together. Although it is important to recognise the enduring impacts of colonialism, and unequal power relationships which extend into the present; I argue that the creative arts, and particularly theatre, can enable people to explore and to challenge the typical colonial relationship between the oppressor and the oppressed, and to transcend it. Reciprocity, or hakakio in Rapanui and reciprocidad in Spanish, is at the heart of any relationship. Reciprocity entails collaboration, negotiation, and sharing between cultures. It involves an equal process of give and take, involving a commitment to return what has been taken from another person over time and through ongoing relationships, but not as the appropriation of cultural products. Respect, mo'a in Rapanui and respeto in Spanish, is another core element in every cultural encounter. There are various ways in which the researcher can be respectful to the communities they are researching with. The most important one is to acknowledge their contribution to the research, not only by citing them, but also by recognising the value of their input, knowing that without their knowledge the research would not have been possible.

Throughout this research process Māori, Samoan, Rapanui, Pākehā, and Chilean theatre practitioners shared ideas and knowledge with me. Each cultural group can potentially benefit from this research; they can use it, change it, or discard it completely, it is up to the reader. In terms of my own practice in Rapa Nui, this research will be used as a model to inform theatre workshops that I have been conducting at different schools and the Anthropological Museum Father Sebastian Englert in Rapa Nui, helping me to adapt 
my work to use more culturally appropriate methodologies. In addition, I will share and pass on to Rapanui practitioners the different approaches and methodologies used in Indigenous theatre practice in Aotearoa, so that they can use and include these methods in their theatre productions, if they wish to.

\subsection{Methodology}

The research methods used in this project combine talanoa (Vaioleti, 2006), communitybased participatory action research (Getty, 2010), insurgent research methodology (Gaudry, 2011), and contain an awareness of my role as a liminal (Bendrups, 2000) and Multi Perspective Culturally Responsive (MPCR) researcher (Clery et al., 2015). The idea of combining Western and Indigenous methods reflects my belief that Western research methods are not the only acceptable and valid ways of gaining knowledge. Indigenous methodologies and protocols are appropriate methods of research within Indigenous communities, in which the researcher welcomes and accepts the differences and similarities between worldviews, enriching the possibilities for dialogue between cultures. These different research methods complement one another, and reflect my desire to look at the research questions from a range of different angles and perspectives. This research is informed by employing this mix of Western and Indigenous methods in the fieldwork undertaken, which was further augmented by other research methods including; semi-structured interviews, library research including textual study, reading plays, watching filmed performances, and my own experience performing in Rapa Nui.

\subsubsection{Combining Research Methods}

Research involving Indigenous peoples should consider the outcomes of the research, and how it might be of benefit to the wider community (L. T. Smith, 1999, p. 191). Although Western researchers may try to utilize post-colonial methodologies and theories "to deconstruct the influence of colonialism, it does not [always produce research that] reflect[s] Indigenous ways of knowing" (Getty, 2010, p. 7). In fact, research using a post-colonial perspective could primarily reflect the values of the researcher (Getty, 2010, p. 7), rather than the values of the community. More often than not the community does "not see themselves represented in texts or if they do see 
themselves, they often do not recognise the representation" (Wilson, 2001, p. 216). To avoid this disconnection with the participants and communities involved in this research, I decided to use methodologies that I consider more appropriate to research which seeks to be of use to Indigenous communities, and to engage with them.

Pacific researchers have developed research methodologies which seek to reflect and respect the protocols of Pacific contexts. Talanoa is a Pacific research method which enables a "personal encounter where people story their issues, their realities and aspirations" (Vaioleti, 2006, p. 21). Talanoa allows people to participate in an open conversation which is not set or pre-determined in terms of its content, engaging participants in an oral and collaborative critical discussion which can generate knowledge on a range of different topics. Violeti also explains that Pacific ways of gathering information and creating knowledge are spoken, interactions which are based on verbal cooperation. In using talanoa as a research method it is very important to pay attention to the way in which people talk about their lives, especially to the language they use and the associations they make, which can help to reveal their worldview (Gilligan 1982, in Vaioleti, 2006, p. 25). This approach enables the researcher to gather more 'authentic' information or data than other research methods, because it involves a profoundly relational and dialogic approach. Talanoa is a culturally-situated research tool.

While conducting field work for my MA research in 2008 in Rapa Nui, I looked for culturally-situated research methodologies in use in the region, and discovered that although no Rapanui specific research methods have yet been developed, the procedure in which the meetings with each participant were held, related well to the ideas and protocols underpinning talanoa as a research method. Talanoa seeks to create relationships between people, and to minimise the space between the researcher and the research participants, giving all participants in the dialogue the opportunity to be reflected, and to feel related to the research in which they are participating (Vaioleti, 2006, p. 25). Talanoa is relevant to this $\mathrm{PhD}$, especially while conducting interviews with Māori, Samoan, and Rapanui theatre practitioners, giving them the opportunity to be active participants in this research project.

Community-based research methodology and insurgent research methods both focus on using an Indigenous world-view, and on putting the community at the centre of the research to help ensure that the results of the research can be used by Indigenous 
communities. Insurgent research methods argue that "the Indigenous community are the final judges of the validity and effectiveness" (Gaudry, 2011, p. 117) of the research. In addition, Gaudry states that insurgent research is "action oriented and works as a motivating factor for practical and direct action among Indigenous people and in Indigenous communities" (Gaudry, 2011, p. 117). Insurgent research methods encourage community-based research as a way of minimizing "colonial interference" (Gaudry, 2011, p. 114) between researchers and Indigenous communities.

As someone who has substantial lived experience in Rapa Nui, but who was born in Chile, my status as a researcher is complex. I am not an 'insider' in the way that an Indigenous Rapanui researcher would be. However, my personal and professional experiences in Rapa Nui and my relationships with people have combined to make me comfortable and familiar with Rapanui patterns of conversation and culturally-situated ways of building rapport. As a result of my experiences in theatre and performance, I am an 'insider' to this particular research topic in some ways. My status as an in/outsider researcher and member of the Rapanui community present "complexities in navigating this dual and somewhat oppositional roles" (Mosavel, Ahmed, Daniels, \& Simon, 2011, p. 145). Conducting research in Rapa Nui, a place I call home, means that I "do not enter the research endeavour as objective bystander" (Mosavel et al., 2011, p. 149). It confronts me with the social, economic and political facts on site and my own thoughts, making it difficult sometimes to remain partial without being emotionally involved with different issues arising during the research. As a member of the Rapanui community, I acknowledge the difficulties of remaining impartial, while seeking to conduct a study that is balanced and ethical.

To help articulate my relationship to the communities I researched with, I conceptualise myself as a Multi Perspective Culturally Responsive (MPCR) researcher. A MPCR is someone with "multiple and hybrid cultural positioning" (Clery et al., 2015, p. 313), who has cultural and linguistic fluency that is based on lived experience in a variety of places and a strong sense of belonging to a range of diverse communities. MPCR researchers are not completely 'insiders' or 'outsiders' to their research communities, but can instead be thought of as researchers who inhabit liminal spaces "...on the threshold between one world and another" (Ven Gennep, 1965, p. 22) "work[ing] within complex and fluid relational continuums" (Clery et al., 2015, p. 303). 
Clery, Cochise and Metcalfe (2015) point out that MPCR researchers 'belong' in and are attached to many places. "MPCR researchers have lived experience in a variety of different spaces, places, cultures, religions, and languages" (Clery et al., 2015, p. 315). Using these lived experiences and levels of cultural awareness and fluency as the basis of their relational approach to working with people "MPCR researches [seek to] work towards achieving mutually emphatic relationships with Indigenous communities" (Clery et al., 2015, p. 316). Relationships grounded in mutual empathy are demonstrated when:

[T]he community feels that the researchers have a good understanding of local cultures, and that they have demonstrated their commitment to the well-being of Indigenous peoples (Clery et al., 2015, p. 316).

MPCR researchers focus on engaging, connecting, and collaborating with communities allowing researchers to be "reflexive and critical without being divisive or excluding researchers or participants on the basis of their race, ethnicity, or location" (Clery et al., 2015, p. 316). This methodology supports the conceptual framework used within this research in which different ways of understanding, knowing and seeing can collaborate and dialogue together for a better understanding of different realities, perceptions, and points of view regarding Māori, Samoan diasporic and Rapanui theatre practice.

The liminal researcher methodology was conceptualised by Daniel Bendrups in his study of Latin American migrant music in Australia, and it complements the concept of the MPCR researcher. Bendrups reflects on the ethical aspects of fieldwork, and especially on the role of the researcher. According to Bendrups "fieldwork should be conducted from a liminal perspective, that is, a position at the point where [your] own culture and the culture of [the] research subject intersect" (Bendrups, 2000, p. 35). The success of this methodology depends fundamentally on the researcher's "ability to interact with other cultures" (Bendrups, 2000, p. 35). This interaction between cultures can be supported by community-based research because it seeks to acknowledge Indigenous worldviews throughout the research process.

The viewpoints of Indigenous performers and artists are at the centre of this thesis. Through dialogue I aim to ensure that their voices and opinions are strongly present. My thesis makes an original contribution to knowledge through representing these original interviews and voices in this research. The research methods I have chosen to draw from and to combine support and enable Indigenous people to be actively involved in the 
construction of knowledge and in the creation of representations about them through "participat[ing] as researchers in partnership with academic researchers" (Getty, 2010, p. 5). I aim to give participants the "chance to state and restate [the] meanings... and to modify, delete, and adapt [the] meanings according to local customs" (Bishop, 1998, p. 206). The concepts of the liminal researcher, the MPCR researcher, and the approaches used in community-based research relate back to talanoa because they allow collaborations based on partnership, reciprocity, and respect on an equal basis. In this case both the researcher and Indigenous peoples are able to ask questions, to challenge different opinions, and to find possible solutions to different issues.

In the case of this research, the limitation I face as a MPCR researcher is that I am in no position to lead the change in the way theatre is practiced in Rapa Nui today. I can only show and propose different examples, methodologies and possibilities within Indigenous theatre practice. The change, if any, has to be initiated by the Rapanui theatre practitioners' community. As a member of the Rapanui community I will share all the information learnt through this research, and comment on possible influences from the experiences of Māori and Samoan theatre practitioners in Aotearoa that may benefit Rapanui theatre. Ultimately, however, it will be the community of Rapanui theatre practitioners who will decide what to take from Aotearoa and how to implement those influences within their cultural context.

\subsubsection{Fieldwork}

The original research undertaken for this thesis was gathered during several different periods of fieldwork. Living and studying in Wellington since 2013 has been a great location for fieldwork, as the city is the site for several important arts festivals. In 2014 the New Zealand Festival, the Fringe Festival, the Pūtahi Festival and the Matariki Development Festival ${ }^{5}$ were organised. During these festivals I was able to see a large number of plays that were performed, produced and/or directed by Māori or the Samoan community in Aotearoa. I was able to interview artists and performers regarding the methodologies, ideas, and approaches influencing their work, and how these notions relate to concepts of the 'traditional' and the 'contemporary.' Festivals held in 2015

\footnotetext{
${ }^{5}$ Pūtahi and Matariki are Māori theatre festivals organised by Tawata Productions held at Studio 77 at the Theatre Studies Department at Victoria University and Circa Theatre respectively.
} 
including the Pūtahi Festival, the Fringe Festival, the Matariki Development Festival, and the Ahi Kaa Festival ${ }^{6}$ were also a source of information and theatrical experience. On these occasions I was able to not only conduct interviews with theatre practitioners, but also to share my own experience of producing theatre in Rapa Nui with some of the festival's participants.

Sharing my experience as a theatre practitioner in Rapa Nui with Māori and Samoan theatre practitioners in Aotearoa allowed me to reflect on my own practice, as well as to find similarities and differences between notions about theatre practice. These talanoa sessions enabled dialogue and collaboration, where Māori and Samoan theatre practitioners could ask questions about the state of the production of theatre in Rapa Nui. The body of knowledge about Rapanui theatre is scant, so sharing my experience contributed to the knowledge that Māori and Samoan theatre practitioners in Aotearoa have about Rapanui theatre.

Between July and August 2014 I conducted another important section of my fieldwork in Rapa Nui. The main purpose of this research phase was to talk with Rapanui artists about how they understand the concepts of 'traditional' and 'contemporary' in relationship to their creative work. These original interviews shed light on current attitudes towards notions of what is 'traditional' and 'contemporary,' and how these influence possibilities for creativity and the development of contemporary performing arts in this Pacific Island. During this phase of fieldwork I recorded performances that took place, and also collected information about performances that had been produced since my departure from the island in December 2012.

Community-based research and insurgent research methods speak of collaborating with Indigenous communities, and putting them at the heart of research. In this same spirit I engaged in a variety of activities with different Rapanui groups and institutions, transmitting my research findings as they emerged during my fieldwork. These activities included a public presentation of my research at the local museum, participation in a radio program about theatre where people could call in and ask questions, and collaboration in a storytelling workshop with children from the community. In addition, I worked in collaboration with the Cultural Corporation of Easter Island, a department

\footnotetext{
${ }^{6}$ Indigenous Theatre Festival organised by Tawata Productions which started in 2015.
} 
within the Rapa Nui City Council whose main responsibility is overseeing the various research projects taking place in the island.

Between August and September 2014, I conducted research at drama school at the Universidad Católica in Chile where I graduated as an actress in 2002. In Rapa Nui biculturalism can be seen as a reflection of the integration and influences of both Rapanui and Chilean cultures. In my quest of uncovering ways in which bicultural theatre unfolds in Rapa Nui, and how Rapanui theatre practitioners have been integrating 'traditional' and 'contemporary' elements in their work, I thought important to re-visit this institution where I trained as an actress because if a Rapanui person wants to pursue tertiary education in theatre and the arts, their main option will be travelling to Chile.

In October 2014 I went to Auckland, where I spent three days at the Pacific Institute of Performing Arts (PIPA). During this time I had the opportunity to observe rehearsals, talk with students and faculty members, and with Pacific Island theatre practitioners. This experience at PIPA allowed me to witness the methodology and theatre techniques used in the rehearsals of a play aimed at children.

During my fieldwork I kept two journals; one written journal and one journal consisting of oral recorded reflections. In these journals I documented my own feelings, impressions, observations, and thoughts, especially after the conversations and plays that I saw. These methods enabled me to keep a "detailed record of both objective observation and subjective feelings" (Spradley, 1979, p. 58). This approach helped me develop my chapter outline and supported the process of connecting the topics that I observed with the theoretical framework used in this research.

This research also involved extensive and ongoing library research, including textual study, reading selected play texts, and watching filmed performances. Library research was conducted at the Central Library at Victoria University, at the Nola Millar Library at Toi Whakaari, and at the William Mulloy Library in Rapa Nui. This archival research provided me with a thorough overview of the development, struggles, influences and achievements of Māori, Samoan, and Rapanui theatre practitioners with a focus on how 'traditional' and 'contemporary' elements were integrated. 


\subsubsection{Interviews}

This research, involved conducting semi structured interviews that had been approved by the Human Ethics Committee in New Zealand. I began our conversations by explaining the broad topic of the conversation, and the participant could ask questions about it and give their own point of view. This methodology arises from the intention of placing participants at the centre of research. During these conversations participants critically reflected on how ideas of the value of 'tradition' impacted upon possibilities for 'contemporary' creativity, creating their own research questions and proposing possible solutions. This dialogic and co-constructed approach also used in talanoa as a research method (Clery, 2014, p. 110).

In Aotearoa interviewees were chosen for their expertise in the field of Māori and Samoan theatre. Most participants were actors, directors and playwrights. Some participants had worked extensively with non-professional performers, and also as teachers of professional actors. The 'expertise' of interviewees was ascertained through factors including the duration of their theatre career and reviews of theatre productions in which they were involved, writing, directing, or performing. The experience of theatre practitioners in Aotearoa who have worked with non-professional actors and in community theatre projects was of great importance to this research, since such experiences of working with non-professional performers are similar to the context in which theatre is produced in Rapa Nui.

In Rapa Nui, I interviewed artists who have been involved in the production of theatre, and people from the community, including elders who have participated as jury members in the theatre competition ${ }^{7}$ during the Tapati Rapa Nui Festival. Since I have been dancing and performing in different Rapanui dance groups, the concepts and names discussed in relationship to Rapanui performing arts and theatre were clear in form, context, and meaning for both parties which led to an ease and fluidity in our conversations, our talanoa. Each conversation took place in a location determined by mutual agreement. Interviews were conducted with one interviewee at a time. Some

\footnotetext{
${ }^{7}$ See discussion in Chapter Four
} 
participants asked to meet in a quiet place where the noise of traffic could not reach us. I recorded each conversation which was later transcribed, and translated if needed.

\subsubsection{The Use of Three Languages}

This research is unique in terms of its intention to connect three different languages and conceptual worlds. This research was undertaken in English, Spanish, and the Rapanui language, according to the preference of the participants involved. Languages not only refer to forms of verbal communication, but they also reveal worldviews, and ways of thinking (Cook \& Bassetti, 2011, p. 80). While translation implies the meanings are similar, the sound, grammatical order and syntax of the translation is different, opening the meaning to another aspect of the same topic. Each title of this thesis has been written in English, Rapanui and Spanish. Titles in the Rapanui language are a translation of the English titles. These titles reflect the street parlance of contemporary Rapanui society in order to connect with the Rapanui audience. By using three different languages I am making sure that the different communities involved see themselves included in this research.

Indigenous and foreign words will not be italicized in this thesis, because placing languages other than English in italics degrades and contributes to the 'othering' of languages. The conceptualization of knowledge in this thesis is inclusive, acknowledging different languages, perspectives, and worldviews. This decision is reflective of my desire to allow different culturally-situated readers to connect with this research in different ways.

This research has brought together a wide range of literature in multiple languages, as a way of reflecting the diverse linguistic realities across the Pacific. Literature about the historical development and influences of theatre in Polynesia has been written in English. This thesis, also written in English, will be translated into Spanish in order to make it available to the Rapanui community, and to share knowledge about the development of Māori and Samoan theatre practitioners in Aotearoa. 


\subsection{Chapter Outline}

This research is divided in three parts. 1) Seed - Karu - La Semilla, 2) Sprout - Tupu - El Brote and 3) Harvest - 'Ahune - La Cosecha. This division emerged before leaving Rapa Nui in 2012 through conversations with my Rapanui uncle, Juan Hey, a pineapple farmer, musician and storyteller, who did not quite understand what I meant by theatre. As I attempted to find a way of explaining this concept to him I came up with this sequence. Planting a seed, karu, or semilla relates to the first steps taken in the process of preparing a theatre production, including the idea, images, and inspirations. When the plant develops and sprouts, tupu, or brota connects to the process in theatre in which ideas are formalised, scripts are written, plays are devised, and rehearsals are conducted. The play is not ready yet, but as with a seedling you can see that it is growing. The final stage is the harvest, 'ahune, or la cosecha. This can be associated to the theatre process when the play is ready to be shown to an audience. The plant is fully grown and we can now enjoy it and share it. This thesis conceptualises theatre processes as comparable to nurturing a plant or crop that needs caring and constant work for it not to dry out.

The first section of this thesis is entitled, Seed- Karu- La Semilla. Following this introductory chapter which explores my positionality in relationship to the research and explains the methodology and research methods used in this study, Chapter Two describes the relationships between Indigenous peoples in Rapa Nui and Aotearoa, and their respective relationship to colonial powers and the nation state. It argues that both Chile and New Zealand have bicultural dimensions which continue to influence the development of theatre. An understanding of colonial history and relationships is important to comprehend the development of theatre practices in each of these cultural contexts. Colonial histories have undoubtedly affected the development of the performing arts. This chapter gives an overview of the ongoing colonial relationship between Rapa Nui and Chile, the colonial relationships between Māori and the New Zealand nation state, and it also explores Samoan migration to Aotearoa.

Chapter Three discusses the theoretical framework guiding this research. It analyses concepts and interpretations of the terms 'traditional' and 'contemporary' from Māori, 
Samoan, and Rapanui perspectives. The idea of exploring cultural encounters through theatre practice is also discussed. This is accomplished a consideration of the different understandings and approaches used in intercultural theatre forms (Pavis, 1996, p. 4), allowing forms of negotiation and collaboration between peoples with different cultural heritage and understandings. Chapter Three will also explore definitions of popular theatre, which is usually performed on an outdoor stage with open access. Rapanui theatre has a direct relationship to popular theatre. Community theatre is another important frame through which we can reflect on the creation of theatre in contemporary Aotearoa and Rapa Nui, because it enables marginalised groups to share their stories with the wider community. In the final section of this chapter, the impact that tourism has had on the performing arts in Aotearoa and Rapa Nui will be analysed. The importance of Rapanui tourist performances to the livelihoods of artists is one of the reasons why the concept of 'tradition' is so firmly rooted in the contemporary Rapanui community.

The second part of this research is entitled Sprout- Tupu- El Brote. This section starts with Chapter Four which analyses the theatre created by Indigenous peoples in Rapa Nui, and the history, development, and influence of Māori and Samoan theatre in Aotearoa. It explores the different creative processes involved and discusses plays which exemplify the integration of 'traditional' performative elements with European theatre techniques. This combination of forms necessarily creates 'contemporary' works. This chapter also proposes a comparative analysis of theatrical historical developments in all three contexts.

Chapter Five explores the theatre training and education opportunities available in in Rapa Nui/Chile and Aotearoa/New Zealand. For the purpose of this research, theatre training refers to all aspects involved in the production of a play; from devising or writing a play, acting and rehearsing, creating props and costumes, to production week, and opening night. Theatre training is a key aspect in supporting actors and artists to combine 'traditional' cultural elements in their 'contemporary' works. Chapter Five opens by discussing the different methodologies used in the teaching of theatre in tertiary educational institutions in Chile and Aotearoa. Theatre education in Chile is included in this chapter, because for a Rapanui citizen, travelling to Chile is currently the main option for seeking formal theatre training due to language, proximity, and financial opportunities. The variety of institutions teaching theatre or performing arts in Chile and Aotearoa is quite large. In the case of Chile, I will briefly describe the state of theatre 
training and discuss the main methodologies used in the teaching of theatre at tertiary institutions in the capital city, Santiago. In Aotearoa I will focus on the different methodologies used at Toi Whakaari: New Zealand Drama School, Pacific Institute of Performing Arts (PIPA), Whitireia Community Polytechnic, and in the Bicultural Theatre course at the University of Otago.

The second part of Chapter Five focuses on the methodologies used in the teaching and learning of theatre and considers pedagogies which involve the training of practitioners through observant participation with theatre companies. Case studies of theatre companies such as Mata Tu'u Hotu Iti in Rapa Nui, Te Rakau Hua O Te Wao Tapu in the case of Māori theatre, and Pacific Underground for Samoan diasporic theatre will be considered. Finally, this chapter discusses creative writing workshops as an aspect of theatre that has proven to be crucial in the development of Māori and Samoan theatre in Aotearoa. This chapter also proposes a comparative analysis of the different methodologies and approaches to teaching and learning of theatre. This chapter sheds light on a range of culturally reflective and culturally-situated theatre training processes and considers the possibilities that learning different methodologies from different cultures may provide to the theatre practitioner.

The final part of this thesis is called Harvest - 'Ahune - La Cosecha. Chapter Six discusses how different approaches towards understandings of the terms 'traditional' and 'contemporary' continue to shape theatre production in these three different cultural contexts. It also discusses the importance of intercultural collaborations in the development of Māori, Samoan diasporic, and Rapanui theatre. The inclusion of community theatre practices in Aotearoa will also be analysed in this section. Community theatre has contributed to developing notions of Indigenous selfdetermination through theatre, as Indigenous theatre practitioners determine what to include and how to present their performances. Theatre becomes a liminal space where cultures intersect, contributing to the creation of performances which can lead to greater cultural understandings, to a reduction in the gaps between cultures, and create spaces where 'traditional' and 'contemporary' practices can be blended. This chapter finishes by underscoring the original contribution of this thesis and by providing an overall conclusion. 


\title{
Chapter Two
}

\section{腾 Histories and Relationships}

\author{
He A'amu o te Hakapiri ${ }^{8}$
}

\section{De a Dos se Baila el Tango ${ }^{9}$}

\subsection{Introduction}

The Pacific Ocean, the world's largest ocean, was one of the last regions of the planet to be populated (Craig, 2004, p. 1). From a Western perspective Polynesia has often been constructed as "thousands of scattered, and often isolated" (Shepardson, 2013, p. 8) islands in a vast sea. The Tongan anthropologist Epeli Hau'ofa proposed a radically different perspective, arguing that rather than being seen as resource-poor and isolated, Oceania and its people should be seen as fundamentally interconnected (Hau'ofa, 2008, p. 27). Hau'ofa asserted that there is a significant difference between "viewing the Pacific as 'islands in a far sea' and 'a sea of islands'” (Hau'ofa, 2008, p. 31). He conceptualised the Pacific Ocean as a highway connecting Oceanic peoples. Hau'ofa argued that the people of Oceania should remember and reclaim their cultural connections as voyagers and navigators. Relationships connecting Oceanic peoples have been traced by scholars including historians, anthropologists, linguists, and archaeologists. These connections can be seen though shared oral histories, customs and

\footnotetext{
8 "He A 'amu o te Hakapiri" literally translated means the story of getting together, where the word a'amu is "story" and hakapiri is "to get together". This phrase refers to the story of how these cultures came to live together, sharing their different languages, land and customs.

9 "De a Dos se Baila el Tango" refers to the relationship between partners. When dancing Tango you need two people dancing together, if one fails the entire dance fails. This phrase is commonly used to signify the responsibility that each party has when working or living together.
} 
heritage, and material culture and linguistic characteristics linking Pacific peoples to one another (Craig, 2004, p. 6). However, Pacific cultures are also incredibly diverse.

This chapter discusses and compares the impacts of colonial and contemporary histories on the possibilities for engaging in the creative arts for Māori and Samoan theatre practitioners in Aotearoa and Rapanui artists in Rapa Nui. To comprehend the development of theatre practices an understanding of the ongoing impacts of colonial history and relationships is important as colonial histories have undoubtedly affected the development of the performing arts in these respective contexts. This chapter considers the influence of the ongoing colonial relationship between Rapa Nui and Chile on contemporary creativity. It also gives an overview of colonial relationships between Māori and the New Zealand nation state, and explores Samoan migration to Aotearoa. This is the first step required to discover how the development of Māori and Samoan diasporic theatre in Aotearoa could influence the future production of theatre works in Rapa Nui.

Oral narratives about the creation and human settlement of the Pacific are an important part of contemporary theatre and creative expression for Māori, Samoan, and Rapanui artists. Oral narratives about the settlement of people in the Pacific differ significantly from dominant science-based understandings of how the Pacific came to be populated. They provide different sets of information about the origin and discovery of the Pacific Islands, and reflect different worldviews, beliefs, customs and social organisations.

Theatre as it is understood in a Western sense as an art form involving scripts, production, staging and audiences, is a relatively 'new' phenomenon in the Pacific. In forms of theatre which try to reclaim and reflect Indigenous worldviews and understandings, oral narratives have been important inspirations for contemporary creation. Following the work of Gilbert and Tompkins, I argue that "codes and conventions [of oral traditions] as modes of communication are already highly theatrical" (Gilbert \& Tompkins, 1996, p. 126). Contemporary Māori, Samoan diasporic, and Rapanui theatre forms often draw upon themes which are taken from or inspired by these older stories. 
Some stories about oral narratives and gods are commonly understood and referenced across the Polynesian 'Cosmo'-vision. For example, narratives about the god of the seas, Tangaroa can be found in Aotearoa (King, 2003, p. 74), Hawai'i (Beckwith, 1970, p. 258), Sāmoa (Meleisea \& Schoeffel Meleisea, 1987, p. 2), Tonga (I. C. Campbell, 2001, p. 52), and Rapa Nui (Englert, 1980, p. 22). Similarities between oral narratives signify a common whakapapa (genealogy), but also the fact that there are differences in the telling of these stories in each site; show the very specific cultural, environmental, political and social environments of Pacific nations. This means that the 'sea of islands' is connected, but also independltly created, managed and understood. Because of these connections, it is possible to consider and to investigate Māori and Samoan diasporic theatre in relationship to, and as a possible model for theatre practices in Rapa Nui.

Although the colonising period will be discussed in this chapter, it is not my intention to explore the broader histories of the Pacific cultures considered in this thesis in depth. The history of the relationship between these cultures and their colonial counterparts, New Zealand for Māori and Samoan communities, and Chile for Rapanui peoples, has been described and analysed in detail by a number of academics (Brooking, 2004; Delsing, 2004; S. R. Fischer, 2005; King, 2003; Salesa, 2011). Instead, this chapter focuses on the significant historical developments during colonialism that have favoured or limited the development of theatre among the Māori and Samoan communities living in Aotearoa and for the development of theatre among the Indigenous people of Rapa Nui. Finally, this chapter will compare and contrast current contemporary theatre practices among Māori, Samoan, and Rapanui artists in their respective contexts.

\subsection{The Relationship between Rapa Nui and Chile}

Rapa Nui has been the subject of countless studies ranging from archaeology to botany, linguistics, geology, and anthropology. A long list of Chilean, international and a few Rapanui scholars and researchers (Andrade, 2004; Arredondo, 2009; Bendrups, 2005; Englert, 2007; Finnegan \& Orbell, 1995; S. R. Fischer, 2005; Fuentes, 2013; Heyerdahl, 1975; McCall, 1994; Metraux, 1940; Moreno Pakarati 2011; Pakarati 2011; Routledge, 2007; Thomson, 2007), as well as painters, sailors, musicians, tourists and ufologists, have told and retold through different lenses, the history of this particular island. Since first contact with European explorers, the name of the island has also gone through a 
variety of changes. The Dutch explorer Roggeveen named it Easter Island ${ }^{10}$ after arriving on Easter Sunday in 1772. Spanish explorers called the island San Carlos to honour the Spanish king Carlos III. Isla de Davis (Davis's Land) is another name given to this island by the English sailor Edward Davis (Métraux, 1971, p. 33). Thompson explains that the origins of the name Rapa Nui, may relate to the story of a kidnapped Easter Islander who returned from Peru in 1863(Thomson, 2007, p. 40). The name Rapa Nui was first used in written text by a Catholic missionary, Father Eugene Eyraud, in 1864. One hypothesis suggests that the name Rapa Nui was given by migrants from the island called Rapa (Oparo or Rapa Iti) located about 3,000 kilometres west of Rapa Nui (Thomson, 2007, p. 40). These migrants called the island Rapa Nui, Great Rapa, because of it larger size. Nowadays the name Rapa Nui is the one used when referring to Easter Island and its inhabitants (Métraux, 1971, p. 34). The name was adopted to emphasize the Polynesian origins of its inhabitants, as a means of distancing themselves from the colonial Chilean culture.

The following section will examine the historical and colonial influences that have impacted upon theatre production in Rapa Nui. It will consider the influence of oral narratives on contemporary theatre works, and look at social changes prompted by encounters with the first European explorers. I will also analyse the establishment of Rapa Nui as a Chilean colony, and its subsequent modernisation that undoubtedly influenced the way in which theatre is produced in this Polynesian culture.

\subsubsection{The Influence of Oral Narratives on Rapanui Theatre}

Oral histories tell of an island called Hiva where the Rapanui people come from. High chief ariki Hotu Matu'a and his people may have fled from the consequences of a natural disaster, the sinking of their island in the sea (Englert, 1980, p. 29), "navigating in the direction of Rapa Nui, where they gave birth to the Rapanui culture as we know it today" (Bustamante Diaz, Viguie Juan, Andoue Lelandais, \& Tuki Tepano, 2008). The ancestors of Rapanui peoples, in this new land were governed by the ariki, and divided into tribes that occupied the coastal areas (Englert, 1980, p. 29).

\footnotetext{
${ }^{10}$ Isla de Pascua in Spanish
} 
Stories narrating the life of ancestral heroes and their deeds are consistently represented in contemporary Rapanui performances and at present theatre productions are solely based on the representation of 'traditional' stories. Through these performances Rapanui people aim to preserve 'traditional' stories, transmitting them to future generations as part of Rapanui history. The arrival of the ancestor Hotu Matu'a is one of the 'traditional' stories most frequently performed in Rapa Nui.

\subsubsection{Rapa Nui, Social Change, and the ongoing impacts of Encounters with European Explores}

The arrival of Western sailors to Rapa Nui's shores led to significant changes to the island. The first contact with foreign explorers came with the arrival of the Dutchman Jacob Roggeveen on April $5^{\text {th }}$ 1722. Captain James Cook visited the island during his second voyage (1772 - 1775) to the South Pacific (Métraux, 1971, p. 37). The French explorer La Perousse also visited the island in 1786 (Métraux, 1971, p. 38).

The next visitors to Rapa Nui initiated a series of events which have enduring significance for the forms and possibilities for contemporary creativity. The Peruvian slavery expeditions of 1862 decimated the Rapanui population, dramatically altering the social, cultural and economic structure of the island. As a consequence of the abolition of African slavery in 1823, Peruvian authorities sought new sources of labour from the Pacific Islands. Peru embarked on four separate slave raids in Rapa Nui, recruiting a total of 1407 islanders, and removing 34\% of the island's estimated population (Maude, 1981, p. 20). By the time some Rapanui slaves had managed to return to their homeland in 1863, many of them were ill with tuberculosis, smallpox, and dysentery (S. R. Fischer, 2005, p. 89). These diseases spread rapidly, killing a great portion of the Rapanui population (S. R. Fischer, 2005, p. 91) and leaving an estimated $25 \%$ of the total Indigenous population alive (Boersema, 2015, p. 143).

These events combined to ensure that there were only a small number of people left to nurture and transmit Rapanui's culture. The surviving Indigenous population felt understandably responsible for maintaining links with their past, and for transmitting knowledge of Rapanui culture and oral histories to future generations. This aspect of Rapanui history is of great importance for this research. The intergenerational transmission of knowledge in Rapa Nui has been severely impacted by histories of 
colonialism which have enduring consequences for creativity in the present. The decimation of the Indigenous population of Rapa Nui has contributed to the weight accorded to the preservation and performance of 'traditional' oral narratives in contemporary Rapanui theatre. The decision to preserve oral histories and traditions through performance is grounded in a necessary and pragmatic strategy for cultural survival.

The arrival of Catholic missionaries between 1864 and 1871 significantly altered the living patterns of Rapanui peoples. Nelson Castro's thesis Misioneros y Milenaristas Isla de Pascua 1864-1914 states that this was the first time that Europeans settled in the island for a period of time. The establishment of the Catholic mission occurred during a moment of crisis in Rapanui society (Arredondo, 2009, p. 41). After the slave raids, Rapanui society lost the spiritual leadership of the ariki who was a symbol of order and command. This apparent lack of leadership in the Indigenous community enhanced a perception of the missionaries as possessing "strong mana ${ }^{11 "(C a s t r o, ~ 1996, ~ p . ~ 24) . ~ T h e ~}$ influence of Catholic missionaries led to the abandonment of many 'traditional' practices, including various forms of Indigenous art and performance. For example, the art of tattoo was stopped because it was seen by the missionaries as an erotic practice involving excessive admiration for the body (Arredondo, 2009, p. 21).

The alteration of social structures and cultural practices in Rapa Nui included the decline and disappearance of the annual Tayata ${ }^{12}$ Manu (birdman) competition. This was an important feature of 'traditional' cultural practice which contributed to establishing leadership structures in Indigenous Rapanui society. This competition was celebrated during September in Oroyo, a village at the top of the southern volcano Rano Kau. From the top of this volcano there three small islets van be seen, Motu Iti, Motu Nui, and Motu Kaokao. During the springtime birds found a perfect nesting place on these islets. The Tayata Manu competition consisted of contestants racing down the cliffs; swimming one kilometre until they reached Motu Nui, finding the first egg laid by the frigate birds nesting there, swimming and climbing back to the top of the cliff, and returning to Oroyo village. The first competitor arriving back at the starting point of the race gave the representative of his tribe the honour of becoming the new governor of Rapa Nui for one year (Métraux, 1971, p. 332). The Tayata Manu competition was performed for the last

\footnotetext{
${ }^{11}$ Power, physical and mental strength

${ }^{12}$ The $\mathrm{y}$ correlates to the "-ng" sound represented in written Māori by the ng and in Samoan by the letter $\mathrm{g}$.
} 
time in 1866. It was witnessed by missionaries Eyraud and Roussel (Museo

Antropológico Padre Sebastian Englert, 2008, p. 3). Although there is no clear evidence that this competition was banned by missionaries, I argue that it is likely that due to the introduction and ever-increasing dominance of the Catholic religion, and the adoption of its leadership structures, the ritual may no longer have seemed necessary for Rapanui peoples.

The work of Rapanui theatre group Mata Tu'u Hotu Iti in the 1970s revived the Tayata Manu ceremony by representing it through theatre in the village of Oroyo. Currently, the Tayata Manu competition is remembered through song, dance, and drama as a regular part of the repertoire performed by the different dance groups existing in contemporary Rapa Nui. The competition has also influenced the production of creative work for the different cultural festivals ${ }^{13}$ in Rapa Nui. ${ }^{14}$

\subsubsection{Isla de Pascua15, a Chilean Colony in the Pacific}

The annexation of Rapa Nui to Chile in 1888 brought significant socio-cultural changes which are recorded through documents including treaties and leases (Bendrups,2005; Delsing, 2004; Fisher, 2005; Fuentes, 2014; Hotus \& Consejo de Ancianos Rapanui, 1988; McCall, 1976; Porteus, 1981). In the late nineteenth century the Captain of the Chilean Navy Policarpo Toro arrived on the island. Toro initiated legal proceedings for the annexation of Easter Island to Chile on behalf of the Chilean President José Manuel Balmaceda (M. Fortin, 2010, p. 36). On the $9^{\text {th }}$ September 1888 the Acuerdo de Voluntades between the Chilean Government and ariki (high chief) Atamu Tekena was signed, formally annexing Easter Island to Chile. This agreement was written in both Spanish and Rapanui languages, and it conceded sovereignty to Chile, whilst allowing Rapanui chiefs keep their titles. This agreement, like the Treaty of Waitangi between a delegation of Māori and the English Crown, set the tone for a bicultural environment which Rapa Nui has lived in to the present day, eventhough no official policy regarding biculturalism has been yet established.

\footnotetext{
${ }^{13}$ See discussion in Chapter Four

${ }^{14}$ In 2014 the High School Aldea Educativa organised a short version of this competition as part of the commemoration of the school's festival Mahana O Te Re'o (Language Day).

${ }^{15}$ Easter Island
} 
The signing of this agreement led to both severe injustices enacted upon the Rapanui people and to progress in terms of the development of infrastructure, communication, and transport. Today the main points of conflict between the Chilean Government and Indigenous Rapanui peoples centres around issues of land ownership, and more recently conflicts regarding the perceived overpopulation of the island due to the arrival of Chilean migrants (Rapu Drago, 2014). Between 2002 and 2012 the population in Rapa Nui has increased 36\% from 3,791 to 5,167 (Instituto Nacional de Estadisticas INE, 2012).

The treaty with Chile did not result in the settlement of Chilean authorities on the island. On the contrary, the island was leased by Chile to the British Williamson Balfour Company between 1895 and 1953 (Fuentes, 2013b). The company exploited the island's natural resources, using most of the island as a giant sheep farm (Porteous, 1981, p. 71). The writings of Porteous, (1981), H. Fischer (1998) and S. R. Fischer (2005) describe this period as full of injustices and abuse against Rapanui peoples. However, Rapanui elder Felipe Pakarati describes the time of the Company on the island as not completely unpleasant (Pakarati, 2011, p. 298). The forced cohabitation to which the Rapanui peoples were subjected by the Williamson Balfour Company had a violent beginning. However, "the domestication of colonial power" (Moreno Pakarati, 2013, p. 287) led foreigners to adopt to some extent the Rapanui life style (Moreno Pakarati, 2011, pp. 7981). The fact that the Company stayed on the island for half a century (S. R. Fischer, 2005, p. 135) allowed Rapanui people to implement a number of strategies that would bring the commercial powers closer to the Rapanui culture. In addition, several company members started families with Rapanui women, hence the concern for the welfare of the islanders was no longer a subject between employer-employee, but became complicated by family relationships. In $2011 \mathrm{I}$ had the opportunity to conduct a theatre workshop together with Annette Zamora Rapu, Rapanui language teacher at Catholic School. In this workshop we took the time of the Williamson Balfour Company as a research topic for the production of a school play. ${ }^{16}$

In 1938 a grand celebration took place in Rapa Nui to commemorate the fiftieth anniversary of the annexation of the island to the Chilean territory. The governor of the time Dr. Alvaro Tejeda Lawrence organised a Rapanui folkloric presentation on the $18^{\text {th }}$

\footnotetext{
${ }^{16}$ See discussion in Chapter Five
} 
September, to coincide with the celebration of the independence of Chile (Bendrups, 2005 , p. 225). For the $50^{\text {th }}$ birthday celebration Rapanui musicians were asked to present old songs, which bewildered the musicians as in the Rapanui culture, old songs were only sung during special occasions and not to be presented in public (Bendrups, 2005, p. 225). Tejeda's request turned out to be complex and challenging, since some lyrics were not completely remembered by Rapanui peoples. This prompted Rapanui musicians to create new fragments. Rapanui artists decided to perform in the form of a koro haka opo ${ }^{17}$ which is a choir competition. The songs chosen for this event were the ones that told ancient stories. This celebration combined Rapanui 'traditional' musical repertoire with "new compositions for the purpose of the celebration" (Bendrups, 2005, p. 226). The 'contemporary' compositions of that time are now understood as belonging to Rapanui's repertoire of 'traditional' music.

The administration of Rapa Nui by the Chilean Navy between 1953 and 1975 brought more changes to the lifestyle of Rapanui peoples that affected social behaviour and artistic production. During this period the annual transportation of imported food and construction supplies in cargo ships was formalized (Porteous, 1981, pp. 167-169). The arrival of food and construction materials was initially seen as a positive step in the development of the island. However the new administration also led to several prohibitions on the Rapanui people. For example Rapanui peoples were prohibited from leaving the island, speaking the Rapanui language at school, and made Rapa Nui citizens ineligible to participate in Chilean elections (Porteous, 1981, p. 171). These prohibitions created a climate of tension between Rapanui peoples and the Chilean administration resulting in a protest march in 1964. The march was led by Alfonso Rapu, an Indigenous Rapanui leader who had returned to his homeland after graduating as a school teacher in Chile (Porteous, 1981, p. 171). The march demanded that prohibitions affecting the island be removed, and claimed that there was a lack of progress in Rapanui society in terms of infrastructure and communication with Chile.

All these antecedents prompted the creation of the first theatre group Mata Tu'u Hotu Iti in 1975 (Paloma Huke, 1995, p. 42). Mata Tu'u Hotu Iti aimed to show to the Rapanui peoples the importance of remembering and celebrating their 'traditional' culture, and to strengthen the Rapanui language, preventing its loss. These aims were pursued through

${ }^{17}$ See discussion in Chapter Four 
theatre, and the company performed 'traditional' stories in different natural settings, and in the Rapanui language to the contemporary Rapanui society. ${ }^{18}$

\subsubsection{The Modernisation of Rapa Nui and Influences on Rapanui Performing Arts}

In the second half of the twentieth century, Rapa Nui went through a series of profound modernisations. In 1967 Mataveri International Airport began operating on the Island. The opening of the route between Santiago and Rapa Nui helped in the development of infrastructure, communication, social services, and transportation (Porteous, 1981, pp. 174-178). The airport also increased the number of visitors to the island (Porteous, 1981, p. 174). Initially the majority of these visitors were archaeologists and researchers from Europe and North America, who began work on restoring and preserving archaeological sites around the island (Porteous, 1981, p. 191). Publications of these research projects changed the way the history of this island was understood. These articles, books and video recordings opened up Rapanui history and archaeological sites for the world to see, which generated the arrival of more researchers, and stimulated interest from the tourist market. Nowadays planes with a capacity of 200 passengers, equivalent to $4 \%$ of the Rapanui population, arrive on a daily basis; some days there are even two or three flights. There are now direct flights to Tahiti, Peru and Santiago from Rapa Nui, considerably increasing the number of visitors (Paoa Aguila, 2014).

Rapa Nui was also brought to the attention of the global marketplace in 1994 through the film Rapa $N u i^{19}$ directed by Kevin Reynolds and Kevin Costner. One interesting aspect of the filming of the movie Rapa Nui was the significant number of Māori and Pacific Island actors that participated in the film. Samoan actor Nathaniel Lees was part of the cast, alongside Māori actors Rawiri Paratene, Rena Owen, and George Henare. During the filming, the Rapanui people who got involved in the movie gained a variety of skills, including learning to use lighting, wireless microphones, and being involved in set design. In addition they had the opportunity to connect with other Māori and Pacific Island actors. During the period of time Lees stayed on the island, he took the opportunity of speaking Samoan with the Rapanui people and the linguistic similarities

\footnotetext{
${ }^{18}$ See discussion in Chapter Four

${ }^{19}$ The Tayata Manu ceremony is the central topic of this movie, indicating that this ceremony is central to a broader popular discourse about Rapa Nui.
} 
"confirm[ed] to him that the indigenous people of the Pacific Islands come from the same roots" (NZ on Screen, 2011). Rapa Nui was seen as a special and spiritual location, and it made quite an impression on Lees who commented that "at times it feels like the whole place is tapu" (NZ on Screen, 2011).

This was followed by the Chilean television series Iorana ${ }^{20}$ in 1998 , which was set in Rapa Nui. The TV series Iorana showed to viewers in Chile a dramatization of life in Rapa Nui. This series promoted Rapa Nui as a culturally distinct place, different from the rest of the Chilean national context (Bendrups, 2005, p. 36).

Both these productions had a significant effects on the Rapanui performing arts scene (Bendrups, 2005, p. 36), increasing tourism to Rapa Nui, adding to a load that was already growing since the opening of the airport. Tourism on the island increased from 15,000 visitors annually in the year 2000, to 90,969 visitors in year 2013 (Paoa Aguila, 2014). In view of the drastic increase in the amount of visitors traveling to the island, Chilean authorities sought help from domestic and foreign institutions to develop strategies for the conservation of the archaeological heritage in Rapa Nui. The preservation of archaeological sites, ahu (platforms), and moai (stone statues) became one of the main priorities for the Rapanui authorities.

In the year 2000 the tourist industry was recognised not only as a source of employment, but also as a source of artistic production. The conservationist agenda being pursued in terms of recording and protecting Rapanui's tangible cultural heritage was also being extrapolated to other areas of the Rapanui culture, including education and the performing arts. In contemporary Rapa Nui, for example, one of the most important subjects at school is Rapanui culture and language (Arredondo, 2014). The Ministry of Education in Chile developed an education program called Educación Intercultural Bilingüe (EIB) which translates as Bilingual Intercultural Education. The EIB program was finally implemented in 1996 (Williamson, 2012, pp. 140-141). It was created to meet the demands of Indigenous peoples of Chile in terms of promoting the development of their cultures and languages. ${ }^{21}$

\footnotetext{
${ }^{20}$ Although Iorana is a Tahitian word, Rapanui culture adopted this word as part of the Rapanui vocabulary meaning hello and goodbye.

${ }^{21}$ In 1993 the Chilean Government, through the enactment of Law No. 19,253, recognized the existence of eight Indigenous groups: Mapuche, Aymara, Rapanui, Likay Antai, Quechua, Colla, Kawashkar or Alacalufe and Yamana or Yagan (Riedemann Fuentes, 2008, p. 173).
} 
Bilingual education programs in Rapa Nui began in 1990, when the Department of Rapanui Language and Culture composed entirely of teachers of Rapanui descent was established (Revista Docencia, 2009, p. 65). Virginia Haoa Cardinali, a Rapanui educator and member of the committee that created the Department of Rapanui Language and Culture, explains that initially the main purpose of the EIB was to implement the Rapanui language as a subject for students aged between ten and fifteen. Later the aim was to include Rapanui language teaching across all levels in high school. Finally, EIB succeeded in the creation of a total immersion class from the $1^{\text {st }}$ to the $4^{\text {th }}$ year of Primary School (Haoa Cardinali, 2014).

The implementation of the EIB was through workshops aimed at developing cultural forms, such as himene (songs), ori and hoko (dance), a'amu tuai (telling traditional stories), kaikai (string figures) with its correspondent pata 'uta' $u$ (recitation), takona (body painting), and tarai (carving) (Haoa Cardinali, 2014). All these workshops focused on enriching language learning. In addition, the EIB focused on complementary subjects which supported the Rapanui language, such as sport and physical education, history, music, and the visual arts. Three of the four secondary schools that exist in Rapa Nui today, Liceo Lorenzo Baeza Vega, Colegio Católico, and Aldea Educativa have implemented this education program.

Socio-cultural norms about what kinds of performance and cultural expression are accepted can also relate to education, and these understandings reflect the ways that different subjects are taught; particularly understandings of 'tradition' and 'traditional' practices. The EIB initiatives have to some extent functioned to dismiss understandings and forms of creativity that come from the outside, both national and internationally. Rapanui art forms have also been produced from a point of view which prioritises cultural preservation. This strategy can be understood as a response to Rapa Nui's colonial past, which seeks to reaffirm the identity of the Rapanui people (Santa Coloma, 2006, p. 133).

Cultural Festivals like Tapati Rapa Nui, the Rapanui version of the Chilean Spring Festival (Andrade, 2004, p. 69), emerged in 1968 and sought to promote 'traditional' Rapanui cultural forms and understandings. The inaugural Rapanui Language Day Festival, Mahana o Te Re'o, was held in 1991. It reflected the need and desire to celebrate the use of the Rapanui language. These cultural festivals have boosted artistic 
development in Rapa Nui; however a clear prioritisation has been given to the enactment of 'traditional' performances. Less space has been given to exploring 'contemporary' forms of creativity, and how these could potentially interact with Indigenous ways of knowing and being. As a response to this challenge, the Chilean government established a liaison office of the Consejo Nacional de Cultura y las Artes (CNCA) ${ }^{22}$ in Rapa Nui in 2008. CNCA's mission is to promote cultural development. In addition, the CNCA aims to preserve and promote Chilean cultural heritage, and to encourage the active participation of citizens in achieving these goals (CNCA, 2003). The Rapa Nui office of CNCA has facilitated applications for funds to finance the creation of new work, especially in music and the visual arts (Oñate, 2014).

However, there has been a recent development in terms of arts education in Rapa Nui. The Rapanui pianist Mahani Teave, in collaboration with other Rapanui artists created the Rapanui foundation ONG Toki in 2010. Teave explains that the purpose of this foundation is to create a School of Music and the Arts where students can explore "our ancestral culture as well as a nest of [contemporary] opportunities to help develop the talents in the young [children] which because of isolation they would not have the chance to do" (Teave, 2014).

ONG Toki is currently in its fourth year of offering free lessons to almost 70 Rapanui children, teaching ukelele, piano, cello, and violin. In the future ONG Toki hope their curriculum will include 'traditional' chants, Rapanui language, voice lessons, and other performing arts (Teave, 2014). Introducing non-Indigenous instruments such as the violin, piano, and cello to the Rapanui culture is understood by Teave as introducing "another colour" (Teave, 2014) with which to make 'contemporary' musical arrangements to 'traditional' Rapanui music. For Teave the introduction of the violin today resembles the introduction of the ukulele from Tahiti to Rapa Nui in the past. The work of ONG Toki indicates that the kind of blending this thesis is interested in, is happening in Rapa Nui in other areas of the creative arts, incorporating musical instruments and rhythms to the Rapanui repertoire. However the combination of cultural influences in Rapanui 'contemporary' theatrical expressions is something as elusive.

${ }^{22}$ National Council for Culture and the Arts 


\subsection{Relationship between Māori Peoples and New Zealand}

Aotearoa, meaning the land of "the Long White Cloud" (King, 2003, p. 39), is an archipelago which comprises two main islands: Te Ika a Māui, referring to the North Island, and Te Waipounamu, or the South Island. Aotearoa also includes numerous smaller islands, such as Stewart Island,The Chatham Island, the uninhabited Kermadec Island, Auckland Island, and Campbell Island (Mein Smith, 2007, p. 1). Present day Aotearoa/New Zealand is a nation enriched with culturally diverse communities, where the main cultural groups are Māori and Pākehā. The modern nation state is founded on the idea of biculturalism, although cultural diversity is an increasing reality in the country. The historical relationship between the Indigenous Māori community and Pākehā settlers to New Zealand has been full of conflicts and disputes about land and sovereignty which continue into the present. These aspects of history have touched many areas of life in New Zealand, including the development of Māori theatre and performing arts.

\subsubsection{The influence of Oral Narratives in Contemporary Māori Theatre Productions}

Oral narratives have been included in a variety of books about the history of New Zealand (Belich, 2001; Brooking, 2004; King, 2003; Locke, 1992; Mein Smith, 2007; Orbell, 1995). These narratives tell us about Indigenous beliefs, and about the arrival of the first inhabitants of Polynesian origin. A variety of oral narratives describe the geological origins of Aotearoa. These stories describe the separation of Ranginui, the Sky father from Papatuanuku, the Earth mother (Belich, 2001, p. 20; King, 2003, pp. 8-9). This separation provided light in the world, and enabled the creation of all the flora and fauna that inhabits the archipelago. Other creation stories tell the story of the demigod Māui (Locke, 1992, pp. 9-10; Orbell, 1995, p. 114) who fished the North Island out of the sea, and named it Te Ika a Māui, meaning "the fish of Māui” (King, 2003, p. 21). Other oral narratives about migration and ocean voyaging as a means of populating the Pacific tell the story of Kupe the explorer (Locke, 1992, p. 9; Orbell, 1995, p. 92) who sailed on a long and dangerous journey across Te Moana Nui a Kiwa, the Pacific Ocean, from Hawaiki to Aotearoa, looking for a new home. 
Many oral narratives have been staged in contemporary Aotearoa. Maui: One Man against the Gods (2007) was directed by Māori artist Tanemahuta Gray. This production combined 'traditional' cultural elements with European dance and theatre techniques, creating a distinct cultural fusion of different styles and influences. The play Te Rau OTe Rangi (2014), directed by Ngapaki Moetara is another example of a contemporary Māori play based on an oral narrative. This play depicts on the legend Kahe Te Rau O Te Rangi, which tells the story of Rangi's heroic swim from Kapiti Island to the mainland with her little daughter on her back. This play balances 'traditional' Māori performing arts such as waiata-ā-ringa (action songs), mōteatea (chant), and haka (dance), with elements drawn from European theatre conventions (Ete, 2013). Oral narratives have been a clear inspiration for creative work to date, contributing to the repertoire of contemporary theatre produced by Māori theatre practitioners in Aotearoa, and reflecting a strong desire to celebrate and to reclaim traditional stories in the contemporary context.

\subsubsection{Historical Influences on the Production of Contemporary Māori Theatre}

The arrival of European explorers marked the beginning of a new era in the history of Aotearoa, in which different stories about how the land was populated came to dominate. The Dutch explorer Abel Tasman was the first European to sight Aotearoa in 1642. Over one hundred years later, in 1769, Captain James Cook rediscovered New Zealand on behalf of the British Crown (Brooking, 2004, p. 24). Subsequently, Māori communities began to make contact with foreigners who came to the shores with commercial intentions. By the 1870s Māori had become involved in commercial whaling, and in the timber and flax trades. The exchange of flax for muskets contributed to intertribal warfare in Aotearoa, especially against the southern tribes in the 1820s (Mein Smith, 2007, p. 37). In 1854 Māori people suffered the first European-introduced measles epidemic, killing “7\% of the Māori population” (Pool, 2012, p. 4).

The historical period of English settlement in New Zealand has inspired many creative works in contemporary Aotearoa. For example the play The Ragged (2010), directed by Jim Moriarty, narrates the story of the first colonial settlements in Port Nicholson, Wellington in 1840 and its relationship with the Māori inhabitants of that area (Atkinson, 2010). 
One of the most important moments in the history of Aotearoa/New Zealand is the signing of the Treaty of Waitangi. The treaty recognises Māori claims and rights to land in Aotearoa (Hayward, 2012, p. 5). It was signed by the British Crown and Māori chiefs on February $6^{\text {th }} 1840$ (Brooking, 2004, p. 7). The Treaty established the obligations and rights that each party would have in this new contract, however much of the legal content of the treaty was not actually implemented in New Zealand courts until the 1970s. In 1975 the Waitangi Tribunal was established to hear all cases that claimed that the treaty had been breached, and to suggest possible responses and solutions (Walker, 2004, p. 252). The Treaty of Waitangi has led to a number of agreements and also conflicts that in some cases persist to the present day. By recognising both Māori and Pākehā as having equal rights in the New Zealand state, the Treaty laid the foundations of biculturalism ${ }^{23}$ in Aotearoa, a founding principle of the modern New Zealand nation state. Pākehā and Māori theatre practitioners continue to explore how biculturalism in Aotearoa/New Zealand has been imagined through their creative work. ${ }^{24}$

The creation of the Treaty of Waitangi did not lead to an end of conflict regarding land in Aotearoa. Between the 1840s and 1860s, a series of "turbulent and unsettling" (Downes, 1975, p. 7) conflicts over sovereignty and the control of land occurred between Europeans and Māori tribes. For example, several Māori chiefs in the region of Taranaki opposed the sale of land to the New Zealand crown, resulting in series of armed conflicts between 1860 and 1861(King, 2003, pp. 212-213). Different committees and parties were created as a result of these conflicts. The establishment of the Native Land Court between 1865 and 1867 which included four Māori parliamentary seats, was froma a Pākehā perspective a formal attempt to end the killings and wars, replacing them with aims to settle disputes over land through the legal system (Brooking, 2004, p. xix; King, 2003, pp. 255-256). However, from a Māori point of view the purpose of the Native Land Court was to release Māori land "from collective ownership and making it available to individual settlers" (Walker, 2004, p. 136). In 1834 the Kotahitanga Unity was formed, bringing together members from around the country until 1840, resulting in the creation of a Māori Parliament between 1892 and 1902 (King, 2003, p. 328).

A formal Māori political party was established in the early twentieth century. The formation of the Māori Party was driven by a group of prominent Māori professionals

\footnotetext{
${ }^{23}$ See discussion in Chapter Three

${ }^{24}$ See discussion in Chapter Four
} 
including the Lawyer Apirana Ngata, Doctor Peter Buck, and Doctor Māui Pōmare (Keane, 2012, p. 4), who were all graduates of Te Aute College. The main objective of the Māori Party at this time was to encourage tribes to participate in health and social reforms designed to improve "the social and economic position of Māori” peoples (Sulivan, 2012, p. 1). Ngata became Minister of Native Affairs between 1928 and 1934 (King, 2003, p. 336) and he is a significant figure in the history of the relationship between Māori and New Zealand. His professional skills and knowledge of the English settlers’ world assisted Māori development (Sulivan, 2012, p. 2).

Ngata also encouraged the preservation of Māori culture and identity through the performing arts. He was one of the main figures responsible for the popularisation of waiata-ā-ringa (action songs) in early twentieth century. These action songs use 'traditional' actions in relation to lyrics and melodies which are often more contemporary than the movements. Waiata-ā-ringa "emerged from the combination of European tunes and Polynesian actions underpinned by Māori narrative” (V. Smith, 2014, p. 3). This is an early example of the blending of 'traditional' and 'contemporary' cultural elements this thesis is interested in, indicating that these cultural blendings have always been part of cultural development. Ngata published Ngā Mōteatea in 1929. This two-volume book on the history and descriptions of waiata-ā-ringa has been a rich source for kapa haka performers, researchers, and academics.

During the Second World War, new allegiances were established in the Pacific Region which have also been an inspiration for contemporary creative works. The Second World War (1939 - 1945) saw the $28^{\text {th }}$ Māori Battalion, commanded by Māori officers such as Arapeta Awatere and James Henare, fight alongside their Pākehā comrades (King, 2003, p. 569). The participation of Māori soldiers in the Second World War has inspired the creation of several Māori plays. Some recent works relate to the experiences of Māori soldiers during battle, includes The Battalion (2006) directed by Jim Moriarty. This play explores the experiences of young soldiers in the $28^{\text {th }}$ Māori Battalion, and follows the stories of the grandchildren of one of the veterans, linking the past with the present ( $\mathrm{J}$. Smythe, 2006). $T \bar{U}$ (2012) written by Hone Kouka, is based on a novel of the same name by Patricia Grace. This play looks at the "effects of war at a personal level rather than global" (Coleman, 2012) exploring the conflicts involved in soldiers leaving their 
families to go to war. Both plays incorporate 'traditional' performance elements such as haka and poi, and depict Māori rituals within the dramaturgy of the play ${ }^{25}$.

The turbulent decade of the 1970s led to the creation of Māori theatre as it is known today. The Land March of 1975 was a turning point for Māori theatre practitioners. Conflicts about land had been a significant issue for Māori, and protests around Aotearoa stimulated the creation of the first full length Māori play, Te Raukura ${ }^{26}$ (1972) written by Harry Dansey (Kouka, 1999, pp. 12-13). This play explores "the life of the Māori prophet Te Ua Haumene, the founder of the hau hau cult in 1860" (Balme, 1999, p. 121), who drew on biblical teachings to make arguments about the restoration of sovereignty (King, 2003, pp. 217-221). The 1970s saw the commencement of the formal development of Māori theatre in Aotearoa, which developed into a movement dedicated to the regular production of new works. Māori saw theatre as powerful tool to communicate their discontent with the New Zealand government, presenting stories based on historical facts in order to explain and assert their point of view, and their perception of this relationship.

This brief history reveals the strong and ongoing commitment of Māori people to obtaining political and cultural self-determination, paving the way for the incorporation of 'traditional' Māori performing arts in new contexts and for new purposes. Theatre and the creative arts have been one of the avenues for this journey towards reclaiming Māori ways of knowing and being, through creating contemporary works which consciously reference cultural experiences both past and present. As one part of a much broader movement towards self-determination and sovereignty, Māori have used the arts as one way of exploring how issues relating to Māori culture and heritage would and should be treated in Aotearoa.

\footnotetext{
${ }^{25}$ See discussion in Chapter Four

${ }^{26}$ See discussion in Chapter Four
} 


\subsubsection{Institutional and Structural Support for the Performing Arts in Aotearoa: Developing Māori Methodologies for Theatre Training and Practice.}

Government initiatives to support the performing arts in Aotearoa began in the 1960s. The visit of Queen Elizabeth II to New Zealand in 1963 inspired the creation of an Arts Council later that same year. The Arts Council was later re-named Creative New Zealand, and it offered funding that led to the establishment of several regional theatres in Aotearoa between 1960 and 1970. In 1970 theatre director Nola Millar founded the Queen Elizabeth II Arts Council New Zealand Drama Training School (Guest, 2010, p. 18). In 1998 the school changed its name to Toi Whakaari: New Zealand Drama School ${ }^{27}$ (Atkinson, 2014), and introduced a new bicultural methodology for theatre training. This bicultural approach involved embracing Māori methodologies as an active element in the learning process. It developed a more dynamic theatre practice, and aimed to nurture theatre practitioners who would learn theatre that was specific to the New Zealand cultural context (Guest, 2010, p. 117) and which would enable students consider theatre through different cultural lenses (Ruth, 2010, p. vi). This bicultural pedagogy sought to honour the spirit of the Treaty of Waitangi which was revived through the significant social activism of the 1970s.

The inclusion of bicultural methodologies in theatre education has enduring impacts on the ways that theatre practitioners have created theatre which is not only in, but also seeks to be of Aotearoa/New Zealand. This approach has facilitated Māori and Pākehā students working together in collaborative processes, and learning from and about the different cultures that make up contemporary Aotearoa. Māori playwright and director Hone Kouka argues that learning different culturally-situated theatre techniques enables theatre practitioners to "gain another perspective and set of tools to choose from when creating a play... being able to combine Māori theatre methods with Western theatre" (Kouka, 2015). By being able to decide what and when to combine during the creation of a play, Māori theatre practitioners have created and produced their own distinct concept of and approach to theatre, narrating stories in their own terms, using methodologies and styles defined by Māori themselves (Potiki, 1991a, p. 58).

\footnotetext{
${ }^{27}$ See discussion in Chapter Five
} 
Another important initiative supporting the development of Māori theatre was the establishment of the Māori Theatre Trust in the late 1960s. The trust was founded as a result of the presentation of the opera Porgy and Bess (1965). Until this point the theatre world had been dominated by Pākehā actors (Downes, 1975, p. 11).This innovative performance featured a cast that included Māori actors such as Inia Te Wiata and Don Selwyn (Derby \& Grace-Smith, 2014, p. 1).

Other significant developments which helped open up the theatrical world to Māori cultural influences and understandings came through the impacts of several research projects that were undertaken in the 1960s. These projects investigated cultural differences in processes of acquiring knowledge, focusing on how Māori learnt and assimilated knowledge within the Pākehā educational system. They not only took into account socio-cultural and environmental differences, but also considered the many social and cultural consequences of Te Reo Māori being absent from the formal education system in Aotearoa (McIntosh \& Mulholland, 2011, pp. 51-52). These research projects highlighted key issues and inspired much debate. They were a catalyst for the establishment of educational systems created by and for Māori in 1980 which included Kohanga Reo (Māori language preschools), Kura Kaupapa Māori (Māori language schools) and Wānanga (Māori tertiary institutions). Māori education aimed to revitalize Māori language and culture, and these institutions were eventually awarded funding by the New Zealand Government in 1990 (Calman, 2013). This emphasis on the importance of learning Te Reo Māori as a way of supporting processes of cultural revitalisation has stimulated a variety of theatre productions including Te Reo week by Taki Rua (1994). During this week plays performed entirely in the Māori language ${ }^{28}$ helped not only in the revitalization of the Indigenous language but also in the development of audiences for Māori theatre.

\footnotetext{
${ }^{28}$ See discussion in Chapter Four
} 


\subsection{Samoan Migration to Aotearoa}

The archipelago of Sāmoa comprises the independent nation of Sāmoa and the unincorporated territory of American Sāmoa (Macpherson, 2004, p. 179). For many years Samoan customs, culture, and language were only found in Sāmoa. Europeans arrived in Sāmoa in the eighteenth century. Explorers, missionaries, and traders arrived in the nineteenth and the twentieth centuries. Successive German, United States, and New Zealand colonial administrations arrived in Sāmoa altering life in the archipelago (Macpherson, 2004, p. 165).

In the following section I will discuss, firstly, the influence of oral narratives as a source of inspiration for creative work amongst the Samoan community living in Aotearoa. I will then consider the impacts of Christian missionaries in Sāmoa, and their enduring influence on Samoan theatre production in Aotearoa. Next, I discuss the historical factors that led Samoans to migrate to New Zealand from the early 1950s onwards. Finally, I will explore the importance of theatre education in Samoan theatre production in Aotearoa.

\subsubsection{Oral Tradition and Samoan Theatre in Aotearoa}

In Samoan epistemologies the supreme god is Tagaloa, the god of creation, who created everything from a rock (Meleisea \& Schoeffel Meleisea, 1987, p. 2). Many other deities existed and served different purposes in Samoan culture. Their deeds were transmitted to the community through fagogo, the 'traditional' form of Samoan storytelling (Lichtenberg, 2011, p. 11). These creation stories, in their many different versions, explain the origin of the islands, as well as the origin of the paramount chiefs and the people of Sāmoa.

Creation stories and myths have been a source of inspiration for the production of Samoan theatre in Aotearoa. The term myth can be translated as tala o le vavau, meaning story from the vavau, where the word vavau means "forever into the future" (Kamu, 1996, p. 71). This Samoan understanding of the concept of myth gives the word "a sense of timelessness, a story that despite changing times and originating from the far distant past is never totally lost” (Lichtenberg, 2011, p. 15). Myths can be understood as connecting the past with the present by allowing the re-interpretations of these stories in 
contemporary Samoan culture in Aotearoa, thus indicating the ever present aspect of innovation in what is considered 'traditional.'

Re-interpretations of 'traditional' oral narratives have been depicted in different Samoan plays produced in Aotearoa between 2013 and 2015. One example of such works is the dance-theatre piece Mixed Nuts-Mythical directed by Olivia Taouma and Lima Productions, and performed at the Mangere Arts Centre during the Auckland Fringe Festival in 2013. This dance-theatre was described as "[a]n ocean of motion" which borrows different 'traditional' oral narratives from across Polynesian cultures to create a contemporary performance (Ashley, 2013). The play starts with a re-interpretation of the Tongan oral narrative, Fale Fa, continuing with a Samoan oral narrative telling the story about how the art of tattoo arrived to the Samoan archipelago, and finishing with the Hawaiian oral narrative of Pele, the goddess of fire and volcanoes. Dances combined "recycled and transformed traditional haka movement[s]" (Ashley, 2013) with hula and street dance to produce a contemporary re-interpretation of 'traditional' Polynesian oral narratives. Another example of contemporary work based on oral histories is the play The Eel and Sina (2015) by Jono Soo-Choon. This play was presented at Measina Festival 2015. It is based on the "popular myth Sina and the Eel" and narrates the "untold side of the story" (Gibb \& Lualua, 2015) ${ }^{29}$ thus re-interpreting this 'traditional' Samoan oral narrative.

\subsubsection{The Influence of Christian Missionaries on Samoan Theatre Productions}

Christian Missionaries sent by the London Missionary Society (LMS) arrived in Sāmoa between 1830 and 1850. Ensuring that Samoan people received a Christian education was one of the main objectives of the early missionaries. In 1834 the LMS Mission in Huahine in the Society Islands - the church's base for the missionisation of Sāmoa and other Pacific Islands - published the first book of hymns, catechism, readings and spelling in the Samoan language. In 1835 the first Samoan dictionary was published, which encouraged missionaries to study the Samoan language, as well as supporting Samoans to learn to read and write in their own language (Meleisea \& Schoeffel Meleisea, 1987, p. 58). Missionaries trained Samoan men as pastors, placing them in

${ }^{29}$ See discussion in Chapter Four 
charge of parishes in the different villages. In this way the missionaries could promote formal education and teaching at the different church schools and colleges (Meleisea \& Schoeffel Meleisea, 1987, p. 59).

Religious teachings have had a great impact on Samoan society. The missionaries imposed their Christian vision of how the Samoan family should be formed, which was based on the ideals of the English middle class family, proposing the man to be the breadwinner and the woman as home-maker (Meleisea \& Schoeffel Meleisea, 1987, p. 67). The introduction of gospels challenged and changed Indigenous Samoan ideas about the chief's ultimate authority. For example, the idea that Samoan chiefs had a divinelyinspired authority changed to an acceptance of the idea that Samoan chiefs now had to obey the Christian God's laws (Meleisea \& Schoeffel Meleisea, 1987, pp. 68-69).

In relation to the performing arts, theatre was introduced to Sāmoa by Christian missionaries, who used theatre as a form of religious education which could reach Samoans who were not able to read or write, staging plays based on the Old Testament (Sinavaiana, 1998, p. 236) during religious holidays. Such performances continue in Samoan Congregational Christian Churches (formerly LMS) as well as other denominations. The most striking example is White Sunday, a day given over to performances by children and young people, which is celebrated on the second Sunday in October. ${ }^{30}$ The Samoan director and performer Tupe Lualua recognises the influence that this religious holiday had in her artistic life, stating that she is "not trained professionally [in theatre], just eighteen years of White Sunday" (Fresh TV, 2011).

\subsubsection{The Samoan Colonial Era: Inspiring Theatre Productions in Aotearoa}

Commercial interests attracted European migrants to Sāmoa. They were seeking cheap land on which to produce cotton and copra. In the nineteenth century the arrival of Germans, British, and people from the United States did not initially have a great impact on Samoan society. Conflicts of power amongst these new settlers enabled the Samoan "to exploit these divisions" (Macpherson, 2004, p. 166). At the close of the nineteenth century, through the Treaty of Berlin (Macpherson, 2004, p. 166), the US acquired the

\footnotetext{
${ }^{30}$ See discussion in Chapter Four
} 
eastern islands of Tutuila and the Manu'a group, while the Germans gained control of Western Sāmoa, ruling from 1899 until 1914 (Meleisea, Schoeffel Meleisea, Sio, \& Suafole, 1987, p. 108). With the outbreak of the First World War, New Zealand troops were sent to Sāmoa to take control from the German authorities (Meleisea \& Schoeffel Meleisea, 1987, p. 126) administrating the archipelago between 1918 and 1961(Macpherson, 2004, p. 166). In 1962 Western Sāmoa gained independence from New Zealand, becoming the first independent island country in the Pacific (New Zealand Government, 2014).

Early in the New Zealand administration of Sāmoa two significant events took place. Firstly, in 1918 the New Zealand Government in Sāmoa allowed the ship Talune to dock in Apia. The ship was carrying passengers with pneumonic influenza. This led to an epidemic which killed one fifth of the population of Sāmoa (Meleisea \& Schoeffel Meleisea, 1987, p. 129). During the commemoration of the $40^{\text {th }}$ anniversary of Samoan independence in 2002, the New Zealand Prime Minister Helen Clark made a speech in which she acknowledged the devastating effects of the influenza epidemic. She officially apologised for "the inept and incompetent early administration of Sāmoa by New Zealand" (The New Zealand Herald, 2002). This significant historical event has stimulated creative works including a dance-theatre piece entitled 1918, written and directed by Tupe Lualua (2015) that was inspired by Lualua's grandmother's memories of the influenza epidemic of 1918 (Gibb \& Lualua, 2015).

The second significant development in Samoan history which has inspired subsequent creative work was the formation of the Mau movement in 1926. This movement highlighted the mistreatment of Samoan people by the New Zealand administration, and sought to gather support for Samoan self-determination (Meleisea \& Schoeffel Meleisea, 1987, p. 133). Led by Tupua Tamasese Lealofi III, the Mau movement pursued a "peaceful, orderly programme of non- cooperation with the New Zealand Administration" (Meleisea \& Schoeffel Meleisea, 1987, p. 135). After years of peaceful resistance, violence broke out in 1929 when resident NZ police attempted to arrest a Mau member during a procession in Apia, and Tamasese and at least seven other Mau members were shot dead and one policeman was beaten to death (Meleisea \& Schoeffel Meleisea, 1987, p. 209). This part of Samoan history is portrayed in the play Think of a Garden (1992) by the American Samoan playwright John Kneubuhl. Set in 1929, in 
neighbouring American Sāmoa, the play narrates the turbulent struggle for independence during the Mau movement.

\subsubsection{Samoan Migration to Aotearoa}

The first significant migration from Sāmoa to Aotearoa began in the late 1950s. New Zealand's manufacturing sector was expanding and "employers turned to the Pacific for unskilled and semi-skilled workers" (Spoonley, 2012, p. 4). In Sāmoa, factors including swift population growth and the impacts of a cyclone in 1966 on food supplies encouraged Samoans to regard migration to Aotearoa with greater interest (Macpherson, 2004, p. 167).

While Cook Islanders, Niueans and Tokelauans migrated to Aotearoa as citizens due to those islands' respective political arrangements with New Zealand, ${ }^{31}$ Tongans and Samoans "required approval to live and work in New Zealand" (Spoonley, 2012, p. 4). During a period of high demand for labour however, such requirements were frequently overlooked. Following the economic downturn after 1973, "police and immigration officials sought to identify and deport those who overstayed their work permit" (Spoonley, 2012, p. 4). This episode in New Zealand's history, known as the dawn raids, was characterised by raids on the homes of migrants and significant police harassment and violence. New Zealand Samoan playwright Oscar Kightley's play Dawn Raids in 1997 narrates the experience of a Samoan family during this period. This play staged a “dark period in New Zealand's recent history" (Mallon, 2002, p. 144) which had often been silenced, from a Samoan perspective. Despite the historically turbulent relationship between Samoan migrants and the New Zealand state, the Samoan community is the largest Pacific Island group currently living in Aotearoa. According to the 2013 Census, Samoans living in Aotearoa numbered 144,138 people, comprising 3.3\% of the total population, and $49 \%$ of the Pacific population living in Aotearoa (Statistics New Zealand, 2014).

\footnotetext{
${ }^{31}$ People from the Cook Islands, Nuie and Tokelau gained the status of New Zealand citizens through different acts. In 1901 the Cook Islands were annexed to the New Zealand territory by The Cook and Other Islands Government Act (Gilson, 1980, p. 110). That same year Niue changed its status of being a British protectorate when New Zealand annexed the island (Chapman, 1982, p. 126). In 1948 by the Tokelau Island Act, the archipelago became part of New Zealand (McQuarrie, 2007, p. 126). The status of New Zealand citizens of all these Pacific Islands has been retained to the present day.
} 
In Samoan culture the concept of migration is not simply understood as involving sociocultural "up rootedness and rupture" (Lilomaiava-Doktor, 2009, p. 1). On the contrary, the Samoan concept of migration, malaga, implies the notion of travelling back and forth between the "i'inei... where one originates from" (Lilomaiava-Doktor, 2009, p. 7) and the new place. The space between both destinations is called in the vāa a term which "connotes mutual respect in socio-political arrangements that nurture the relationship between, people, places, and social environments" (Lilomaiava-Doktor, 2009, p. 12). Samoan migration leads "to a reshaping of boundaries and reconfiguration of culture, community, and spirituality, as well as an expanded territorial distribution" (LilomaiavaDoktor, 2009, p. 10).

The concept of the vā allows Samoan migrants to carry and maintain the concept of "fa'aSāmoa, or Samoan language, customs and practice" (Macpherson, 2004, p. 171) in a new context. It recognises that there are always spaces between people which need to be navigated, nurtured and understood:

Fa'aSāmoa has an elusive quality, for although it undoubtedly exists, it derives ultimately from people's emotions and situations... there are many perceptions of what fa' aSämoa is and means... [yet] every Samoan is very clear about what their perception of the fa' aSämoa is (Anae, 2002, p. 152).

Fa'aSāmoa has undergone changes and adaptations in Aotearoa. For example, the concept has been adapted to include the increasing number of non-Samoan or nonSamoan speaking people involved in different Samoan ceremonies, or to incorporate events such as graduations "which were not typically Samoan” (Macpherson, 2004, p. 173 ) into the culture and worldview. Despite these changes fa'aSāmoa remains essential to the worldview of the Samoan community in Aotearoa. It is this aspect of fa'aSāmoa, which involves recognising, understanding, and adapting to change, that has helped to facilitate the production of Samoan theatre in Aotearoa as a form which draws upon a variety of diverse influences, cultures, and traditions. By understanding the space between the place of origin and the place where one resides as a liminal space, it is possible to adapt 'traditional' practices and ceremonies to the new context without losing them completely. This understanding could be useful for Rapanui performers, as it is applied to the space between the 'traditional' and the contemporary alike: a liminal space 
where these two concepts are used, negotiated and adapted in the representation of Samoan theatre in Aotearoa.

\subsubsection{Tertiary Education and the Samoan Community in Aotearoa}

Aotearoa provides assistance to Sāmoa in terms of supporting the development of education through bilateral relations with Sāmoa which were established by the 1962 Treaty of Friendship. Forms of assistance include providing scholarships to attend tertiary institutions in New Zealand (New Zealand Government, 2014). Access to specialist education in theatre and the creative arts has been a key aspect in the development of Samoan theatre in Aotearoa. Most prominent theatre practitioners from the Samoan community are graduates of Toi Whakaari: New Zealand Drama School. For example, actors Lani Tupu Jr and Eteuati Ete were the first and second graduates of Samoan heritage from Toi Whakaari in year 1979 and year 1984, respectively. Australian-based Lani Tupu founded Screen Actor Studios in the late 1990s and in 1995 directed one chapter of the Tala Pasifika series showcasing Samoan talent (NZ on Screen, 2012). Eteuati Ete is one of the founding members of New Zealand's first Pacific island theatre groups Taotahi, formed in 1981. He is one of the comedians in the group Laughing Samoans, and a playwright of The Johnny Smith Myth which tells the story of a Samoan rock star who becomes famous worldwide (Mallon, 2002, p. 143).

Another Toi Whakaari graduate of Samoan descent is Anapela Polataivao, who is an actress and the co-producer of the theatre company Kila Kokonut Krew. Polataivao also co-produced the first Samoan musical entitled The Factory in 2013. Sāmoa's first female filmmaker Sima Urale also studied at Toi Whakaari. She directed the short film $O$ Tamaiti in 1996 which focuses on the life of an eleven-year-old boy forced to play guardian and protector to his four siblings with adult maturity (O'Leary, 2008). Another example is the Samoan actor and playwright David Fane who, alongside with Oscar Kightley, was the founding member of the performance troupe Naked Samoans and took part in a number of significant Samoan diasporic productions such as Fresh Off the Boat (1993), and the feature film Sione's Wedding (2006). Other examples include Niuean Samoan Vela Manusaute and Samoan Victor Rodger who trained as actors at Toi Whakaari and then later became playwrights. The list of successful actors with formal education in theatre continues to grow, bearing in mind that Toi Whakaari: New Zealand 
Drama School, Whitireia and Pacific Institute of Performing Arts (PIPA) graduate new actors, directors, and writers of Samoan descent each year. ${ }^{32}$

\subsection{Comparing Histories and Theatre Productions from Three Different Pacific Cultures in Two Different Contexts}

At first glance the territories and the demographics of Aotearoa and Chile may seem almost incomparable. The former is an archipelago in the South Pacific with a total population of about five million people. The latter is a long and thin country in South America which has about sixteen million inhabitants. The capital city of Chile, Santiago, has a population that exceeds the entire population of Aotearoa. It is also difficult to compare Aotearoa to Rapa Nui. The total population of Rapa Nui is equivalent to $0.1 \%$ of the total population of Aotearoa; therefore monetary resources available to these populations are radically different. It is in these radically different contexts, Aotearoa and Rapa Nui that I will compare and contrast the relationship between their respective governments, specifically in relation to the production of theatre. It is not my intention to compare Aotearoa with Chile and Rapa Nui to determine who has better or worse infrastructure for the development of Indigenous theatre. The purpose of this comparison is to identify differences and similarities in the social, cultural, and economic environments influencing the development of Māori and Samoan theatre in Aotearoa, and Indigenous theatre in Rapa Nui, and to see in what aspects can the Indigenous theatre practice in Aotearoa influence the theatre practice in Rapa Nui.This comparison will demonstrate the different ways in which Indigenous theatre practitioners have used historical events as a source of inspiration for the creation of theatre productions.

\subsubsection{The Influence of History on Contemporary Theatre Production}

Both New Zealand and Chile signed treaties which have framed the relationship between the respective governments and the Indigenous people of these countries. The Treaty of Waitangi (1840) and the Acuerdo de Voluntades (1888) established the rights and obligations that each party would have in respect to these contracts. The bicultural

\footnotetext{
${ }^{32}$ While most Pacific Island theatre practitioners in Aotearoa are of Samoan heritage, hence the decision in this thesis to focus on Samoan diasporic theatre production, actors, directors and playwrights from Fiji, Tokelau, Niue, and the Cook Islands have also made important contributions to the development of theatre created by Pacific Island migrants in Aotearoa.
} 
political environment and social imaginaries created through these treaties has resulted in many ongoing conflicts. Issues concerning land ownership and the loss of sovereignty of Indigenous groups have been at the centre of debate and division in both nations.

To address some of these issues, Māori and Samoan theatre practitioners have chosen to use theatre to share their version of history with the rest of the population. Through theatre, these communities have created strong counter narratives which challenge official versions of history, for example Kightley's Dawn Raids. In both Aotearoa and Rapa Nui, theatre has been used as a tool to revitalise Indigenous languages. However Rapanui theatre to date has not been overtly politicised, or used to communicate discontent with the Chilean government.

The history and production of theatre in Chile and Rapa Nui were significantly impacted by the military dictatorship of Augusto Pinochet. Pinochet ruled Chile between 1973 and 1990. During this seventeen-year period, the production of the arts was severely impacted. The Pinochet government saw artists as subversive political agitators and during the early years of the dictatorship some artists were assassinated (Soto \& Delgado, 2015). Nearly $25 \%$ of Chilean theatre practitioners were forced into exile in neighbouring countries (Alvarado, 2006, p. 1). During this period university theatre programs offered at the Universidad de Chile and the Universidad Católica were closely monitored by the government. The independent theatre groups who remained in Chile decided to disguise their discontent with the government using comedy. In fact, between 1974 and 1982, Chilean theatre groups produced around 45 plays protesting against the dictatorship (Alvarado, 2006, p. 1).

During Pinochet's regime Rapa Nui was placed under martial law. Pinochet visited Rapa Nui in 1974, 1980, and in 1987 (S. R. Fischer, 2005, p. 227). During this period of military rule private property rights were restored in Rapa Nui, and considerable construction was completed to expand infrastructure on the island. In terms of the production of creative work, Rapanui anthropologist Paloma Huke explains that the presentation of Rapanui performing arts decreased enormously. The few performances that were created were framed for the tourist industry of that time. Huke blames the Pinochet dictatorship for transforming the Rapanui culture into an 'artistic show' with content geared towards the tourist industry (Paloma Huke, 1995, pp. 57-58). 


\subsubsection{Governmental Support for the Development of the Creative Arts}

New Zealand and Chile have government departments dedicated to providing financial support for artistic and cultural projects. In New Zealand, Creative New Zealand provides funds and supports the development of the creative arts in the country. All New Zealand residents are eligible to apply for support and resources from Creative New Zealand. This includes Pāhekā, Māori, and Pacific Islanders, although there are separate dedicated funds for supporting creative projects by Māori and Pacific Islanders.

Between 2013 and 2014, 23\% of the total funding for arts projects was allocated to theatre projects. Overall $11 \%$ of Creative New Zealand funding was awarded to Māori groups, $8 \%$ to multicultural projects, $6 \%$ to Pacific Islanders, and $0.02 \%$ was awarded to joint projects between Māori and Pacific Island artists (Grant \& Wallace, 2014, p. 19).

In Chile the creation of an institution with similar aims and objectives to Creative New Zealand is fairly recent. The restoration of democracy in Chile in 1990 led to the production of the arts slowly returning to Chilean society. In 1993 the Culture Department of the Ministry of Education established the Fondo Nacional de las Artes Visuales (FONDART) ${ }^{33}$ FONDART grants both full and partial funding for artistic projects, contributing to the artistic and cultural development of Chile (P. Fortin, 2014). In 2003 the Consejo Nacional de la Cultura y las Artes (CNCA) ${ }^{34}$ was created under the government of President Ricardo Lagos (2000-2004). The CNCA led extensive discussions in parliament regarding how the Chilean government could, or rather should, foster and promote the production of arts in the country. On the $23^{\text {rd }}$ of August 2003 Chile appointed its first Minister of Culture, Jose Weinstein. This appointment signified the arts as being back on the cultural and political agenda (CNCA, 2003).

Nearly ten years after the establishment of Creative New Zealand (1994), Chile created a similar entity to provide funds to develop artistic and cultural projects around the Chilean territory. Because Rapa Nui is not physically located within Chilean territory, securing finances for projects was difficult, and funding was rather sparse. In the early stages of the CNCA, applications could only be made on paper. They then had to be posted to the central office in Santiago via the weekly aircraft flying to Santiago from Rapa Nui. Information regarding the opening dates and the deadlines for each piece of funding

\footnotetext{
${ }^{33}$ National Fund for the Visual Arts

${ }^{34}$ National Council for Culture and the Arts
} 
offered by the CNCA often reached Rapa Nui late, and it was common to initially learn that funding applications were open only days before the closing date. Another problem with applications from Rapa Nui was the lack of support and assistance with completing applications (Oñate, 2014). These issues meant that artists and community groups in Rapa Nui often failed to successfully apply for funding. Another reason for the lack of success in applying for funding was the overwhelming amount of questions and details that applicants had to provide. This was information that in many cases, Rapanui artists were not sure how to formulate in their application. For example, questions regarding the background and main purpose of the project, budgets, and obtaining support letters from all the participants, often seemed a daunting task for Rapanui artists (Oñate, 2014).

A lack of information and accessibility issues surrounding obtaining funding offered by CNCA often resulted in funding being given for projects about Rapanui peoples and culture which were created and developed by outsiders. This generated tensions, as the Rapanui artistic community felt that their cultural heritage was being appropriated by outsiders who did not always appreciate, recognize, or respect it adequately (Oñate, 2014). In response to these issues the CNCA opened a liaison office in Rapa Nui in March 2011. Macarena Oñate Paulo was in charge of this office. Her task was not only to assist artists who were applying for funds, but also to train a future liaison officer from the Rapanui community, who would eventually be in charge of the office. Oñate explains that her work at the liaison office had a significant effect on the number of applications made by Rapanui artists:

[B] efore 2011 Rapanui applications were scarce, only one per year, that is if anyone applied... after the liaison office opened, applications have been increasing, and now for the proceeds of this year [2014], there are ten Rapanui applications (Oñate, 2014).

The opening of the CNCA liaison office has supported Rapanui artists to create and develop their own artistic projects. 


\subsubsection{Cultural Encounters with Polynesian Peoples and their Influence on the Rapanui Creative Arts}

One of the main disadvantages for the development of the creative arts on Rapa Nui is the geographic isolation of the island. Although the Rapanui population is connected to Chile and the rest of the world via the internet, mainly through Facebook and You Tube, travel to and from the island is physically difficult, and expensive. Although aircraft land on Rapa Nui daily, the cost of transportation is high. $\mathrm{LAN}^{35}$ is the only airline serving Rapa Nui and they have a monopoly on travel to and from the island. Although the airline provides a low number of subsidized 'special' seats for Rapanui residents at half the price a tourist would pay, preference is given to the revenue that tourist seats bring with them. This situation also makes it difficult for artists from overseas, whether from Chile or another Pacific island, to reach Rapa Nui and to collaborate with Indigenous artists.

In spite of these difficulties, interesting intercultural artistic encounters have taken place in Rapa Nui. In 1973 the Chilean socialist government supported cultural exchanges with New Zealand under the prism of 'folkloric encounters.' These exchanges supported the examination of Rapanui identity and cultural heritage (Bendrups, 2005, p. 35).

Another significant intercultural encounter took place in 1995, when a meeting of peoples representing a variety of Polynesian cultures was held in Rapa Nui. Mana Tupuna involved representatives from Polynesian communities in Oceania. The name Mana Tupuna was given to the gathering in remembrance of an ancient Polynesian ceremony and gathering which would have in the past taken place to mark the winter solstice (Edmunds Paoa in El Mercurio, 1995). The ceremony was also held to mark the completion of restoration work on Ahu Tongariki, the largest archaeological monument of Polynesia, comprising an ahu (ceremonial platform) of about 600 tons and 200 meters long, and featuring 15 moai (El Mercurio, 1995). Representatives of Hawai' $i$, Tahiti, the Marquesas Islands, Aotearoa, and the Cook Islands were invited to this ceremony. Alberto Hotus, President of the Rapanui Elder's Council explained that Mana Tupuna would enable Pacific peoples to "share milestones of our histories and realities as Polynesian nations" (Hotus, A in La Estrella, 1995).

${ }^{35}$ Linea Aerea Nacional (National Airlane). 
Another significant event in the development of the creative arts in Rapa Nui took place in 1999 when the Hawai ‘i-based Polynesian Voyaging Society's ocean-going canoe Hokule'a arrived in Rapa Nui. The Hokule'a demonstrated and celebrated the canoe building skills of Polynesian ancestors who navigated the ocean reading stars, winds, and currents (Kreifels, 1999b). This voyage navigated the Polynesian triangle. After seventeen days of sailing between Mangareva and Rapa Nui, a distance of approximately 9,000 miles, the journey was completed. Rapanui archaeologist Sergio Rapu described the arrival of the Hokule'a to Rapa Nui as a "great gift of tremendous symbolic value, a dream come true" (Kreifels, 1999a). Rapu hoped that the visit of the Hokule'a would "inspire a renaissance of Polynesian culture and pride" (Kreifels, 1999a) as well as enticing the "Rapanui community to look more to the Pacific than to Chile" in terms of cultural connections and influences (Rapu in Kreifels, 1999a).

Student exchanges have also contributed to keeping connections with Polynesia alive. In 2005 Aldea Educativa high school created a student exchange program between Rapa Nui and Aotearoa. Students from Rapa Nui stayed with both Māori and Pākehā families for one month, and went to a New Zealand high school. New Zealand students also went to Rapa Nui to study, usually staying for a month of cultural immersion. These exchanges enabled both parties to learn from each other's life style, worldview, culture, and customs. This exchange program ended in 2007 due to a lack of financial resources. Tapati Rapa Nui Festival ${ }^{36}$ (Tapati) is an annual cultural festival and has been another opportunity for connections between Rapanui and Polynesian artists. Visitors to Tapati have included Tahitian, Marquesan, and Māori dance groups. The Tapati lasts for two weeks; however workshops and creative exchanges between Rapanui dance groups and visiting performers have not been a significant feature of the festival to date. Although watching a performance may influence or inspire your own work as an artist, creative interactions between the groups should be encouraged and seen as important. Since reaching Rapa Nui is so difficult and expensive, these rare opportunities for creative exchange should be maximised for both parties, involving embodied cultural exchanges of practice, through which both groups could learn from each other.

Another significant encounter between Pacific peoples includes the Māori Waka Tapu sailing expedition, which arrived in Rapa Nui in October 2012. The Waka Tapu

${ }^{36}$ See discussion in Chapter Four 
expedition stayed in Rapa Nui for around two weeks and two young Rapanui, a man and a woman, were invited to sail with the Māori Waka Tapu crew to Tahiti. The Rapanui woman, Serafina Moulton, was invited to stay with the voyage all the way back to Wellington, arriving in New Zealand in 2013.

\subsubsection{Cultural Encounters in Aotearoa and their Influence on the Creative Arts}

Despite the construction of Aotearoa/New Zealand as a bicultural nation, the contemporary reality is multicultural. This cultural diversity ${ }^{37}$ enables regular cultural encounters between people, supporting Māori and Samoan theatre practitioners to be aware of and to see what artists from different cultural communities are creating. A variety of festivals in Aotearoa support the exchange and understanding of different cultural ideas. Initiatives such as the Pūtahi Festival, the Matariki Development Festival $^{38}$, and the community group Kava Club support interactions between Māori and Samoan artists. These initiatives provide Māori and Samoan artists with the opportunity to share their new work, either works in progress or finished products. In this context Māori, Samoan, Pākehā, and all the other cultures that live in Aotearoa are constantly feeding into and inspiring each other's artistic work.

In addition to larger national arts festivals, local arts festivals are organised around the country. These festivals are held every two years in each city, rotating so that there is at least one arts festival in each major city each year. These Arts Festivals are held in Auckland, Tauranga, Taranaki, Wellington, Nelson, Christchurch, and Dunedin, and often feature Māori and Samoan diasporic theatre. The annual event Polyfest, formerly known as the Auckland Secondary Schools Māori and Pacific Islander Cultural Festival, was established in 1976 and celebrated its $40^{\text {th }}$ anniversary in 2015. Polyfest is a schools festival held in Auckland which celebrates the diverse Indigenous and Pacific cultures that are a significant part of contemporary Aotearoa (Tennent Brown, 2015). During this festival Māori and Pacific communities get together and celebrate through music, dance, and oratory both differences and similarities across Pacific cultures. The festival creates a creative cultural exchange, which may result in the strengthening of bonds already

\footnotetext{
${ }^{37}$ See discussion in Chapter Three

${ }^{38}$ See discussion in Chapter Four
} 
existing between diverse Pacific cultures. Polyfest has the potential to stimulate collaborative work between different cultural groups, thus enriching the production of performing arts in Aotearoa.

In contrast, Rapanui artists are not able to access this wide range of possibilities for intercultural exchange and collaboration which are available through the structure and rotation of local and national festivals in Aotearoa. These cultural exchanges made possible through festivals are something that Rapanui artists lack access to. In order to see what other artists are doing and creating, to learn, and to support interpersonal collaborations, Rapanui peoples must travel to Chile. This encounter between different cultural worldviews causes its own challenges, as the epistemologies of each group are often not well understood by the other. Based on my lived experience in Rapa Nui I argue that because of the complex and ongoing colonial relationship between the two countries, Rapanui peoples often want to distance themselves from the Chilean culture. By focusing on the work of Pacific artists as a source of inspiration, Rapanui peoples build on cultural links and continuities which are already established and well recognised, reflecting the current desire to preserve and protect Indigenous ways of knowing and being in the performing arts. The framing of Rapanui performances in Chile generally describes them as 'folkloric' presentations that are perceived as being of greatest value to the tourist market. In my experience no art gallery or theatre in Chile has yet scheduled exhibitions or the performance of Rapanui art.

There are opportunities for Rapanui peoples to meet with Pacific artists every four years, during the Festival of Pacific Arts. While participating in this festival is quite costly in terms of travel and accommodation, Rapanui artists prefer to participate in this festival for two main reasons. Firstly, this festival is a major event that brings together various Pacific cultures to perform not only music and dance, but also to share visual arts, crafts, tattoo, storytelling, and theatre among other art forms (Sanitoa, 2012, pp. 34-35). Although the Festival tends to emphasize 'traditional' rather than 'contemporary' performances, participating in this festival allows a variety of Pacific artists to meet and network.

Secondly, Rapanui artists choose to participate in the Festival of Pacific Arts because they value the artistic exchange of knowledge, methodologies, techniques, and tools that it affords. One example of this knowledge exchange can be seen in the recent 
performances of Rapanui Dance group Maori ${ }^{39}$ Tupuna. The work of this group was inspired by the works they were exposed to at the Pacific Arts Festival. In my interviews the director of Maori Tupuna Carlos Lillo Haoa explained, that "this festival is the only time where I can see what other people are doing, what they are creating... for example for our show in 2013, we had been working on the idea for a while, but when I saw a Hawaiian play during the Festival in Pagopago, the idea became clearer" (Lillo Haoa, 2014).

\subsubsection{Theatre Training in Two Different Contexts}

Learning the craft of theatre has been a key aspect in the success of Māori and Samoan theatre in Aotearoa. This success can in large part be attributed to the bicultural pedagogy that Toi Whakaari, Whitireia, and the Pacific Institute of Performing Arts (PIPA) ${ }^{40}$ have introduced into their theatre programs. Toi Whakaari for example has incorporated Māori methodologies, "as an essential element in the life of the School" (Penny, 2014, p.

2). These methodologies seek to build a unique drama school in Aotearoa based on Māori epistemologies. Whitireia's core value is manaki meaning to show respect. This approach values cooperation and sharing, and seeks to promote confidence among learners by creating "a positive and supportive learning environment" (Whitireia, 2012b). PIPA is a Pacific focused school were students and staff from across the Pacific work together (PIPA, 2010). PIPA is led by a team of directors who reflect the institution's intercultural approach. Letti Chadwick is of Samoan heritage and Sean Coyle is a Pākehā. This staff composition acknowledges the importance of maintaining an intercultural perspective in theatre education.

If Rapanui people want to study theatre formally they have to enrol in courses offered in Santiago, Chile. Chile does not yet have an institution that teaches theatre with a bicultural or intercultural vision such as has been developed in Aotearoa. The main theatre schools ${ }^{41}$ are located in Santiago, the capital city of Chile. There, it is possible to find theatre schools within a university context, such as Universidad Católica, Universidad de Chile, Universidad Mayor, and private theatre schools such as the

\footnotetext{
${ }^{39}$ In Rapanui language the word 'Maori' refers to the teacher or someone who is knowledgeable in a specific art or craft. It is written without macron.

${ }^{40}$ See discussion in Chapter Five

${ }^{41}$ See discussion in Chapter Five
} 
Fernando Gonzalez Theatre School and La Mancha among others. Out of these five schools, four are framed under the European model of theatre teaching Stanislavsky's and Grotowski's methodologies. La Mancha is the only institution in Chile which takes a different approach, focusing more on teaching physical theatre and clowning. Although Chile recognises four main Indigenous groups, the Aymara, Diaguita, Mapuche, and Rapanui the idea of introducing a bicultural or multicultural perspective within the theatre learning experience seems far away.

\subsection{Conclusion}

Colonial histories have undoubtedly affected the development of the performing arts in Aotearoa and Rapa Nui. This chapter considered historical and contemporary histories between Indigenous peoples from Aotearoa and Rapa Nui with their colonial counterparts New Zealand and Chile, respectively. It reflected upon the possibilities for engaging in the contemporary theatre scene for Māori and Samoan theatre practitioners in Aotearoa and Rapanui artists in Rapa Nui.

Indigenous theatre practitioners in both contexts have performed 'traditional' stories, reclaiming oral materials creatively to portray an Indigenous point of view on history. Through these performances they have consciously connected the past with the present by allowing the re-interpretation of 'traditional' stories in 'contemporary' works.

The signing of treaties between New Zealand and Māori, and Chile and Rapanui, contributed to the creation of a bicultural environment in both countries. The bicultural political environment and the social imaginaries created through these treaties have resulted in many ongoing conflicts. Issues concerning land ownership, the loss of language, and sovereignty of Indigenous groups have been at the centre of debate and division in both nations.

The bicultural relationship between the Rapanui peoples and the Chilean government is more theoretical than practical. Living on an island that is located 3,000 kilometres away from Chile has not enabled the development of a bicultural relationship to the same extent as in Aotearoa. The migration of Pacific peoples to Aotearoa since the 1950s has changed the socio-political environment from bicultural to multicultural, fostering intercultural collaborations in the production of performing arts. 
Since colonisation, Indigenous peoples of Aotearoa and Rapa Nui have both fought to gain legal recognition from within their respective administering nation-states. This chapter has revealed the strong and ongoing commitment of Māori and Samoan theatre practitioners in Aotearoa to obtaining political and cultural self-determination. They have used theatre to create strong counter narratives based on historical facts, in order to explain and assert their point of view and perception of the colonial relationship. In Rapa Nui, theatre has not yet been used as a tool for overt political expression: rather, focus has instead been on preserving and reclaiming 'traditional' knowledge and practices. Self-determination is a notion that could be beneficial in the production of Rapanui theatre, enabling Rapanui practitioners to voice their own perspective of socio-political issues through theatre.

Theatre education has been a key aspect in the development of Māori and Samoan theatre in Aotearoa. Access to theatre education which accepted and recognised bicultural theatre methodologies and pedagogies in New Zealand as important has helped immensely in the creation of theatre groups, as well as in the production and writing of plays, which will be explored further in a subsequent chapter. The lack of formal theatre education in Rapa Nui has inhibited the trajectory of the development of Rapanui theatre to date, and this is an aspect in which Indigenous theatre practice in Aotearoa could become a great influence in Rapanui theatre practice.

Rapanui peoples have focused on the work of Pacific artists as a source of inspiration, often as ways of distancing themselves from the Chilean culture whilst seeking reclaiming pre-colonial connections. Building on cultural links and continuities which are already established and well recognised in the wider Pacific, Rapanui peoples reflect the current desire to preserve and protect Indigenous ways of knowing and being in the performing arts. 


\section{Chapter Three}

\section{Theoretical Framework}

\section{Hai Aha He Anga Te Me'e $\mathrm{Ne}^{42}$}

\section{Al Pan Pan y al Vino Vino ${ }^{43}$}

\subsection{Introduction}

In Chapter Two, I showed that both Aotearoa and Chile have bicultural dimensions which continue to influence the development of theatre. This research is informed and inspired by my own practice and lived experience as a researcher and a performer in Aotearoa and Rapa Nui. My experiences have taught me that cultural encounters between two or more cultures are possible in the creative arts. The idea that intercultural collaboration through theatre and dialogue is possible reflects the inclusive theoretical framework underpinning this thesis. This chapter will define and describe this theoretical framework from different angles, drawing on key texts and ideas in Pacific Studies and Theatre Studies.

This chapter will begin by discussing different concepts and interpretations of the terms 'traditional' and 'contemporary'. It will consider the different attitudes towards these concepts from Māori, Samoan, and Rapanui perspectives. Secondly, the notion of

\footnotetext{
${ }^{42}$ With what [knowledge] am I going to do this [research]

${ }^{43}$ Calling things by their name. This Chilean saying prompts to define and describe things as well as possible.
} 
cultural encounters will be explored through a consideration of the different understandings and approaches used in bicultural (J. Greenwood, 2002, p. 7), and intercultural (Pavis, 1996, p. 8) theatre forms. Plays produced through cultural encounters can be understood as a form of negotiation, collaboration, and dialogue between people with different cultural heritage and understandings.

Thirdly, this chapter discusses the concept and definition of popular theatre. The way in which theatre has been performed in Rapa Nui has a direct relationship to this type of community theatre which is freely accessible, and is usually performed on an outdoor stage. The fourth section of this chapter considers community theatre an important tool used in Aotearoa to enable Indigenous groups to share their stories with the wider community. In the fifth and final section of this chapter, the impact that tourism has had on the performing arts in different communities of the Pacific will be analysed. The importance of tourist performances to providing Rapanui artists with a sustainable income and livelihood is one of the reasons why the concept of 'tradition' is so firmly embedded in the Rapanui creative community.

\section{2 'Traditional' and 'Contemporary'}

The term 'tradition' has relatively recent historic origins (Jolly \& Thomas, 1992, p. 241). Scholarly critiques of the concepts question notions of 'tradition' that imply something fixed, static, and timeless (Balme, 1998; Handler \& Linnekin, 1984; Hobsbawm and Ranger, 2012; Jolly and Thomas, 1992; Mallon, 2010; Stevenson, 2008; Thomas, 1995; Turner, 1997; Urry, 1979; Wendt, 1982; Whimp, 2010) Although definitions vary and are contested, 'tradition' often suggests a fictitious continuity with a historic past. Hobsbawn and Ranger define the term 'tradition' as:

a set of practices... of a ritual or symbolic nature, which seek to inculcate certain values and norms of behaviour by repetition, which automatically implies continuity with the past (Hobsbawm \& Ranger, 2012, p. 1).

Mallon articulates how 'tradition' emphasises material culture "the old, the authentic, and the most-treasured artefacts and cultural practices" (Mallon, 2010, p. 363). Other academic explorations of the term traditional express that when cultures are labelled 'traditional' it usually involves an assumption that the culture in question is stable and 
unchanging functioning as a "well-ordered system which remains constant over time" (Urry, 1979, p. 14). Ideas about 'tradition' are constantly negotiated in and through ideas and discourses in the present: "tradition demands a constant re-creation rather than a passive maintenance" (Handler \& Linnekin, 1984, p. 275). Therefore "writing an account of 'traditional' society is impossible, but more importantly it involves a view of society that is untenable" (Urry, 1979, p. 15). In this understanding 'tradition' is actively created and recreated by members of a culture. It is not a "motionless entity, a legacy obediently transmitted from generation to generation" (Handler \& Linnekin, 1984, p. 275).

Similarly, Barba explains that "the word 'tradition' is ambiguous. It brings to mind something that we are given, that we have idly received from the past" (Barba, 2002, p. 12), giving to the notion of 'tradition' a somewhat lazy quality, distancing it further from the contemporary acts of recreation that these understandings actually involve.

Wendt asserts that Pacific cultures cannot return to a past "utopia," instead they must embrace the use of "contemporary forms to express [their] uniqueness, identity, pain, joy and [their] own vision of Oceania and earth" (Wendt, 1982, p. 212), whilst also acknowledging a unique cultural legacy. Following the work of Wendt (1982) and Kouka (2007) I argue that notions of 'tradition' contribute to ideas about the identity and positionality of artists, and define the places and spaces from which artists face the world, delineating possibilities for contemporary creativity. As Albert Wendt points out in Towards a New Oceania, "knowledge of our past cultures is a precious source of inspiration for living out the present" (Wendt, 1982, p. 207).

In our talanoa, former head of Aldea Educativa high school ${ }^{44}$ in Rapa Nui, Ana Maria Arredondo stated that:

Everything that today is presented as traditional is valid. It is valid to the extent that it's what has remained in the memory... it's what remained as ancestral... giving an identity and that's what matters! (Arredondo, 2014)

For Arredondo, Rapanui identity has not been lost and it is being reclaimed through the arts, whether what it has been shown is old or not. During our talanoa, Julio Hotus, the

\footnotetext{
${ }^{44}$ Until 2007 this high school had several extra-curricular art workshops. These workshops included music, dance, theatre, sculpture, painting and literature. In 2014 during our talanoa the current Head of School Katherine Ringeling explained that the workshops were no longer carried out due to a lack of Municipal resources. The compulsory subjects of music and visual arts are the only arts subject taught today at this high school (Ringeling, 2014).
} 
Rapanui Regional Cultural Adviser at the National Council for Culture and the Arts (CNCA), agreed with Arredondo in terms of the need to reclaim Rapanui identity, however, he sees 'tradition' from another perspective. Hotus states that 'tradition' in Rapa Nui primarily involves the maintenance of the tourist gaze "the maintenance over time of something that somehow points to satisfy the curiosity of others... to meet the expectations of tourists" ${ }^{45}$ (Hotus, 2014). This involves leaving aside "your truth, your reality, your only point of reference" (Hotus, 2014). Hotus's words highlight the importance of assessing and understanding the concept of 'tradition' with regard to each specific Polynesian culture. There is a big difference between what the English speakers understand by 'tradition', and the meaning of this word in other Pacific Island languages, such as "kastom or pas in tumbuna in Melanesian pidgins, vakavanua in Fijian, fa 'aSāmoa in Samoan" (Jolly \& Thomas, 1992, p. 214), and I add haka ara in the Rapanui language. These Indigenous understandings acknowledge the continuity of the past into the present.

Notions of what is 'traditional' and arguments about the importance of upholding 'tradition' have often been constructed by colonial powers who assumed that Indigenous peoples were in processes of gradual and inevitable decline, which would led the 'death' of their culture and 'traditions' (Mallon, 2010, p. 365). This assumption led colonising powers to construct culture as something that needed to be recorded and preserved, thus rendering static and fixed forms of cultural expression which were, in fact, always changing and in flux. Mallon (2010) discusses that as a consequence, the development and evolution of culture is automatically fixed, and the acceptance of these ideas about tradition presents a considerable deterrent to the creation of new forms of cultural expression. Thomas (1995) states that the:

$[\mathrm{M}]$ ost regrettable stereotype concerning tribal societies is the idea that indigenous knowledge is dominated by the reproduction and perpetuation of tradition. This would deny the interpretation and innovation always present in Pacific cultures (Thomas, 1995, p. 36).

'Contemporary' creativity is defined in relation to how notions of 'traditional' have been constructed. Because this is a definition which is created through opposition, it could be said that 'contemporary' concerns everything that is not 'traditional.' The Oxford

${ }^{45}$ See discussion about Touristic Performances in this chapter. 
dictionary defines the term 'contemporary' as something "[1]iving or occurring at the same time"; "[d]ating from the same time"; [b]elonging to or occurring in the present"; "[f]ollowing modern ideas in style or design" (Oxford University Press, 2014). From my perspective, the problem with these two terms 'traditional' and 'contemporary' resides in the perspective from which Pacific performances are often looked at. It seems that the term 'contemporary' refers only to something that dates from the same time, without applying the latter definition of 'following modern ideas.' This situation may happen especially when observing new work by Indigenous communities. It is as if the latter definition of the word 'contemporary' was out of reach for these artistic communities, because what is expected from them is to preserve 'tradition' for the foreign observer (Tahana \& Oppermann, 1998, p. 26). ${ }^{46}$

The preservation of 'tradition' is contested by Jolly who explains that:

tradition is never an inert object... but is always a symbolic constitution of the past in the present. It entails continual recreation rather than passive perpetuation (Jolly, 1992, p. 56).

Similar ideas are expressed by Handler \& Linnekin (1984), Mallon (2010), West Turner, (1997), Wendt (1982), and Watson (2002). Jolly talks about a continual recreation of culture and 'tradition,' suggesting that everything that has been considered 'contemporary' today is a recreation of the 'traditional.' This idea ties 'contemporary' creativity inextricably to 'traditional' practices. To some extent it is like asking, what came first, the chicken or the egg? One of them gives birth to the other, but it is not possible to clearly determine which one comes first. What is now understood as 'traditional' may in the past have been considered contemporary: new, strange, and foreign. West Turner (1997) explains that "traditional practices are those that are believed to have originated in the past and are seen as a thread of continuity between past and present" (West Turner, 1997, p. 348). Therefore, if we understand that there is continuity between the past and today's practices, then it is possible to suggest that what is considered as 'contemporary' today may become the 'tradition' that will influence and determine customs and cultural practices in the future. This ideational cycle has happened over and over again, and will continue to happen. Cultures develop, change

\footnotetext{
${ }^{46}$ This idea also relates to the discussion about performances for tourist audiences which will be analysed later on in this chapter.
} 
and adapt over time, due to internal and external influences to which they are subjected to over the years:

Culture is not a fixed, localized entity that is easily, if at all, transportable intact. Culture, like behaviour, is a discursive space that is permanently 'in action' rather than a completed product or object frozen in space and time (Watson, 2002, p.3)

Cultures are in a continual process of creation and recreation. Mallon (2010) reminds us that human beings have been carving, singing, dancing, painting, and generally being creative, for a very long time. Wendt (1982) recognised the importance of reaffirming and validating the past, so that the people of the Pacific could create and generate their own voice and creativity in new contexts.

However, it seems that in some cases, the concept of 'tradition' and ideas about the necessity of 'preserving tradition' have been more powerful than the idea of promoting creativity which is not explicitly tied to notions of the past. Julio Hotus explained in our talanoa that in Rapa Nui "contemporary creation is not understood.... because it is not something that has been passed on from generation to generation” (Hotus, 2014). Hotus's reflections suggest that, contrary to scholarly critiques of 'tradition,' popular understandings of the concept in Rapa Nui continue to see it as knowledge fixed in time, rather than seeing it as a recreation of the past through the values and perspectives of people in the present.

An example of the tension between 'traditional' and 'contemporary' creative expressions is illustrated in the work of the well-known Rapanui sculptor Benedicto Tuki Pate, whose career has enabled him to travelled around the world carving the moai. ${ }^{47}$ Pate's carvings are part of the collection at Te Papa Tongarewa, the New Zealand National Museum. In our talanoa Tuki Pate explained that he does not like creating 'contemporary' works, because "it feels as if I'm mocking the ancestors" (Tuki Pate, 2014). This example connects with the idea that 'contemporary' art in Rapa Nui is uncomfortable for many artists as it is understood as a rupture with 'tradition,' which does not adequately honour what has gone before, and is disrespectful of ancestral ways of knowing and being. Contemporary art is something that is often perceived as coming from the outside. Julio Hotus explained in our talanoa that:

\footnotetext{
${ }^{47}$ The moai is a stone statue by which Rapa Nui is commonly known. The replica of this statue is the bestselling souvenir in the Rapanui tourist industry.
} 
The mere fact that a person of 40, 30, or even 25 years old creates something new makes it no longer valid, because is not something that was orally transmitted, therefore it is seen as something that comes from outside (Hotus, 2014).

This perspective of not acknowledging the fact that Rapanui artists are reinterpreting their 'tradition' themselves is paradoxical. During the talanoa sessions I conducted during my fieldwork in Rapa Nui, I discovered that there are negative reactions "against anything that might break with 'tradition'... especially in a culture that has survived from the past" (Arredondo, 2014). Issues of cultural survival are not new in the Pacific, and the region is marked by the reclaiming of culture to ensure the survival of stories and practices denigrated and damaged by colonialism.

Creators of what is now considered 'traditional' were in fact considered subversive and in opposition to others at the time of their creative practice. Barba states that "[a]11 founders of $20^{\text {th }}$ century traditions... who have marked our personal tradition and become its cardinal point, were in opposition to their time" (Barba, 2002, p. 17). In addition, Wendt emphasises the notion that "there are no true interpreters or sacred guardians of any culture" (Wendt, 1982, p. 208). Moreover, he encourages Pacific Island artists to use contemporary forms of expression if they wish to do so. Wendt's statement reminds me of a comment that Rapanui theatre practitioner and sculptor Karlo Huke made in our talanoa. He argued that:

Rapanui people should stop copying the moai and start creating their own things; it's an insult to the ancestors that Rapanui people are still living today from their ancestors' deeds, instead of creating something new (K. Huke, 2011).

Huke's statement is of great importance for Rapanui theatre practitioners to express their unique identities, and worldviews through contemporary forms of theatre, blending 'traditional' practices and 'contemporary' influences, and creating new forms of expression.

The concept of 'tradition' can involve the belief that it is wrong to alter any practice that originated in the past. Yet, paradoxically, theatre is an art form "which, by definition, creates alteration through repetition" (Balme, 1998, p. 54). Each presentation of a play, despite the fact that the same script is followed day after day during the performance season, is different. While the physical condition of the play (set and stage) may be the 
same, the mental and psychological condition of the actors and the audience is different every day. This causes the performance to change, adapt, and reinvent itself with each new presentation.

In the case of Rapanui arts and culture, the concept of 'tradition' is seen as something to recover, to preserve as model for future generations. In 2012, the National Council for Culture and the Arts (CNCA) decided to acknowledge elders from the different Indigenous cultures living in Chile through the creation of the Tesoros Humanos Vivos, or Living Human Treasures Award. To apply for this award someone from the community had to nominate an elder who had greatly contributed to the preservation of 'tradition.' The first awardee was Rapanui elder and singer Federico Pate, who has been teaching 'traditional' Rapanui riu (sad songs) and ute (songs of celebration) to the younger generations. In a documentary about his work released with the award, Pate stated that "it is crucial for the new generations to follow tradition... because without it we die" (Moreno, 2012). In this documentary, Pate talks about a riu he composed around the year 2000. This riu narrates the sad feelings he had when his wife had to stay in Santiago, leaving him alone for one year. This riu is new, but it is not perceived as 'contemporary' by Federico Pate because it uses 'traditional' forms and structures.

In contrast, Māori and Samoan theatre practitioners in Aotearoa have both drawn from 'traditional' practices and ideas as a form of inspiration as "an 'authentic' foundation for their own creativity" (Mallon, 2010, p. 366). The Samoan actor Iaheto Ah Hi explained in our talanoa that "tradition is part of who you are as a person and as an artist, the starting point, your guide" (Ah Hi, 2014). Similar perspectives have been articulated by the Māori director Hone Kouka. However, Kouka explained during our talanoa that in addition to asking for guidance from elders in the community it is also important to seek out people with expertise in your field "talk to the elders that understand theatre and what you are doing" (Kouka, 2015):

Sometimes the elders will not agree with what you want to do, and you'll get a firm 'No, you can't do that'... but by explaining what you want to achieve, then they may say 'ok, you can't do that, but you can do this instead' (Kouka, 2015). Compromise and dialogue seems key in these negotiations between 'traditional' values, and more 'contemporary' forms of creativity. Negotiations can be crucial when it comes to the production of plays which include 'traditional' elements. One example is the play 
Tatau: Rites of Passage (1996) by Pacific Underground. This play depicts stories of postwar Polynesian migration to New Zealand, using as a basis for storytelling the ancient tradition of tattooing. The production team had to compromise with the elders in terms of the way in which a 'traditional' tattoo ceremony was going to be included in the play, because the public display of this 'traditional' ceremony, a rite of initiation of great importance in the Samoan culture, was strongly criticized by Samoan elders in Aotearoa. ${ }^{48}$

Differences in attitudes to concepts of 'traditional' and 'contemporary' can be attributed, at least in part, to the different histories and cultural contexts involved. As we saw in Chapter Two, Aotearoa is a territory shared by a diversity of cultures, with a large population, and a close proximity to one another. This diversity leads to a high likelihood that people and groups will have the opportunity to inform, influence, and nourish each other. Institutions and funding supporting the arts and collaborations between different cultural expressions also support possible connections and collaborations. Rapa Nui is relatively geographically and socially isolated; therefore chances to see other artistic expressions and performances, and to exchange knowledge, especially with other Polynesian cultures, are rare.

The idea of preserving 'tradition' is understandable, especially in communities where a significant loss of cultural practices has taken place. In this case the relationship that the community has with 'tradition' today is linked to "ideas of what is 'authentic' and what is 'inauthentic' - what is 'traditional' and what is 'contemporary"'(Mallon, 2010, p. 366). In other words, it is the community who attributes the concept of 'tradition' to a particular practice, depending on what they consider to be 'authentic.' The word authentic "connotes traditional culture and origin, a sense of the genuine, the real or the unique" (Sharpley, 1994, p. 130). In the case of the performing arts this notion links authenticity closely to the past and the 'original' version. However ideas of what is 'traditional' or 'authentic' may change depending on the viewer's background, therefore changing the perception of 'tradition' and 'authentic.' Like the different versions of a story that may exist, ideas of 'tradition' and 'authenticity' may also be seen through different versions, perspectives, and interpretations. The statement "[ $t$ ]radition does not

${ }^{48}$ See discussion in Chapter Four 
exist. I am the tradition" (Barba, 2002, p. 28) corroborates the idea that notions of 'tradition' are in fact flexible, fluid, and context specific.

Constructivist theory articulated by Swiss Psychologist Jean Piaget describes "mechanisms by which knowledge is internalized" (Bhattacharjee, 2015, p. 65), where, through processes of assimilation, people construct their own understanding and "knowledge of the world, through experiencing things and reflecting on those experiences" (Bhattacharjee, 2015, p. 65). The concept of 'tradition' is site and context specific, constructed based on experience on a daily basis through the work of the artist. Understanding 'tradition' as a continuum allows the boundaries between 'tradition' and 'contemporary' to become more permeable, thus better reflecting reality. One example of this permeability is the play The Beautiful Ones (2013) by Hone Kouka. In this play Kouka creates a specific and ad-hoc pōwhiri (welcoming ceremony), therefore creating his own version of 'tradition,' through modifying and adapting 'traditional' cultural elements to his theatrical needs.

In the case of Rapa Nui, artistic practices that emerged around 1975 came to be considered 'traditional' and therefore 'authentic.' Mata Tu'u Hotu Iti (MTHI) emerged as an influential group, whose work was motivated by and responded to the many political and social changes that had happened in Chile and on the island, since Rapa Nui came to be under the administration of the Chilean Navy. Contemporary Rapanui society saw the work of MTHI as 'traditional' due to the use of "authentic'elements from the Rapanui culture for example wearing hami (loin cloth) and decorating their bodies with takona (body painting). However, some elements that are believed to be part of 'traditional' Rapanui culture are in fact 'contemporary' recreations, adapted from Tahitian and Chilean influences. Rapanui performers adapted the creation of flower garlands, belts and hair ornaments, grass skirts and pareu dresses and shirts from Tahitian culture, thus giving performances a more 'Polynesian' look. Form the Chilean culture Rapanui performers adopted an ornament called verevere, which is made of natural fibre that is placed on the calves and arms, and it was adapted from:

$[\mathrm{H}]$ uaso, or peasants from the Chilean culture, who used to wear leather puttees to work in the field to protect them from the clay; this working gear was over time transformed and is now used to dance the cueca, the national dance of Chile. In 
Rapa Nui this Chilean dancing ornament was transformed again into the verevere and is used in dances mainly as an ornament for men. (M. Fortin, 2010, p. 127)

Early twentieth century literature regarding aspects of daily life of the different cultures of the Pacific, for example The Mystery of Easter Island (1919) by Katherine Routledge, and Coming of Age in Sāmoa (1928) by Margaret Mead, created romanticised and idealised ideas of life before contact with Europeans. In the European imagination 'traditional' Polynesian societies were characterised as 'pure' and untouched by contact with any other cultures. These ideas negated and rendered invisible pre-contact practices of navigation, trade, allegiances and conflicts between Pacific Islanders. In addition, it was also assumed that the way in which Polynesians lived was uniquely interrupted and disturbed by the arrival of the Europeans. However, Mallon explains that:

Europeans were not the first outsiders to sail over the horizon. There were centuries of outside intrusion on these seemingly isolated Pacific Island societies. The canoes of other Pacific peoples appearing offshore preceded many moments of contact and disruptions of supposedly "traditional cultures" long before the arrival of explorers from Europe (Mallon, 2010, p. 364).

The use of the term 'tradition' only causes to decline the vitality and creativity of Pacific peoples (Wendt, 1978, p. 108), giving the impression that Pacific cultures are "without history" (Jolly \& Thomas, 1992, p. 241). The use of 'tradition' or the " $t$ ' word" (Mallon, 2010, p. 372) is associated with a static vision of culture. The use of words such as "custom and customary" (Mallon, 2010, p. 372) imply a more dynamic process and that things can adapt. However, by fixing the concept of evolution or development to a single word, there is the danger of overusing these new words in the same way as with 'traditional' and 'contemporary.' Once 'customary' and 'custom' become the new 'c' word there will be a need to find other words that better explains constructivist notions of culture.

A good alternative to this predicament could be to stop emphasising differences between the 'traditional' and the 'contemporary.' Rather than constructing these terms as binary opposites, we need to look critically at the way in which the existence of one supports the continued existence of the other. To avoid generalizations, it will be crucial to describe perceptions and ideas of the 'traditional' and 'contemporary' clearly "according to locality, movement, people and dates" (Mallon, 2010, p. 371). 
This section has considered definitions of 'traditional' and contemporary' highlighting the variety of different approaches and attitudes towards these concepts. Ideas which understand notions of 'tradition' as cyclical can help us to understand the continuous processes of creation involved in art forms that we may come to regard as 'traditional.' A specific way of doing a performance or a piece of art might have appeared a long time ago. From here aspects are selected and built upon, thus adding layers of knowledge about specific ways of carving, dancing, or acting that are informed by contemporary practices and perceptions. It cannot be said that this 'new' way is completely contemporary because it references the past.

Contemporary refers to creativity which occurs in and references the present day, but what we do in the present day is inevitably based on what we did yesterday. It is impossible to understand the notion of 'contemporary' in isolation from ideas of 'tradition.' Having a connection with the past, imagining, or reinterpreting it, is not only "an act of creation" (Whimp, 2010, p. 386), but also reaffirms the identities of theatre practitioners from the Pacific today. Therefore "the goal should not [simply] be the revitalization of a culture" (Wendt 1982, p.206), but to focus on "living as creatively as possible in the present, walking the tightrope between memory and the future" (Whimp, 2010, p. 386).

The following section of this chapter deals with another set of problematic concepts. Scholars in the field of Theatre Studies including Pavis (1996), and Lo \& Gilbert (2002) have argued that cultural encounters made and interpreted through theatre and the creative arts can be understood as being bicultural, intercultural, and/or cross-cultural. Sometimes the line separating these concepts is very fine and difficult to establish. I will discuss how the application of these concepts, especially interculturalism, has affected the production of Māori and Samoan theatre in Aotearoa, and Rapanui theatre in Rapa Nui. 


\subsection{Intercultural exchanges within Theatre Practice}

The Māori of Aotearoa and the Indigenous peoples of Rapa Nui both signed treaties with colonial powers from another culture, that created bicultural recognition of Indigenous peoples at the state level, and systems which were intended to recognize the equal legitimacy of two different cultures. In the case of Aotearoa the Treaty of Waitangi was signed the $6^{\text {th }}$ February 1840 . The Acuerdo de Voluntades between the Chilean Government and high chief ariki Atamu Tekena was signed the $9^{\text {th }}$ September 1888. Despite their differences, both treaties established broad principles of partnership, consultation, and active protection (Durie, 1989, pp. 280-299; Mendoza Uriarte, 2011, pp. 131-132), where reciprocity and mutual collaboration become key elements for both bicultural contexts. It is not my intention in this section of the thesis to give a detailed description of the events pre and post signing of these treaties. ${ }^{49}$ However, I think it is important to consider how situations at the state level in turn impact upon cultural encounters that take place on a daily basis in both contexts as these have been reflected through theatre and the creative arts.

The relationship between cultures has influenced the development of theatre in both Aotearoa and Rapa Nui. This research explores a complex and contested concept such as bicultural theatre, in order to understand theatre as a liminal space where different cultures meet, dialogue and collaborate. Bicultural theatre developed in Aotearoa as a response to wider political and conceptual movements in the country, which aimed to give equal respect and inclusion to Māori and Pākehā (European settlers) cultures and worldviews. Bicultural theatre is defined as theatre that arises "in response to the influence from both Māori and Pākehā cultures" (Greenwood, 2002, p. 57) creating a "hybrid cultural space" (Bhabha, 2012, p. 11) for sharing and collaborating in the creation of artistic work. The term 'hybrid' derives from biological origins, referring to "the offspring of a mating by any two unlike animals or plants" (Stross, 1999, p. 254). The term hybrid has also been used in cultural studies expanding its biological definition to represent "the blending of traits from diverse cultures or traditions" (Stross, 1999, p. 254). Professor Homi K. Bhabha adopts this term in post-colonial discourse, and defines

\footnotetext{
${ }^{49}$ Ian Hugh Kawharu's edited collection Waitangi: Māori \& Pākehā Perspectives of the Treaty of Waitangi (1989) explores issues surrounding The Treaty of Waitangi through a series of essays by Māori and Pākehā scholars. In the case of the Acuerdo de Voluntades between the Chilean Government and Rapa Nui, a good source of information is the book Chile, Un País Colonialista: El Caso Del Pueblo Rapanui (2011) by Oscar Mendoza Uriarte. This book analyses the agreement and its ongoing consequences.
} 
it as a "third space" (Bhabha, 2012, p. 56), a liminal space where different cultural principles, perspectives and influences are translated and reformulated (Bhabha, 1990, p. 216). The notion of the hybrid can be adapted to cross-cultural theatre as it facilitates a cultural fusion in the process of conceptualization and rehearsal, to create a brand new form of expression in the performance. Bicultural theatre acknowledges the impacts of cultural influences in the process of creating theatre. This approach could also be applied in the Rapanui context, to support the creation of contemporary works that are grounded and influenced by both Rapanui and Chilean cultures, rather than defined by fixed ideas of 'tradition'.

In the case of Samoan theatre produced in Aotearoa, the presence of a cultural group outside of the assumed Māori/Pākehā bicultural binary that the modern New Zealand nation state is based upon means that bicultural theatre is not an applicable theoretical framework for understanding and conceptualising creativity in the Samoan community. To understand creativity amongst Samoans living in Aotearoa the concept of multicultural theatre is more appropriate. Multicultural theatre is a theatre that utilizes several languages, and is performed to audiences from varied cultural backgrounds, because it is theatre that arises from contact between multiple cultures, including other Pacific Island and Asian cultural groups living in contemporary Aotearoa. This theatre can be created in a country whose political system "recognizes, if only on paper, the existence of cultural or national communities and encourages their cooperation" (Pavis, 1996, p. 8).

To understand the concepts of bicultural and multicultural theatre, it is important to understand what the theorists who have developed and used these concepts mean by the term 'culture.' This term is both complex and contested. Pavis (1996) provides four definitions of culture. The definition that informs my writing in this thesis is of culture as "a system of significations which allows a society or a group to understand itself in its relationships with the world" (Pavis, 1996, p. 2). In other words, culture is a kind of social fabric that covers the various forms and expressions of a given society. Therefore, customs, practices, ways of being, rituals, and norms of behaviour are included within the boundaries of the concept of culture. This definition of culture talks about the relationship of a society with the world in which they live, giving space for this society to adapt, move and change its ways of knowing and being in relationship to the world and its circumstance, enabling them to dialogue with others. From a Pacific point of view the 
term culture refers to tikanga Māori (S. Turner, 2002, p. 71), Fa'aSāmoa (Macpherson, 2004, p. 171) and the Rapanui term Haka ara which reflect protocols, values and ways of being and knowing that are deemed as the correct way to do things in Māori, Samoan and Rapanui context respectively.

Bicultural and multicultural theatre recognises and acknowledges the existence of various cultures without homogenising cultural diversity within the facade of national identity (Pavis, 1996, p. 8). However, bicultural and multicultural theatre are understood by Pavis (1996) as cross-cultural influences. Cross-cultural encounters through theatre "inevitably entail a process of encounter and negotiation between different cultural sensibilities" (Lo \& Gilbert, 2002, p. 31), promoting the incorporation of different languages and other performative cultural elements, creating a performance that recognises the "multicultural origins" (J. Greenwood \& Plum, 2002, p. 8) of the people involved. Therefore, the focus of cross-cultural theatre should be on "intercultural exchanges within theatre practice" (Pavis, 1996, p. 1) Intercultural theatre is interested in the overlaps between different cultural forms, because it is "situated at the precise intersection of the two [or more] cultures and the two [or more] theatrical forms" (Pavis, 1996, p. 4). This thesis focuses on these marginal spaces, where different 'traditions' interact with and influence one another, and in which new cultural forms and expressions are created.

This perspective suggested by Pavis would be in accordance with the description Watson (2002) gives of relations between cultures. Watson states that "relations between cultures are a complex interaction of entities which are in a permanent process of negotiating their identity" (Watson, 2002, p. 3). The keywords for both statements are exchange and negotiation, indicating that the encounter between cultures is not defined beforehand. It changes, evolves, and adjusts as the event unfolds.

As I argued in the discussion of the concepts of 'traditional' and 'contemporary' in the previous section of this chapter, culture is not static, it moves and changes with time and external influences, including being influenced by decisions about what aspects of 'tradition' to select and replicate which are made in the present. Similarly, the relationship between cultures is not fixed. As cultural intersections influence one another more deeply, these cultural relationships may create forms which are bicultural or "hybrids" (Kouka, 2007) otherwise known as "syncretic theatre" (Balme, 1999). 
In the case of Aotearoa a variety of different names have been given to theorise and understand Māori theatre. Kouka stipulates that Māori theatre can only be understood as a hybrid that:

mixed and matched the two worlds - that of theatre and the Te Ao Māori (the world of Māori). Traditional Māori concepts and Western theatre practices integrate seamlessly and become a healthy theatrical hybrid (Kouka, 2007, p. 240).

The application of the concept of hybridity can be seen in Kouka's plays including $T \bar{U}$ (2012), and The Beautiful Ones (2013), where elements of Māori culture such as the haka, poi, and pōwhiri, are integrated with European theatre techniques. In these examples 'tradition' serves as a springboard for the recreation of 'traditional' elements in new contexts, changing their meaning ${ }^{50}$ without losing the identity from which it comes, in this case Māori cultural forms and practices.

Another definition given to help understand Māori theatrical forms has been to consider them as examples of syncretic theatre. This notion was inspired by concepts found within the study of religions, specifically when "elements of two or more religions are merged and absorbed into one another" (Balme, 1999, p. 2). Balme uses the concept of syncretic to define Māori theatre as involving an "amalgamation of indigenous performance forms with certain conventions and practices of the Euro-American theatrical tradition, to produce new theatrico-aesthetic principles" (Balme, 1996, p. 180). In addition, Balme describes contemporary Māori plays as a fusion between traditional elements and "European dramatic conventions" (Balme, 1990, p. 149).

To some extent, the concept of hybrid theatre proposed by Kouka is similar to Balme's notion of syncretic theatre. Both concepts talk about bringing together two different theatrical and cultural worlds, the Māori and the Western world. From Kouka's definition of hybrid theatre it can be inferred that the amount of information shared between both worlds is equal. The syncretic notion proposed by Balme explains that the exchange of information between both worlds might entail a higher level of Indigenous knowledge than Western content. However, Wendt explains that the use of the term hybrid and hybridity should be avoided, because it may still be of colonial origin. He proposes

${ }^{50}$ See discussion in Chapter Four 
instead the use of terms such as "blend or new development" (Wendt, 1999, p. 99) when referring to new work from Pacific artists, and this would include Māori and Samoan theatre in Aotearoa. The word 'blend' implies the union of two different perspectives of the same subject, where the union is so good that the joints become invisible. The limits of both visions disappear giving life to a new development.

The most useful way of understanding Māori, Samoan diasporic, and Rapanui theatre is to think of these forms as based in collaboration and dialogue. According to Brazilian educator Paulo Freire, the art of dialogue is a human phenomenon that occurs in the encounter between people (Freire, 2013, pp. 97-98). This encounter proposes two central dimensions: action and reflection. The collaboration between the two proposes a creative act; in other words, action leads to reflection that could in turn lead to developing a new action. Continuous cycles of this process take place. In these encounters, people seek knowledge in collaboration, acknowledging the contribution of others (Freire, 2013, pp. 101-102). Bakhtin explains, that dialogue leads to many possibilities, because it recognises the many and varied perspectives that exist regarding the same subject (Romney, 2005, p. 61). These ideas and perspectives do not oppose each other, but are understood as ideas that need to be heard and considered, providing "open-ended possibilities generated by all discursive (conversational/theoretical) practices of a culture" (Stam, 1988, p. 132).

This thesis seeks to discover how artists have enabled two or more cultural visions of theatre to collaborate together and dialogue with one another. European and Polynesian theatre are both part of the same branch of the performing arts, theatre. From a European point of view theatre can be defined as an "act of communication between two groups of people present in person in the same space on the same night" (McGrath, 1996, p. 19), in which takes place a:

constant process of translation: from original concept to script (when there is one), to producer/director's interpretation, to contribution by designer and actor/actress, to visual and/ or aural images (Gostand, 1980, p. 1)

From a European perspective theatre constitutes a meeting space, a place where an encounter, and therefore a dialogue, between people of different backgrounds can occur. This encounter can be through a performance or through the invitation that theatre makes to society to reflect on itself. It is important to remember that the origins of European 
theatre are also in oral traditions and storytelling (Morande, 1990, p. 100). While it is true that every culture has its own ways of representing, it is also true that what is mixed in this equation of bi/multi/inter/cross-cultural theatre are also elements created in Europe, which can be traced back as far as "Italy in 1545" (Barba, 2002, p. 19). Therefore it is possible to say that theatre, as an art form, comes with a high dose of bi/multi/inter/crosscultural elements. Analysing the production of theatre from the perspective of an intercultural exchange allows us "not only to overcome ideological barriers and cultural phenomena, but to demonstrate that bi/multi/[inter/]cross-cultural theatre has no boundaries, only different outcomes" (De Toro, 1991, p. 21).

Theatre practice has evolved; it has changed through internal and external influences, adapting to the context of each country, culture, nation, group, or community. As seen in Chapter Two the historical antecedents of Māori, Samoan diasporic, and Rapanui theatre forms arose as a response to social and political issues that were happening in each context. From a Māori perspective theatre has been defined as a part of enacting claims to sovereignty in Aotearoa. It is "Tino Rangatiratanga [sovereignty] in action" (Potiki, 1991a, p. 57). According to Potiki, the main purposes of Māori theatre are to "reestablish cultural identity, to work with our own stories and people and to re-assert the mana of the tangata whenua" (Potiki, 1991a, p. 57). Over time Potiki's quite radical definition of Māori theatre has been maintained; however nowadays Māori theatre involves greater levels of collaboration with Western methodologies and techniques. For Samoan theatre practitioners, theatre has become a vehicle through which current topics or concerns for Samoan communities living in Aotearoa can be considered (Mallon, 2002, p. 143). In the case of Rapa Nui, theatre is often practiced as part of a wider ethic of cultural custodianship in the creative arts; it has become a way to reconstruct and maintain old stories for future generations (Paloma Huke, 1995, p. 45). ${ }^{51}$

Viewing these creative cultural encounters between Indigenous peoples and colonial powers through the lens of collaboration across cultures might have an interesting influence. For example in the play The Ragged (2015) by Te Rakau company, marae rituals were used alongside western theatre techniques. According to Nicola Hyland, a Māori actress taking part in the play:

\footnotetext{
${ }^{51}$ See discussion in Chapter Four
} 
[D]uring the rehearsals, we had the hui (meeting) at the beginning and end, but for the creation of the characters we used exercises from Grotowski and Stanislavski (Hyland, 2015).

These European influences were brought to the company by Māori actor Jim Moriarty who also directed the play. In the 1970s Moriarty was part of the Amamus Theatre Company that travelled to Poland, met with Grotowski, and learnt his theatre methods, ${ }^{52}$ therefore using Western theatre methodologies in this Māori play seemed natural and logical. From Hyland's statement it appears that these different cultural methodologies did not clash. The use of one did not disallow the use of the other. The rehearsal process for this play seems to have involved collaboration across cultures which resulted in the creation of a unique piece of theatre, which combined contemporary dance with elements of the haka, Western theatre methodologies, and the extrapolation of the rules that apply to the marae (Māori meeting grounds), to the rehearsal space.

Other examples of cultural encounter, providing another layer of dialogue between cultures are exemplified in works such as Whaea Kairau (1995) by Apirana Taylor, and Ngā Tāngata Toa (2006) by Hone Kouka. These plays are also examples of "canonical counter-discourse" (Helen Tiffin, 1987a, p. 22) of Mother Courage and Her Children by Brecht, and The Vikings at Helgeland by Ibsen, respectively, by questioning and critiquing the authority and power portrayed in these 'traditional' texts (Gilbert \& Tompkins, 1996, p. 16), providing their own version of historical events. In this case, the original texts were deconstructed, re-created and its contents were transferred into an Indigenous context. In this respect, Taylor and Kouka used a 'traditional' European text to create a contemporary Indigenous text, were they could question the 'authorised' Pākehā version of historical events concerning Māori people.

Home Fires $(1998)^{53}$ is an additional example of intercultural theatre practice in Aotearoa. The play was written by Māori playwright Hone Kouka, directed by Samoan actor Nathaniel Lees, and choreographed by Cook Islander dancer Teokotai Paitai. Different cultural backgrounds were blended in the production of a new creative work. Maui: One Man against the Gods (2006) directed by Tanemahuta Gray, and Aroha Nui (2011) directed by Tanemahuta Gray, Tapeta \& Anette Wehi, Jim Moriarty, and Helen

\footnotetext{
${ }^{52}$ See discussion Chapter Four

${ }^{53}$ See discussion in Chapter Four
} 
Pearse-Otene, are plays which represent collaboration, and encounter through theatre practice. Both plays blend elements of 'traditional' kapa haka performance with 'contemporary' dance, music, and lights. The production of these performances created a "third space" (Bhabha, 2012, p. 56) for intercultural theatre practice where a wide variety of stories can be found in order to create and produce theatre in collaboration with other cultures, and maintaining a strong connection with its audience.

The concept of intercultural theatre as well as notions of creating 'blends' and 'new developments' which were proposed by Greenwood (2002) and Wendt (1999), can be applied to the Rapanui context. This research proposes that theatre can be a method of understanding and reflecting upon interactions between Rapanui and Chilean citizens. One quality of collaborating between cultures is that of integration, which is:

based on the assumption that people from different cultures can not only work together successfully but can harmonize different aesthetic, social, and belief systems, creating fusion... that are whole and unified (Schechner, 2013, p. 251).

My purpose is not to focus on the negative aspects of colonisation, but on the advantages of living with two or more cultures (O’Donnell, 2011b, p. 109).

The construction of identity in a bicultural/multicultural context such as Aotearoa cannot simply be understood from a Māori, Samoan, or a Pākehā viewpoint. During suggests that this construction of identity should be created by "Māori-ising Pākehā formations and vice versa" (During, 1991, p. 35). However, the homogenisation of cultures could be understood as a new form of colonialism. Greenwood explains that in a bicultural or multicultural society, there is no need for cultures to merge, "[t]hey can share a space and remain separate" (J. Greenwood, 1999, p. 113). However, it can be argued that identity is not just individual, but also collective, highly influenced by social and cultural norms. This could be true when talking about the concept of nation, in which the identity of its inhabitants is defined by territorial, political, environmental, social and economic aspects. However, in contemporary Aotearoa the amount of different cultures that can be seen on the streets on a daily basis is quite large. Each of these cultures maintains their distinctiveness, in terms of factors such as language, dress codes, and customs. I agree with Greenwood, I firmly believe that each group should keep their own identity. It is their difference that makes their theatre 'marriage' interesting and unique. The main aspect when it comes to bicultural/multicultural theatre is that each person should 
maintain their own identity, which does not prevent them from reaching agreements among partners. Collaborations connecting cultures should work both ways in the encounter, involving Indigenous and Western theatre practitioners:

Each partner, thought of more as a person than as an abstract system, preserves his/her own autonomy and identity and yet avoids assimilating or annihilating the other; seduced but not reduced (Pavis, 1996, p. 11).

Pavis speaks of an invitation to work together without crushing the other, without placing the other in a "zone of non- being" (Fanon, 1970, p. 7), but creating instead the opportunity for individual expression within the group, while keeping their distinct identities and viewpoints. Again, the concepts that emerge here are of collaboration and respect between the parties.

Rapanui peoples share their land with people from different cultures, not only Chilean, but people with French, English, and German ancestry as well. This allows the people living on the island, whether Rapanui or not, the opportunity to learn multiple languages, and to share experiences and stories with other cultures through theatre. This exchange of stories or texts could become another meeting point with other cultures; especially when finding similarities between texts from different cultures.

Chapter Two discussed the use of oral narratives in theatre. It is interesting to see the different versions of the same story that exist across the Pacific; for example Tangaloa (or Tangaroa), god of the seas. The repetition and variation of oral histories about the same characters points towards the existence of intertextuality in Oceania. The concept of intertextuality arises from the direct relationship of a text with another or with several more texts. Pavis considers the concept of intertextuality to involve not only the actual text, but also "the contexts and cultures that are embedded in the transfer of foreign texts" (J. Greenwood, 1999, p. 149). These texts stimulate audiences to think about and discuss the themes conveyed by the play. O'Donnell states that the use of intertextual allusions by Indigenous writers “emphasises kinship between cultures"(O'Donnell, 2011 b, p. 110). From a theatrical point of view, the use of intertextual references from Indigenous as well as from Western texts helps to break the "stereotypes of colonial oppressors and Indigenous victims" (O’Donnell, 2011b, p. 110). 
Samoan theatre in Aotearoa can be understood as a "social remittance" that "activates reciprocal relationships between communities...building solidarity, and mediating between local concerns and global forces" (Looser, 2012, p. 452). The term remittance usually refers to money or goods that a migrant sends home, however Looser extends concept to culture. Looser explains that the concept of "cultural remittance" describes "ideas, behaviours, identities, narratives, values, and social capital that flow reciprocally between the homeland and diaspora, circulating continuously in a process of adaptation" (Looser, 2012, p. 454). This new perspective provides a "multifaceted" (Looser, 2012, p. 452) vision of Samoan theatre, shifting it beyond its geographical limits. She states that Samoan theatre that is created and performed in other parts of the Pacific is a form of cultural remittance, which promotes and emphasises the cultural functions of theatre.

Reciprocity is a fundamental part of theatre. It supports the generation of transnational networks, where citizens from multiple sites can come together and debate common affairs. The concept of social and cultural remittance (Looser, 2012) is important to this research. Rapanui theatre has the potential to become a vehicle for communication with artists and cultures from other Polynesian islands, as well as acting as a catalyst for entering into dialogue with art forms and peoples in Chile, and other Latin American nations. Through theatre, Rapanui peoples might be able to share their stories, negotiate and renegotiate their cultural identities, and express and reflect upon their experiences, desires and frustrations with other people whom might share similar values and customs.

This section has highlighted the importance of collaboration among different cultures. The concepts and theory discussed in this chapter, bicultural, multicultural, intercultural, hybrid and syncretic theatre, point towards the possibility of working in collaboration with another culture. These concepts open up the conceptualisation of theatre and theatre production, making performances more relevant and appealing to culturally diverse audiences. Audiences represented in culturally inclusive and diverse theatre performances may be more interested in going to the theatre to see culturally collaborative art forms; as they better represent their cultures, beliefs, worldviews, and experiences. These approaches which seems to have been achieved in Aotearoa, made theatre more relevant and popular amongst all aspects of its contemporary society.

The following section will discuss the production of Māori, Samoan diasporic, and Rapanui theatre from the perspective of popular theatre. It explores how this Western 
concept can also be found in some Pacific Island performing arts practices, and how different views about popular theatre may be important to consider when discussing the production of Māori, Samoan diasporic, and Rapanui theatre.

\subsection{Popular Theatre}

The Western term popular theatre comes from the French "théâtre populaire"(Schechter, 2002 , p. 3) referring to the people's theatre. The origins of popular theatre can be traced back to the Middle Ages. During this period, performances about religious topics where initially played inside the church, but these performances were later taken from the portal outside the church, to the church square, and into the marketplace (Berthold, 1991, pp. 228-229). This new and open location made these performances accessible to a wider segment of society, including the working class.

This type of theatre which was seen as capable of "mould[ing] the morals and manners of the citizens" (Schechter, 2002, p. 3), and it became popular again in 1778, when a disciple of Rousseau and Diderot, Louis-Sebastien Mercier, suggested a new way of doing "theatre [that was] affordable and educational to the masses" (Schechter, 2002, p. 3). The idea of making theatre available to all types of audiences contrasted with the classic European concept of theatre, where theatre had become a middle class and somewhat elitist art form. Popular theatre aims to use not just the written text, but also other "elements of the language of the theatre" (McGrath, 1996, p. 38) such as music, movement, characterisation, costumes, props, and lights (Gostand, 1980, p. 2) in order to make theatre approachable and understandable to the working class population.

The main features of popular theatre is that it is "publicly supported, highly visual and physical, portable, orally transmitted, [and] readily understood" (Schechter, 2002, p. 4). The notion of a theatre for the people connects to one whakatauāki or proverb in Māori language:

He aha te mea nui o te ao? He tāngata, he tāngata, he tāngata. (What is the greatest thing in the world? It is people, people, people) (Reilly, 2011, p. 348) 
This proverb can be related to popular theatre, an art form where people are the "main target... without restrictions" (Pradenas, 2006, p. 331). Popular forms of theatre have been available to diverse populations. Although their names may vary from place to place, popular performances may appear as mime, pantomime, shadow puppetry, and clowning. Indeed they "may be called folk art or traditional entertainments, rather than popular theatre" (Schechter, 2002, p. 4).

Clowning is a common form of Polynesian popular theatre (Hereniko, 1994, p. 4). Traditions of clowning can be found in Tonga, Sāmoa, Rotuma, Fiji, Tokelau, Hawai'i, Tahiti, and Rapa Nui, creating through comedy a "populist link with the masses" (Hereniko, 1994, p. 4). As well as entertainment, the main function of clowning was to raise awareness about critical social issues affecting the community through "public performances" (Hereniko, 1994, p. 2). One example is the Samoan faleaitu or "house of spirits" (Mallon, 2002, p. 137) which Sinavaiana describes as a "form of comic theatre" performed by men who play with language to indirectly critique authority figures in satiric sketches (Sinavaiana, 1992, p. 201). This practice is still popular in Sāmoa, and to some extent in Samoan diasporic communities. Mallon explains that the main difference between faleaitu created in Aotearoa and Sāmoa is in a different reliance on language; in Aotearoa the humour lies more in the physicality of the performer, "where body language and actions are more important in conveying the message or idea" (Mallon, 2002, p. 139). This difference is important as a way of including New Zealand-born Samoans in the audience who may not be fluent in the Samoan language.

Descriptions of faleaitu remind me of an old Rapanui performance with elements of comedy, called koro ei. The ei is a type of song with a comic text, a song of mockery and disdain. The German missionary and researcher Father Sebastian Englert saw several koro ei during his stay in Rapa Nui between 1935 -1967. Englert states that koro ei was performed to avenge an offence by making fun of the offender in a public performance (Englert, 2007, p. 305). Koro ei is no longer performed in Rapa Nui; however, a choir competition which is based on the same structure proposed by koro ei is performed each year in Tapati. ${ }^{54}$

\footnotetext{
${ }^{54}$ See discussion in Chapter Four
} 
Some features of popular theatre relate with theatre forms performed in Rapa Nui. In popular theatre artists "kept the work alive by performing it, and passed scenarios to future generations through oral transmission and apprenticeship" (Schechter, 2002, p. 3). A similar approach underpins the methodology used by Rapanui theatre group Mata $\mathrm{Tu}^{\mathrm{u}} \mathrm{u}$ Hotu Iti in the 1970s. ${ }^{55}$ Theatre performed in Rapa Nui today is based on orally transmitted stories that are well known among the Rapanui community. Māori theatre also contains elements of popular theatre, particularly when considering community performances held at the marae, the complex of meeting houses and grounds usually associated with Māori groupings. Performances at the marae make theatre accessible to the community, and performances are usually offered at low cost or for a koha (donation), if not for free. Unlike Rapanui theatre, where it is possible to find one main venue, Māori theatre has the possibility to travel with a play, taking it to different places and communities around Aotearoa. Through these popular performances the Māori community connects, not only through kinship, language and culture, but also through the shared experience of theatre.

When discussing theatre I am referring to what McGrath describes as "a social event, and a very complex social event, with a long story and many elements" (McGrath, 1996, p. 5). Since there are a variety of popular performances, and an equal diversity of audiences, it can be inferred that not all stories are universal, and the social values reflected in these popular performances are not the same for all audiences. This characteristic is similar for both Western and Indigenous popular theatre. The most well-known form of European popular theatre is the Italian Commedia dell' Arte, which is a form of theatre that began during the sixteenth century and lasted until the second half of the eighteenth century (Oreglia, 1968, p. 1). In this art form, characters were identified by costumes and masks since they "remained the same regardless of the plot" (Sprinchorn, 1968, p. i) of the story. Performances usually took place on outside temporary stages, and as dialogues and actions were largely improvised actors could satirize local scandals and current events.

Italian Commedia dell' Arte and Samoan faleaitu both create work that is closely linked to the reaction of the audience during performances. Their audiences are assumed to be local and likely to understand the contexts that both popular art forms are referring to. Through the audiences' response, popular theatre artists can assess and modify their

${ }^{55}$ See discussion in Chapter Four 
performances accordingly. Mazzone-Clementi \& Hill state that in popular theatre, audience responses are key: "[t]he piece[s] [are] colored by the local audience, by the moods and responses" (Schechter, 2002, p. 85). In other words, it is the people among which popular theatre is performed who give additional layers of meaning, emphasis, and direction to the story (McGrath, 1996, p. 2). Therefore characters in popular theatre "are not always neatly separated from the rest of culture" (Schechter, 2002, p. 5).

Each context has its own methodology when it comes to the creation of a theatre piece. Schechter (2003) reflects on the transfer of knowledge about theatre in Western popular theatre groups.

The artistry was passed from father to daughter, son, or colleague, or from master to apprentice. Successors were not necessarily taught a wide range of roles, either... Those trained were generally guaranteed a character part upon competition of apprenticeship. They learned through imitation and study of popular traditions initially performing much like their master teacher did, until they were on their own (Schechter, 2002, p. 6).

This genealogical and relational approach to the handing down of knowledge about popular theatre also relates to the methodology used by the Rapanui theatre group Mata Tu'u Hotu Iti (MTHI). ${ }^{56}$ Today people performing in Rapa Nui are self-taught performers, who were, as children, part of MTHI. Those children, now musicians, learnt to dance and to sing with the theatre troupe. Oral transmission and apprenticeship, as in Western forms of popular theatre, was one of the key elements in the troupe's work. One indirect apprentice ${ }^{57}$ of MTHI is Carlos Lillo Haoa, the primary composer and vocalist of one of the main dance troupes in Rapa Nui, Maori Tupuna. Lillo has taught theatre workshops at Aldea Educativa high school, directing performances with the students. His career as a theatre director started in 2008 when he staged The Story of Hetereki A Rau Nui during Mahana O Te Re`o (Rapa Nui Language Day). This was the first attempt to integrate different Rapanui performing arts in a play. Later, during the 2013 Tapati Rapa

\footnotetext{
${ }^{56}$ See discussion in Chapter Five

${ }^{57} \mathrm{He}$ defines himself as an indirect apprentice, because he did not take part in the work of the troupe. However, he saw many rehearsals and performances promoting to some extent his inclination to music and the performing arts.
} 
Nui Festival, he directed the production Kave Heke, which showed for the first time on stage, parts of Rapanui's colonial history. ${ }^{58}$

Festivals are also popular art forms. In a Western context it is possible to find a variety of different festivals combining music, dance, theatre and the arts. The New Zealand Festival (formerly the International Festival of the Arts) brings together creative forms including music, dance, theatre, and literature. During one month it is possible to see Māori and Samoan productions alongside national and international performances. In Chile, Teatro a Mil is the main theatre festival. It began in 1994 with the mission to make theatre affordable to the masses. Teatro a Mil used to refer to the ticket price for each performance. The word mil (thousand) told people that they only had to pay $\$ 1000$ Chilean pesos (around \$2 New Zealand dollars) to see high quality theatre productions, that included works by international theatre companies. In time, as the festival's popularity grew, the organisers began to realise the profits they could make with the festival, due to the substantial number of people attending. Teatro a Mil no longer refers to the ticket price, but to the 'thousand' theatre performances you can see, of course at a much higher price. Nevertheless this festival has remained popular.

Rapanui theatre is performed twice a year, in February during Tapati Rapa Nui Festival (Tapati), and in November during Mahana o te Re'o (Language Day). Both festivals are $100 \%$ subsidized by the state, making the event free and open to all viewers, and this is greatly appreciated by the Rapanui community. Tapati "the annual cultural festival of Easter Island" (Bendrups, 2008, p. 15), is a recent invention which has been attributed to the arrival of large number of Chilean visitors in the late 1960s (Bendrups, 2008, p. 19). The first Tapati was organised by Chilean authorities living on the island in 1968, in order to provide recreation for its residents. It is based on a Chilean festival held at the beginning of spring called Fiesta de la Primavera (Spring Festival) (Andrade, 2004, p. 69). Tapati Rapa Nui has the same characteristics as any regular Chilean celebration including; dances, costumes, a parade, and the election of a festival queen. The motives and iconography used in the early years of the festival were based on designs and motives that at that time were fashionable in Chile, and that hardly related to the Rapanui culture (Andrade, 2004, p. 69).

\footnotetext{
${ }^{58}$ See discussion in Chapter Four
} 
Rapanui family groups influenced the transformation of Tapati into a festival more pertinent to Rapanui reality (Andrade, 2004, p. 71). In 1985, Rapanui Physical Education teacher Rodrigo Paoa became one of the organisers of Tapati, and instigated a change from Chilean-influenced decorated parade floats to Rapanui decorated boats.

The competitions inherited from the Chilean festival were gradually replaced by Rapanui sports and games such as fishing, Polynesian canoe racing, haka pei, which consists of sliding down the hillside on banana tree trunks tied together, and 'traditional' arts and crafts such as clothing in mahute (bark cloth), body painting, and Rapanui dance ensembles (Andrade, 2004, p. 69). The election of the Queen changed from a beauty contest to a contest between local families, who demonstrated their skill and worth as members of Rapanui society by competing to win each sport, craft, and performance competition.

In February 2000 Tapati was moved from the municipal gymnasium Koro Paina Kori to Haya Varevare, a small bay in Haya Roa Town, to increase the seating capacity for the event. This is now the largest and the most important outdoor stage for the community. This new outdoor venue "combined with the festive atmosphere helps to bring the audience together" (Orenstein, 1998, p. xii). The entire setting changes in two weeks, and "[w]hat had once been a bare green lawn is transformed into a theatrical space"(Orenstein, 1998, p. ix).

In the mid-1990s, the Rapanui community viewed the Tapati as a success in terms of encouraging the creation of performances which remember and appreciate 'traditional' practices, as well as involving the use of the Rapanui language (Bendrups, 2008, p. 26). Likewise, the community saw the stage at Haya Varevare as the main stage for future presentations during the year. Subsequently, a new festival called Mahana O Te Re'o, or Language Day, was created and developed. This is a festivity that lasts a single day and is held in November every year in Hana Varevare. Rapanui language teacher Virginia Haoa Cardinali explained in our talanoa that "this celebration arose due to a need to revitalize the use of the native language" (Haoa Cardinali, 2014). The main objective of this festivity is to celebrate the use of Rapanui language, whether in the recitation of poetry, in songs, or through theatre with a focus on the representation of 'traditional' stories. 
In addition to local and national festivals, another regular gathering that has contributed to the popularity of Pacific performances is the regional Festival of Pacific Arts (FPA). Originating in 1972 , this festival celebrated its $40^{\text {th }}$ anniversary in 2012 . The origin of this festival can be attributed to one key factor: the fear that younger generations of Pacific Island peoples might lose their 'traditional' art forms, due to the introduction of Western entertainment into their life styles (Stevenson, 2012, p. 1). Organisers of the 1972 festival describe its aim as follows:

We hope that this Festival will not only encourage the preservation of the best in Pacific Island culture, but that it will also serve to re-establish much that is in danger of being lost. In particular, we hope that it will re-emphasize the need for the retention of classical art forms, for the best taste, for the highest ideals and dignity. It may also enable a recapturing of some of the old chants and dances as they were when they were originally created and in the form they were enjoyed by the peoples of the Pacific long ago (South Pacific Arts Festival.1972. Souvenir Booklet in Stevenson, 2012, p. 2).

Although highly focused on the 'traditional' side of the Pacific performing arts, the FPA provides:

important points of contact between [Pacific Island] people[s] ... contributing to the complex processes by which issues of identity and indigeneity are explored and mediated (Bendrups, 2008, p. 14).

This Festival is organised by and for Pacific peoples (Stevenson, 2012, p. 8), acknowledging the principles of Western popular art forms, but from a Pacific Island perspective. The Secretariat of the Pacific Community (SPC) decided that each quadrennial event should be "hosted by a different island nation" (Stevenson, 2012, p. 3) thus providing spaces and places for Pacific Islanders to "meet, share and celebrate their cultural heritage" (Stevenson, 2012, p. 1). In addition, the success of the FPA in attracting visitors and bringing in revenue for the host nation shows how beneficial Pacific Island performing arts could be to an island's "economic, diplomatic and national development" (Bendrups, 2008, p. 18).

Rapanui peoples have increasingly emphasized their cultural independence from Chile, especially since returning to democracy in 1990. This independence has been expressed 
through the participation of Rapanui artists representatives in regional and international events such as the FPA (Bendrups, 2005, p. 35). Rapa Nui has participated in the Festival since 1976 (Bendrups, 2008, p. 18), and great value has always been attributed to 'traditional' knowledge in any cultural representations that have been created:

Traditional knowledge has become highly valued, as illustrated by the degree of care that is taken in rehearsing traditional performances, or in the production of replica artefacts for the tourist market (Bendrups, 2005, p. 35).

The participation of Rapanui artists in the FPA has enabled an exploration of "Polynesian cultural heritage in the company of other Polynesians" (Bendrups, 2008, p. 18). Through connections made during these festivals, Rapanui artists have generated new contacts, especially with Tahiti. These encounters were used to build a profile of Rapa Nui as an "idyllic Polynesian tourist destination" (Bendrups, 2008, p. 18) by the local authorities. Nowadays, tourism provides a sustainable income for many islanders in Rapa Nui.

In this section definitions and characteristics of Western and Indigenous forms of popular theatre have informed the analysis of theatre production in Aotearoa and Rapa Nui. As with Māori and Samoan theatre productions in Aotearoa, Rapanui performances are viewed not only by Rapanui people, but by a variety of people from different backgrounds. Rapanui theatre is performed at cultural festivals where the population of the island doubles (if not triples) for the duration of the event. Therefore, notions of popular theatre are important to keep in mind during creative and production processes. The next section in this chapter concerns the concept of community theatre which may be seen as a more site-specific version of popular theatre.

\subsection{Community Theatre}

In the book Community Theatre: Global Perspectives (2001) Eugene van Erven explains the functions of this theatre form, stating that:

Community theatre is an important device for communities to collectively share stories, to participate in political dialogue, and to break down the increasing exclusion of marginalized groups" (van Erven, 2001). 
Community theatre can be understood as an "artistic process that always evolves under very particular local sociocultural conditions" (van Erven, 2001, p. 1). Definitions of community theatre may vary from "fine original plays authored by the people of the same area" (Cocke, Newman, \& Salmons-Rue, 1993, p. 28), to a theatre that "chooses content according to local market forces" (Maunder, 2013, p. 19). These definitions highlight the main purpose of community theatre: devising a play from shared stories between participants from a community, where they themselves have an active role in the creative process and take on the role of actors in performances of the play (van Erven, 2001, p. 2).

In Community theatre the process of creating theatre became community specific, meaning that a community from a specific location made "theatre their own" (Boal, 2000, p. 119). Similar to popular theatre, community theatre presents stories in open areas at low or no cost, thus allowing the whole community to participate and enjoy the performances. Probably the main difference between popular theatre and community theatre is that the former may not necessarily be about the local people where the production is performed, whereas in the latter, stories performed as community theatre are stories from the community where the performance is presented.

Community theatre is a worldwide phenomenon and examples of this theatre form can be found in the Netherlands, the United States of America, Costa Rica, Kenya, Australia (van Erven, 2002), the Philippines (J. Royal \& Campbell, 1987), Chile (Alfaro \& Sura, 2007), Fiji (Clery, 2013), and Aotearoa (Maunder, 2013) to name a few. The theatre styles used by these groups are as diverse as the places where community theatre can be found. Groups create their repertoire based "on local and/or personal stories (rather than pre-written scripts) that are first processed through improvisation and then collectively shaped into theatre" (van Erven, 2002, p. 2). Lo \& Gilbert explains the main features of community theatre:

The constitution of a performance group and the subject matter may be organised around common interest (such as gender, ethnicity, or shared social experiences) or defined in terms of geographical location (Lo \& Gilbert, 2002, p. 14).

The concept of community was first used in connection with patterns of migration which emerged during the nineteenth century, when a large number of people living in the same geographical location, such as rural areas migrated to cities. Migratory groups were 
called communities because they shared the same story; they migrated to the city, possibly from the same village. These "[r]ural communities revolved around personal relations and stories of place and landscape" (Maunder, 2013, p. 13). These groups of people shared experiences, a sense of belonging to a physical location and shared the stories tied to these particular places.

A strong sense of belonging can also be applied to the process of theatre production. Working and collaborating in the creation or production of a performance creates a sense of belonging that Victor Turner calls "communitas" (V. Turner, 1988, p. 44). This concept arises from the social experiences and choices of individuals who become part of a group (V. Turner, 1988, pp. 44-45). From these social experiences, a 'we' feeling emerges, where loyalty, sacrifice, and companionship for its members are its basic common characteristics (V. Turner, 1988, p. 44).

In relation to the idea of a 'shared experience,' the case of Rapa Nui is quite particular. Living in a small territory of only $164 \mathrm{~km}^{2}$ creates a very strong sense of belonging. According to the last census, the total population of the island reached 5,800 inhabitants (Labbe, Carrasco, \& Mathews, 2012). During commemorative events and on local TV, it is very common to hear local authorities, such as the Mayor and the Governor, speak about the 'Rapanui community.' During our talanoa former Rapanui Governor Marta Hotus Tuki stated that the term Rapanui community refers to "all people living in Rapa Nui/Isla de Pascua; that is Rapanui descendants, as well as Chilean and foreign migrants" (M. Hotus Tuki, 2014).

The perspective of theatre communitas could be of great value to the process of theatre production in Rapa Nui. Within the Rapanui community, different groups and subcommunities can be found; for example the community of artists, athletes, craftspeople, farmers, and fishermen. Within the artists' community it is also possible to find subcommunities which include dancers, musicians, visual artists, and sculptors, however no sub-community of theatre practitioners can yet be found in Rapa Nui. It is important to take care of the few Rapanui people that decide to take part in theatre practice in order to promote and foster the creation of a 'we feeling,' building a sense of communitas among Rapanui theatre practitioners so that they keep working together.

The characteristics of communitas can be found in the methodology used by Hone Kouka when rehearsing a play. He describes the Māori theatre communitas as involving a strong 
sense of companionship and whanaungatanga (family relation). Kouka explained in our talanoa that for him the most important aspect of working in a theatre company is to foster a strong sense of belonging to the group. Kouka strives to:

make sure that the people working and/or collaborating with us are taken care of, that they feel comfortable within the group, especially if they are new to the group, and encouraging them to feel confident of their artistic performance, whether writing, acting or directing (Kouka, 2015).

The sense of belonging and companionship that draws from the concept of communitas, while applicable to the group with which one collaborates directly, could also be applied on a larger scale; for example to Polynesia or to the Pacific region. Polynesia is defined not only geographically but also according to shared language and customs across different islands of the Pacific. Cultures that are within these boundaries have multiple micro and macro senses of belonging. Each belongs to one community within one island in particular (micro). Since "cultural identity is a process" (Hereniko, 1999, p. 138), they can also feel a part of the wider sub regional group of Pacific islands called Polynesia or to the broader Pacific Island region (macro). These latter 'senses of belonging' draw on what I call a Pacific communitas; a space/place where not only stories and experiences are shared by the Pacific communitas, but also mythologies, customs, language, cuisine, and theatre among many other aspects.

From my own experience living in Rapa Nui for more than ten years, the Pacific communitas seems far away. Rapanui people are Polynesian. However, their sense of belonging to Polynesia is defined more by demarcations on a map than through regular collaboration with other Polynesian groups. As discussed in Chapter Two, although there have been significant encounters between Rapanui and other Pacific cultures in the past, and especially with Māori, little sense of Pacific communitas have been reinforced. Creative encounters with other Polynesian cultures, have been structured in a way which enables each group to show their art to the other, but there have been few instances where peer collaboration occurs resulting in the creation or development of something together, thus creating a shared sense of cultural heritage.

In the context of Aotearoa the sense of belonging to a broader Pacific communitas is stronger. This is due to the fact that the territory is shared by various Polynesian cultures that regularly interact and share with one another. Multicultural theatre companies 
mainly involving Pacific Islanders living in Aotearoa have been established which seek to draw from and emphasise shared heritage and worldviews. Negotiation and cultural encounters within these theatre companies allows for the development of a sense of belonging from a cultural and theatre perspective. Examples of Pacific Island diaporic theatre communitas are the Auckland based company Multinesia, and Massive Theatre Company. Massive Theatre Company is a collaboration between artists of Samoan, Tongan, Niuean, Fijian, Tokelauan, Tuvaluan and Pākehā heritage. Pacific Island theatre companies such as these produce community theatre, since the ideas expressed through these performances are shared in close relationship among both actors and audience members.

An interesting aspect of community theatre is that it rescues the (somewhat forgotten) true sense of theatre: its relationship with the audience. Theatre creates a relationship between audience and actor (Grotowski, 2002, p. 20), because it is an event we live with others (Dubatti, 2011, p. 35). This characteristic of theatre is what Dubatti calls "convivio" (Dubatti, 2011, p. 35). From the theatrical encounter, and through dialogue between actors and spectators, convivio multiplies the activity of giving and receiving (Dubatti, 2011, p. 36). A characteristic of community theatre is that it is a social engagement, in which the activity of giving and receiving is a continuum. In community theatre, this reciprocal continuum happens not only during the performance, social engagement also occurs during the creative process, because "the aesthetics of community theatre are shaped by the culture of its audience" (Lo \& Gilbert, 2002, p. 14).

Another relevant aspect of community theatre relates to the methodology used to create performances. Stories are shared by community members, and subsequently plays are collectively devised after the stories shared are improvised by the participants (van Erven, 2001, p. 2). This process happens with the guidance of either a trained actor or a skilled artist who leads or facilitates the work (van Erven, 2001, p. 2; Maunder, 2013, p. 21). This artist "usually, but not always, from the outside the community - work[s] with the community group and contribut[es] a variety of skills" (Maunder, 2013, p. 21). In the case of Rapa Nui, besides my own theatre work, other theatre practitioners from the Chilean capital city Santiago have travelled to Rapa Nui to conduct theatre workshops, although these 'outsider' theatre workshops have had little impact on the ways in which 
theatre is produced in Rapa Nui. ${ }^{59}$ The Rapanui artistic community is involved in a range of different performing arts, and has a long history of artistic expressions, songs, dances, and years of experience on stage. However, workshops offered by 'outsiders' to date have failed to connect theatre with theses aspects of the Rapanui culture. Theatre practitioners from Santiago have often travelled to Rapa Nui without much knowledge of the Rapanui culture. Only Western theatre techniques are used, and there is often no acknowledgement of (or interest in) any Rapanui performing art form within these workshops. The few Rapanui theatre practitioners that go to these workshops have shown little interest as they feel that there is nothing being offered that they can relate to (Lillo Haoa, 2014).

The New Zealand film director, playwright, actor, and director Paul Maunder (2013) has been involved in community theatre in New Zealand for at least three decades. His main influences are Grotowski and Boal's community theatre methodologies. Maunder established the Amamus theatre company in 1971 (later known as Theatre of the Eight Day) where he explored bicultural theatre with the assumption that Māori and Pākehā could work together. In his book Rebellious Mirror (2013), Maunder explains that 'good' community theatre practice should be based in the principles of engagement proposed by Cohen-Cruz in her book Local Act (2005). These core principles for conducting community theatre are firstly 'communal context' where issues dealt within community theatre are part of the reality that the community lives in. Secondly, community theatre encourages 'reciprocity' in which all participants are equally involved nourishing the creation and production of a theatre performance. Thirdly, the concept of hyphenation allows us to understand that community theatre can serve a wider purpose in the community; it can be educational, celebratory, therapeutic, political or developmental. Possibly the most developed and explored concept proposed by Cohen-Cruz (2005) is hyphenation. Finally, community theatre involves the active participation of the community. Maunder refers to this aspect as "active culture" (Maunder, 2013, pp. 2324). Roma Potiki, Māori actor, director and former participant at Maunder's company has critiqued Maunder's appropriation of Māori elements in the past, commenting that she felt "plundered for content" and "unable to fully participate in the process in terms of decision-making" (Balme, 1996b, p. 174) during rehearsals. Potiki's critique indicates the tensions involved in actualising the ideals of community theatre that Maunder relays.

\footnotetext{
${ }^{59}$ See discussion in Chapter Five
} 
Concepts of community theatre relate to Māori, Samoan diasporic, and Rapanui theatre to some extent, as the notion of a communal cultural context is strong in all three theatre settings. The stories performed in these different forms of Indigenous theatre are often either known by the audiences or they seek to reflect experiences shared by the audiences. In all three contexts, theatre has been used as a tool for educational purposes. In Māori and Samoan theatre this educational orientation is primarily related to the use of Indigenous languages and using theatre as a tool for Indigenous communities to express creators' own version of historical events involving them, whereas in Rapa Nui, theatre has been related primarily to the use of the Indigenous language. ${ }^{60}$ The notion of active culture has been more visible within Māori and Samoan disporic theatre production. Rapanui theatre focuses on the first two concepts explained by Maunder about good community theatre practices.

There are several examples of good community theatre practice in Aotearoa, some of which have managed a very interesting collaboration between 'traditional' and 'contemporary' theatre forms, ${ }^{61}$ as well as developing audiences for Indigenous theatre in Aotearoa. An example is the play devised in 1990 by He Ara Hou theatre company, Whatungarongaro, directed by Roma Potiki and John Anderson. The work of the group Te Rakau Hua o Te Wao Tapu (1990) created by Jim Moriarty, is another example of community theatre practice in Aotearoa. ${ }^{62}$ This theatre company collaborates with different rural communities, schools, prisons, and marae around Aotearoa, creating and presenting plays that resonate not only culturally and artistically with members of the public and participants, but in some cases provide therapeutic help as well (Maunder, 2013).

Pacific Underground and Kila Kokonut Krew could be considered as examples of Samoan community theatre companies in Aotearoa $^{63}$. Both groups have developed their work with and for people in their own communities and both have addressed common issues in their work such as migrating from the Pacific Islands to Aotearoa, depicted in Pacific Underground's Fresh Off the Boat (1993) and Kila Kokonut Krew's Taro King (2002).

\footnotetext{
${ }^{60}$ See discussion in Chapter Four

${ }^{61}$ See discussion in Chapter Four

${ }^{62}$ See discussion in Chapter Five

${ }^{63}$ See discussion in Chapter Four
} 
The discussion about community theatre in this section has provided interesting perspectives through which to consider theatre production in Aotearoa and Rapa Nui. Especially in the case of Rapa Nui, community theatre can become a tool to foster communitas. The production of community theatre could also help in promoting a broader sense of belonging and companionship among other theatre practitioners from the Pacific. Festivals can be important places to share, show, connect, and to possibly workshop new work among theatre practitioners from the Pacific. However, depending on the festival, a substantial part of the audience may not in fact be the local or even regional 'community', but rather foreign tourists. The following section discusses the concept of touristic performances, and issues that these performances raise for envisaging contemporary theatre in the differing contexts of Aotearoa and Rapa Nui.

\subsection{Touristic Performances}

Indigenous performing arts, like any other cultural aspect of society, change and transform over time. These changes and transformations are due to multiple factors, for example the incorporation into another territory; processes of westernization that the incorporated culture suffers; the sense of loss of identity in the face of colonialism and the consequent revitalization; the impacts of media and of tourism (Van den Berg, 2004, p. 1196). Tourism has substantially impacted the production of contemporary performing arts in Pacific communities (Arthur De La Maza, 2009; Balme, 1998; Balme, 2007; Crompton \& McKay, 1997; Farrell, 1979; 1980; D. J. Greenwood, 1972; Guevara Brenes, 2012; Jolly, 1992; MacCannell, 1973; Macnaught, 1982; Mallor, GonzalezGallarza Granizo, \& Fayos Gardo, 2013; Mazer, 2011; Morales Gonzalez, 2008; Tahana \& Oppermann, 1998; Van den Berg, 2004; Werry, 2011).

Tourism, one of the most remarkable economic and social phenomena of the past century is characterised by its strong overall global expansion, and the increasing tendency of tourists to visit new destinations for which diverse tourist products are created. Niche industries have arisen such as Indigenous-tourism, ethno-tourism, and cultural-tourism. Indigenous-tourism refers to the "participatory development of ethnic groups in the offering of tourist services... seeking to interact with the visitors, in a critical and responsible way with nature and their cultural identity" (Morales Gonzalez, 2008, p. 123). Ethno-tourism is defined as an activity where tourists "actively participate in 
various activities in which 'peoples' or 'race' are involved... where elements of historical and cultural value as well as their worldview and daily activities are articulated" (Guevara Brenes, 2012, p. 51). Cultural-tourism is defined as a form that follows the needs and motivations of consumers, so its boundaries are highly subjective (Mallor et al., 2013); it can range from experiencing historical commemorations, crafts, music festivals, and dance, to the "distinct lifestyle of Indigenous people" (Tahana \& Oppermann, 1998, p. 23).

An issue with these tourist products is the expectation, or "destination image" (Desmond, 1999, p. 12) created around a particular place and culture. Tourist products are of great relevance to this thesis, since the tourist, traveller, explorer, or hiker reaches a certain place "with his or her preconceived construction of local life and landscape" (Farrell, 1979, p. 124), and a set of expectations of what they want to see. The result of organizing tourist attractions through the prism of ethno-tourism/cultural-tourism is the "commercialization of cultural elements" (Van den Berg, 2004, p. 1197). The cultural elements that get mostly affected by the impact of tourism are the performing arts. In our talanoa, this was the main problem Julio Hotus saw in Rapa Nui:

The problem is not the tourist itself... but the tourist machinery... because what sells is the romantic image of a South Pacific island... I mean, sand, palm trees and light clothing... this vision has been implanted here and it is what dictates in the end what we have to present to the next visitor... transforming our culture into a performance (J. Hotus, 2014).

Rapanui performing arts such as dance, music, and theatre are re-produced and constructed to satisfy the eye of the visitor, rather than to satisfy the artistic need to create something new. This construction somehow dissolves the difference between what is "real" and what is the "show" (MacCannell, 1973, p. 591), especially as tourists are increasingly travelling with "a desire to see life as it is really lived" (MacCannell, 1973, p. 592) in a particular place.

Internet search engines suggest a wide range of activities to see and to do when visiting Aotearoa and Rapa Nui that might fall under the rubric of Indigenous-, ethno-, or cultural tourism. For example Mitai Māori Village is advertised as an "authentic traditional Māori 
experience!" $" 64$ Te Puia is described as a "Māori experience," ${ }^{65}$ Whakarewarewa's website states that they are "the living Māori village, ${ }^{66}$ and Tamaki Māori Village define their show as "the experience that awaits you"; this performance being New Zealand's "most awarded cultural-tourism attraction". ${ }^{67}$ In the website for the Pacific dance support organisation Pacific Dance New Zealand, in its directory section, it is possible to find a variety of groups offering performances, not only for tourists, but also for special events and businesses. Reviewing some of the websites I noted that one of the words used most frequently is 'entertaining.' In their website, the Cook Islands Anuanua Dance Troup writes "[1]et us entertain you with Cook Islands [d]ancing at its [b]est" (Anuanua Dance Troupe, 2013).

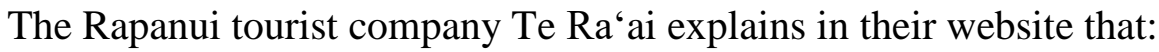

Our mission is based on the visitor's expectations on the island, our culinary and cultural experience, through an interactive service. We developed a program which starts with a greeting ceremony, then we present the opening of the umu pae [earth oven], following with the dance show that is explained in English and Spanish. We also speak Portuguese, Italian, French (Ika \& De Arruda, 2013).

This family tour company openly expresses what the others do not, that what the visitors are seeing is the representation of 'real' 'traditional' life only for the visitor's satisfaction. This may be one of the reasons why among the performing arts, touristic performances are often dismissed and suffer the worst reputation:

Tourist art... is not art in any proper sense, but more or less mechanically produced kitsch, or trashy souvenirs for the less sophisticated traveller (Fagg, 1973, p. 45).

Tourist performances are viewed as an art form of "inferior execution" (Webb, 1994, p. 61) when compared to non-touristic art forms. In addition, touristic performances bring together negative characteristics such as "inauthenticity, [and] lack of aesthetic innovation" (Balme, 1998, p. 54). As discussed in the section 'Traditional' and 'Contemporary' at the beginning of this chapter, the notion of authenticity "demands

\footnotetext{
${ }^{64}$ http://www.mitai.co.nz Accessed 12 March 2015.

65 http://www.tepuia.com Accessed 12 March 2015

66 http://www.whakarewarewa.com Accessed 12 March 2015

67 http://www.tamakimaorivillage.co.nz Accessed 12 March 2015
} 
sources, forms, style, language and symbol [that] all derive from supposedly homogenous and unbroken tradition" (Rushdie, 1991, p. 67). Therefore, these touristic performances "are positioned as signifiers of past events, epochs or ways of life" (Taylor, 2001, p. 9). The most important aspect of authenticity is "dialectic between object and subject" (Taylor, 2001, p. 8).

Ethno-tourism and cultural-tourism appeal to peoples whose motivation to travel involves a "quest for authentic experiences" (MacCannell, 1973, p. 593). For example, this might involve witness an 'authentic' wedding ceremony, something that is not usually included as part of the service. This 'authentic' wedding was especially staged or "manipulated by humans to have certain effects" (Wilke, 2010, p. 131) on the tourists, however, becoming therefore a touristic performance. Although staged, it is the visitors (subject), who according to their own expectations measures how 'authentic' and therefore 'traditional' (Tahana \& Oppermann, 1998, p. 26) the wedding (object) may be. In the case of the performing arts, dance and theatre, this quest for "staged authenticity" (Balme, 1998, p. 53; Linnekin, 1997, p. 215; MacCannell, 1973, p. 595) seems paradoxical. It would be peculiar to see an 'authentic' performance, when performances, by definition, are in a constant state of alteration (Balme, 1998, p. 54).

In spite of scholarly critiques regarding 'authenticity' in touristic performances, the market for such performances is quite large. In Rapa Nui, hotel performances used to be a 'must-see' when visiting the island. Until 2005, the Rapanui dance group Kari Kari performed three times a week at Hotel Haya Roa, one of the oldest iconic Hotels in Rapa Nui. Although hotel performances may be seen as a "form of fast-food culture for quick consumption" (Balme, 1998, p. 57), each performance was viewed by a big audience. Thanks to the revenue earned from these hotel performances Kari Kari was able to build its own venue which opened to the public in 2006.

In Aotearoa, the production Lost in Our Own Land by Tamaki Heritage Experiences is an example of a tourist performance which has been described as a "Māori tourism reenactment spectacle" (Willis, 2014, p. 161). The performance produced between 2008 and 2011 in Christchurch took place in a set of five different sites specifically constructed for this purpose; Raro Heka - House of Understanding, Matuku-moana, a replica Māori village, a battlefield, and the Ferrymead Heritage Park an unused tourist attraction depicting a colonial town (Willis, 2014, p. 169). Within these different 
performance stages, the group invited the audience to "act as symbolic witnesses" (Willis, 2014, p. 162) of "true account[s]" (Willis, 2014, p. 169) about colonial injustices and violence towards Māori people. Weaving 'traditional' Māori cultural elements such as the haka, Māori protocols and European theatre conventions, Tamaki moved away from the typical “"hāngi and haka' format of cultural tourism” (Willis, 2014, p. 164). Lost in Our Own Land acted as a counter-discourse questioning not only the "authenticities" provided by the more widely Paakehaa [sic] (white New Zealanders) dominated [tourist] industry" (Taylor, 2001, p. 16) but also providing their own version of real historical events. This tourist performance differs from the tourist performances produced in Rapa Nui where performances are mostly based on dance, songs and craft, recreating the Western idyllic version of the Pacific. Lost in Our Land presents a recreation of historical accounts from an Indigenous point of view effectively engaging the audience in the performance and satisfying at the same time "the perceived traditional cultural tourism appetite" (Willis, 2014, p. 164).

In Hawai' $i$ the Polynesian Cultural Center (PCC) is the biggest venue providing Pacific tourist performances all year round. Established in October 1963 by The Church of Jesus Christ of the Latter-day Saints (also known as the Mormons) PCC has been harshly described as "anthropological science fiction" and "the Mormon Zoo" (Webb, 1994, p. 61). Other scholars have described PCC as a place which "offers a spectacular example of the theatricalization of Polynesian culture" (Balme, 1998, p. 55), a "carefully orchestrated display of traditional Polynesian cultures for entertainment" (Wilke, 2010, p. 132), and as a "complex work of tourist arts" (Webb, 1994, p. 62). None of these last three descriptions regard the shows presented at PCC as performances of inferior execution or mechanically produced as suggested earlier as one of the qualities of touristic performances.

PCC markets itself as a "cultural theme park" (Balme, 1998, p. 55) that offers the visitor "a chance to travel through Polynesia in a single day, and participate in the celebration of centuries of Polynesian culture-no passport required" (Ariyoshi, 2003, p. 3). The slogan that is proudly displayed on its website is "Where old legends live forever. And are retold daily." ${ }^{68}$ The cultures of Tonga, Tahiti, Marquesas, Hawai'i, Fiji, Aotearoa, and Sāmoa are the main islands displayed around the Centre. Each island has its own 'village' where

${ }^{68}$ http://www.polynesia.com/purpose-and-history.html\#.VWAPL1LY9wQ Accessed 23/05/2015 
the 'traditional' life of these islands is exhibited and where different activities such as crafts-making are shown to the visitors (Webb, 1994, p. 59). Although there is no Rapa Nui village, Rapa Nui is visually represented in PCC by a moai which is carved onsite by Rapanui artisans.

Most PCC performers are students of Polynesian heritage at Brigham Young University in Hawai'i (Balme, 1998, p. 55; Webb, 1994, p. 59). Through various performances in both individual villages and in the theatrical night show (Balme, 1998, p. 55) these 'villagers' provide a view of Polynesia that evokes "preconceptions of the unspoiled, uncomplicated life of the islands where natives still live in grass shacks" (Webb, 1994, p. 59). The construction of "timelessness" (Wilke, 2010, p. 133) that has been used to represent Polynesian cultures is influenced by the narrative of the rise, fall, and restoration (Webb, 1994, p. 81) of Polynesian cultures. This narrative is used to structure the different shows, and it is part of what makes PCC so successful and profitable, because "this fascination also happens to be shared by tourists from around the world" (Webb, 1994, p. 81).

Tourism has also become a major industry in other Pacific countries including Fiji, French Polynesia, Vanuatu, the Cook Islands and Sāmoa, creating thousands of jobs (Scheyvens \& Russell, 2009, p. v). Due to the apparent isolation and limited resources of many Pacific Island countries, tourism has been seen as "a strategy for economic diversification and growth" (Harrison, 2003, p. 2) as it is the only sector to have seen sustained growth in recent years (Scheyvens \& Russell, 2009, p. 2). In 2000, the total number of tourists travelling to twelve Pacific Island nations examined by Scheyvens \& Russell ${ }^{69}$ was 954,260 people. By 2008 , visitors travelling to the same islands increased to 1,378,852 people (Scheyvens \& Russell, 2009, p. 6). Between 2004 and 2008 the amount of tourists visiting the islands grew $36.4 \%$, and the amount of money spent in these islands increased from US\$M 1,522.8 to US\$M 1,769.6 (Scheyvens \& Russell, 2009, p. 8).

In Rapa Nui, the number of tourists visiting the island annually significantly increased between 2000 and 2013, from 15,000 to 90,969 visitors. It is expected that the number of tourists visiting Rapa Nui will reach 136,000 visitors annually by 2020 (Paoa Aguila,

\footnotetext{
${ }^{69}$ Cook Islands, Fiji, Kiribati, French Polynesia, New Caledonia, Niue, Papua New Guinea, Samoa, Solomon Islands, Tonga, Tuvalu, and Vanuatu
} 
2014). Translating the number of visitors in $2013(90,969)$ into economic growth, the amount of money generated by tourism annually on Rapa Nui is \$CLP24 million (\$US 44 million) (Paoa Aguila, 2014). The economic contribution that the tourist industry brings to Pacific communities is undeniable, and this in turn has a variety of both negative and positive consequences for cultural identity and expression in Rapa Nui.

Webb states that performances for tourists should not be "examined as a degradation of some earlier style, but as a distinct social and aesthetic phenomenon" (Webb, 1994, p. 61). He explains that this particular type of performance should be understood primarily in terms of its function, which is to provide a living for the performers involved. Being able to provide for your family is very important and if tourist performances provide the opportunity to live well, it does not make sense to stop performing for tourists.

The fact that tourist performances exist is not the problem. The problem arises when their existence inhibits and prevents the creation of anything that is not centred on the tourist market. In Rapa Nui the ideas and boundaries underpinning and influencing the creation of tourist performances seem to be generalised to all forms of creativity, offering to the audience an idealized 'Pacific experience' by presenting them 'authentic' performances of 'tradition'. 
In countries such as Hawai' $i$ and Aotearoa art forms and venues not dedicated to the tourist market coexist with performances created for the tourist market. Indigenous theatre practice in Aotearoa embraced community and intercultural theatre practices which has enabled them to release notions of 'tradition' and conservation enabling them to be flexible and also rooted in terms of new forms of creativity. These methodologies have guided the creations of stories which reflect peoples values and stories, both past and present, moving away from the performances targeted for the tourist industry. In Rapa Nui, the overwhelming majority of performances are targeted towards the tourist market. Even the schools festival in November, Mahana o te Re ${ }^{\circ},{ }^{70}$ has turned to some extent into a touristic attraction rather than keeping its initial educational purpose. Community theatre practices, intercultural collaboration through theatre and the concept of counter-discourse may provide Rapanui theatre practitioners the opportunity to create not only touristic performances but also community -based theatre reflecting their positionality in the contemporary world, as well as their own version of historical events happening in Rapa Nui.

\subsection{Conclusion}

The discussions in this chapter considering concepts of the 'traditional' and 'contemporary' took us through a variety of definitions, approaches, and attitudes. Moving away from binary ideas of these concepts, and towards ideas that notions of the 'traditional' and 'contemporary' are part of an ongoing cycle can help us to understand the continuous processes of creation involved in art forms that we may come to regard as 'traditional.' It is very difficult to understand the notion of 'contemporary' in isolation from a consideration about ideas of 'tradition,' because they are interdependent and intertwined. Having a connection with the past, imagining, recreating or reinterpreting it, is not only a creative act (Whimp, 2010, p. 386) but it also reaffirms the identity of theatre practitioners from the Pacific today. In Rapa Nui however the relationship between 'contemporary' creations and upholding ideas about 'tradition' is still seen as something fixed that cannot be changed, and bears no relationship to 'contemporary' theatre creations. Rigid understandings of the concept of 'tradition' result in performances focused on recreating the past as 'authentically' as possible. In addition,

\footnotetext{
${ }^{70}$ See discussion in Chapter Four
} 
contemporary creativity is generally seen as something that comes from the outside, with many Rapanui artists being very reluctant to perceive or to describe their own creations as contemporary adaptations, or as reinterpretations of past practices. The attitudes and experiences of Māori and Samoan theatre practitioners in Aotearoa towards the concepts of 'traditional' and 'contemporary' show different and more flexible ways of dealing with the relationship between cultural heritage, identity and performance possibilities that are not currently seen as acceptable in the Rapanui context.

This chapter has also highlighted the importance of collaboration among different cultures. The concepts discussed here including bicultural, multicultural, intercultural, hybrid theatre, and syncretic theatre, pointed towards the possibility of working in collaboration with another culture. This understanding fundamentally opens up the ways in which the production of theatre can be conceptualised, making performances more relevant and appealing to culturally diverse audiences, and pointing towards new possibilities for intercultural collaboration and exchange.

Chapter Three has also discussed the production of Māori, Samoan diasporic, and Rapanui theatre from the perspective of popular theatre and community theatre. Community theatre could be a useful tool to foster a Rapanui theatre community and help connect them to the wider Pacific communitas. Community theatre usually involves collaboration between arts professionals and community members, where theatre skills are taught and stories from the community are shared to be performed. Using these aspects of community theatre as a method for the creation of contemporary Rapanui theatre provides a useful template for the future development of Rapanui theatre. This methodology could also help to promote a greater sense of belonging and companionship among Rapanui artists, and with Indigenous theatre practitioners from across the Pacific. Community theatre can re-enact 'traditional' stories, as well as exploring more 'contemporary' stories and experiences. The Māori and Samoan experience with popular and community theatre demonstrates how powerful these two approaches can be in terms of engaging the community in theatre processes. Ways of engaging the community may vary from devising a performance based on stories shared by a small group of people, or through inviting the community to discuss the play at the end of the performance thus developing audiences for Indigenous theatre. 
Finally, this chapter discussed the impacts that tourism has had on the development of performing arts in different Pacific communities. In Aotearoa there are a wide variety of tourist performances offering 'authentic' cultural experiences to visitors. However, in this context, art forms and venues not dedicated to the tourist market coexist with touristic performances, providing different performing options for artists and audiences to experience all the different aspects of the performing arts. In Rapa Nui, most performances are targeted towards the tourist market, promoting a strictly 'traditional' point of view. I suggest that the creation of community theatre might support the production of artistic material that is community-focused instead of tourist focused. The key question therefore becomes how might be possible to accommodate creativity which is not geared towards and shaped by tourist expectations within the local repertoire of Rapanui performing arts? That question should be answered by the local artists and local authorities in Rapa Nui. 


\section{ค濷 Sprout}

1 Tupu

El Brote 


\title{
Chapter Four
}

\section{狖酓 Historical Development of Rapanui, Māori and Samoan Diasporic Theatre}

\author{
Hakaara o te a'amu o Rapa Nui, Māori \\ e Sāmoa ${ }^{71}$
}

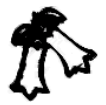

\section{De Tal Palo Tal Astilla}

\subsection{Introduction}

In the first part of this research the Seed-Karu-La Semilla of theatre was planted in the Rapanui community in Rapa Nui, and in Māori and Samoan communities in Aotearoa. The Spanish title of this chapter is a Chilean saying which is used to refer to parents and their offspring. Where the seed was planted and how it has been taken care of will determine the quality and the strength of the sprout. The historical development of theatre determines how theatre is performed today, linking the ancient with the modern, the 'traditional' with the 'contemporary,' history with the present and future.

In this chapter I use a wide number of examples and case studies. I acknowledge that there are many examples of Māori, Samoan and Rapanui theatre, but I chose the ones that better illustrate the blending of 'traditional' and 'contemporary' elements and the blend of Indigenous and Western theatre techniques.

\footnotetext{
${ }^{71}$ The History of Theatre for Rapanui, Māori and Samoan peoples
} 
This thesis is part of an ongoing life research which is related to theatre practice in Rapa Nui. Conducting this research in Aotearoa has been a unique opportunity to do both: share as many examples and information about Rapanui theatre with the Indigenous theatre practitioners in Aotearoa, and to take back home to Rapa Nui and Chile as much information about the state of Indigenous theatre in Aotearoa. I will be translating the thesis into Spanish, making this information available to the Rapanui theatre community to hopefully inspire future theatre production in Rapa Nui.

In this chapter, which opens the second part of this thesis, entitled Sprout-Tupu-El Brote, I will discuss the historical development of Indigenous theatre in Rapa Nui, Māori and Samoan theatre in Aotearoa. Different plays will be used to illustrate how performative elements considered to be 'traditional' have been integrated with European theatre techniques in the creation of a 'contemporary' works in Rapanui, Māori and Samoan diasporic theatre. This chapter compares and contrasts different aspects of these three theatre practices, including context, the use of community theatre practices, and Indigenous languages. I will also explore the role of the storyteller, the influence of intercultural negotiations, and Shakespeare's influence on Māori and Samoan theatre in Aotearoa.

\subsection{Historical Development of Rapanui Theatre}

Rapa Nui is known worldwide for its moai (stone statue) and archaeology. Although archaeology has been the main focus of research about Rapa Nui, nowadays other aspects of this culture have also been considered important to investigate, for example the Rapanui performing arts. Ancient rites and festivities in Rapa Nui have been studied by authors such as Barthel (1962), Englert (2007), Métraux (1971), Paoa, Aranda, \& Sandia (1983), and Routledge (2007). The theatrical elements that some of these rites and festivities denote, suggests that in Rapa Nui different forms of representation were constantly created and re-created. While the concept of theatre as conceptualised within a Western framework does not exist in the Rapanui language (Paloma Huke, 1995, p. 37), there are several different ways of referring to the art of representation, illustrating the importance of storytelling and oratory in Rapanui culture. For example; haka tike'a atu (to show you), hakararama i te me'e ta'ato'a i te a'amau tuai o Rapanui (to show 
everything related in the telling of Rapanui stories), haka ite atu (to let you know), mo pata'u ta'u atu (to tell you).

My Master's thesis, The Development of Theatre in Rapa Nui: Hakararama i te A'amu Tuai o Rapa Nui (2010) discusses in detail the development of Rapanui theatre, from the ancient rites and festivities, to school theatre performances created in 2008. For the purpose of this research, the following section will briefly describe the main elements that have fostered the creation of Rapanui theatre today.

Throughout Rapanui history, it is possible to find a variety of artistic performances. Some are very old, for example the koro feast that took place well before the arrival of missionaries to the island in the 1860s. Any event celebrated with songs and the sharing of food with a large group of people was known as a koro (Englert, 2007, p. 299). Generally a koro was organised to honour "a living father, mother, father in law or mother in law" (Metraux, 1971, p. 346). A koro had a choir composed of the hatu (director) and the singers, which prepared and rehearsed songs especially for the occasion. This choir consisted of a row of men called pere who were placed behind the women's row named ihi, who painted and adorned their bodies with natural pigments using " the yellow juice of the bulb pua, red soil called kie'a, white clay and charcoal" (Englert, 2007, p. 300). Nowadays, people from the Rapanui community remember having heard of a procession in which a high status person was placed on a platform and carried on the shoulders (Pamela Huke, 2009). Pamela Huke, former member of Mata Tu'u Hotu Iti, believed that the name of this procession was koro paina (Pamela Huke, 2009). According to the description found in the writings of Metraux (1971), Englert (2007), and Paoa et al. (1983), the koro paina was not related to a celebration called paina which was celebrated to honour the "memory of a dead parent" (Metraux, 1971, p. 343), or in memory of "an important person some years after his death" (Paoa et al., 1983, p. 450). 


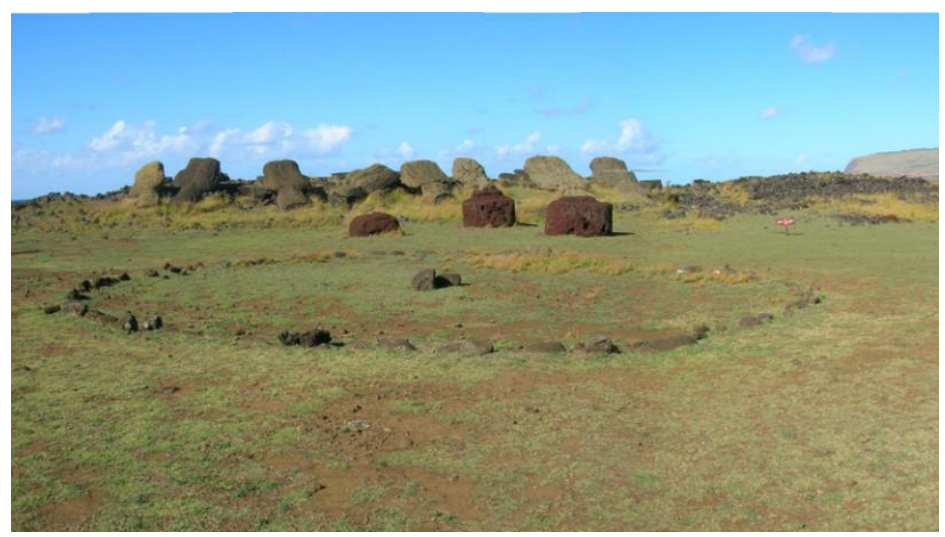

Figure 1. Paina site in front of Ahu Haya Te'e. Photo by Moira Fortin

The paina celebration was held in front of the ahu (platform) "where the honoured dead relative was buried" (Metraux, 1971, p. 344) (see Figure 1). For this event, the host commanded to build a figure, "an image that represented a tribute to the dead person" (Paoa et al., 1983, p. 450) that was three or four metres high. The figure consisted of a hollow head and body, so that the heva (sufferer), the host of the feast could "enter the figure and delivered a long speech" (Metraux, 1971, p. 345) from the mouth of the figure (see Figure 2). Pamela Huke understood this performance from the host more as a representation of the deceased's life, similar to drama than to a simple plain speech (Pamela Huke, 2009).

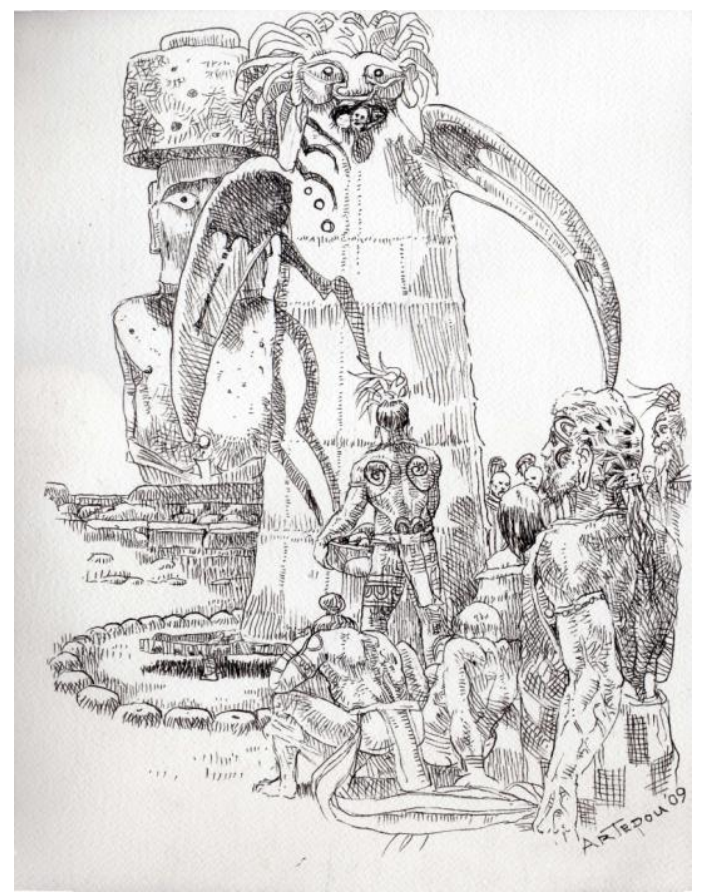

Figure 2. An artist's impression of a paina ceremony, by Te Pou Huke 
While koro and paina have ceased to be performed, there are other performances today that are arguably derived, or rather, are the contemporary versions of festivities performed long ago. Koro haka opo and the parade during Tapati Rapa Nui draw from koro ei and narinari respectively (see Figure 3). The ei was a type of song with a text involving mockery and disdain. If people became enemies, it was very common to take revenge by celebrating a koro with the famous ei song (Englert, 2007, pp. 305-306). It seems that its only aim was to offend and make fun of a person in a public performance, whose conduct had previously insulted a person. Each team prepared and rehearsed in secrecy songs that spoke of the physical defects of the opponent. In the performance, the first team, to get angry, lost the competition. The koro haka opo (choir competition), held during Tapati, could be considered a 'contemporary' version of koro ei, because they share a similar features; both are a choir competitions, the way in which the performance unfolds is the same, taking turns to sing, and both are prepared and rehearsed in secrecy before the performance ${ }^{72}$. While the purpose of koro haka opo is not to offend the other party, effort is directed to make the opposing team lose the contest. In this competition, the objective is to sing as many songs without repeating or making any mistakes. The first group repeating a song loses the competition. This contest used to start at $9 \mathrm{pm}$ taking place until 4 am without a break. Nowadays and for the purpose of the festival, the winning team is decided by a set of judges who end the competition around midnight.

Narinari refers to the art of disguise, people who dress up and paint their bodies so that they are unrecognizable. It was not possible to verify the time period when narinari began. Cristian Madariaga Paoa, a Rapanui language teacher, explained that yoyoro narinari "was performed when the missionaries were already on the island" (Madariaga Paoa, 2009), confirming that this celebration was relatively contemporary, or at least from the late nineteenth century. Rapanui elder and storyteller Felipe Pakarati remembers that narinari usually involved teasing another person in the form of a satire, using imitations and songs of derision (Pakarati, 2009). The disguised person was designated with the term narinari hakaatua or narinari hakavarua which means 'as a deity' and 'emerging like a ghost' respectively (Barthel, 1962, p. 656). According to Barthel,

\footnotetext{
${ }^{72}$ There are plenty of examples in Rapanui culture that show the recycle cultural forms of expressions, for example the use of an old ahu (platform) as the base from where to build a new one, a moai (stonestatue) half carved which is the base for another moai, the re-creation of Miro $\mathrm{O}^{\prime}$ one features in the celebration of weddings by surrounding the married couple in a white fabric resembling the form of a boat. I argue that koro haka opo could be a re-creation of an old, no-longer performed choir competition, acknowledging the notion that in Rapa Nui contemporary creativity can evolve from within cultural practices.
} 
narinari could also relate to the postures and gestures that a person performed while disguised. There seems to be some parallel here with Samoan faleaitu, in the sense that the performers can get away with behaviour that would normally be considered antisocial because they are masqued, and it is not really the individual but the deity or ghost talking and behaving through them.

According to Lynn Rapu, Director of the Cultural Ballet Kari Kari, the contemporary version of narinari occurs every year during Tapati in the parade (Rapu Tuki, 2009) where each person dresses up in "a small garment similar to underwear made of bark cloth called hami” (M. Fortin, 2009, p. 154), and walks down the main street singing and dancing.

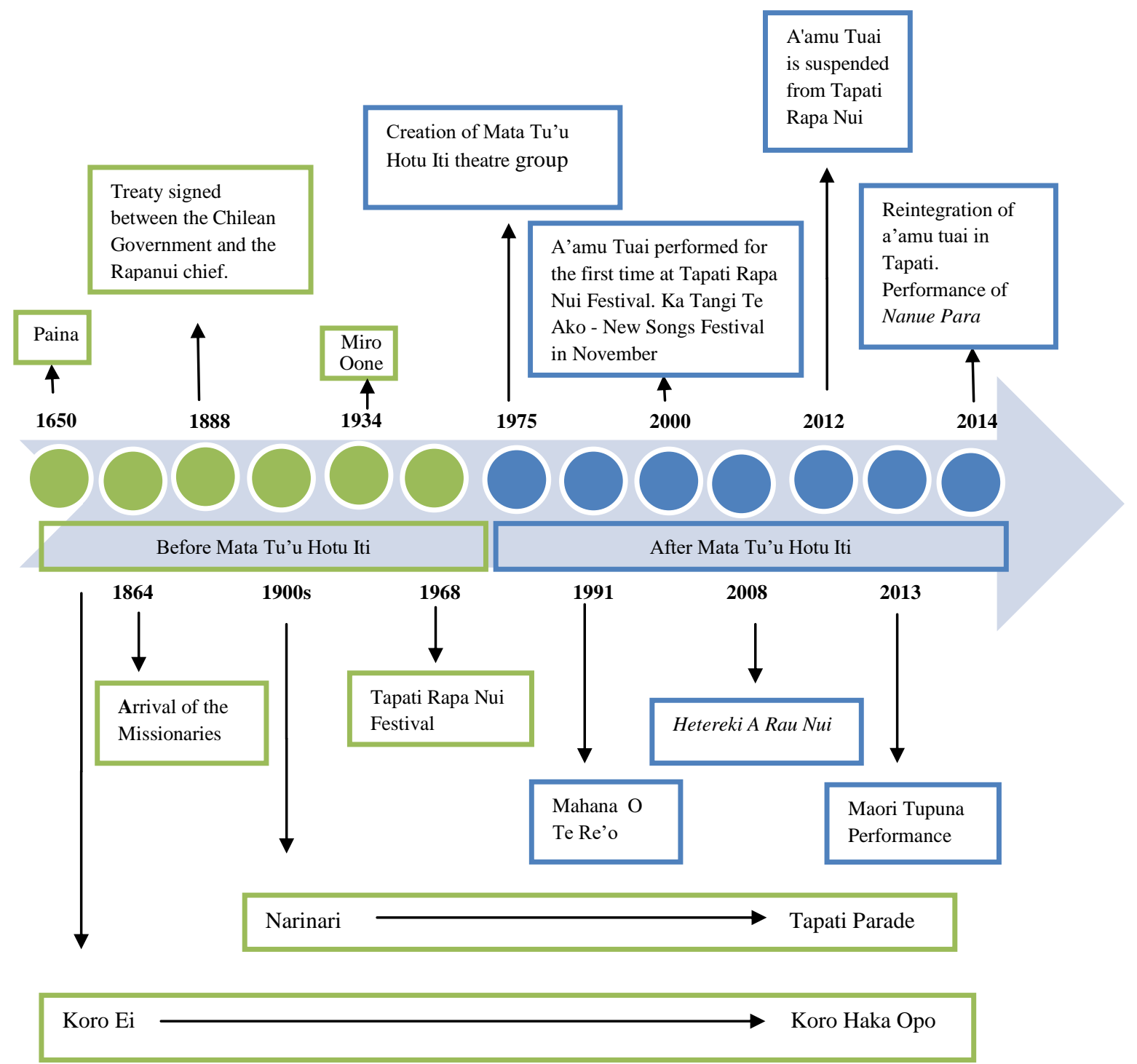

Figure 3. Chronology of the development of Rapanui theatre 
In the timeline above, there are three clear milestones, points at which ritual and festivities gave way to theatre; Miro O'one (1934), the work of Matu Tu'u Hotu Iti (1975) and A'amu Tuai (2000). Miro O'one was the name of a figure made of earth that had the shape of a boat, in which was held a boat festivity (Englert, 2007, p. 301). During the eighteenth and nineteenth century the ships that visited the island must have impressed Rapanui peoples. The manoeuvres of the crew on board seen by the Rapanui peoples were translated into a ballet or pantomime that was subsequently performed every year on a platform of land representing the foreign ship (Paoa et al., 1983, p: 428). This performance, known as Miro O'one, was created around 1934, was annually performed on the first day of the year, and consisted not only in representing the manoeuvres, positions and language of the crew, but also the Rapanui performers dressed up in uniforms of the Chilean Navy.

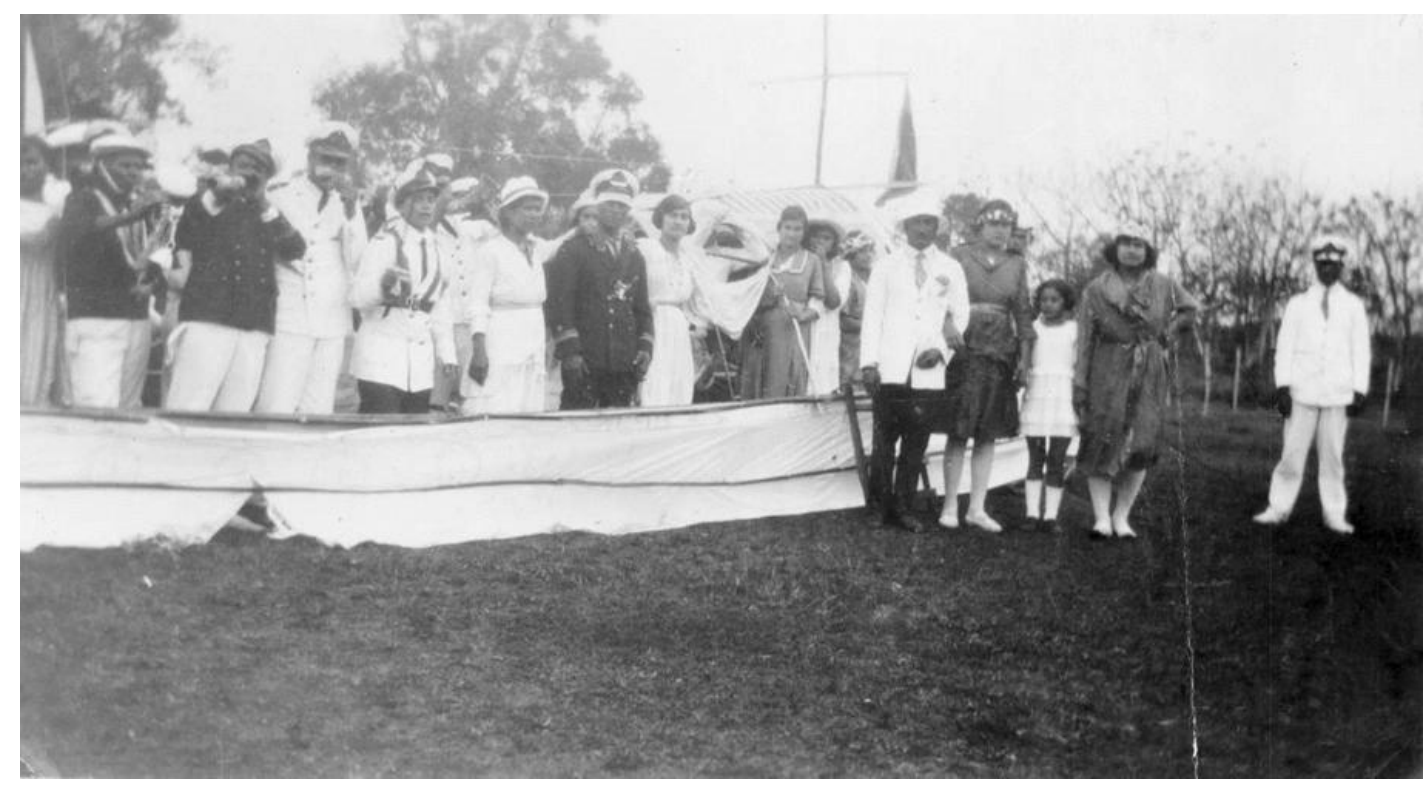

Figure 4. Rapa Nui group performing a Miro O`one (1934). Photo courtesy MAPSE ${ }^{73}$

Some Rapanui performers were the mataroa (sailors) and others the officers and performed exercises imitating a ship's crew. This feast was prepared long in advance, and every detail was carefully studied. A month before the performance, regular dance lessons were given in the huts of Rapanui instructors. Metraux provides a description,

\footnotetext{
${ }^{73}$ Museo Antropologico Padre Sebastian Englert
} 
explaining that the performers stood in a line, each with hands on their hips, and stepped forward followed by one or two steps back. Two people in uniform guided the first row of dancers, where one of them was carrying a sword and the other a sheath of the same weapon. Turning to their troops, they pronounced different orders in different languages such as French, German and English. At a signal, all the dancers moved their arms in a gymnastic movement inspired by the signalling training exercises observed aboard a ship (Metraux, 1971, pp. 361-362). During one of the last performances of Miro O'one, the Rapanui catechist Timoteo Pakarati performed the captain, giving orders in a language that resembled English, chewing and spitting his tobacco. Timoteo Pakarati is still in the memory of the contemporary Rapanui community for having successfully played the role of captain.

The performance of Miro $O$ 'one could be seen as a 'contemporary' Rapanui representation. In Chapter Three, Julio Hotus stated that in Rapa Nui the concept of 'contemporary' art was understood as something that came from the outside. However, the example of the Miro $O$ 'one shows the contrary. In this contemporary performance, Rapanui people were representing the other, the outsider, and not themselves. Miro $O$ 'one may have been based on oral transmission, observation and memories, allowing the permeability of the old and the new from a Rapanui point of view.

Moving forward in time to the 1970s the group Mata Tu'u Hotu Iti (MTHI), emerged as the first theatre company in Rapa Nui. The Huke and Tuki families established this group in 1975. The name of the group "was drawn from the shared ancestral lands of these clans" (Bendrups, 2005, p. 309), where the word Mata means clan and Hotu Iti refers to a specific site on the Northern part of the island. These families sought to tell and remember their own histories, creating performances not for tourists, but for the Rapanui people (Paloma Huke, 1995, p. 43). MTHI emerged as an influential group, motivated in part by the many political and social changes that had happened in Chile and on the island; for example the prohibition on speaking the Rapanui language in the early years of the establishment of education on the island, "because the first priority was to teach Spanish" (Arredondo, 2012, p. 69).

The company had three main objectives: firstly, to recover, rebuild and maintain the Rapanui history; secondly, to raise their cultural heritage as an effective tool for the development of their culture, demonstrating the value of past practices; and thirdly, to 
avoid loss of language (Paloma Huke, 1995, p. 45). MTHI reconstructed their stories depicting legends and traditions using songs, dance, and poetry, as well as incorporating elements of Western theatre techniques such as the pantomime. Over time, the Rapanui community validated these theatre performances, because the troupe was embracing tradition, becoming therefore an extension of ancient cultural practices and reflecting both contemporary culture and ancestral traditions (Huke, 1995, p. 43) thus "influencing many current Rapanui performances” (Bendrups, 2005, p. 311).
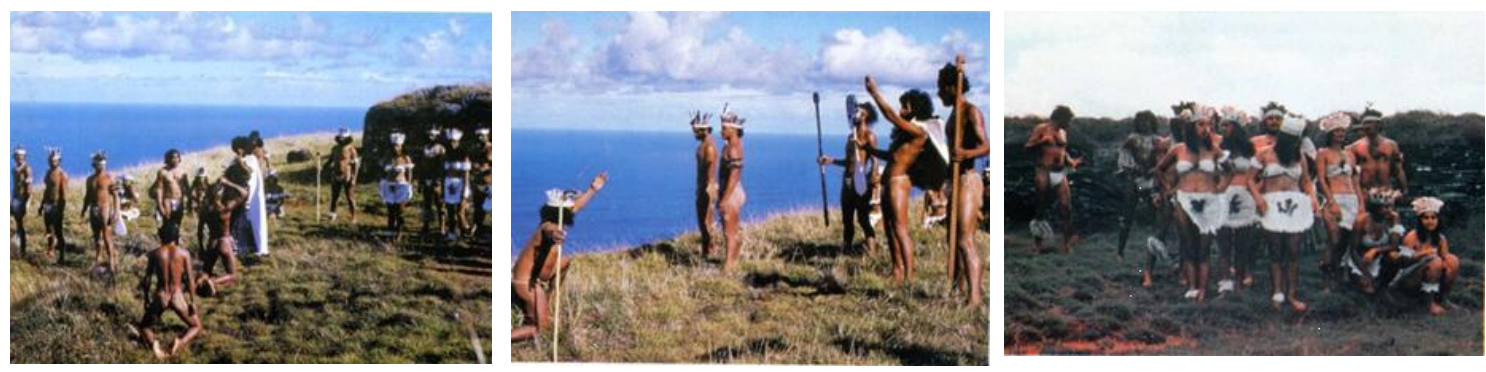

Figure 5. Mata Tu'u Hotu Iti performing at Orono. Photo courtesy of MAPSE

In the case of the work of MTHI, Rapanui forms of representation served as tools to explain to the world and its people the meaning of their existence. With their performances, the company forged identity and gave a sense of belonging to different generations, due to the three hundred young Rapanui people who became involved in the group's activities between 1974 and 1999 (Paloma Huke, 1995, p. 43).

MTHI performed at the Pacific Festival of Arts in 1976 and 1985 (Paloma Huke, 1995, p. 63). Their performances and participation in the Festival, created a strong sense of belonging and communitas among its participants. The participants not only were part of the troupe, they also discovered a sense of belonging to the wider Pacific community. In the history of Rapanui performing arts it is possible to draw a line defining the time before and after MHTI (see Figure 3), setting the foundation for future Rapanui performances. 


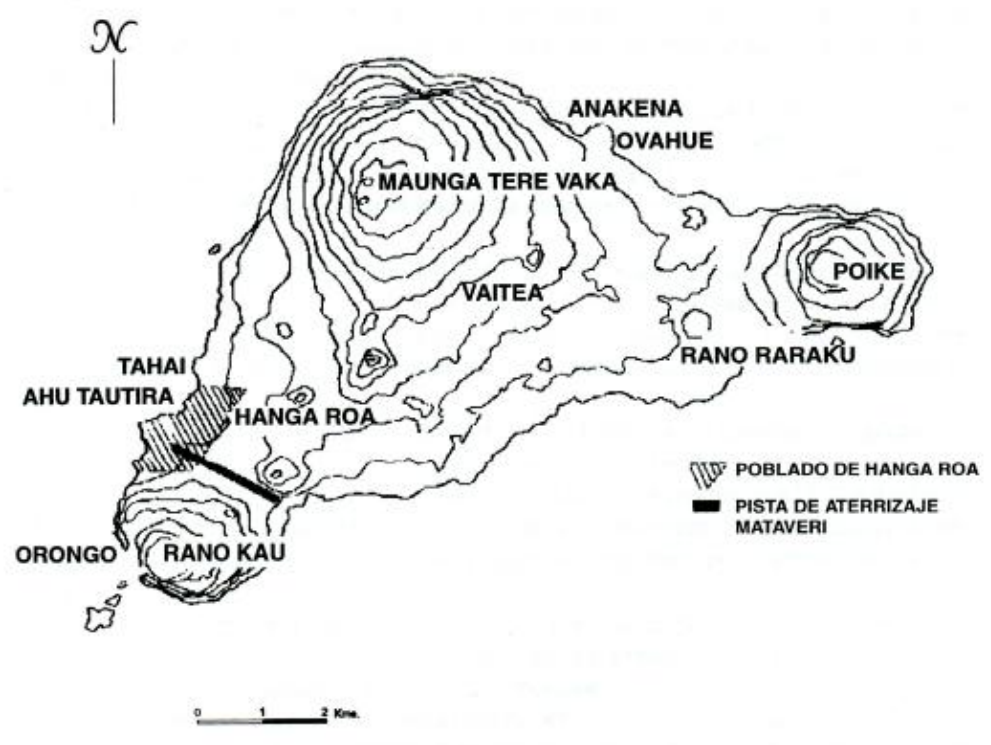

Figure 6. Map of Rapa Nui

The group performed stories and legends in different parts of Rapa Nui. Natural settings were used as stage for the different performances. For example "Anakena, Ovahe, Ahu Tautira, Tahai [and] Orongo" (Paloma Huke, 1995, p. 52) (see Figure 6). Kaiga (1993) was performed at Ovahe Beach. This story is about war between two clans, the Miru and the Tuopahotu, in which avenging the deaths of the main characters is the central action of the story. MTHI chose to use the entire beach for its representation of this story (see Figure 7), and this natural stage also included a cave and the sea. There was no predetermined space for the audience, and during the performance it seemed as if the audience was in some way invisible to the actors. Claudia Quiroga, a Chilean citizen living in Rapa Nui at that time, remembers that sometimes the actors came running towards or close to the audience, without acknowledging the presence of people (Quiroga, 2009). Audience members explained that experiencing a theatre performance on a beach, lit only by torches, and featuring actors wearing 'traditional' costumes or body painted and hearing only the Rapanui language "was very impressive" (Quiroga, 2009). This naturalistic performance allowed audiences to feel transported to a different time and place as if "you had travelled back in time and you were watching something that was truly happening here and now... but not a play" (Quiroga, 2009). 


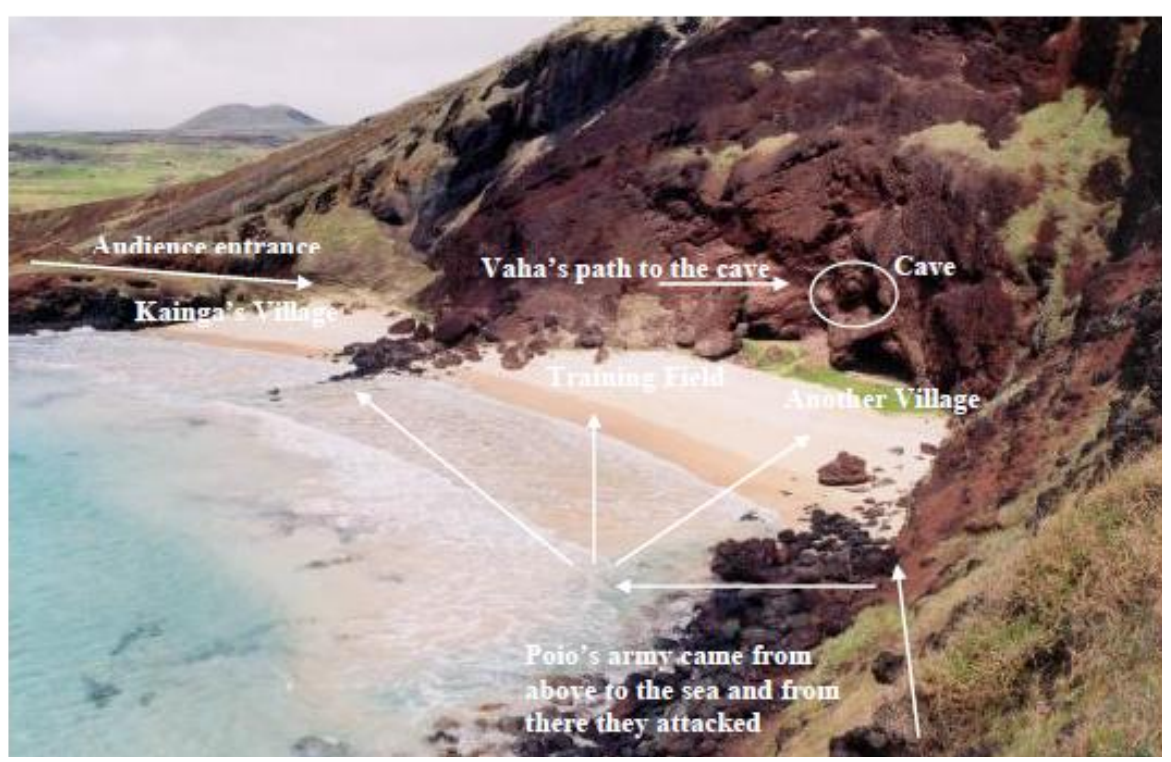

Figure 7. Use of space in Kaiga (1993). Photo by Moira Fortin

Through choosing Ovahe beach for performances, MTHI selected a natural amphitheatre with lots of features perfect for the representation of theatre. The different locations narrated in the story were easily translated onto the stage that Ovahe beach provided, including the audience entrance, Kaina's village, the cave where one of the characters hid, and the different paths used by the enemy clan to invade and kill. Something that happened during the performance, that possibly nobody thought about, was that the tide begun to get higher and higher, so the stage became smaller and smaller. The audience had little room and the actors had difficulty moving around. The use of the space in this performance by MTHI can be compared to Lost in Our Own Land by Tamaki Heritage Experience in Aotearoa. In both examples the story is framed and performed in a space that resembles the 'real' space in which these events may have happen in the past. Audiences are immersed in these social and emotional environments, giving the impression that what it is been performed is 'authentic' and therefore a 'traditional' product.

The most anticipated performance was MTHI's representation of The Arrival of Ariki ${ }^{74}$ Hotu Matu 'a during Tapati. This performance represented through dances and songs the arrival of what it is believed to be the first migration of Polynesians to Rapa Nui. The performance used to take place in Oromana, nowadays knows as Anakena beach, where

\footnotetext{
${ }^{74}$ High chief
} 
according to oral narratives Hotu Matu'a arrived. Usually the performance started at the beach where it was possible to see Hotu Matu'a and his people chanting while walking towards a moai platform that is currently located in Anakena. Other times, the group adorned a fishing boat, starting the performance from the water. You could see a boat full of people dressed in 'traditional' costumes sailing towards the beach, where the performer representing Hotu Matu'a would disembark and start walking towards the platform followed by the group of people chanting and dancing.

The last performance by MTHI took place during the Tapati in 1999. As a response to the loss of performances by this group, during the 2000 festival organisers created a competition based on the practice of $\mathrm{a}^{6} \mathrm{amu}$ tuai ${ }^{75}$. A panel of judges were chosen who evaluated fidelity to oral traditions, creativity, choreography, expression and organization of a'amu tuai performances. These plays were performed in largely the same way MTHI used to perform them ${ }^{76}$ except that rather than being held in a natural setting the performances are on a stage, and made use of technology including lighting and wireless microphones.

Despite the technological advances that Tapati has gone through, especially in a amu tuai, in my interviews Tiare Iti Araki Pont, a member of the organizing committee of the Tapati Rapa Nui Festival, explained that "a'amu tuai was removed from Tapati in 2012 for the lack of commitment of the participants" (Araki Pont, 2014). The problem with $a^{6}$ amu tuai, according to Araki Pont was that "there is no rehearsal, no methodology and in the end the performers put something together in the very last minute before going on stage" (Araki Pont, 2014). Carlos Lillo Haoa, director of the dance group Maori Tupuna, states that having theatre or rather including a'amu tuai within the context of Tapati is a good idea, but:

There is no work behind it... I don't know if there is a lack of people involved in $a^{\prime} a m u$ tuai or what.... But the truth is that no one prepares to perform, there are no rehearsals... from what I've seen lately, those plays were not rehearsed, presenting a bad and poor work... no one understands a thing of what is going on on stage, and it is not entertaining to watch" (Lillo Haoa, 2014).

\footnotetext{
75 Telling old stories. Nowadays it is the Rapanui term commonly used when referring to theatre.

${ }^{76}$ See discussion in Chapter Five.
} 
In 2005 I was fortunate to participate in a'amu tuai at Tapati performing the story Ure A Oho Vehi (Mata O Te Rapa Nui, 2005). The play tells the story of two spirits who kidnap a boy to kill him and take him to the spirit's world. While in captivity, the boy starts chanting and is heard by fishermen who tell the boy's father, organising the rescue of his son. At that time I was a dancer at Kari Kari Cultural Ballet. One of the Queen candidates for Tapati was a member of Kari Kari, so the entire group decided to support her dancing, singing and performing in the different competitions. Lyn Rapu director of Kari Kari said one afternoon that for $\mathrm{a}^{6} \mathrm{amu}$ tuai we were going to perform the story of Ure a Oho Vehi. The main reason for this decision was that this story has not been performed in a while, and it would be good in term of points, to perform something that has not been performed the year before. In addition, the way in which the stage was used that year provided all the different sites mentioned in the play giving us the opportunity to use the whole stage.

The next day, the director organised a meeting to talk about the play. There we discussed the plot of the story, and the way in which we wanted to perform the story. We also discussed who from the group could perform the different characters, based solely on our physical characteristics. That day we decided that we wanted to start with a prologue showing a section that is half way through the play: the spirits chasing the old woman. The idea was that the storyteller would go on stage right after the prologue commenting on that scene, and connecting it with the beginning of the play. Up to this point nobody had taken any notes of what had been discussed. The director was cast as the storyteller; one part of the group was cast as the community, another as the fishermen, and another as the warriors. Two sisters were cast as the spirits, the old woman called black crab; the child Ure and his father Oho Vehi were also cast from the group. To some extent these meetings acted as a rehearsal of sorts. As a group we knew the story very well, each of us knew what we had to do. As much as I would have like to rehearse the play, there was not much time left to practice, because each of us were busy during the day either at school or at work until 5pm, and because Kari Kari continued to performed at Hotel Hanga Roa three times a week, leaving little time to practice anything else.

After only a few days of organizing what we were going to present, the performance day arrived. For Tapati each group performs only once, so there is not much room for error. The night of the performance, the person playing the Old Woman did not show up. Since 
the remaining cast knew the story very well, her absence was 'easily' solved. The original idea was that each main character would have its own text, but under the circumstances, we reorganized the groups, decided behind the scene who would replace the missing person and decided to let the storyteller narrate and be in charge of the whole story. In the end we followed the storyteller on stage, who explained the story in Rapanui and Spanish while we mime actions at the back. The group feeling after the performance was of frustration, this performances could have shown a different perspective on how to perform a'amu tuai, however due to the circumstances and to salvage the situation, we had to repeat a format that was not appropriate for this particular performance. In addition, it became clear that the person who was missing from the performance did indeed not care about the presentation.

Rapanui artists are mainly self-taught; only a few have gone to tertiary educational institutions in Chile to study the arts. Possibly the lack of knowing the craft of theatre may be the main issue here. Rapanui dancer Vai a Heva Rapu Drago stated in our talanoa that "the problem is that they don't know how to do it, and that they don't ask for assistance either" (Rapu Drago, 2014). If there is no theatre training facilitating theatre conventions, creative process and rehearsals, it is very difficult to achieve a good result when staging a play.

In 2009 the play Uho Te Uka was performed at Tapati. The play tells the story of Uho a young woman who is taken to another island by a turtle. There she gets married and has a son, but she is constantly missing her family back home. One day she finds the turtle again, and asks the turtle to take her back home. One of the main aspects in a'amu tuai is the role of the storyteller. In this play the storyteller moved from one side of the stage to another, or followed the characters during the performance to make sure that the actors were in the right positions and doing what they were supposed to do. Sometimes the storyteller had to vocally state what, when, and how things were supposed to happen in the performance. For example, the storyteller said "E Uho! kararama i to"ou taurareya! ka rarama, ka ui, ka kimi (Uho! Look for your belt! look, search)" (Tapati Rapa Nui, 2009) until the performer enacted the action. 


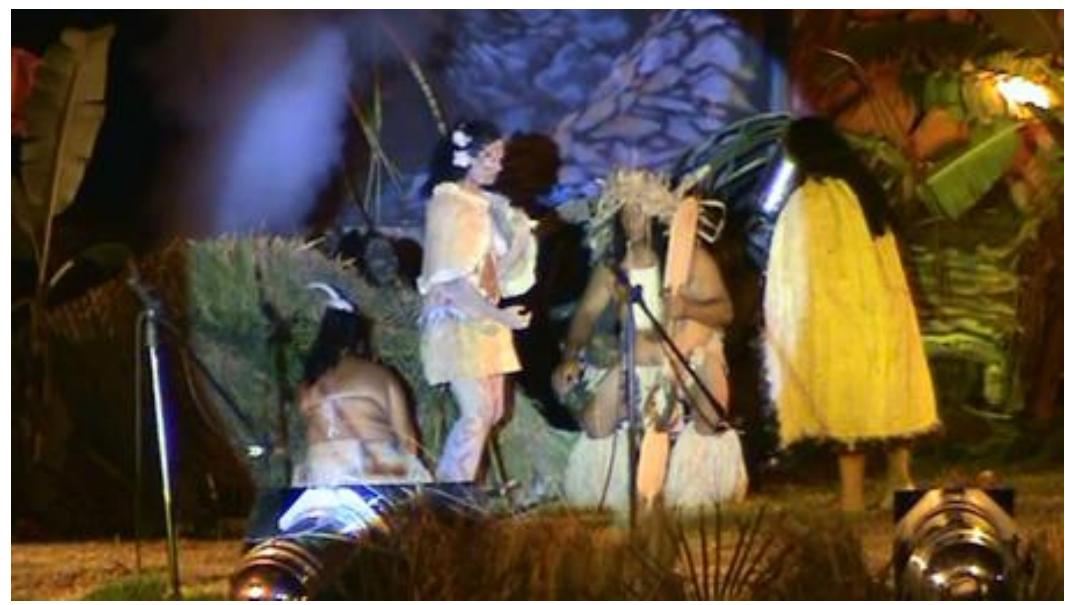

Figure 8. Uho, Te Uka. Tapati Rapa Nui 2009. Photo by Moira Fortin

That year the play Ure a Oho Vehi (2009) was performed again. In this play each performer knew exactly what they had to do and when. The rehearsal period is evident in the performance, making it, to some extent, easier for the audience to follow the overall story. Different actions such as cooking, fishing and planting were mimed. However, sometimes it was difficult to depict the meaning of these movements, leaving part of the audience out of the experience of theatre due to a "lack of knowledge in the craft of theatre" (Lillo Haoa, 2014). For an audience member who understands the Rapanui language, the lack of clarity and precision in the execution of each movement was not seen as a problem, because they could still follow the action. However it has to be taken into consideration that these performances are part of a cultural festival where its main audiences are tourists that do not speak or know the Rapanui language and culture. Therefore actions and movements must be rehearsed in order to avoid lack of understanding from the non-Rapanui speaking audiences.

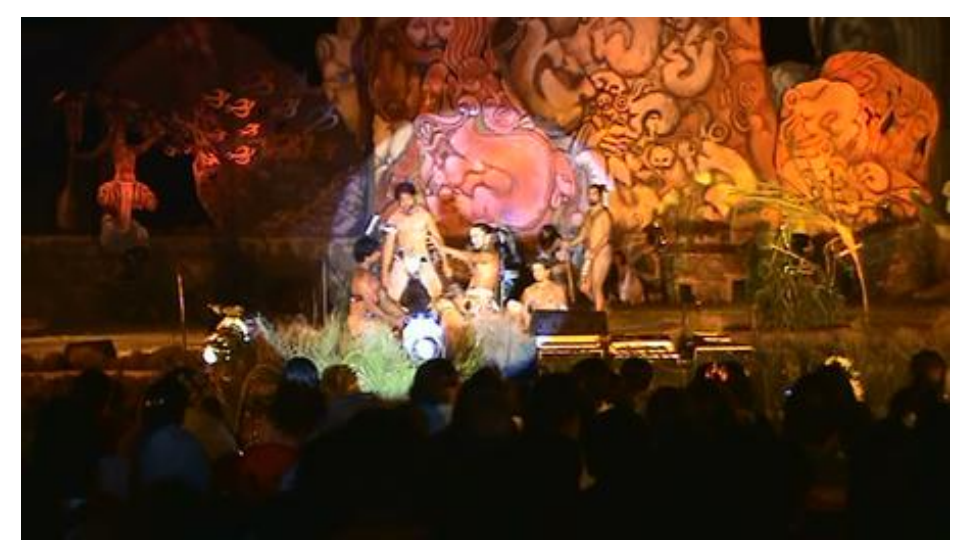

Figure 9. Ure A Oho Vehi during Tapati Rapa Nui 2009. Photo by Moira Fortin 
Fortunately a'amu tuai performances have become a popular part of contemporary Rapanui society. In the last eight years a'amu tuai has become part of the school system. When he is not working at Maori Tupuna, Lillo Haoa works at Aldea Educativa high school teaching music with a strong connection to storytelling. In our talanoa Lillo Haoa explained that initially the main idea for him to work at school was to teach Rapanui music. He states, “I don't know how to read music or notes... but I know lots of old Rapanui songs... and stories! And those stories are the ones I use to create music... so I guess going from music to a'amu tuai wasn't so strange” (Lillo Haoa, 2014).

Each year schools organise Mahana O Te Re'o (Rapanui Language Day), where the work of students around the use of Rapanui language is presented and shared with students from other schools on the island. Lillo Haoa stated in our talanoa that "this is the best place to do a'amu tuai, telling stories in Rapanui [language]!” (Lillo Haoa, 2014). When he first started working at Aldea Educativa and preparing the presentation for Mahana $\mathrm{O}$ Te Re'o he thought "what am I going to teach the kids!? I know nothing about theatre" (Lillo Haoa, 2014). The idea of doing theatre was terrifying, but after re-reading some of the 'traditional' Rapanui stories, and remembering performances and rehearsals he saw of Mata Tu'u Hotu Iti, the idea of doing a'amu tuai with the students was a lot more appealing, "so we started doing a'amu tuai... our own version of theatre" (Lillo Haoa, 2014).

In 2012 Lillo Haoa and the students performed the a'amu tuai called Pou Va'e Tea. This play tells the story of the last governor elected through the Tayata Manu (Bird Man) competition. In 2013 Lillo Haoa directed Haka Haere Moai, a performance based on the orally transmitted story of Tu'u Ko Ihu, a man who sculpted the first moai kavakava, a wood carving of a man without flesh, showing its bones representing the spirits. For the 2014 Mahana O Te Re'o, Lillo Haoa explains that the idea was to continue telling ancient Rapanui stories. However, in the last school meeting, Katherine Ringeling, the Head of Aldea Educativa, asked Lillo Haoa if he could do something "less violent" (Ringeling, 2014), and more like what Maori Tupuna did in the Tapati during 2013. In our talanoa Ringeling explained that she would like the students to learn not only about the 'traditional' Rapanui stories, but also about the 'contemporary' history of the Rapanui people: 
Why not producing a play about the time of the establishment of the Williamson Balfour Company in Rapa Nui, the arrival of the first plane or the first horse, or our lifestyle before mobile phones and internet arrived? Those stories have not yet been told" (Ringeling, 2014).

The idea of looking at 'contemporary' Rapanui history draws from an educational perspective. Ringeling is concerned about the amount of violence portrayed in Rapanui oral narratives. She used the performance of Maori Tupuna in Tapati 2013 as an example of a less 'war only topic play' where they still talked about issues of death and cruelty, but it was not the only aspect portrayed on stage. "Rapanui stories are full of other aspects, not only war, death and killings" (Ringeling, 2014). Ringeling encourages students and teachers to represent the old stories, but from other points of view. For example, one of the main characters in the story Ure A Oho Vehi is an elderly woman named Nuahine Pikea Uri who takes care of the boy while he is in captivity. One possibility for re-interpreting the story would be to tell the story as it is, taking death as the main enemy which has to be defeated by every means. Another option would be to represent this story focusing on the relationship between the boy and the elderly woman; this perspective could emphasize the support that young people can find in their grandparents. Another option for the same story would be to focus on the "the community,' a character that usually remains in the background. The main focus of Rapanui stories is on the central character, the hero. However, 'the community' is centrally important in bringing news and collaborating in restoring social balance. The role of 'the community' and their constant umana (collaboration) in the maintenance of the social balance is an interesting view point to develop in the representation of this story. Through proposing the consideration of new perspectives on old stories, Ringeling is fostering creativity in her students. In this way 'traditional' stories act as a guide for future performances, giving the 'contemporary' generation a voice, and the freedom to tell their own stories.

Ringeling takes the presentation that the group Maori Tupuna did in Tapati 2013 as an example of a Rapanui performance that shows parts of the contemporary history of Rapa Nui. In fact it was the first time Rapanui's contemporary history was shown at the most important stage of Rapa Nui, Tapati. In 2013 the Maori Tupuna dance group had already confirmed their participation in Tapati as a show apart from the competition. Each year for Tapati, two or three girls from different families participate as candidates to be 
crowned queen of Tapati. In 2013, young women were not interested in participating, and no one signed up as a candidate for the title of the Queen of Tapati. The municipality and organizing committee of Tapati suggested a male crowning, as an alternative; an aito (brave) Rapanui man would be crowned. In addition to participating in the sports competitions during the day, male candidates had to show their abilities in singing, dancing, and takona (body painting) during the night show. The overall structure of Tapati had some changes in 2013, especially during the night performances at the outdoor stage of Haya Varevare. That year, a'amu tuai and the dance ensemble competition, two of the most anticipated contests during the Tapati were removed. The dance ensemble for Tapati involves three categories, children, youth, and adults where everybody is invited to dance, even the tourists who are passing through the island, giving them the opportunity to see and learn songs, dances and how to make a Rapanui costume.

As there was no a'amu tuai and dance ensemble in Tapati 2013, Maori Tupuna decided to put together a show that included aspects of both disciplines. The group Maori Tupuna performed Te A'amu O Te Hakaara Maohi o Rapa Nui translated as The History of the Polynesian Rapa Nui. Although this performance is mainly dance, music and songs, Maori Tupuna manages to integrate a few significant dramatizations within their work. Its significance is based in the fact that for the first time it was possible to see the symbolic representation of an object through the dancer's body and periods of the contemporary Rapanui history that had never been showed before at the main venue during Tapati.

Usually in Rapanui performances when fire, a tree, a fish, or a moai is needed, what you see on stage is the real object. In other words, the performers light fire, 'plant' a tree, and freshly caught fish or a big wooden moai are brought on stage. This time however, instead of installing a giant moai platform on stage, the representational tool chosen was the human body. The female dancers in the front rows bent forward, creating the platform where the moai are placed. Male dancers stood behind them in a line representing moai that can be found around the island. The moai is considered the aringa ora (living face) of Rapanui peoples. In this performance, representations of the ancestors were embodied by dancers, bodies as corporeal palimpsetsts, representing the living whakapapa (genealogy), thus giving true meaning to the expression arina ora o te tupuna, meaning the living face of the ancestors, linking the past with the present. 
The fall of moai was also portrayed in this performance. This is a moment in the history of Rapa Nui that is not frequently shown. A section of the orally transmitted story Kave Heke was used as the basis for recreating the fall of the moai. The story is about the master moai carver Kave Heke, who teaches a young apprentice to correctly carve the neck of the moai. At the end of the story, an old woman who had been the cook for the carvers discovers that the workers ate all the food leaving her without anything to eat. In her rage, due to the ingratitude of the workers, the old woman curses all the moai to fall. Isabel Veriveri, one of the elders involved in the performance, enacted the character of the cook. On stage the 'human moai' is standing, Veriveri delivered a very angry and full of sorrow speech in Rapanui language, bringing on stage another character representing her kuhane (spirit), and making the moai fall (Rapu, 2013).

Te A'ати O Te Hakaara Maohi O Rapa Nui (2013) also showed for the first time aspects of history including the arrival of Peruvian slave raids and the arrival of missionaries to Rapa Nui. Performers dressed in Marines uniforms and carrying weapons entered the stage, pushing male performers to the ground. A character dressed as a priest crossed the stage with a book symbolizing the Bible. When he reached the other side of the stage he made the sign of the cross in front of a banner where the image of Rapanui God Makemake was painted (Rapu, 2013). In our talanos Rapanui dancer Miriam Pakarati Gula, who was participating in the performance, expressed that this play was significant because

it showed topics that nobody talks about.... everyone knows what happened, because they've read it in a book... but another thing is to see it performed... and I think this time the message did reach the local audience (Pakarati Gula, 2014).

Such representation of historical events can serve as a healing tool, and act as a way of coming to terms with the past. So many issues in Rapanui 'contemporary' history remain unspoken and performances are a way of breaking these silences and initiating conversations and reflections. Ancient stories of migration, war and heroes are told and retold; however, the relationships of Rapanui peoples with the outside world and all its influences are often silent and left unexplored.

Theatre has become significant art at the Festival of Pacific Arts in recent years, and in return the Festival has had a significant impact on the development of Rapanui culture. This festival has allowed Rapanui artists to "explore their Polynesian cultural heritage in 
the company of other Polynesians" (Bendrups, 2008, p. 18), fostering a sense of belonging and a wider sense of Pacific communitas, through the arts. These creative collaborations and explorations, happening at least every four years, have resulted in the creative styles through which Rapanui artists have chosen to represent themselves, not only to the local community, but also to other Pacific Islanders and tourists alike.

Rapanui artists have had access to a range of different performances as part of the Festivals they have been part of causing a great impression. During our talanoa Lillo Haoa remembered a play he saw in one of these Festivals:

The play, I don't know the name of the play... showed the history of Hawai'i... how the island merged from the sea.... the only thing I remember was how the character of the shark was performed... a guy on a skateboard with a Shark fin on the back... moving around the stage... you couldn't see it at first because it was dark and foggy... but the shark was there moving around pieces of blue cloth that represented the sea and the waves... I didn't get a lot of things because it was in English... but I did understand that the shark was the one creating the islands (Lillo Haoa, 2014).

This experience drew Lillo Haoa to a'amu tuai, and has been inspiring his work in terms of style with the students at school and with Maori Tupuna. Lillo Haoa wishes that "we could make something like that play here in Rapa Nui... I don't know how... but for now, we do what we can" (Lillo Haoa, 2014). From Lillo Haoa's statement it can be inferred that theatre training, in other words learning the craft of theatre, would be very beneficial for his work directing a'amu tuai.

\subsubsection{Rapanui Theatre: Case Studies}

The plays that I am discussing in this section, Hetereki a Rau Nui (2008) and Nanue Para (2014), are examples of Rapanui plays performed in different contexts. Hetereki was perfomed at Mahana o Te Re'o, a festival which focuses on the use of the Rapanui language. The significance of this play is that it tried to integrate different Rapanui performing arts with in the dramaturgy of the work. Nanue Para was performed at Tapati after the competition of a'amu tuai was reincorporated to the festival. Nanue Para 
integrated two storytellers, in Rapanui language and Spanish, allowing a wider audience to follow the play.

\subsubsection{Hetereki A Rau Nui}

During Mahana O Te Re'o in 2008, Lillo Haoa and the students of Aldea Educativa high school performed their first a'amu tuai. On that occasion they showed He A'amu Tuai o Hetereki A Rau $\mathrm{Nui}^{77}$, a performance which dealt with the intertribal warfare occurring before the arrival of the Europeans to the island. This performance was based on the rules and style that the competition of a'amu tuai has within the context of the Tapati, and it was also influenced by the performance aesthetic and characteristics used by Mata $\mathrm{Tu} u$ Hotu Iti. For example, the troupe of 1975 used to perform in places that were related to the story that was being performed. In that same spirit, Lillo Haoa and the team of teachers who coordinated the performance decided to represent a story that was related with the location of the Aldea Educativa. Near the school there is a petroglyph depicting a foot print. According to oral tradition, this foot print was made by Hetereki A Rau Nui, a great warrior who trained in the art of war along with his brothers.

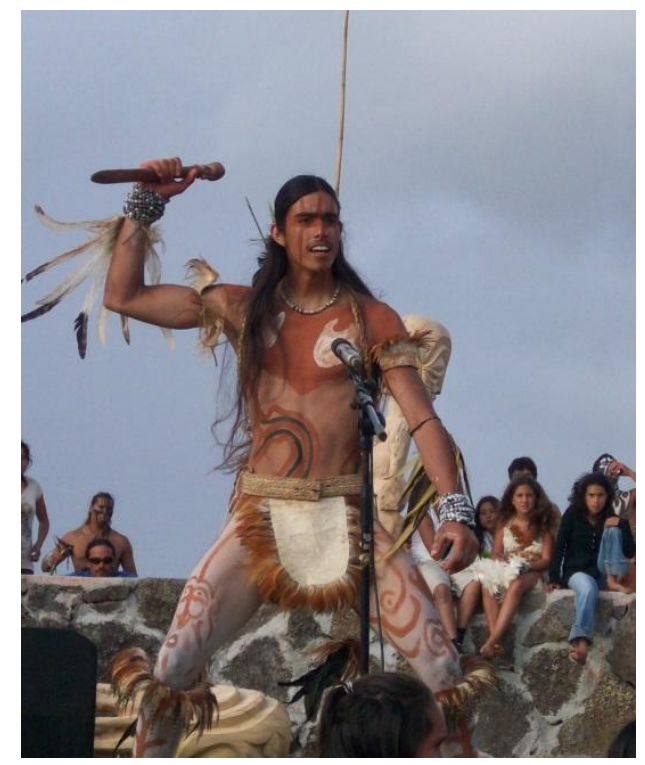

Figure 10. Koro Pate Tuki as Hetereki (2008). Photo courtesy of Aldea Educativa

\footnotetext{
${ }^{77}$ This analysis is based on my own viewing of the recorded performance
} 
The main objective of this work, according to Ringeling, was that students could gain knowledge of other Rapanui performing arts such as kaikai (string figures), pata' $u$ ta' $u$ (recitation), takona (body painting), ori (dance) as well as practicing the use of the Rapanui language through storytelling and theatre (Ringeling, 2014). Therefore all those Rapanui performing arts were included in the performance, utilised one after the other, narrating the story of Hetereki from different perspectives. For example, once the story finished, the songs began. Performers filled the stage, sat down and sang a ute (song of celebration) related to the story of Hetereki. Next the hoko and a pata' $u$ ta' $u$ about the story were performed, and finally music, guitar and ukulele, started, announcing the beginning of the dances. Performers stood up and danced a song created for the presentation, based on the previously recited patat ${ }^{6} u$ ta $^{6} u$.

The lack of information regarding some performing arts, made it difficult to be integrated as a whole in the performance. The first task of the work was to collect and read the different versions existing about this story. Lillo Haoa studied for several months with Rapanui elder Papa Kiko, who was one of the last persons who had knowledge about ancient Rapanui stories. The following task was to seek information about songs, dances, kaikai and pata'u ta' $u$ that were related to the story of Hetereki. This task proved to be difficult because contemporary Rapanui society remembered the existence of a kaikai related to the story "but nobody remembered how to do this kaikai, well at least we used the pata' $u$ ta' $u$ " (Lillo Haoa, 2009). This performance is a good attempt of combining different 'traditional' Rapanui performing arts in the creation of 'contemporary' work, but these performative elements were not yet organically integrated in the performance.

\subsubsection{Nanue Para}

In 2014, a'amu tuai was re-established as part of Tapati Rapa Nui festival. Two years without performances of a'amu tuai and the performance of Maori Tupuna in 2013, changed the attitude of the performers towards a'amu tuai. A'amu tuai performances that year were well prepared; rehearsal process was evident in each performance. For a'amu tuai performances in 2014, a group decided to perform the story Nanue Para. This story is about a woman and her baby who has been crying for a long time. Thinking that the baby may be hungry, she goes to the beach to collect sea food. However, waves from the 
high tide separate the mother and her child. In this moment two spirits take the child away and put him in the water, transforming him into a yellow fish.

Each year in early January, the Tapati Rapa Nui Committee commissions a group of local artists to construct the stage background which will adorn the stage for the two weeks of competition. Each year, a different theme related to a legend or a specific part of the island is chosen for the construction of the set. In the case of Tapati 2014, the inspiration for the stage background was the orally transmitted story Nanue Para (see Figure 25).
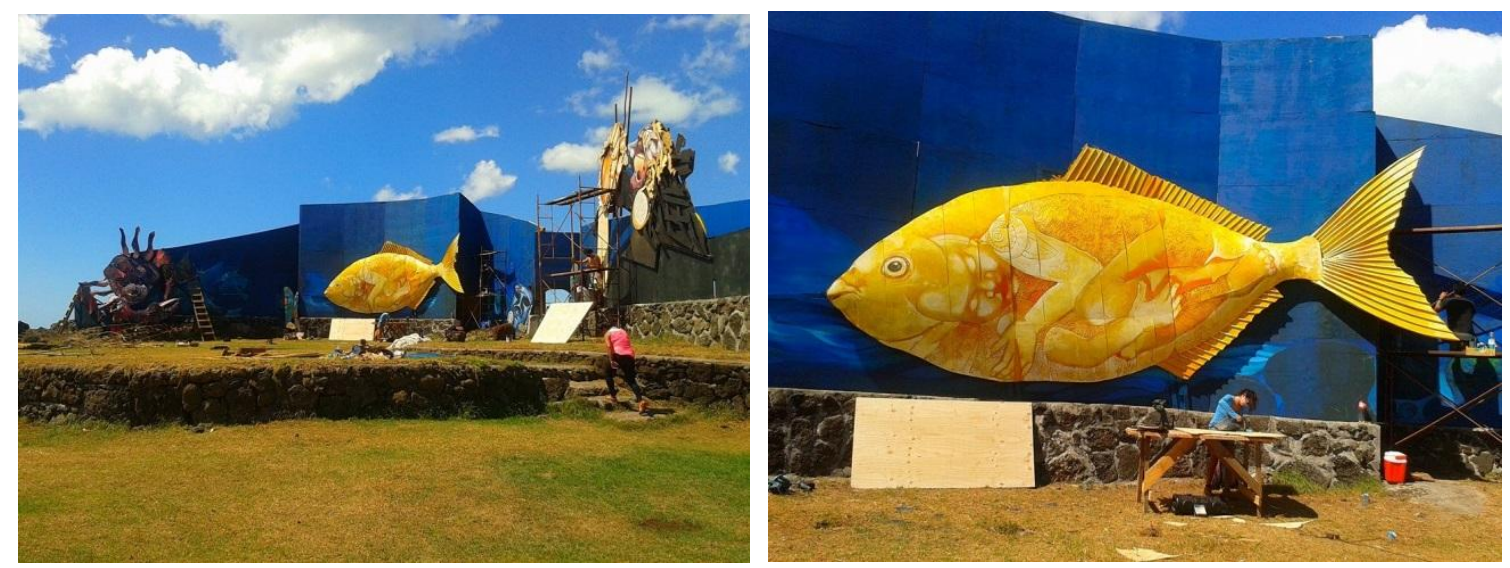

Figure 11. Stage background under construction for Tapati 2014. Photo courtesy of Juliet Hotus, Tapati Rapa Nui Organising Committee

The performance ${ }^{78}$ opens with a group of children asking a woman to tell them an old story. The storyteller begins and the narration is done in two languages, Rapanui and Spanish. The inclusion of a Spanish-speaking storyteller helped the non-Rapanui speaking audience to follow the story. After a specific action was narrated, it was followed by Rapanui chants describing the action, integrating the chants to the dramaturgy of the work.

As customary in a'amu tuai, the performance relied on the storyteller. However in this case, all the performers were alert and ready to do their part without having the storyteller to tell them what, when and how. In addition, the use of the stage and props was clearly well rehearsed. The stage was empty, only what was needed for each scene appeared on stage at the precise time, unlike other a'amu tuai from past Tapati. Paper

\footnotetext{
${ }^{78}$ This analysis is based on my viewing of the recorded perfomance
} 
mache puppetry of a yellow fish, a crab, a black fish, and a frigate bird were created in advance for the occasion (see Figure 12). Also, the waves from the sea were made by manipulating blue pieces of fabric.

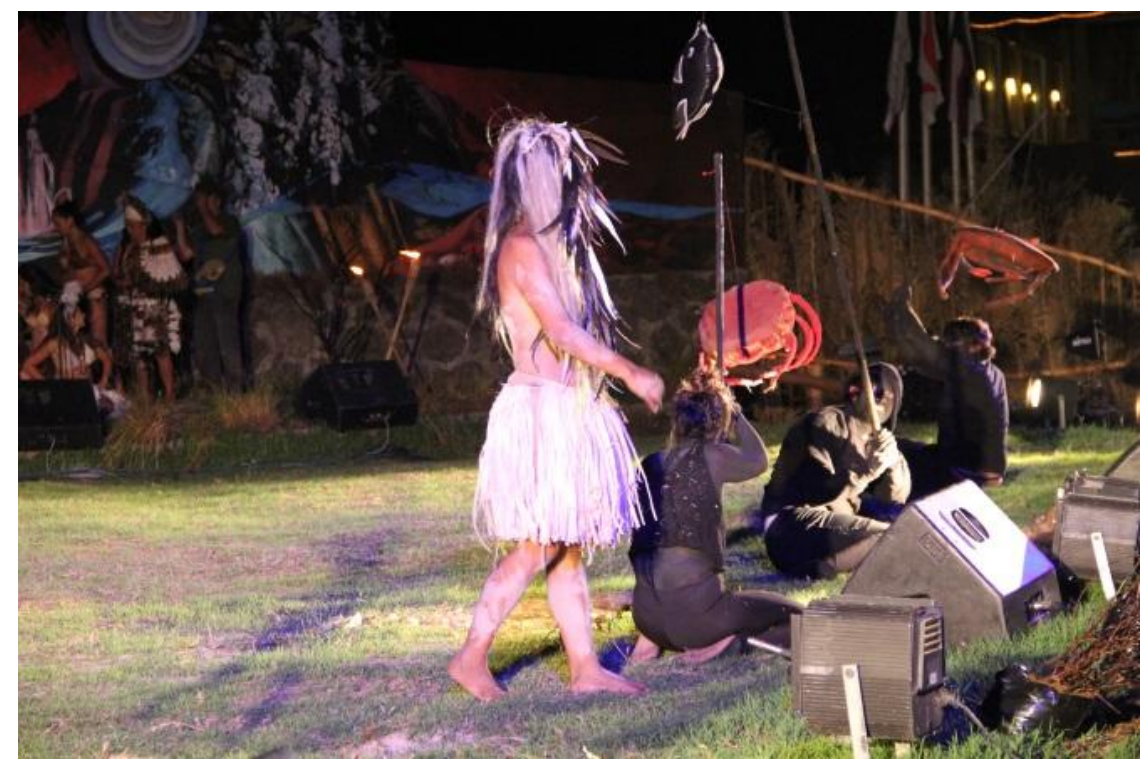

Figure 12. Nanue Para (2014). Photo courtesy of Juliet Hotus, Tapati Rapa Nui Organising Committee

This play was performed by Rapanui people who had been living and studying in Santiago, Chile, for a long period of time. Unlike Lillo Haoa, who finished high school in Rapa Nui and stayed on the island, the performers involved in Nanue Para included a range of white collar professionals, including a Rapanui-based psychologist, anthropologist, teachers, and an interpreter. Chilean theatre performances are likely to have influenced the group's views and attitudes towards representation of the 'traditional' and 'contemporary'.

The performance of Nanue Para within the context of the cultural festival of Tapati Rapa Nui is significant. In the representation of this 'traditional' story, new elements were included, allowing a more 'contemporary' view on a'amu tuai as a part of Tapati. This may be the way in which a'amu tuai is heading in the future, where 'tradition' can guide the performances in terms of what to present, but allowing the how to come from a more 'contemporary' perspective.

Throughout its historical development, Rapanui theatre practitioners have been performing 'traditional' Rapanui stories in order to preserve the Indigenous language and 
culture. The historical development of Rapanui theatre can be divided in two periods before and after Mata Tu'u Hotu Iti- a group that emerged in response to social, political and economic injustices that Rapanui people had to endure during the colonial era. This theatre company applied principles of self-determination in the production of each play. Through the representations of 'traditional' Rapanui stories, MTHI showed a clear difference between the Chilean and the Rapanui culture. The group determined what stories to tell, how and where. The how strongly linked with 'traditional' practices, bringing some of them back to 'contemporary' Rapanui society. Through theatre the group revitalized not only the use of the language, but the Rapanui culture itself, empowering them to tell the stories from their own perspectives. Later this selfdetermination also helped to frame and shape the cultural festival Tapati Rapa Nui, highlighting the Rapanui way of doing things, including competitions relevant to contemporary Rapanui society.

The role of the storyteller is one of the main characteristics in Rapanui theatre. Performances rely on the character of the storyteller to guide the action of the story. In early stages of a'amu tuai in year 2000, the storyteller also told performers what to do and when during the performance. In 2014, after a'amu tuai being banned from Tapati, groups presenting plays are increasingly rehearsing them, highlighting the role of the storyteller, who tells the audience what characters do not know, allowing the audience to connect with the performance and empathizing with the different character's fate.

The use of the Rapanui language is another important aspect in Rapanui plays. Theatre in this case has served the purpose of revitalizing the use of the language. Especially important are the theatre productions performed at Mahana $\mathrm{O} T \mathrm{Te} \mathrm{Re}^{\text {'o }}$, where students can practice the use of 'traditional' Rapanui language alongside its contemporary version. They can learn the significance of concepts that are no longer in use in contemporary Rapanui society, but because they are part in the play students and teachers have to learn their meaning to be able to express them in the play. 


\subsection{Historical Development of Māori Theatre}

In the past five decades considerable attention has been paid to the historical development of Māori theatre in Aotearoa (Balme, 1990; 1996a; 1996b; J. Greenwood, 1999; 2002; Kouka, 1994; 1997; 1999; 2007; Kouka \& McNaughton, 1999; O’Donnell, 2003; 2007a; 2007b; 2009; Potiki, 1991; 1992; Maunder, 2013; T. A. C. Royal, 1998; 2007). The origins of Māori theatre can be traced back to Indigenous stories of origin, when the first kapa haka was conceived by Hine-te-iwaiwa, who performed in a whare tapere in ancient Hawaiki (T. A. C. Royal, 2007, p. 195). Early observations of Māori culture describe established places for entertainment called whare tapere, described as a “traditional village based 'houses' of entertainment, storytelling, music and dance" (T. A. C. Royal, 2007, p. 194).

The concept of theatre as we understand it today, "did not exist in traditional Māori society" (Kouka, 1999, p. 10), however, the Māori culture was deemed to have "a high degree of innate theatricality" (Balme, 1996a, p. 182) which was represented on a daily basis through rituals at the marae (Māori meeting grounds). One example of these performances is the whaikōrero, which is the art of oratory used by elders at the marae. In an interview conducted by Christopher Balme (1996b), Māori theatre practitioner Roma Potiki argues that for some Māori theatre practitioners the rituals and oratory performed at the marae could be seen as theatre, thus suggesting the idea that rather than theatre being a 'new' or 'foreign' cultural form, Māori people have in fact had theatre "for hundreds of years" (Balme, 1996b, p. 173).

Contemporary Māori theatre began with the inclusion of Māori elements in theatre which was created by Pākehā theatre practitioners. Early Pākehā plays such as The Land of the Moa (1895) by George Leitch and Tapu (1903) by Arthur Henry Adams, both incorporated Māori cultural elements such as the haka within their works (Harcourt, 1978, pp. 19-22). Later forms of cultural integration in theatre included Māori actors being cast to perform in Pākehā films such as Hinemoa (1914) directed by George Tarr. Princess Te Puea Herangi of Waikato was also significant to the early development of Māori culture in performing arts. In 1930 Princess Te Puea Herangi noticed that songs and other performative arts that had been orally transmitted were disappearing. Therefore, she gathered a group of people from her community who worked together to 
create Māori concert parties, which is what today is known as kapa haka (Kouka, 1999, p. 11).

In time theatre work was produced in which the lead roles were performed by Māori actors. For example The Pohutukawa Tree (1957) by Bruce Mason, featuring Māori actress Hira Tauwhare in the lead role (Derby \& Grace-Smith, 2014). The successful production of the opera Porgy and Bess (1965), in which Māori actors performed in leading roles led to the creation of the Māori Theatre Trust in the late 1960s (Maunder, 2013, p. 68). Balme (1990) explains that:

[T]he founding of the Māori Theatre Trust in 1966 can be seen as the first attempt to establish a Māori theatre involving Māori performers and dedicated to presenting Māori subject matter (Balme, 1989, p. 150).

Hone Kouka recognises three phases in the development of Māori theatre (see Figure 15). Firstly it evolved a highly politicised voice between 1960s and 1980s with a focus on Māori "land issues, language, culture and identity" (Kouka, 2007, p. 238). Māori theatre then developed a more 'mature' voice between 1990s and 2000, where issues and claims against the dominant culture were made in a more subtle way (Kouka, 1999, p. 20). Māori theatre became a distinct cultural landmark in the development of Aotearoa theatre from 2000 to the present day (Kouka, 2007, p. 237). Māori political activism, especially in 1970s led to the establishment of key Māori theatre companies. Kouka describes that time saying:

The 1970s was a turbulent time in the political history of Māori and Aotearoa; it also gave rise to Māori theatre as we know it. The political agenda of Māori had changed dramatically. We were more vocal- speaking out against past injustice (Kouka, 1999, p. 12).

In light of all this political awakening, a very important issue to address in Māori plays during the first phase was the land. Te Raukura: The Feathers of the Albatross, written by Māori journalist Harry Dansey, premiered in 1972 at the Auckland Festival (Dansey \& Dansey, 2013, p. 1). This play was "based on the Taranaki passive resistance movement of 1879-81" (Dansey \& Dansey, 2013) which opposed the confiscation and sale of land by the crown, and the story is told from a Māori perspective. The play had a cast of 65 actors, which included Māori, and it was directed by New Zealand actor John 
N Thomson, therefore addressing both Māori and Pākehā audiences (Looser, 2014, p. 116). A letter on behalf of the Auckland Festival Society from that time reviewing the play, described it as "a new type of Māori art form that is a product of the modern Māori" (Looser, 2014, p. 116). In 1975 Te Raukura was performed during the Māori Language Week. The play has many parts written in Māori. Dansey explained that "once the Māori sentences began to flow from their lips, [performers] could seldom resist the temptation of carrying on in Māori” (H. Dansey, 1974), the use of the Māori language did not interfere in the overall understanding of the play by Pākehā and non-Māori speaking Māori audiences.

Issues and conflicts surrounding land tenure in Aotearoa and the Land March of 1975 led to the establishment of theatre companies in Aotearoa. Tired of watching Pākehā directing Māori stories, in 1976 Rowley Habib founded the theatre group Te Ika a Maui Players. Their first play The Death of the Land (1976), written by Habib, toured around community halls and marae in Aotearoa. The play debates whether a portion of Māori ancestral land should be sold or not, dramatising injustices over Māori land which Habib had debated during the 1975 Māori Land March (Playmarket News, 2008). Through these community theatre performances, Te Ika a Maui Players aimed to show to different communities "the power of theatre, its immediacy and relevance" (Kouka, 1999, p. 13). Other examples such as the play In the Wilderness without a Hat (1977) by Hone Tuwhare, the work of the group Maranga Mai (1979), and the play Roimata (1988) by Riwia Brown, also contributed to encouraging Māori practitioners to produce more Māori theatre around the country.

The Depot theatre was established in Wellington in 1983, and was mainly dedicated to promote New Zealand-only theatre works. Later in 1994 the Depot was re-named Taki Rua and re-focused on Māori theatre, eventually becoming "the backbone and the home of Māori theatre in this country" (Kouka, 1999, p. 15). Taki Rua not only fostered the production of New Zealand work, it also assisted in promoting and developing Indigenous theatre production in Aotearoa, by encouraging not only new Māori writers, but also Pacific writers to create new work (O’Donnell, 2009, p. 11). Taki Rua, translates as "two currents" (Maunder, 2013, p. 143). Through its name and its collaborative, intercultural ethos, Taki Rua acknowledges the Treaty of Waitangi and the bicultural environment in which theatre practitioners are immersed in the Aotearoa/New Zealand context. 
By accommodating Pākehā, Māori, and Pacific Island theatre practitioners in one place, Taki Rua also acknowledges possibilities for intercultural exchanges within theatre practice, fostering a sense of theatre communitas in Aotearoa. Taki Rua has become "a forum for a whole range of traditional and contemporary Māori art” (Balme, 1999, p. 240), communicating and using different world views through "interweaving Māori protocols with Western theatre practice" (O'Donnell, 2009, p. 12). It is through this theatre communitas that Māori theatre practitioners have been able to work towards creating "an original theatrical form, a 'new' kind of perceptual 'frame" for performance, informed by Māori tikanga ${ }^{79 ", ~(O ’ D o n n e l l, ~ 2009, ~ p . ~ 10) . ~ I n ~} 1999$ Balme called this purpose/vision "utopian" (Balme, 1999, p. 62), however I argue that this utopian vision has become a reality.

During this first phase of Māori theatre (see Figure 15), other theatre companies were also trying to explore issues concerning intercultural exchanges between the different cultures living in Aotearoa. In 1984 Paul Maunder founded the experimental group Theatre of the Eight Day, formerly known as the Amamus Theatre Group (Maunder, 2013, p. 76). This group was composed of both Pākehā New Zealander and Māori artists who sought to explore the relationships between Māori and Europeans through theatre (Balme, 1996b, p. 172). One Māori member of this company, Roma Potiki, explains that Maunder was consciously "trying to facilitate a bicultural development" (Balme, 1996b, p. 174) and to provide a space where Māori and New Zealander theatre practitioners could test the ideas of intercultural exchanges. However, the main point of difference was the way in which culture was understood. According to Potiki, from a European point of view culture and knowledge are available and open to everyone, whereas from a Māori perspective "that is not acceptable" (Balme, 1996b, p. 174). Potiki explains that in Māori culture, "some knowledge is available for certain people when it is deemed time" (Balme, 1996b, p. 174), especially if this knowledge relates to the use of a specific language, to a particular tribe, or a specific gender.

Theatre of the Eigth Day embraced Grotowski's Poor Theatre (Maunder, 2013, p. 50), and Boal's community theatre methodologies (Maunder, 2013, pp. 87-89). Grotowski defined through his work key elements in actor training and methods of preparation for the performance, giving theoretical and practical definitions regarding theatre, the actor,

${ }^{79}$ Māori customs 
and the audience. Grotowski developed a methodology known as Poor Theatre, explaining that theatre can exist without makeup, lights, costumes, set, music, and text, but it cannot exist without the actor and the audience (Grotowski, 2002, p. 32). Boal saw theatre as a tool for social change and development, and developed his ideas and practices working with marginalised communities in South America. His methodology focused on conducting theatre workshops with specific communities, where participants could expose the root cause of their issues and struggles, and form connections with one another which would support processes of social change based on principles of equity and social justice. Boal developed a series of theatre processes including game playing and problem solving, through which communities could critically analyse the issues affecting them, and find possible solutions in their own real contexts (Boal, 2000, pp. $120-153)$.

The use of intercultural methodologies within the work of Theatre of the Eight Day influenced the development of Māori theatre in Aotearoa. Grotowski was searching for the origin of theatre, separating it from "the Tower of Babel that continuing globalisation has produced in the cultural sphere" (Maunder, 2013, p. 52).Theatre of the Eight Day adapted Grotowski's methodologies for actor training and composing works (Maunder, 2013, p. 51). Boal's methodologies and processes are concerned with giving marginalised communities a voice, where they could express their discontent with the dominant power, allowing communities to voice their issues "in that people were called upon to confront 'the system' and to rehearse social change” (Maunder, 2013, p. 89). This 'confrontation' was achieved through theatre practice and by incorporating Indigenous rituals specific to the community participating in the play. In the same way, Māori theatre has developed unique forms of expression, rooted and drawing from Indigenous cultures, which separate them from the dominant Pākehā culture. Māori theatre practitioners who participated in Maunder's theatre company were able to learn about these different methods, spreading the word by re-interpreting, adapting and incorporating them to their own theatre work.

One of the main influences in the development of Māori theatre was the intercultural collaborative work done with the Philippine Educational Theatre Association (PETA) (Maunder, 2013, p. 20). The work of the community theatre group PETA is based on Boal's ideas of theatre for social change. The group toured around Aotearoa in 1987, holding workshops on community theatre at different marae. This project involved Roma 
Potiki and the Dutch theatre scholar Eugene van Erven. ${ }^{80}$ In these workshops PETA members and people from Māori communities shared stories and experiences about topics such as "land, land proprietorship, the feeling of alienation and the loss of cultural identity" (J. Royal \& Campbell, 1987, p. 9). These topics were explored in three day theatre workshops where the community were encouraged to work and create as a group (J. Royal \& Campbell, 1987, p. 10) with the purpose of developing theatre devising skills and political awareness (J. Royal \& Campbell, 1987, p. 9).

One of the main characteristics of community theatre is that skilled artists or trained actors work with a community to devise a theatre piece through which the community can explore and share their own stories. During the community workshops offered by PETA and Māori theatre practitioners, the group worked with communities in a creative process which would culminate in a performance, because "theatre does not exist without an audience" (J. Royal \& Campbell, 1987, p. 10). The creative process in these workshops started with exercises and games that would "serve as ice-breakers, energisers, and also serve the idea of exchange of cultural forms" (J. Royal \& Campbell, 1987 , p. 10). These methods used in the first day of workshop were framed under the notion of "mutual partnership" (J. Royal \& Campbell, 1987, p. 9) which would develop team building and trust amongst the participants, creating a "healthy group process" ( $\mathrm{J}$. Royal \& Campbell, 1987, p. 10). Later, Potiki explains that the work moved on to building necessary theatre and communication skills (J. Royal \& Campbell, 1987, p. 10). Finally, production day allowed the participants to start the process of adding and developing dialogue, characters, and dealing with issues and conflicts emerging from stories shared in the previous days. The workshops ended with performances of these stories which were written, acted in, produced, and shared by the community. They took the form of a short theatre piece. An important aspect of conducting these workshops was the involvement and consolidation of new networks of Māori theatre practitioners ( $\mathrm{J}$. Royal \& Campbell, 1987, p. 9). This network was built through a period of evaluation, where participants could reflect on the best possible ways to use and retain the knowledge acquired during these workshops (J. Royal \& Campbell, 1987, p. 10).

\footnotetext{
${ }^{80}$ This project was produced in association with several institutions such as the QEII Arts Council, the Youth Initiatives Fund, Māori Affairs Department and others who financially supported the visit and coordinated the tour of this theatre company (J. Royal \& Campbell, 1987, p. 9).
} 
In 1988 Roma Potiki travelled to the Philippines to study the methodologies used in community-based theatre, and this experience led to the formation of the Māori theatre group He Ara Hou in 1989 (Balme, 1996b, p. 172). Their first play Whatungarongaro (1990), facilitated by Roma Potiki and Pākehā director John Anderson, was based on the community theatre methodologies learnt from PETA (Balme, 1996b, p. 172). This production was further devised by He Ara Hou members, who had different levels of theatrical experience but were all enthusiastic to share "stories of their lives" (Kouka, 1999, p. 21). The stories in Whatungarongaro were devised during a working period of nine months, when the play was collectively written with a group of about fourteen people (Potiki, 1992, pp. 155-156). The stories shown in the play are based on the reallife experiences of the actors, some of whom were street kids who had never acted before (Potiki \& Anderson, 1990). In aesthetic and linguistic terms, the play shows issues faced by Māori communities in the twentieth century: stories of issues facing urban Māori, characters who wore jeans and sneakers, drank beer and watched TV. The departure from notions of 'traditional' themes was clear.

Whatungarongaro was performed in 1990 in Wellington, and the following year the production toured around the North Island, and to Australia. The play was presented at several different marae, and on each visit, at the end of the performance, a conversation between the actors and the audience was conducted. During these conversations the audience could express their thoughts, ideas, sensations, and feelings about the play (Potiki \& Anderson, 1990) enabling audiences to process what they had seen with the group, and to link these stories to their own life experiences. The inclusion of these discussions at the end of performances not only helped in terms of developing audiences for Māori theatre, they were also a crucial part of the community theatre process which reinforced a sense of belonging to the community. A shared experience became evident through the audience's spoken words. As the community reflects together it fosters a deeper sense of communitas as a consequence of this shared theatrical and reflective experience.

'Traditional' Māori symbols and 'contemporary' Māori theatre were able to dialogue and blend in Whatungarongaro. For example, the characters of the Wairua Manu the spirit birds, represent links with the ancestors, the guardians who carry 'traditions' linking the past and present (Potiki \& Anderson, 1990). The bird characters, an allegory of the spiritual world, walked on their tiptoes bending the back leg back in a sharp movement 
every time they stepped forward as if walking on one line, reminiscent of the way of walking of a kapa haka performer (Potiki \& Anderson, 1990). Reinterpreting this way of walking can be seen as transforming a 'traditional' element into a 'contemporary' one within the context of the play and the themes that are explored within it.

Kouka states that "[t]he amalgamation of the traditional and the contemporary was seamless" in Whatungarongaro, and the characteristic that "lifted it above previous work was the modern interpretation of traditional Māori symbols and ceremony" (Kouka, 1999 , p. 22). Whatungarongaro included a tangi (funeral) scene, an element often seen in previous Māori plays, however the company did not use images and symbols 'traditionally' associated with the tangi, such as "the koauau... to announce that a change had occurred" (Potiki, 1992, p. 157). Nevertheless, they kept the main features of the tangi by reinterpreting this 'traditional' ceremony with theatrical elements. For example, death was portrayed in a more symbolic fashion, by "making audible the breathing sounds of the person dying" (Potiki, 1992, p. 157), instead of showing the wailing of young women dressed in black on stage, offering a new perspective in the representation of a tangi in 'contemporary' Māori theatre. 




Figure 13. Whatungarongaro (1990) directed by Roma Potiki and John Anderson

The modern interpretation of 'traditional' Māori symbols and ceremony in Whatungarongaro (1990) created an interesting collaboration between 'traditional' and 'contemporary' cultural elements, giving Māori theatre particular and unique characteristics that were distinctive to the Aotearoa context at the time.

Thanks to their own hard work and the influence of PETA, Māori theatre practitioners found and explored theatre as a tool to express their frustrations, ideas, perspectives, and concerns, in their own terms. Theatre became a tool for exploring Māori epistemologies, and for expressing distinct Māori world views. Potiki states that Māori theatre can be understood as an example of "tino rangatiratanga in action" (Potiki, 1991a, p. 57). Tino rangatiratanga translates as: 
self-determination, autonomy, full authority, chiefly authority, authority of the people, sovereignty, and chiefly sovereignty by different people at different times (Dahlberg, 1996, p. 62).

It seems that self-determination is the more adequate term to use when translating tino rangatiratanga in relationship to theatre practice, because it "captures the essence of Māori ownership and active control” (Durie, 1995, p. 46). Māori theatre is about Māori people telling their own stories, "learning to communicate with ourselves and our own people... deciding what to show" (Potiki, 1991a, p. 58) and determining how to "present our own work in the way which we deem most suitable" (Potiki, 1991a, p. 57), including sharing it with Māori and the non- Māori audiences. Kouka also states that Māori theatre asserts "a Māori point of view, a Māori voice" (Kouka, 2007, p. 242). In order to express issues relevant to the Māori community, and to be called Māori theatre, the theatre work must be controlled by Māori: that is be directed, produced, scripted, and performed by Māori people (Potiki, 1991b, p. 11).

The second phase of the development of Māori theatre (see Figure 3) is characterised by plays that discuss issues featured in the first phase of Māori theatre, such as acculturation and the loss of identity, but in a more subtle way. O'Donnell (2007) states that once Māori artists recognised the opportunities that theatre could give them as a means of communication in terms of narration, expression, and searching for an appropriate mean by which to articulate their identity, they developed a unique theatrical voice "which increasingly utilises Māori language and performance traditions as dramaturgical strategies" (O'Donnell, 2007b, p. 18). One example of this is the conception of marae theatre, which was created by Jim Moriarty and Rangimoana Taylor. Potiki understands the concept of Marae Theatre as treating the theatre as a marae, incorporating 'traditional' forms of oratory and ritual involved in visiting a marae (Balme, 1996b, p. 177). Audiences are greeted with a karanga (welcoming chant), and then given the option to reply to this karanga. A karakia (prayer chant) is also made to bless the space (Balme, 1996b, p. 177), making the theatrical experience a shared cultural experience for Māori and non- Māori audiences. This approach allowed Māori theatre practitioners to appropriate theatre as a space and as an art form, where the topics discussed were more related to personal or collective experiences, with the concerns and stories of the Māori community at the centre. 
Moriarty and Taylor developed marae theatre in the context of the 1990 New Zealand Festival of the Arts. As discussed in Chapter Three, festivals are "dynamic contact zones" (Bendrups, 2008) that allow local, national, and international artists to share their art with other artists and with a wider audience. A sense of communitas amongst Māori theatre practitioners enabled the development of marae theatre, making the Māori language available to broader audiences through theatre.

Purapurawhetu (1997) by Briar Grace-Smith is an example of a play from this second phase that integrates Māori language and cultural elements. Purapurawhetu tells the story of a small community named Te Kupenga, a place with a painful past that affects its inhabitants and prevents them from moving on. The plot of the story features an old lady who reveals secrets of times past to a young man who is trying to complete a woven tukutuku panel for the opening of a marae. Tukutuku is a 'traditional' Māori ornamental weaving used mainly to adorn the inside walls of a whare nui, or meeting house. On a framework constructed by vertical and horizontal wooden laths coloured patterns are produced by lacing around thin strips of different native grasses (Kahutoi, 2014, p. 3).

During the play a tukutuku panel is continually woven by one of the characters, but it will not be completed unless past problems are solved. The use of both Māori and English languages in this play is an important way of defining and describing the characters' backgrounds. During the play “a rapid shift between languages” (Huria, 1999, p. 11) occurs, from Māori to English and back again, making the play a linguistic puzzle, reflecting the lived reality of Māori people in contemporary Aotearoa, where linguistic shifts are an everyday part of life. When reading the play it is possible to see that single words have not been defined, possibly because they do not alter the meaning of the rest of the sentence. However, sentences and longer sections of the text in the Māori language have been translated "as there lies the most room for meaning to be misconstrued" (Huria, 1999, p. 12). Huria explains that in the performance, the meaning and understanding of the Māori texts rely on the command that the audience may or may not have of the Māori language. Grace-Smith solved this situation in part by creating scenes in which one character explains and translates the meaning of a Māori word/concept to another character:

TYLER: In the direction of the urupā.

RAMARI: Urupā? 
TYLER: Cementery!

RAMARI: Urupā cementery. Urupā cementery (Grace-Smith, 1999, p. 30)

Briar Grace-Smith was inspired to write Purapurawhetu "while weaving a tukutuku panel” (Samant, 2010). 'Traditional' and 'contemporary' Māori worlds in the context of Purapurawhetu are linked by the weaving of the tukutuku panel, which visually and metaphorically represents the "oral revelations of painful events that occurred some time ago" (Huria, 1999, p. 15). The stories orally transmitted by the ancestors "spill from the panel into drama on the stage" (Samant, 2010).

According to Kouka's periodisation, the third phase of Māori theatre (see Figure 15) started around 2005 and continues into the present. At this time, Māori theatre began to be conceptualised as "hybrid" (Kouka 2007), "syncretic" (Balme, 1996b), and "bicultural" (Greenwood, 2002), although all these definitions could also apply to the work from previous phases. Kouka stipulates that Māori theatre should be understood as a hybrid that integrates traditional Māori cultural elements and European theatre techniques in the creative process becoming a "healthy theatrical hybrid" (Kouka, 2007, p. 240). In a related vein, Balme says that Māori theatre can best be understood as syncretic theatre, as it is a fusion of 'traditional' elements with "European dramatic conventions" (Balme, 1989, p. 149). However, this fusion may also be due to the mixed ancestry of the Māori theatre practitioners involved, who contribute to creating a diversity of themes, styles, use of languages, and sense of humour in theatre. This thesis conceptualises Māori theatre as collaboration between cultures. In this collaboration theatre enables us "to interpret the emergent space between cultures" (J. Greenwood, 1999, p. 3). Furthermore, it is the collaborative aspect of theatre that will support an understanding of different cultural points of view and perspectives on life: supporting empathy between peoples from different cultural backgrounds, and closing the spaces between cultures.

The revival of the whare tapere by Charles Royal is another example of the collaboration of Māori performing arts and European theatre techniques. Prior to colonisation, the whare tapere were traditional 'houses' of entertainment where numerous performing arts took place (T. A. C. Royal, 2007, p. 194). In the late nineteenth century whare tapere fell into disuse, and many of their associated customs were lost (Derby \& Grace-Smith, 2014). In 2008 Charles Royal formed the Ōrotokare Trust, a space in which to re- 
construct the Whare tapere. This enabled the expression of world views and philosophies that are strongly identified with Māori culture today (T. A. C. Royal, 2007, p. 204). Ōrotokare Trust's main purpose is to create or develop Māori theatre that is based on 'traditional' Māori knowledge, especially kapa haka, rather than maintaining practices and processes deriving from Western theatre (T. A. C. Royal, 2007, pp. 194-195). However, productions which blend cultural forms have also been created, for example the performance Te Karohirohi: The Light Dances (2010), which is a modern interpretation of whare tapere, using elements of Western techniques such as contemporary dance (Potiki-Bryant \& Royal, 2010). Several other performances have taken place at Ōrotokare, some of them featuring "traditional Māori instruments and marionette-type puppets known as karetao, but also modern elements such as digital soundscapes" (Derby \& Grace-Smith, 2014).

Another example of collaboration and cultural negotiation is the play The Ragged by Helen Pearse-Otene. This play was presented in February 2015 at Soundings Theatre at Museum of New Zealand Te Papa Tongarewa by Te Rakau Hua o Te Wao Tapu theatre company and it was directed by Jim Moriarty. This work combines different theatre approaches including community theatre and intercultural collaborations, utilising European and Māori elements within the work. The play had a cast of 30 people, and only a small portion of the actors were professionals. Te Rakau is known for producing theatre with non-professional actors, ${ }^{81}$ and of a cast of 30 people, only a small proportion were professional actors. This approach allowed Moriarty to develop an inclusive "fullyfledged community-based theatre model" (Maunder, 2013, p. 95) where everybody is welcomed. The story is set in 1840, when the first European colonisers and the New Zealand Company settled in Petone in Wellington. The play narrates the relationship between the settlers and the Māori, including interracial marriages and conflicts over land possession.

An interesting aspect of this play was the use of Māori tikanga (Māori customs), alongside theatre methodologies developed by Grotowski. Jim Moriarty was part of Maunder's theatre company, Amamus (Maunder, 2013, p. 94) that embraced Grotowski's theory and theatre methodologies in their work. In 1973 Grotowski visited New Zealand and gave a seminar in Wellington (Maunder, 2013, p. 56) where Amamus

${ }^{81}$ See discussion in Chapter Five 
was based. After Amamus' travelled to Poland (Maunder, 2013, p. 56), Moriarty joined the company allowing him to be influenced by Grotowski's methodologies. This influence can be seen in Moriarty's own methods of working, in that he gives predominance to the work of actor, only using props that are indispensable in the play. In the play The Ragged, for example, the main stage prop used were a boat that was placed at the back of the stage and sand that covered the stage. This boat was moved and used in different situations representing diverse scenarios and settings.

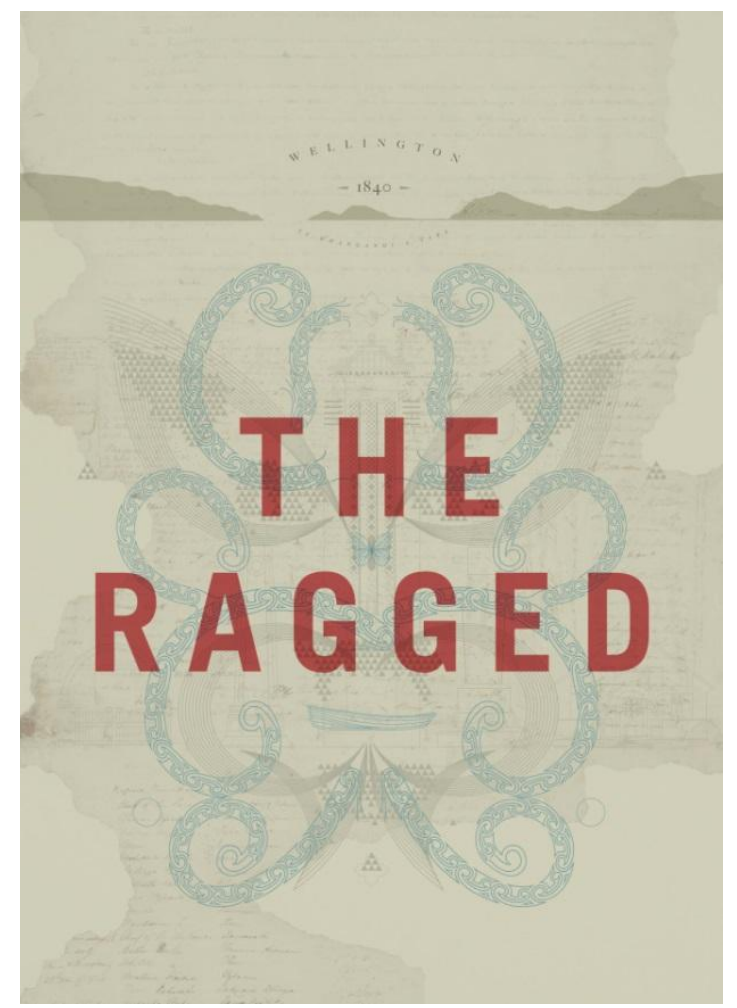

Figure 14. The Ragged (2015) by Helen Pearse-Otene

Nicola Hyland, a Māori actress in The Ragged, explained the ways in which tikanga Māori was used during rehearsals (Hyland, 2015). As I interviewed her, Hyland remembered that rehearsals were democratic processes, involving collaboration between cast members, writer and director. Moriarty encouraged collaboration between group members by allowing them to "offer ideas to the group... which is part of kaupapa ${ }^{82}$ Māori” (Hyland, 2015). Hyland explains that tikanga marae theatre is an essential part of the process:

\footnotetext{
${ }^{82}$ Process
} 
$[R]$ ehearsals started and finished with a karakia, we had a group warm up where everybody had to be involved, and group discussion where everybody was encouraged to raise any issues that may have occurred to the group, so that the issues could be solved as a group (Hyland, 2015).

The openness with which issues were discussed and the willingness to build a collaborative process among cast members created a strong sense of belonging in $\mathrm{Te}$ Rakau. In fact the communitas built within this company led them to define themselves more as a whanau or family than as a theatre company. Hyland explains the difference between a theatre whanau and a theatre company: [T] he whanau is less structured... you share challenges as a group... you share strong relationships, because young and old people share the rehearsal space..." (Hyland, 2015).

Whanauantanga, or a family sense of belonging, is key characteristic of Māori theatre practice. The application of tikanga Māori and Grotowski's methods interpreted from a Māori point of view, gave The Ragged unique characteristics, highlighting the intercultural relations and negotiations that may have taken place during rehearsal. A group of people from different backgrounds and cultures, including Māori, Pākehā New Zealanders, and Germans shared a stage and a purpose, to tell the story of the first European settlers in Wellington through theatre.

In recent years new events have developed where Māori theatre practitioners can present their work defining the cusp of a fourth phase in Māori theatre (see Figure 15) where Māori theatre practitioners are the driving force in the production and organisation of festivals and research spaces for and about Māori theatre. The main driver of these initiatives has been Tawata Productions, which was founded in 2004 by Hone Kouka and Miria George. In 2010 Tawata Productions developed the Matariki Development Festival at Circa Theatre in Wellington. The aim of this festival is to present new Māori and Pacific Island theatre works. Some of these works are still work in progress during this festival, therefore reading sessions are organised allowing the artist to see on stage what works and what does not in the play.

Another initiative developed by Tawata Productions in collaboration with other Wellington based Māori theatre practitioners, such as Jim Moriarty, was Te Putahitanga a te Rehia, an independent Māori theatre collective. This collective created the Pūtahi Festival in 2014 as a response to the lack of Māori theatre in the larger festivals taking 
place throughout the country. Pūtahi Festival aimed to "strengthen the Māori theatre community," and to "share and create Māori works/experiences for Wellington/ NZ and the world" (Moana Ete, 2015). ${ }^{83}$ In 2015 the Pūtahi Festival launched the Global Centre for Contemporary Indigenous Performance (GC). This initiative started at the 2014 Australasian Drama Studies Association (ADSA) Conference organised by Victoria University and Massey University. During this conference Jim Moriarty and Hone Kouka laid down a wero (a ritual challenge) to the universities to support and foster the development of contemporary Indigenous theatre in Aotearoa. From this wero arose a working group formed by Hone Kouka, Miria George, and members of the Victoria University Theatre Programme, which culminated with the launch of the GC. The main purpose of the GC is "to create a space which is initiated and driven by Māori and Pasifika theatre makers, to nurture, build and strengthen the contemporary Indigenous theatre whanau" (Hyland \& Te-Wiki, 2015).

\footnotetext{
${ }^{83}$ The Pūtahi Festival is held at Studio 77 at Victoria University of Wellington
} 
Creation of the Global Centre for Contemporary Indigenous Performance by Hone Kouka, Jim Moriarty Rangimoana Taylor, and Victoria University of Wellington. Ahi Kaa Festival of contemporary Māori theatre was celebrated for the first time in Wellington.

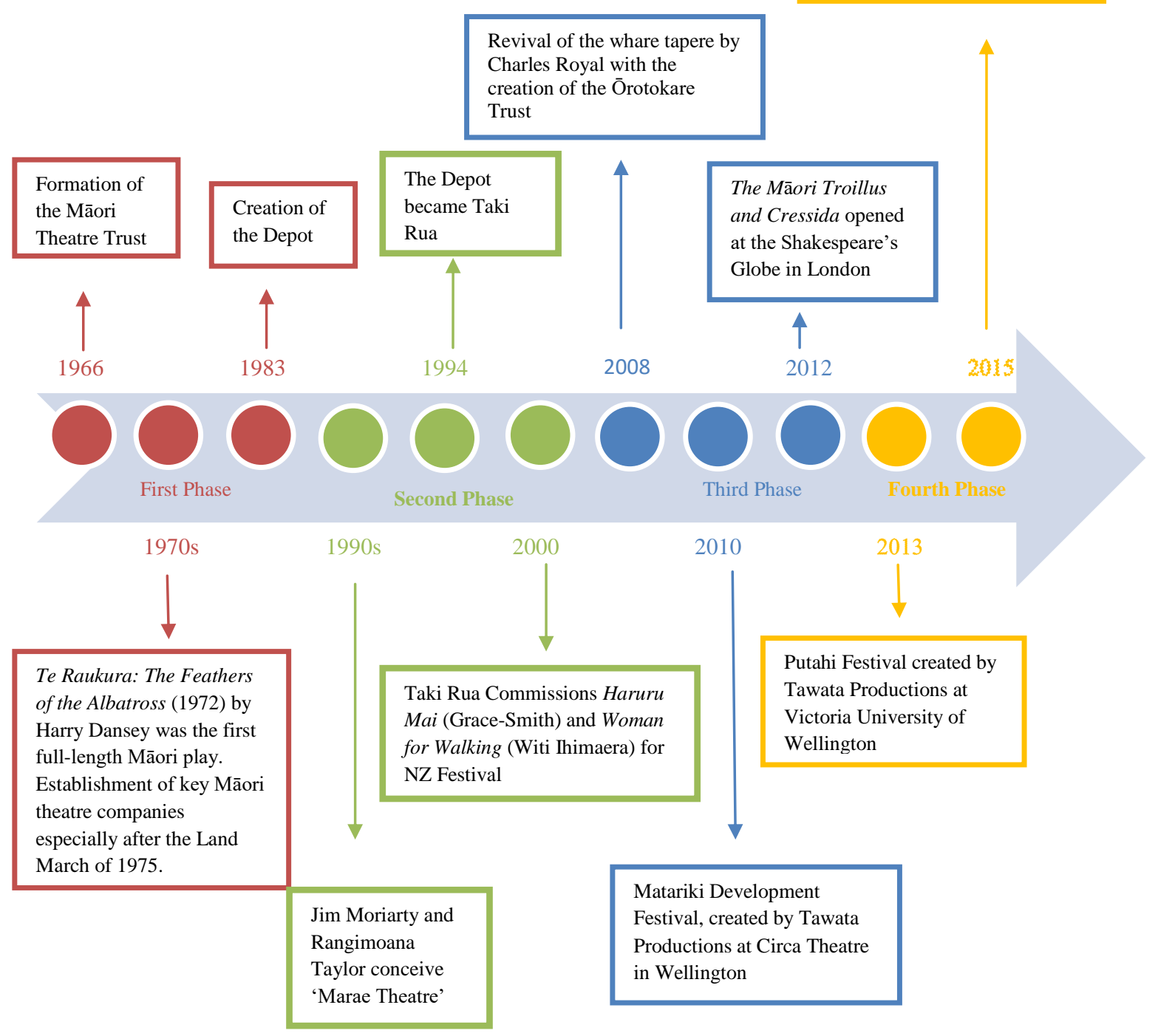

Figure 15. Chronology of the development of Māori theatre 


\subsubsection{Māori Theatre: Case Studies}

This section will discuss Maui: One Man against the Gods (2005), and $T \bar{U}$ (2012), as clear examples of Māori plays where elements of the Māori culture that are perceived as 'traditional' are integrated with Western theatre techniques, producing 'contemporary' Māori theatre. These plays have different themes and aesthetics. Maui is based on a combination of different Māori oral narratives, narrating the deeds of demigod Māui. $T \bar{U}$ is based on a book of the same name written by Patricia Grace, narrating the conflicts that lead to the decision of one family member to enlist in the army and go to war. Both plays integrate 'traditional' elements of Māori performing art and Western theatre techniques. These plays are relevant examples in relation to the development and rethinking of possibilities within Rapanui theatre. Maui is based on an oral narrative which includes the presence of the storyteller, reflecting the Rapanui theatre reality. $T \bar{U}$ shows how 'traditional' cultural elements can be included in the dramaturgy of the text making the presence of these cultural elements an important aspect in the structure and aesthetic of the performance.

\subsubsection{Maui: One Man against the Gods}

Maui: One Man against the Gods directed by Tanemahuta Gray, premiered in 2005. The play was described as "Māori mythology on an epic scale" (Pinfield, 2011). The play used "dance, music and theatricality" (Nixon, 2007) integrated with kapa haka and Māori world views to portray the life and deeds of demi-god Māui. This style of representation is known as "haka theatre" (Sciascia, 2011, p. 10), and it is not new to the Māori world. In 1930 it was developed by Princess Te Puea Herangi of Waikato as means of revitalising the use of orally transmitted Māori performing arts such as "waiata, haka, karakia, patere" is known as kapa haka. Overtime kapa haka performances have grown in popularity to the point that it has its own competitive festival, Te Matatini, which is held every two years in a different city around New Zealand.

\footnotetext{
${ }^{84}$ Action song, dance, prayers and chants, respectively
} 
From a Pākehā perspective, the idea of combining Māori 'traditional' stories with European theatre and music was not new. In 1968 the New Zealand musician Jenny McLeod created Earth and Sky (Harcourt, 1978, p. 142). The performance was based on the Māori story of creation. It was produced with school children, and reportedly left audiences "tingling with excitement, breathless with delight" (Harcourt, 1978, p. 142).

The essence of haka theatre is that it brings together "kapa haka innovation" (Sciascia, 2011, p. 10) with theatre, connecting "theatre to Māori and Māori to theatre" (Sciascia, 2011, p. 10). In Maui, kapa haka innovations were evident for an audience member who had seen a haka or poi performance before. Haka and poi were de-constructed to be reconstructed as new elements within the context of the play. For example, at the beginning of the play performers formed the amo or pillars supporting the roof structure of a marae. In order to get to their positions the performers combined contemporary dance movements with sharp movements reminiscent of the way of walking of a kapa haka performer: walking on their tiptoe and bending one leg to the back very quickly steping forward.

During the scene when Māui fished the north island 'traditional' and contemporary musical elements were used. The scene started with four performers rowing on a boat made out of fabric. They are chanting in Te Reo Māori to keep the pace while rowing, while a performer that represents the rear keel of the boat uses the poi to mark the pace and the passing of time. At some point in the scene the performers pick up the pace and turn the Māori chant into a rap that they sing until Māui, who was hiding in the boat, appeared and starts fishing the north island.

Throughout the play, the use of the poi represented the passing of time in Māui's life, especially towards the end of the performance. String figures were also used in this performance as a symbolic representation of oral tradition combining poetry, string figure, and movement. In this performance, the teaching of a string figure to Māui is done in a choreographed style, where the audience never sees the string figure complete but the movements tell us that the knowledge is being transmitted. 


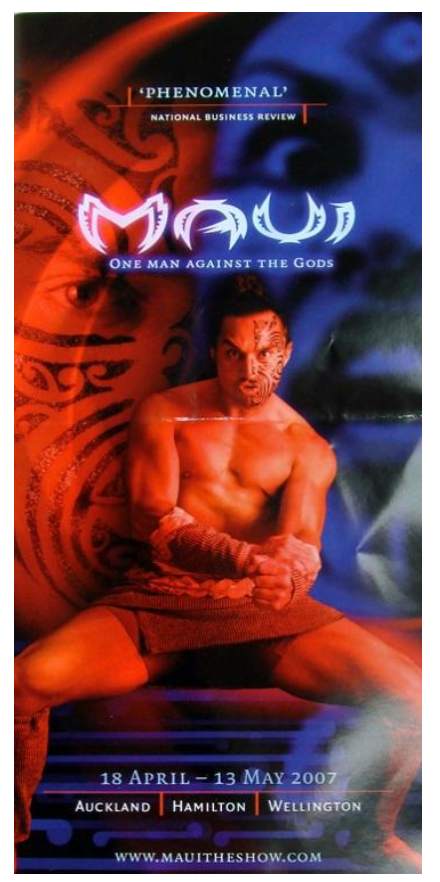

Figure 16. Maui: One Man against the Gods (2007) directed by Tanemahuta Gray

Dialogue and collaboration between 'traditional' and 'contemporary' Māori elements, as well as the integration of Māori and European theatre elements, can be seen throughout the performance. For example, the costumes were 'contemporary' versions of 'traditional' clothing, using materials that looked similar to the texture of woven flax. The 'contemporary' reinterpretation of 'traditional' costumes visually let the audience know in a subtle way that this performance was "rooted in tradition but expressed with contemporary skills and technological flair" (J. Smythe, 2007). The use of aerial theatre techniques was quite distinctive, and from my point of view the most striking element of this performance. The use of aerial work came about because Gray spent five years as a company member of the Argentinean theatrical troupe De La Guarda, one of the world's leading aerial theatre companies (Lee, 2015). In the performance of Maui, Gray integrated the knowledge acquired with this company.

The storyteller in Maui was not only translating from Te Reo Māori to English what was happening on stage; he acted as a mediator between performance and audience. The performer's use of a calm tone of voice and demeanour guided the spectator's experience of the performance. He transmitted emotions and feelings to the audience connecting with them on an emotional level, enabling the audience to empathize with Māui's journey. 
The combination of different performative elements including; aerial work, opera, dance, and European theatre, alongside "kapa haka, karanga, waiata, patu, taiaha and poi" (J. Smythe, 2007) which are all 'traditional' elements of Māori performing arts, resulted in a play that showed Māori epistemologies on stage.

\subsubsection{T̄}

The work of Tawata Productions, especially the play $T \bar{U}(2012)$ by Hone Kouka ${ }^{85}$, is a clear example of the relationship between the 'traditional' and the 'contemporary.' In this play 'traditional' cultural elements have been integrated into the dramaturgy of the play and combined with European theatre techniques without losing sight of the Māori worldview which guides the production of this play. Scene seven exemplifies the use of 'traditional' cultural elements in this work (Kouka, 2012, p. 16). In this scene the male characters are working in a factory in Wellington using heavy machines. The movements used when handling the machine start with the initial movements of the haka; stomping with one foot and slapping thighs and chest with the hands. Slowly the movements of the arms becomes more extended and staccato, until the haka movements become the movements utilised by a factory worker when closing a floodgate.

In this scene, the haka, a 'traditional' cultural element, is deconstructed and then reconstructed into a new movement in a new context. The use of the haka in this scene is not only an element of transition from one movement to another. The haka, on the one hand, symbolises the effort of the factory workers when manipulating the machinery, which would be equivalent to the physical exertion that the performer uses when performing a haka. On the other hand, the use of the haka in the play may also represent family history, the connection with the whanau, and iwi (tribe), links with the past, and the reassurance that the family will keep their memory alive after they had gone to war. $T \bar{U}$ illustrates an elegant and effective way of integrating 'traditional' cultural elements into a contemporary play. These elements are part of the structure and aesthetic of the play, so they are included because they have a function within the play. Rapanui theatre could draw inspiration from this play, by including in their scripts the different 'traditional' elements, such as the hoko and takona. In doing so, Rapanui theatre productions will give these 'traditional' elements a function within the play.

\footnotetext{
${ }^{85}$ I saw this performance in June 2013 at Circa Theatre in Welington.
} 


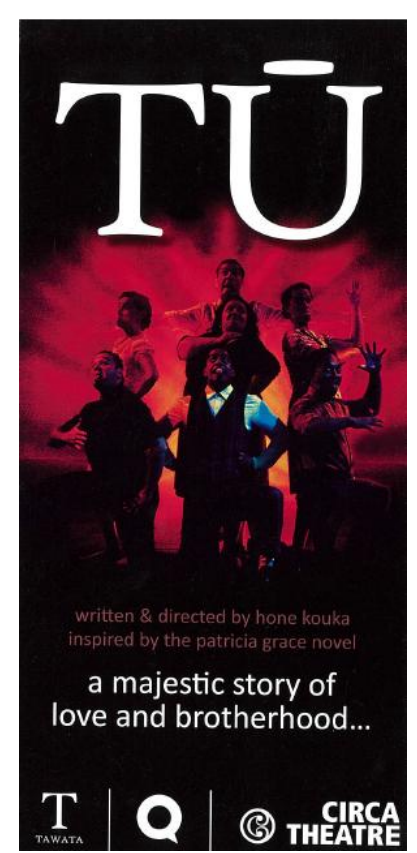

Figure 17. $T \bar{U}$ (2005) by Hone Kouka

The poi is another 'traditional' cultural element used in the play. In scene forty-eight the script reads " $[\mathrm{t}]$ he whirl of Poi striking skin begins slowly and gradually grows in volume and intensity" (Kouka, 2012, p. 86). The use of the poi in this case, is part of the script that the actors will read during rehearsals, incorporating the poi to the structure of the play. This shows that the use of 'traditional' cultural elements is well thought out and integrated into the dramaturgy of the play, and not just present as an ornament. In addition, the poi is not used in the same way it is used in a kapa haka performance. The movement of the poi acquires other meanings and symbolism within the context of the play. In the war scenes, the use of poi represents for example the passing of time, the sound of bullets during an attack, and emphasises the general pace of the scene.

Throughout its historical development Māori theatre companies and plays have shown a constant search for new forms of representation. 'Contemporary' Māori creations draw from their constant dialogue and relationship with 'tradition.' Without losing sight of the Māori world view, Māori theatre openly collaborates with European theatre techniques in the creation of new work.

Community theatre has been one of the foundations of Māori theatre. PETA and Boal's methodologies were combined with knowledge of community theatre enabling Māori 
people to tell their stories, and to share their point of view on different issues, making theatre relevant to Māori theatre practitioners and to Māori and Pākehā audiences. This methodology of producing theatre has allowed Māori theatre practitioners to gain control over their theatre work, allowing them to determine what and how to share with different audiences.

The use of Te Reo and the inclusion of Māori rituals have also become important aspects of community Māori theatre. Through theatre, Māori language became available to nonMāori speaking Māori audiences, helping in the revitalisation and prevention of the loss of language. Rituals associated with protocols used at the marae have been applied to the rehearsal space, framing theatre practice within Māori protocols, and making it specific for the Māori community.

For some Māori theatre practitioners, Shakespeare's work has been one of the main reasons for getting involved in theatre. This intercultural encounter is quite interesting, where an English writer perceived as 'traditional,' from the perspective of the Western theatre canon, speaks directly to the 'traditional' Māori culture, that Māori practitioners can linguistically and contextually translate text and stories, transforming them into a 'contemporary' Māori theatre production. All these elements, methodologies and influences show the historical development of Māori theatre and its relevance in the contemporary theatre scene in Aotearoa. 


\subsection{The Historical Development of Samoan Theatre in Aotearoa}

Theatre created by Pacific Islanders living in Aotearoa has been called "[O]ne of the most significant development in New Zealand theatre of the 1990s" (Balme \& Carstensen, 2001, p. 35). In the book chapter Taking Centre Stage: Pacific Theatre in New Zealand, Anton Carter narrates in four scenes the development of Samoan theatre in Aotearoa, explaining that:

Pioneering Pacific actors such as Lani Tupu Jnr, Nathaniel Lees, Maiava Eteuati and Jay Laga'aia, along with significant theatre groups such as Taotahi Ma Uo in Wellington, Pacific Theatre in Auckland, producer Makerita Urale in Wellington and Pacific Underground in Christchurch have all contributed to making Pacific Island stories come to life on stage (Carter, 2002, p. 148).

Notably, all of the theatre practitioners and many in the theatre companies mentioned by Carter are of Samoan descent. Scholars note this dominance of Samoans in the development of Pacific theatre (O’Donnell \& Tweddle, 2003, p. 124) and Samoan theatre in Aotearoa has been studied by a variety of scholars (Balme \& Carstensen, 2001; Betz, 2003; Carter, 2002; Fülöp, 2012; Keown, 2007; Looser, 2012; 2014; Mallon, 2002; O’Donnell \& Tweddle, 2003; O’Donnell, 2004b; Sinavaiana, 1998).

One of the main features of Samoan diasporic theatre is comedy. The main comedic influence on Samoan theatre in Aotearoa is the Samoan comic form of faleaitu, "the oldest surviving form of Samoan theatre" (Sinavaiana, 1998, p. 261) is a Samoan form of comic theatre and is described as involving "satirical sketches that commonly serve as interludes between sets of songs and dances in a traditional program of entertainment... among Samoans" (Sinavaiana, 1992, p. 202).

The role of the lead actor in faleaitu is to raise awareness about critical social issues using humour. Through comedy the performer openly comments on the ways that the socio-cultural "hierarchy constrained and stifled creativity and individual expression," using a " linguistic code and down-to-earth view of society" (Hereniko, 1994, p. 1). The performer is able to express these contentious issues as they were protected by aitu or spirits. Although it is the actor's voice speaking, in the Samoan worldview the faleaitu is understood to be a departed spirit or ancestor who is speaking to audiences through the actor's body. This practice is still quite popular in Sāmoa, and it also "maintains a strong 
presence and popularity in Samoan communities overseas" (Mallon, 2002, p. 139). In 1996 the Pacific Theatre company worked alongside faleaitu expert Caroline Sinavaiana and performer Siaki to develop and offer week long faleaitu workshops (Mallon, 2002, p. 140). During this week, elders with expertise in faleaitu met their contemporary counterparts to teach this art form to the younger generation (Mallon, 2002, p. 140). The contemporary faleaitu troupe The Brownies was created by Vela Manusaute and Canada Alofa as a result of this workshop. Their first production F.O.B. - Fools of the Bacific (1997), "brought some memorable scenes and humorous but hard-hitting commentary to the stage" (Mallon, 2002, p. 140). This is an example of a 'traditional' Samoan art form that was re-created in the present producing its 'contemporary' version by adapting this practice to the Aotearoa context.

Indigenous forms of theatre have interacted with and have been influenced by European theatre forms. Diana Looser explains that "[w]ritten drama by Pacific Island playwrights is a relatively recent phenomenon, arising mainly as a result of, and in response to, colonial intercession" (Looser, 2014, p. 7). In the early nineteenth century, colonialism and " $[\mathrm{t}]$ he arrival of Christianity and Western education provided Pacific Islanders with new material to dramatise... and encouraged the performance of sketches or longer plays" (Hereniko, 1993, p. 66). Christian missionaries introduced theatre to Sāmoa, staging plays based on the Old Testament (Sinavaiana, 1998, p. 236) during religious holidays. During the early twentieth century, Samoan itinerant troupes comprised of either all male or all female casts, "would set up makeshift stages, lit by torches" (Sinavaiana, 1998, p. 237), performing plays influenced by European stories in the different villages (Fülöp, 2012, p. 75). For example, in 1928 a Samoan version of Shakespeare's The Winter's Tale was performed in Sāmoa where the English play was adapted through the "use of local materials" (Hereniko, 1990, p. 75; Sinavaiana, 1998, p. 237) and the text was translated into Samoan language.

Since the 1980s, theatre practice has become a "powerful medium of expression" (Carter, 2002, p. 147) for Pacific Island people living in Aotearoa. They recognized the possibilities that theatre gave them to express themselves when telling their own stories to an audience. Actor Eteuati Ete was one of the first Samoan students to be admitted to Toi Whakaari: New Zealand Drama School. Regarding his experience at Toi Whakaari, Ete states that "it certainly gave me the skills and tools to work in theatre" (Mallon, 2002, p. 143). However, the acquisition of theatre skills did not change the fact that getting 
employed as an actor was a challenge since "there weren't roles for Samoans" (Mallon, 2002, p. 143). Ete explains that after graduating, he was offered mainly Māori characters to perform; realizing that no one was writing Samoan roles, he decided to start writing them himself (Mallon, 2002, p. 143). The development of Samoan theatre in Aotearoa has been a process of searching for identity, with Samoan artists trying to differentiate themselves not only from European culture, but from Māori culture as well (O’Donnell \& Tweddle, 2003, pp. 123-124).

Within the development of Samoan diasporic theatre (see Figure 23) several milestones can be recognized. In the early 1970s Samoan actor Nathaniel Lees created Statement Theatre, in South Auckland. Lees saw theatre "as an opportunity for Samoans and Pacific Islanders to be able to tell their stories" (Mallon, 2002, p. 149). Unlike Mercury and Theatre Corporate in Auckland that performed European plays that "had no relevance... to anything that was going on out at Otara" (O’Donnell, 2007a, p. 332) in South Auckland, Statement Theatre began performing New Zealand and Māori short stories devised in collaboration with other New Zealand theatre practitioners, Elizabeth McRae and Raymond Hawthrone. Statement Theatre embraced community theatre methodologies within the educational context, helping Pacific Islanders to realize that theatre was also available for them. Members of Statement Theatre went to different schools in South Auckland, talked to the students and asked them about issues happening in the neighbourhood, so that the theatre group could perform those issues back to the children. Through community theatre Statement Theatre managed to connect theatre with the cultural and social environment in which they were performing. An important aspect of this method was that the children collaborated together to the point where two or more versions of the same story were devised (O'Donnell, 2007a, p. 333). In this way the story was not fixed in one vision only, the 'authentic', 'original', or the 'traditional' point of view, but different angles were allowed in the creation of a different narration based on another perspective of the same story.

Another milestone in the development of Samoan diasporic theatre was the production of the first full-length Samoan play Le Matau (1984), written by Samoan journalist Samson Samasoni and New Zealander Stephen Sinclair. The play was produced by the youth theatre company Taotahi Ma Uo, which was established in 1981 and was the first MāoriPacific theatre company in Aotearoa. Taotahi Ma Uo consisted of young people with Polynesian and Māori heritage, most of whom were former students of Wellington High 
School (Mallon, 2002, p. 142). Le Matau narrates the experiences of Samoan migrant Ioane Leota, who has to pay a high price in order to succeed in his "search for employment opportunities" (Keown, 2007, p. 212). The cost of his success depends on abandoning his customs and traditions and becoming "his 'white' self, John Leith" (Looser, 2014, p. 60). This play contains themes of cultural alienation, and emphasises the importance of ongoing connections with culture and traditions, arguing that tradition and culture should be your stand point, the point from which you look at and dialogue with the world.

Pacific Theatre company, founded in 1987 by Justine and Paul Simei Barton in Auckland, was the first theatre company where most of its members were of Pacific Island descent (Fülöp, 2012, p. 77). This company was created to better reflect Pacific perspectives as a response to the lack of texts, roles, and stories that relate to this world view. The lack of Pacific plays led Justine Simei Barton to produce the play Feiva/Favour (1987), a musical from Papua New Guinea (Fülöp, 2012, p. 77). With this production, Simei Barton discovered not only the possibility of creating a market around Samoan diasporic theatre, but also discovered in theatre the possibility for Samoan voices to be heard (Herrick, 2007). This company produced a variety of plays in the 1990s, for example Othello (nd), and Lupe and Sina: A Love Story With Cannibals (1990) which was selected by the Playwrights Conference in 1990 for further development (Fülöp, 2012, p. 78).

Pacific Underground (PU) have been described as "one of the most influential New Zealand-based Pacific Islander theatre companies" (Looser, 2014, p. 60). The company was established in 1991 in Christchurch by Erolia Ifopo, Mishelle Muagututi'a and Oscar Kightley because of a "lack of material written for Pacific people living in Aotearoa" (Hills, 2004, p. 5). After twenty years in existence, PU is "the longest established PI company" (O’Donnell \& Tweddle, 2003, p. 124) in Aotearoa, building a "unique reputation for its fresh approach to presenting Pacific theatre and music" (Hills, 2004, p. 3). PU produced short plays that could be performed and toured in different schools, as well as working on full-length plays that could be performed in a mainstream theatre. This strategy enabled them to create and produce many plays in a short period of time. Fresh Off the Boat (1993), Dawn Raids (1997), and Romeo and Tusi (1997) were part of the repertoire they created for mainstream theatre, alongside " 13 theatre-in-education 
plays [performed] throughout the country" (Hills, 2004, p. 7) which contributed in the development of audience for Samoan theatre in Aotearoa.

The play Romeo and Tusi (1995), by Erolia Ifopo and Oscar Kightley, was "shaped around the greatest hits from Romeo and Juliet" (Houlahan, 2009, p. 284) and arranged to depict cross-cultural relations "exploring through comedy, the tension between Samoan and Māori families" (Maufort \& O'Donnell, 2007, p. 22) in contemporary Aotearoa. The play developed in a school holiday programme run by PU in Christchurch "where young people expressed their experience of communal conflict" (Hyland, 2011, p. 150). Through community theatre Pacific Underground illustrated part of the reality lived in these communities, by adapting the play to reflect the particular environment where the play was being performed, so that audiences could recognise and relate this story to their own (Hyland, 2011, p. 151).

Originally conceived to be performed at local high schools, Romeo and Tusi premiered publically at the Summer Festival in Christchurch in 1997. This play was designed to be performed "to large audiences... mostly in outdoors and community venues" (Maufort \& O'Donnell, 2007, p. 22) making this play an example of Samoan popular theatre in Aotearoa. With the use of a colourful stage and live music that introduced each character and different scenes, PU successfully captivated "a large number of audience members" (Houlahan, 2009, pp. 281-282). O'Donnell states that PU has the ability to "balance contemporary issues with humour, often strongly based in media and popular culture" (O’Donnell, 2007, p. 309). Elements of popular culture in Romeo and Tusi included reference to popular New Zealand and international music from the 1990s. For example, pieces of Ricky Martin's 'Livin' La Vida Loca', alongside the Spice Girls, the song 'Ten Guitars' and the 'traditional' Māori song 'E Papa' could be heard during the performance (Houlahan, 2009, p. 282). In addition, the play references the musical West Side Story by setting action at West-side College, where the main characters, Samoan girl Tusi and her Māori boyfriend Anaru rehearsed Romeo and Juliet for the school production. 


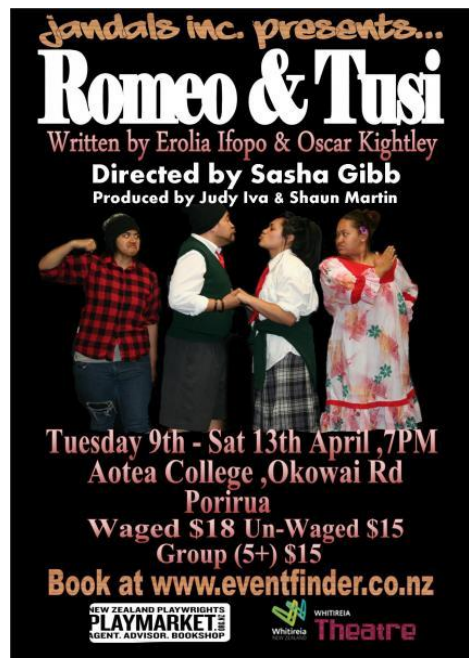

Figure 18. Romeo and Tusi (2013) by Erolia Ifopo and Oscar Kightley

Romeo and Tusi has been described as "a celebration of Polynesian identity and a recognition of difference between different Polynesian communities" (Maufort \& O’Donnell, 2007, p. 22) living in Aotearoa.

Since the 1950s, a significant amount of Samoan people have migrated to urban centres such as Auckland, Wellington and Christchurch, and consequently Aotearoa has become a key site for Samoan diasporic theatre (Balme \& Cartensen, 2001. p. 35). Theatre productions in these communities create a new "ongoing transnational network" (Clifford, 1994, p. 311) in which to share and to reflect upon mental and emotional ties between "people from the same cultural background" (Balme \& Carstensen, 2001, p. 36) living overseas and in the homeland. Samoan diasporic theatre also combines different styles of representation (Balme \& Carstensen, 2001, p. 41) creating a performance that addresses both the place of origin and the place where the performance is presented.

One example of this combination of representational styles is the play Home Fires, which premiered in 1998 during the International Festival of Arts in Wellington. This play is about two sisters, one that leaves home to become a traveller trying to stay one step ahead of her memories while the other stayed home keeping the ahi kaa (home fires) alight. This play depicts how identity and self-determination are influenced by memory and the impact that past, present and future may have in how we interact in a culturally diverse environment (Balme \& Carstensen, 2001, p. 35). In this play, artists from different parts of the Pacific joined in the production which was written by Māori Hone Kouka, directed by Samoan-born Nathaniel Lees, and choreographed by Cook Islander 
Teokotai Paitai. Kouka explains that working with culturally diverse artists gave them the opportunity to explore similar understandings and experiences of being minority groups, "because we all are part of minority communities living in New Zealand" (Kouka, 2015). This is an issue that many Pacific Islanders have experienced transitioning between the old and the new, the 'traditional' culture and "the modern Western lifestyle" (Balme \& Carstensen, 2001, p. 41).

This collaboration resulted in a work in which the cultural understandings of being minority was "transformed into theatrical signs designed for universal understanding" (Balme \& Carstensen, 2001, p. 41). For example, in scenes where no words were used, performers had to create specific gestures and movements to represent emotions such as "love, pain, happiness, sister, desire, [and] guilt" (Balme \& Carstensen, 2001, p. 41). This play, described by Balme and Cartensen as theatre of remembering, focuses on "rediscovering cultural roots in order to fashion a new identity" (Balme \& Carstensen, 2001, p. 35), encouraging actors to "search for gestures within their own cultural memory" (Balme \& Carstensen, 2001, p. 42). The result of this search gave the audience the power to understand and therefore value the proposed gestures, regardless of their cultural background. The intercultural collaboration created in the production of this play is significant, since it not only covered the actor's work, but it also kept in mind the multicultural nature of audiences in Aotearoa.

A core topic in Pacific Island plays in Aotearoa to date has been the re-negotiation, redefinition of “cultural identity” (O’Donnell \& Tweddle, 2003, p. 128). Cultural restoration is often not portrayed in the way in which "cultural values" (O'Donnell \& Tweddle, 2003, p. 128) are often represented; in the form of elders passing knowledge to the younger generation. Samoan diasporic theatre instead encourages representations of different situations from a Pacific world view, thus giving "equal value to high culture and pop culture icons, where global culture reigns" (O'Donnell \& Tweddle, 2003, p. 128). PU has allowed Samoan theatre practitioners to tell their own stories from their own distinct experience and point of view, using as a tool any performative style or technical element they saw fit; and combining 'traditional' and 'contemporary' elements in their work.

One example of the ways in which 'traditional' and 'contemporary' and popular performatives styles are combined is the play Rangi and Mau's Excellent Adventure 
written by Oscar Kightley in the late 1990s. This play drew inspiration from the movies Bill and Ted's Excellent Adventure and Bill and Ted's Bogus Journey. The play tells the story of "a Māori and a Samoan who don't get along... the play is about peace and unity" (T. Muagututi'a, 2014). Using that same structure as the movie the two characters in the play meet a Genie that gives them the chance to go on an adventure "where these two characters meet political leaders from our time... Gandhi, Tamasese and Mandela for example” (T. Muagututi‘a, 2014). This play blends popular elements using a movie format, in combination with exploring historical episodes from the past and from across the globe. Reflecting the company's expertise in theatre-for-education, the play was used as a teaching tool for introducing the history of the Samoan Mau movement through including the movement's leader Tamasese. (T. Muagututi 'a, 2014). The blending of 'traditional' and 'contemporary' elements in Rangi and Mau's Excellent Adventure responded to the main purpose of Pacific Underground as a theatre company which was "to develop professional theatre that explored current issues" (Mallon, 2002, p. 143) relevant to Samoan community in Aotearoa. The use of this format and referencing popular culture can be seen as a conscious strategy used by PU to connect through theatre with younger generations, especially the New Zealand-born Samoan generations who may not speak the Samoan language and may not know details about Samoan history. In 2015 PU created Rangi and Mau's Amazing Race which takes its format and structure from the TV show The Amazing Race, where competitors race across a variety of locations and have to complete daily challenges. The completion of each challenge gives participants a clue that leads them to the next challenge.

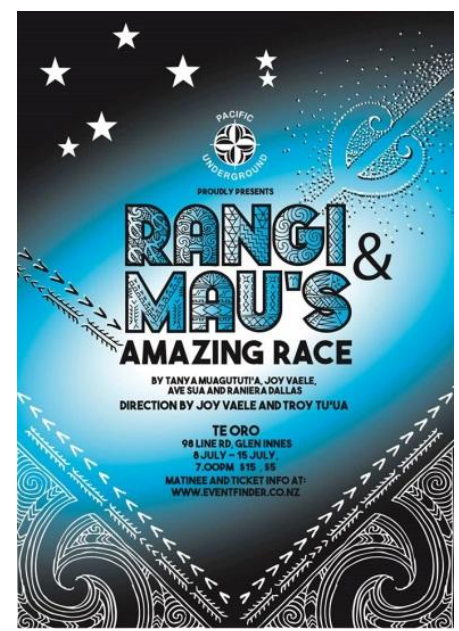

Figure 19. Rangi \& Mau's Amazing Race (2015) by Tanya Muagututi'a and Joy Vaele 
Rangi and Mau's Amazing Race is also an example that explains the concept of cultural values within Samoan diasporic theatre. Carter emphasizes that the most important aspect of Samoan theatre is not only the story, but also the "use of Pacific languages, symbols, [and] locations" (Carter, 2002, p. 147) in which memory is highly engaged, due to the fact that the story is narrated "from a Pacific person's perspective on life" (Carter, 2002, p. 147). This engagement with memory helps Samoan theatre to explore, rediscover and redefine cultural roots, to re-create and create new identities and to "build on the old routes while connected with the modern world" (Balme \& Carstensen, 2001, p. 35), consciously connecting 'traditional' and 'contemporary' cultural aspects through theatre practice.

One example that connects 'traditional' and 'contemporary' elements in the production of Samoan diasporic theatre was the play Tatau-Rites of Passage (1996), co-produced between Pacific Underground and the Australian community theatre company Zeal Theatre. The play tells the story of a Samoan family that migrates to New Zealand where the troubled son prepares himself to receive a pe'a (Samoan tattoo) reuniting him with his roots (Looser, 2014, p. 60). The play uses the Samoan tradition of tattooing as a basis of storytelling and as a "metaphor for the journey undertaken by the protagonist" (Mallon, 2002, p. 144). At the beginning of the process PU had some issues with elders in the Samoan community in Aotearoa, because the play "featured an actual tatau (tattoo) ceremony on stage alongside the dramatic action" (Looser, 2014, p. 60). The 'traditional' tattoo ceremony is a rite of passage, and initiation into adulthood which retains great cultural significance in contemporary Samoan culture (Balme, 2007, p. 197), thus publicly displaying this ceremony was strongly criticized by Samoan elders in Aotearoa (Balme \& Carstensen, 2001, p. 44). With the inclusion of 'traditional' cultural elements within 'contemporary' work, following cultural protocols is of paramount importance and adherence to protocol "becomes a major player in how things are to be done" (Carter, 2002, p. 151). After securing the participation in the play of a Samoan tattoo master, Su'a Sulu'ape Paulo, the performance was validated by the Samoan community (Balme \& Carstensen, 2001, p. 44). The community and cultural protocols that were part of the process of creation illustrates the importance of incorporating the elders' vision in the use or the representation of a particular 'traditional' cultural element in a 'contemporary' dramatic work. This play is an example of how Samoan diasporic theatre: 
incorporates traditional Indigenous cultural texts into the framework of European theatre to achieve a bi- or multicultural communication situation (Balme \& Carstensen, 2001, p. 45).

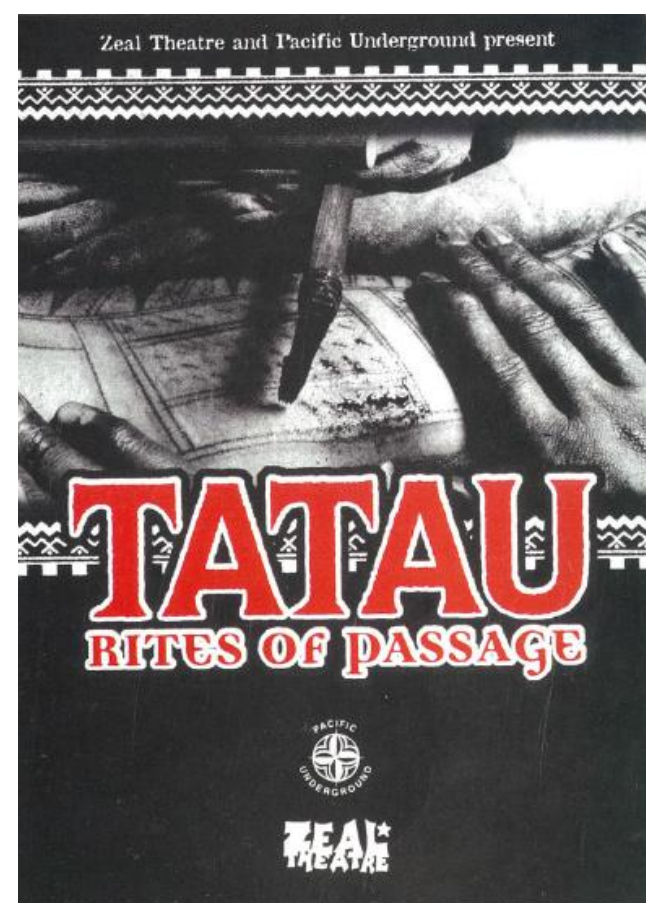

Figure 20. Tatau-Rites of Passage (1996) by Zeal Theatre and Pacific Underground

In 2000, Samoan actors graduating from drama school still faced challenges finding work; in this regard, not much had changed since the 1980s. Niuean/Samoan writer, actor and director Vela Manusaute graduated in 1995 from Toi Whakaari. Although he participated in The Brownies in 1996, he narrates a struggle to find employment similar to Ete's experience a decade earlier. Motivated by the lack of acting opportunities for Pacific Islands actors, in 2002 Manusaute formed Kila Kokonut Krew (KKK) in Auckland. Manusaute started writing his own plays, beginning with the Taro King (2002) (Manusaute, 2012, p. 103). Manusaute was joined by Anapela Polataivao, also a Toi Whakaari graduate, and in collaboration with Stacey Leilua, Aleni Tufuga, and Glen Jackson they formed the creative team and became key members of the company (Fülöp, 2012, p. 91). With a history of more than twelve years since its foundation, KKK "has stimulated important new work" (Looser, 2014, p. 62) including Once Were Samoans (2006), and Strictly Brown (2009) becoming “ [o]ne of the most dynamic companies working today... in South Auckland" (O’Donnell, 2012, p. 8). KKK states that their 
main purpose is "to create art with a strong political and social focus that the rest of the world could not ignore" (Kila Kokonut Krew, 2009).

This group is dedicated to the production of Samoan theatre in Aotearoa. In addition to their mission of recognising and celebrating Pacific Island voices, they also seek to develop and support the work of new Pacific Island talents (Kila Kokonut Krew, 2009). In 2010 they formed the mentoring initiative Kila Theatre Creatives, where they supported and produced two plays; the first full-length Tongan diasporic play Kindom of Lote (2010) written by Suli Moa, and Four Women (2010) written by Leilani Salesa.

Since then, Kila Creatives Theatre has seen the creation of several Pasifika works, which later have been supported and subsequently funded by Creative New Zealand (Fülöp, 2012, p. 93).

The Factory (2011), New Zealand's first Niuean/Samoan musical written by Vela Manusaute (Delilkan, 2011) was inspired by families that came to Aotearoa from the Pacific Islands and worked on the factory floors (Fresh TV, 2011). This production exemplifies the company slogan "[f]rom the Pacific we rise" (Kila Kokonut Krew, 2009), showing strength, determination and resilience; despite the lack of acting opportunities for Samoan actors, Samoan theatre practitioners have been writing their own characters and important plays for the Samoan theatre community in Aotearoa. The Factory demonstrates the company's ability to create a story that resonates with diasporic Pacific Island performers and audiences. It also shows their ability to successfully integrate 'traditional' Samoan songs with "original music score composed by Poulima Salima [of Samoan descent]" (Delilkan, 2011), using the format and style of a Broadway musical without losing the Samoan point of view. 


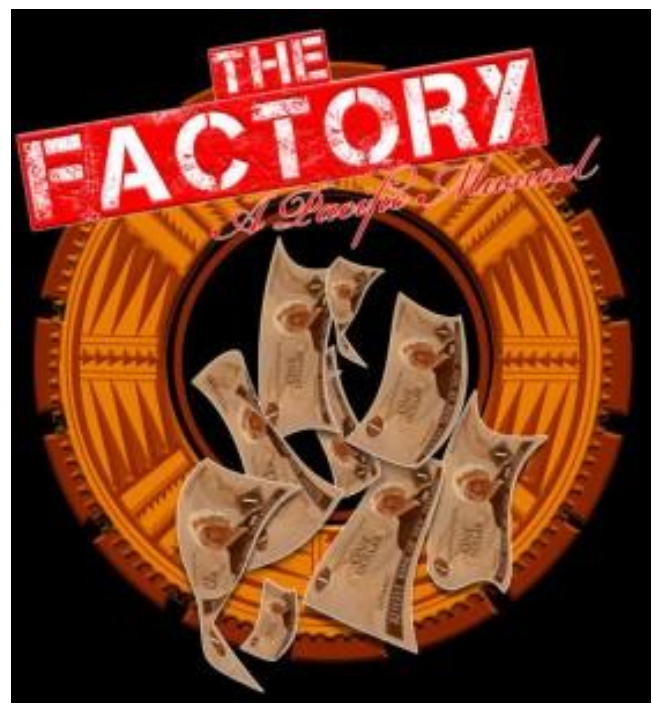

Figure 21. The Factory (2011) by Kila Kokonut Krew

Black Faggot (2013) by New Zealand-born Samoan Victor Rodger, produced by the multicultural theatre company Multinesia, follows a series of characters facing the challenges of being gay “in New Zealand's immigrant Pacific Islands communities” (Multinesia, 2014). The play was directed by Pākehā Roy Ward, and portrays the collaboration and the negotiation between cultures: the Pacific world view is shown through European theatre techniques. It resembles, or is inspired by, the play Bare (2007) by Toa Fraser, a playwright of British and Fijian descent (Cohen, 2013), where the characters are on an empty stage - a 'bare' stripped back aesthetic that puts emphasis on the actors as storyteller. Black Faggot differs significantly from the previous examples. It could be said that this play is European theatre, mainly because the staging and the performance style and techniques are from European theatre. However, to me, Black Faggot is nevertheless a Pacific Island play, because the topic, the story, the point of view and the performers are from the Pacific. These actors, Iaheto Ahi of Samoan descent and Taofia Pelesasa of Tokelauan heritage, bring into the performance their cultural backgrounds, language, sense of humour, and their point of view on the topic of the play, and it is this embodiment that makes it a multicultural Pacific Island play. 


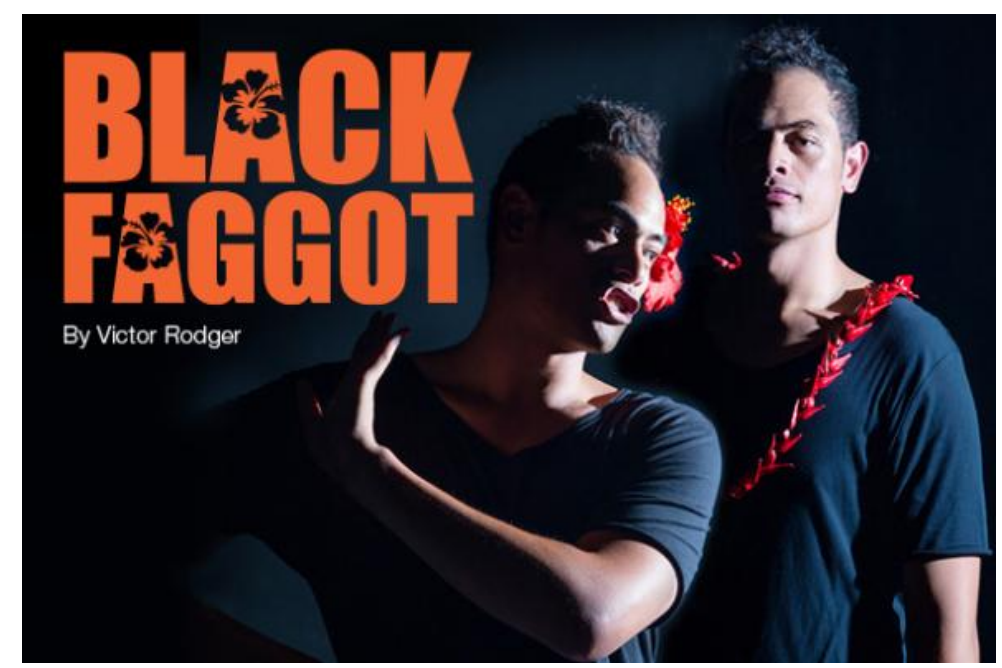

Figure 22. Black Faggot (2014) by Victor Rodger

Another example of integration of 'traditional' and 'contemporary' elements in the performance is the play The Eel and Sina (2015) by Jono Soo-Choon of Sāmoan descent. This play, presented at Measina Festival in 2015, is based on the "popular myth Sina and the Eel" and narrates the "untold side of the story" (Gibb \& Lualua, 2015). Soo-Choon creates his own version of this oral narrative, which tells how the coconut tree and its fruit came to be, reinterpreting the 'traditional' story through a 'contemporary' point of view. The 'traditional' version of the story "Sina and the Eel" tells Sina's version of this story. Soo-Choon's creation used the perspective of the Eel to tell a story that is more about disapointment and a very greedy Sina. This is a very interesting way of working with a oral narrative that Rapanui theatre could benefit from. This performance shows how to tell the 'traditional' story in its entirety looking at it from another point of view.

In this play, actors perform on an empty stage dressed in black. This style of acting gives them the versatility to portray all the characters included in the 'contemporary' version of this 'traditional' story. Another interesting aspect of this play is that it combines Sāmoan cultural elements, such as music and dance, with popular culture. The play starts with a 'traditional' Sāmoan song and dance that tells the story of Sina and the Eel (Soo-Choon, 2015). One scene shows how the elders created that particular song. The performance uses music by Christina Aguilera, Beyoncé, and Snoop Dog as the elders'suggestion to create this 'traditional' song. The group used other references to popular culture in the play to ridicule stereotypes of Pacific Island people and to laugh at their own culture, by saying that the song about Sina and the Eel "has been played 4.568.738 times!" (Soo- 
Choon, 2015). They tell the whole story, in their own version, without losing the Sāmoan world wiew.

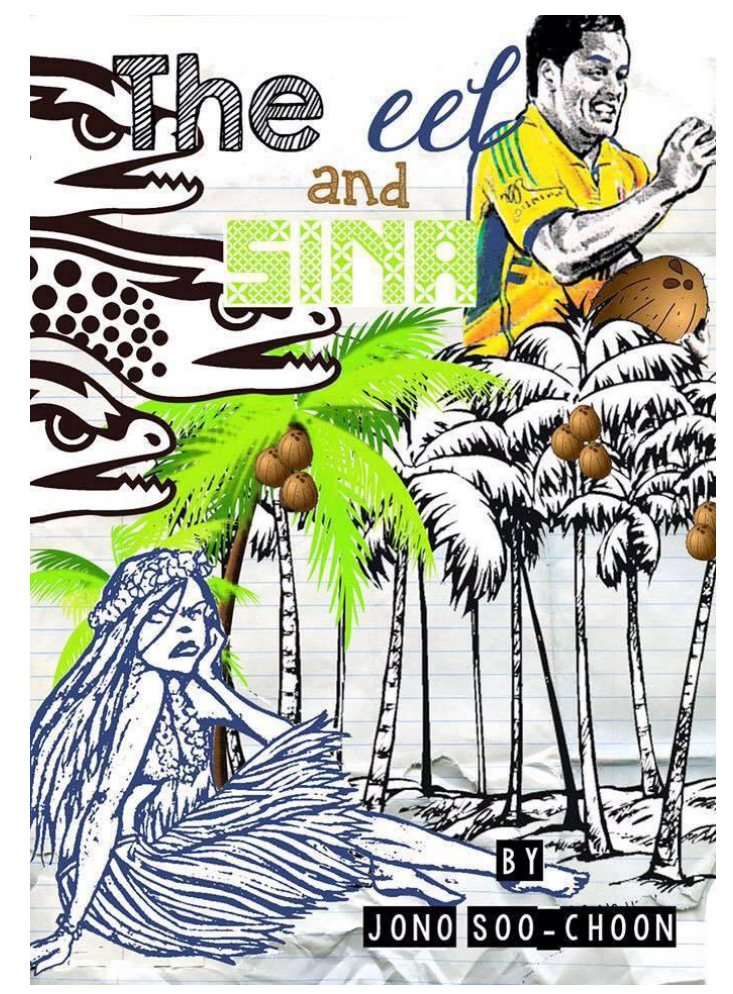

Figure 23. The Eel and Sina (2015) by Jono Soo-Choon 
Creation of Pacific Underground in Christchurch and Maidment Youth

Theatre in Auckland later known as Massive Company
The First Pasifika Playwrights Development Forum was held, funded by the Auckland City Council

\begin{tabular}{l} 
Le Matau by \\
Stephen \\
Sinclair and \\
Samasoni \\
\hline \multicolumn{1}{c}{} \\
1984
\end{tabular}

1984

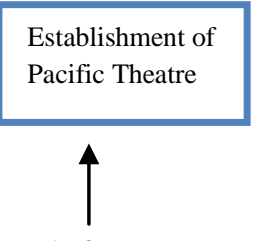

1987

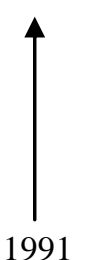

Theatre was included for the first time as part of the program of Pasifika Festival

1991

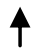

1993

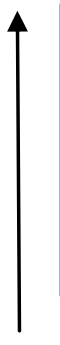

First Measina Festival in

Wellington, co-produced by Jandals Inc and Le Moana, was organised to showcase contemporary Samoan Arts and celebrate Samoan culture, language and stories through dance, music and theatre.

\section{4} 2014
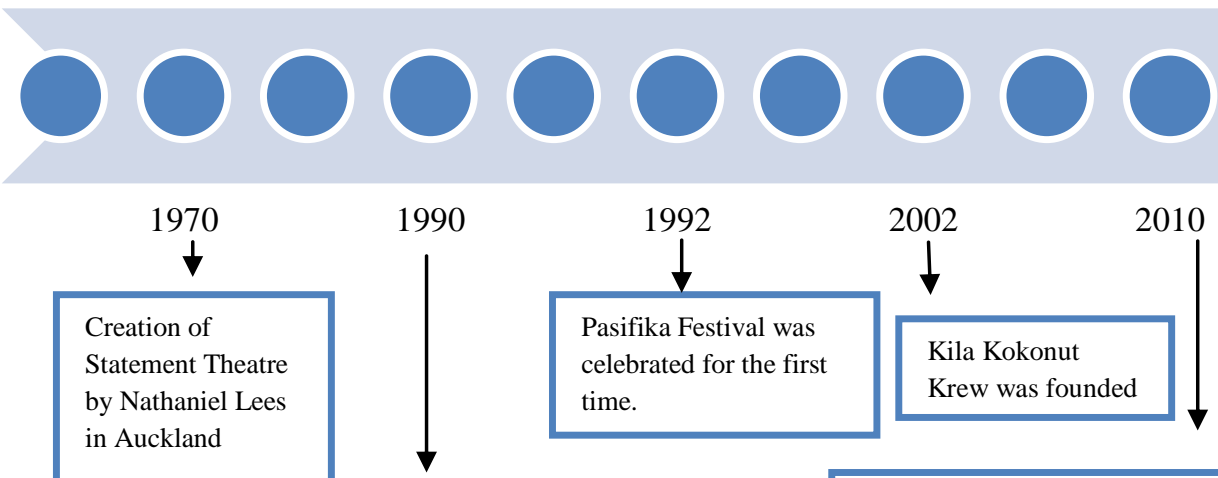

Creation of Whakarite Theatre In September the Mangere Arts Centre - Nga Tohu O Uenuku opened in Auckland focusing on presenting Māori and diasporic Pacific arts. Company in Chrsitchurch. A group of artists of mixed Polynesian heritage called Pacific Sisters, started working The Kila Theatre Creative was formed to promote the work of diasporic Pacific Island in Auckland talents.

Figure 24. Chronology of the development of Samoan theatre in Aotearoa 


\subsubsection{Samoan Diasporic Theatre: Case Studies}

The plays that I discuss in greater detail in this section, Fresh Off the Boat (1993) and Frangipani Perfume (1998), are examples of Samoan theatre where elements of the Samoan culture perceived as 'traditional' are integrated with Western theatre techniques and popular culture producing a form of expression of contemporary Samoan theatre in Aotearoa. Themes of migration, cultural clash and post migration reality are depicted in Fresh Off the Boat and Frangipani Perfume. Both plays are important to this research, because they show how 'traditional' elements of Samoan performing arts and elements from other cultures were adapted and integrated.

\subsubsection{Fresh Off the Boat}

Stories of migration are one of the main themes in Samoan theatre in Aotearoa. In the 1980s Samoan theatre practitioners became involved in Māori theatre (Mallon, 2002), creating plays based on topics such as migration, and depicting the clashes between cultures in Aotearoa. The play Fresh Off the Boat (1993) by Oscar Kightley and Simon Small, narrates the "dislocation and struggle... to fit into a very foreign way of life" (Kightley \& Small, 2005, p. i) and explores "the contrast between the migrant dream and the post-migration reality" (Fülöp, 2012, p. 46), thus resonating with Samoan audiences and other Polynesian communities who had migrated to Aotearoa.

The play has many layers, one is the cultural differences between "a more rural, traditional Island setting and a modern urban lifestyle"(Kightley \& Small, 2005, p. i). The play ${ }^{86}$ opens by showing on a screen on stage, footage of Samoan lifestyle, in this video it is possible to see children smiling, and people at the local market buying fruit. While video screens, character Charles sits in the middle of the stage miming the movements involved in the preparation of kava. Following the kava ceremony Charles stands up and does movements of a Samoan dance as if happily welcoming the audience to the performance. During this opening scene, melodic female voices sing a Samoan song acapella, creating different harmonies. The play finishes with the same song, but this time a video shows images of Charles walking aimlessly on New Zealand streets while he performs an exhausted version of the dance he did at the beginning. This change

\footnotetext{
${ }^{86}$ This analysis is based on my viewing of the recorded play
} 
of energy illustrates the struggles that Charles went through trying to adapt, finding a job, speaking English and fitting in this foreign culture. Fa'aSāmoa, the Samoan way, is still there but much more debilitated (Pacific Underground, 1995).

The loss of language amongst the Samoan diaspora, and the accompanying loss of connection to roots and 'traditions' is another aspect present in the play. This can be seen in the relationship between characters Charles, who is an island-born Samoan speaker, and his nieces Evotia and Ula, who are raised in Aotearoa and do not speak the Samoan language (Kightley \& Small, 2005, p. iii). One scene that shows the loss of connection to Samoan roots and traditions is when Charles performs the ritual of gift giving. The girls are not really sure how the ceremony proceeds; they need to be told where to sit. Charles then takes the role of the chief giving a speech in Samoan language before giving the gifts away and praying afterwards. Everybody attempts to stand up, thinking that the ceremony is over, but Charles starts singing indicating that the ceremony is not over yet (Pacific Underground, 1995).

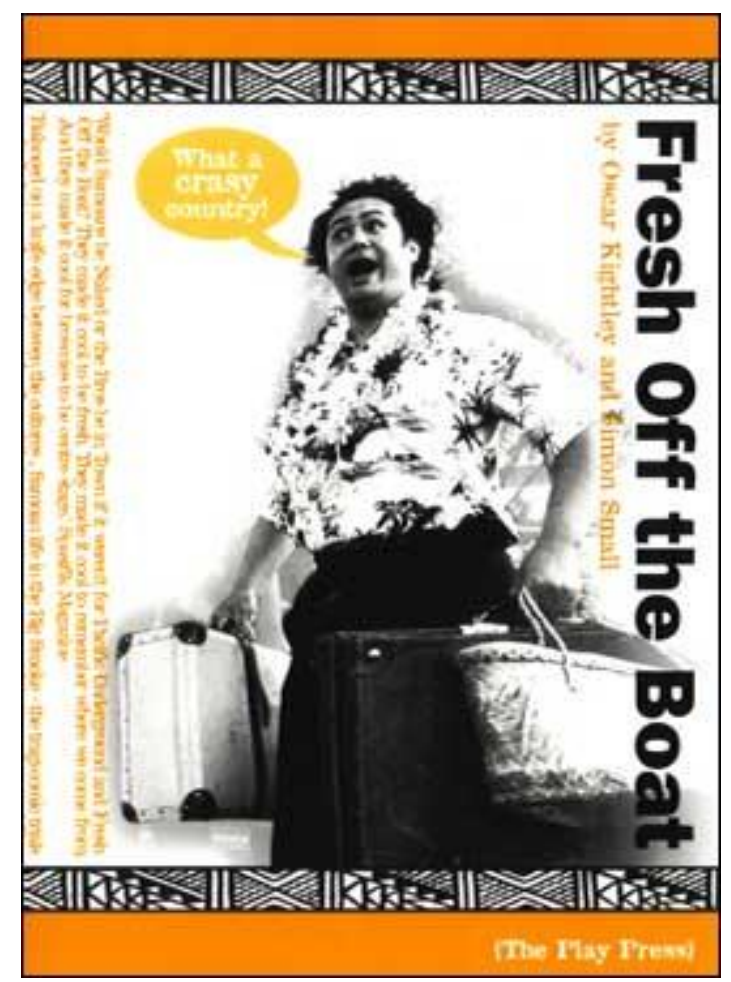

Figure 25. Fresh Off the Boat (1993) by Oscar Kightley and Simon Small

One interesting scene in the play is when Evotia asks her uncle about 'traditional' dances in Sāmoa. She is curious to learn if indeed every movement has a meaning. Charles gives her some examples showing her dance movements associated with daily activities done 
back in Sāmoa, such as squeezing and grinding the kava (Kightley \& Small, 2005). Evotia carries on showing to her uncle her version of Samoan dance by miming some of the daily tasks performed in New Zealand, for example vacuum cleaning, hanging the washing and ironing. Both characters join in a 'contemporary' Samoan dance incorporating 'traditional' movements and the new ones created by Evotia (Pacific Underground, 1995). The clear and simple structure of this scene transmitts with humour a strong social critic, connecting with the audience and offering the opportunity to reflect on the way in which modern life and the urban environment have changed 'traditional' ways of knowing and being.

Fresh Off the Boat shows in a 'simple' way how to incorporate 'traditional' cultural elements in a contemporary production. This scene could be a great example to draw inspiration from for Rapanui theatre practitioners, because they can learn to work with what they have. Simplicity in the staging will enable them to concentrate and focus on effectively transmitting the message to the audience.

This play dealt with themes that were specific to the Samoan community in Aotearoa, and was received very differently when performed to audiences in Sāmoa; who were shocked to see the struggles involved in migration depicted on stage.

They did not find it funny... all the laughter heard in New Zealand was turned into concern... because the idea of going to New Zealand and failing... or that things were not so easy over there, was very shocking for the people in Sāmoa (T. Muagututi'a, 2014).

The speech of the character named Sāmoa at the beginning of the play, when he states: "a land of milk and honey - well I think milk's has gone off... as for the honey side of the deal... it tastes sour" (Kightley \& Small, 2005, p. 3) may have been shocking for an audience that though that they were going to see a play about a successful migration experience to New Zealand, confirming their expectations about leaving Sāmoa and moving to the land of milk and honey. 


\subsubsection{Frangipani Perfume}

Frangipani Perfume (1998) by Makerita Urale was the first Samoan play "to be written by a woman writer for an all-female cast" (O’Donnell, 2004a, p. i) and is a landmark in the production of Samoan diasporic theatre, because its staging combined 'traditional' elements with elements from other cultures, creating a unique work.

The play ${ }^{87}$ follows three sisters, two born in Sāmoa and one born in Aotearoa, who work as cleaners "while dreaming of romantic fulfilment" (Welch, 1998). This play satirises popular "stereotypes of PI women as exotic and alluring" (O’Donnell, 2004b, p. 32) dusky maidens. The play begins with a scene showing the three sisters dancing to Offenbach's Barcarolle "in a balletic mode" (Budd, 1997) "to which they dance as if hypnotised" (Atkinson, 1997), which contrasts with the movements of cleaning toilets which reflects their real world full of chlorine and chemicals.

In our talanoa, Urale explained that she wanted to portray strong Pacific women, from a feminine perspective, taking as a source of inspiration her "love of opera and Hong Kong kung fu movies where you see these strong women fighting but never losing their femininity" (Urale, 2015). For example during Scene 6: Ka Isu!, Tivi and Naiki are doing kung fu movements while Pomu talks about her grandmother's friendship with anthropologist Margaret Mead (Nga Taonga Sound \& Vision - TVNZ Collection, 1998). This scene relates to the Rapanui performance Miro O'one, where foreign movements are copied and translated into a dance. Miro $O$ 'one became a representation of the other by adapting and translating maneuvers seen on ships visiting Rapa Nui in the eighteenth and the nineteenth century. In Frangipani Perfume, ‘foreign' movements, copied from kung $\mathrm{fu}$, are adapted and translated into the context of the play adding another layer of physicality to the performance. In Scene 6: Ka Isu!, one or two kung fu movements were chosen and repeated throughout the scene, connecting with the sister's tedious and repetitive work routine. This routine contrasts with the sister's femininity, reinforcing the strength of these sisters who do not to get discouraged by the hostile environment in which they are placed. The process of copying, adapting and translating foreign movements in Frangipani Perfume and Miro O'one, gave to these movements another meaning within the performance.

\footnotetext{
${ }^{87}$ This analysis is based in my viewing of scene footages provided by Nga Taonga Sound \& Vision TVNZ Collection
} 
Inspiration can come from any source, and Urale interpreted kung fu from a Samoan perspective, giving life to these three sisters that are caring, nostalgic for home, but strong enough to do a powerful machete dance towards the end of the play. This machete dance has been described as "demonic" (Welch, 1998) and "fast and furious" (Urale \& Fuemana, 2004, p. 32) where movements choreographed by Cook Islander Teokotai Paitai show the sisters fighting with imaginary swords referencing the 'traditional' Samoan sapelu or knife dance (NZPA, 1997) threatening the audience and miming sexual antics of men (Budd, 1997). The physicality expressed in this play through the bodies of the actors to recreate the story of these three sisters could be a source of inspiration for Rapanui theatre, since most of those involved in theatre in Rapa Nui have a broad background in dance.

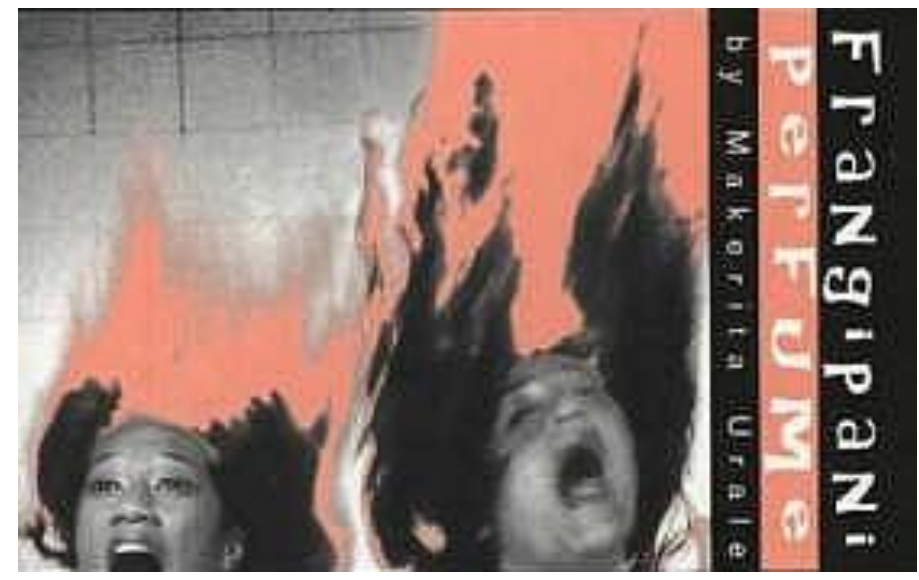

Figure 26. Frangipani Perfume (1998) by Makerita Urale

Although Urale had previously produced theatre, she had little experience writing a play. In my interviews Urale explained that the play is very testimonial, almost autobiographical, portraying some of "the memories from my childhood when I arrived here in New Zealand, and memories from Sāmoa" (Urale, 2015). For Frangipani Perfume she only had images; she states that "I wrote what I saw" (Urale, 2015). Separate visions later became the different scenes composing the play. According to Urale, these scenes found "their own order and sequence, like a big puzzle" (Urale, 2015) during the rehearsal period. This play illustrates "the blend of European and Polynesian cultures" (Budd, 1997) through this series of “ fast-cutting” (Urale \& Fuemana, 2004, p. 
2) scenes in which the search for balance between both worlds, Sāmoa and New Zealand, is one of the main points of the play.

Throughout its history, Samoan theatre in Aotearoa has been blending 'traditional' elements with 'contemporary' issues and referencing popular culture within their performances. Intercultural relations run free in Samoan theatre, giving its performers the freedom to look for inspiration in any direction, and to include those sources of inspiration in their creations, reinterpreting their own 'tradition' from a 'contemporary' point of view. These intercultural relations include working with artists with different Pacific heritages, adapting Shakespeare's texts to a Polynesian context, and integrating Hong Kong kung fu sequences and opera within the dramaturgy of a play.

The application of community theatre principles in the creation of different plays, has allowed Samoan theatre to differentiate itself from Māori and New Zealand theatre. Issues and themes of interest to the Samoan community living in Aotearoa, such as migration, culture clash, and historical episodes of Samoan history, have been incorporated in the different plays. The use of the Samoan language has also been an important aspect incorporated in Samoan diasporic theatre, highlighting the importance of New Zealand-born Samoan to keep the Samoan language alive. 


\subsection{Comparative Analysis}

The motivations behind the historical development of Māori, Samoan diasporic and Rapanui theatre realate, in some way, to the continuing effects of colonialism and the resulting disempowerment experiences in terms of representation. For Māori it seems that anger and disappointment about past colonial injustices, and finding theatre as a way of asserting Māori voices and political identities, were some of the key aspects that prompted the creation of Māori theatre groups in the 1970s. In the case of Samoan theatre, the lack of plays portraying Samoan characters, experiences and epistemologies, was the main motivation for the creation of Samoan theatre companies. For Rapanui theatre, the main purpose has been to preserve, revive and prevent the loss of the Rapanui language and 'traditional' customs as stipulated by Mata Tu'u Hotu Iti (1975) (Paloma Huke, 1995, p. 45).

Theatre developed by Māori and Samoan communities in Aotearoa comes from the integration of "written drama... a relatively recent phenomenon, arising as a result of, and in response to, colonial intercession" (Looser, 2014, p. 7) with an abundant 'tradition' of Pacific performances of

song, dance, storytelling, religious ceremony, oratory, the playing of musical instruments, and formal displays of combat skills, as well as -in some areasmore representational theatrical forms such as puppetry and dramatic sketches (Looser, 2014, p. 7).

Although Rapanui theatre focuses on performing oral narratives, Looser's (2014) statement can also be applied to the development of Rapanui theatre, because they also have a wide tradition of performing arts.

This section compares and contrasts Māori, Samoan diasporic and Rapanui theatre practices from different perspectives including context, intercultural negotiations through community theatre, the use of Indigenous languages, storytelling, and Shakespeare's influence on Māori and Samoan diasporic theatre. 


\subsubsection{Comparing the Contexts where Theatre is Performed in Aotearoa and Rapa Nui}

Māori and Samoan diasporic theatre is being largely performed at local community theatres, mainstream theatres, and schools, as well as featuring at different festivals organised around Aotearoa. Some of these festivals are arts festivals including music, dance, literature, and theatre such as the New Zealand International Festival of Arts ${ }^{88}$. Other festivals like the Young and Hungry Festival and the Fringe Festival include theatre productions created by young practitioners and experimental work, respectively. The inclusion of Māori and Samoan theatre in these festivals has encouraged theatre practitioners in the creation of 'contemporary' work.

In recent years new theatre festivals have been created in Aotearoa, specifically in Wellington; Matariki Development Festival (2013), Pūtahi Festival (2014) Ahi Kaa Festival (2015), all organised by Tawata Productions, and Measina Festival (2014) organised by Jandals Inc. and Le Moana. The difference between these comparatively new festivals and the others mentioned above is that the former are directed and organised by New Zealanders, where Māori and Pacific Island theatre has been included, whereas the latter are Māori and Samoan driven and specifically promote and showcase the work of Māori and Samoan theatre practitioners. The historical development of Māori and Samoan theatre in Aotearoa may seem distant and separate from each other; however there have been many times when they have worked together. As Polynesian siblings and ethnic minorities living in Aotearoa Māori and Samoan theatre practitioners have supported their respective creative processes. In my interviews Hone Kouka expressed that, it has been very important to get to this point in the development of Māori and Pacific Island theatre in Aotearoa:

self-determination is the reason why we are putting these festivals together... for us to lead these projects, so we can determine the what, when, where and how (Kouka, 2015).

The creation of these new Māori and Samoan festivals brings us back to Roma Potiki's statement of theatre being tino rangatiratanga (self-determination) in action, where Māori and Pacific Island people determine what to show, how to show it and where to perform

${ }^{88}$ See discussion in Chapter Two 
their stories. The creation of Matariki, Pūtahi and Ahi Kaa Festivals has not only promoted and encouraged Māori and Samoan theatre practitioners to create new work, but have also guided the creative process. During the Matariki Development Festival held at Circa Theatre, one of the mainstream venues in Wellington, new work is read to the audience. This is usually work in progress, featuring texts that are not finished where Māori and Samoan playwrights are actively looking for feedback and comments from audiences. The Pūtahi Festival, held at Studio 77 at Victoria University in Wellington, is the next step in the process of developing theatre. During this festival, work that was read during Matariki is performed. These are still works in progress, and the directors and cast members are looking for further feedback to improve their overall performance. Ahi Kaa Festival is where the final product is performed. Works that have been developed as part of the Matariki and Pūtahi festivals are ultimately performed in mainstream theatre venues around Wellington including Bats, Circa, and Hannah Playhouse. In this way, over the course of a year, new work by Māori and/or Samoan theatre practitioners is being created. With the aid of audiences a theatre communitas is created, a collective who help with feedback and comments during the creative process. This way of working and producing new work highlights the creative process, as a long period of hard and constant work, which in this case is not isolated from the theatre community, but supported by it throughout its conception to opening night, ensuring that at least one Māori or Samoan diasporic play will be fully produced each year.

Measina Festival is a Samoan-driven festival held at Whitireia Performing Arts School in Wellington as part of the Sāmoa Language Week celebrations. In this festival different art forms are included; dance music and theatre, sharing old and new stories. Some of these are works in progress and some others are finished products. In 2015, finished products included the dance performance 1918 by Le Moana. This dance piece featured movements of 'traditional' Siva Sāmoa dance combined with contemporary dance and Samoan language to represent memories and feelings that Samoan elderly women have about the influenza epidemic of 1918. The Briefcase (Life in a Briefcase) by Ben Uili also featured in this festival, presenting a 'contemporary' hip hop dance piece portraying the overwhelming experience of speed, routine and human relations when working at an office. Works in progress included Spirits - Tatau by Sepeleni Mua'au and Ian Lesa, and Versions of Allah by Mo Ete, who explicitly at the end of their performances asked the audience for feedback and comments. 
In the case of Rapa Nui, theatre is being performed at cultural festivals, Tapati Rapa Nui and Mahana O Te Re'o. Tapati focuses on the preservation of 'traditional' Rapanui practices from games, customs, and language, to storytelling through a'amau tuai, and Mahana O Te Re'o encourages the use of the Rapanui language among the school community. The development of Mata Tu'u Hotu Iti between 1975 and 1999, which was probably seen as new and 'contemporary' at that time, set, without intending it, the framework in which Rapanui theatre should be produced, becoming the 'tradition' for Rapanui theatre and dance performances.

There are several possible reasons as to why the Rapanui performances currently adhere to strict ideas of 'tradition'. One reason may be that a'amu tuai is performed during a cultural festival that explicitly celebrates 'traditional' practices, and does not have a remit for encouraging the creation of new work. Another reason is that national and local tourist industries have a tight grip on what is performed and how Rapanui performances should be presented to tourists. In Aotearoa such tourist shows also exist, however they are separate from the production of performances with an artistic function. In fact their audiences are also different allowing both styles, touristic and artistic to co-exist.

Chapter Three showed that in Rapa Nui there is a resistance towards moving away from 'traditional' understandings of cultural creativity. The main reason for a reluctance to create openly and explicitly 'contemporary' theatre works may be the attitude that the Chilean people have towards notions of 'traditional' and 'contemporary' which influences the Rapanui perspective. Ana Maria Arredondo, former head of Aldea Educativa high school, explains that Chile and therefore Rapa Nui "has very conservative view of education" (Arredondo, 2014). The Rapanui educational system draws directly from the Chilean system, and school curriculums are basically the same in Rapa Nui and in Chile. However, in the late 1990s two Rapanui teachers Lucia Tuki and Catalina Hey, travelled to Aotearoa to participate in a seminar on Polynesian Languages. After returning to Rapa Nui, they proposed to the Chilean Ministry of Education the creation of an Intercultural Bilingual Educational (Educación Intercultural Bilingüe, EIB) program in Rapa Nui (Arredondo, 2013, p. 135). Although EIB has been of great importance in the Rapanui school curriculum, Arredondo is very critical of it stating that this educational program "focuses on mainly teaching the traditional aspects of the Rapanui culture" (Arredondo, 2014). A tradition-focused education has corresponding impacts in terms of the possibilities for contemporary creativity in the wider society, and it may be 
one of the main reasons why Rapanui theatre has focussed on performing 'traditional' stories rather than creating new stories and/or re-interpreting stories from contemporary perspectives.

Although there are currently no festivals promoting the production of contemporary theatre in Rapa Nui, there was a festival fostering the creation of Rapanui new music which ran from 2000 until 2011. Ka Tangi Te Ako (New Song Festival) (see Figure 17) was financially supported by the Corporación Nacional de Desarrollo Indigena $(\mathrm{CONADI})^{89}$ and this was the only festival promoting a 'contemporary' point of view. Ka Tangi Te Ako started as a music festival, however over time the organisers included other forms of artistic expressions, such as takona (body painting), and following the wider aims and ethos of the festival the creation of new designs was encouraged. Ka Tangi Te Ako was "the perfect space to discuss, confront, and present Rapanui 'contemporary' art to a local audience” (M. Fortin, 2010, p. 74) where artistic forms from the past could dialogue with the present and the future.

\subsubsection{Community Theatre practice in Aotearoa: Intercultural Encounters and Collaborations through Theatre Practice}

When PETA visited New Zealand in 1987, a learning experience was generated; Māori theatre practitioners could learn from experience about community theatre and its methodology. Roma Pokiti who was involved in the workshops PETA conducted in Aotearoa, went to the Philippines to learn more from PETA, and when she came back she adapted their process to a Māori framework. The theatre company He Ara Hou, which was created on her return was composed by people with different levels of experience with theatre. This encounter shows that it is not crucial to train as an actor in an institution in order to produce a play; however, the skills of theatre, the craft of this art form, have to be learnt and experienced. These learning experiences can come, as in $\mathrm{He}$ Ara Hou, by working with a trained actor. Another example of a theatre company composed of people with different levels of theatre experience is Te Rakau Hua o Te Wao Tapu, directed by Jim Moriarty ${ }^{90}$. This company works with people of all ages and

\footnotetext{
${ }^{89}$ Corporation for Indigenous Development

${ }^{90}$ See discussion Chapter Five
} 
theatre experience using community theatre as a means by which to share their life experiences to the wider community.

In the case of Samoan diasporic theatre, this chapter showed completely different experiences based on collaboration. Pacific Underground collaborated with Australian Zeal Theatre Company in the production of Tatau Rite of Passage. This collaboration had the problem of showing a 'traditional' and very important Samoan rite on stage during the performance that the Samoan elders did not approve. After dialoguing, these two different perspectives, old and new, 'traditional' and 'contemporary', eventually reached a resolution which allowed each party to feel comfortable with the performance. The idea of working with the elders, and asking them for assistance and permission, is a very interesting way of combining 'traditional' and 'contemporary' practices. Both elders and performers were able to learn from the other's point of view and perspective; sometimes even improving the original idea by further grounding it within cultural roots and relationships. For some Māori theatre practitioners, working with a kaumatua (cultural advisor) may be essential, especially when integrating 'traditional' cultural elements within 'contemporary' work. Kouka, who worked with the same kaumatua, Bob Wiki, for several projects in the 1990s, states that the challenge in that case is to find an elder that understands what you want to do, so that they can guide you and help you decide the best way of integrating both worlds, the 'traditional' and the theatrical. Intercultural collaborations through theatre can also come in the form of theatre education and training which is crucial to express your own stories. Before doing any type of theatre, whether it is political, community, popular, or any other form of European or Polynesian theatre like faleaitu, whare tapere, haka theatre and a'amu tuai, theatre skills should be learnt:

It is useful to reflect on those skills, and their sophistication: of enabling storytelling, of then choosing the theatre form, embodying the content in a classic play frame, or a popular theatre format, or devising a theatre form specific to the content (Maunder, 2013, p. 34).

Ways of learning are many and learning can occur through multiple pathways, as seen in this second part of this research project. Māori and Samoan theatre practitioners have taken and created a variety of learning opportunities including working with skilled actors and trained artists, participating with theatre groups, and/or studying theatre at 
tertiary institutions. Hone Kouka explains that learning different culturally-situated theatre techniques enables theatre practitioners to "gain another perspective and set of tools to choose from when creating a play... being able to combine Māori theatre methods with Western theatre" (Kouka, 2015). By being able to decide what, when and how to combine during the creation of a play, Māori theatre practitioners have created their own distinct concept of and approach to theatre, creating and producing stories in their own terms, with methodologies, and styles defined by Māori themselves (Potiki, 1991a, p. 58).

\subsubsection{The Use of Indigenous Languages in the Production of Māori, Samoan diasporic and Rapanui Theatre}

Early Māori theatre was mostly in English, because the Māori language was in such a steep decline meaning that "the majority of Māori do not have a strong grasp of our language" (Potiki, 1992, p. 153). In the 1990s Taki Rua used theatre as a tool for education. Every year they organised a week of theatre where a number of plays were performed in Te Reo Māori. These performances later toured around the country to different "kohanga reo, kura kauapapa, marae and community centres and also to secondlanguage learners of Māori in universities" (Maunder, 2013, p. 143), where artists could collaborate with a range of "Māori speakers and learners" (Maunder, 2013, p. 144). English has also been used alongside the Māori language, as a means of acknowledging people who did not speak Te Reo, and "to explain what is being said to the audience" (Potiki, 1992, p. 153), for example in the play Purapurawhetu (1997) by Briar GraceSmith.

The use of Indigenous languages within performances has been used to highlight lack of Māori and Samoan language use in wider Aotearoa society. For example Waiora (1996) by Hone Kouka, narrates the struggles of a Māori family adapting to a new life in an urban environment away from culture, language, and traditions. The play uses Te Reo to illustrate this struggle. Young characters are told by their parents that they are not allowed to speak Māori, and that it is "for your own good" (Kouka, 1997, p. 20). The use of Te Reo also represents the ways in which 'tradition' speaks to 'contemporary' Māori, linking character Rongo with the spiritual world, and the ancestors. She uses Te Reo 
when addressing her ancestors, mourning the loss of language, stating that she is afraid that she "will forget our words" (Kouka, 1997, p. 30).

Samoan theatre has also included texts in the Samoan language, for example in the play Fresh Off the Boat (1993) by Oscar Kightley and Simon Small. The play highlights the loss of language amongst the Samoan diaspora, and the accompanying loss of connection to roots and 'traditions'. This can be seen in the relationship between characters that are island-born Samoan speakers, and the ones who are raised in Aotearoa and do not speak the Samoan language (Kightley \& Small, 2005, p. iii). In both cases the use of the Indigenous languages do not interfere with the audience's overall understanding of the play, usually because what it is said in Māori or Samoan is being supported by the action or the context in which these words or sentences have been said. For example, the play The Factory (2011) by Kila Kokonut Krew, which depicted working life in New Zealand factories was perceived as "very accessible" (Delilkan, 2011) although the characters were sometimes speaking in the Samoan language.

In Rapa Nui, a'amu tuai are performed completely in Te Re'o Rapanui. Since these performances are part of the cultural Festival Tapati, and Mahana O Te Re'o, it can be argued that the first requisite of contemporary Rapanui performances is to use the Rapanui language. The inclusion of a'amu tuai in Mahana O Te Re'o added significant layers of meaning to this celebration, as in previous years the festivities had concentrated on dancing and singing, but not on the spoken expression of language. As an aspect of Rapa Nui's rich oral culture, Te Re'o Rapanui was reinforced and extended through the use of theatre as an art form which assisted in "the maintenance of spoken languages that are essential to oral traditions and their transmission of history, culture, and social order" (Gilbert \& Tompkins, 1996, p. 167). Some of these stories were recorded in old Rapanui language by German missionary Father Sebastian Englert (1980) as well as others being orally transmitted by Papa Kiko, one of the last knowledgeable persons about 'traditional' Rapanui narratives (M. Fortin, 2010, p. 123).

The decision to perform in the Rapanui language only arose from the wider purpose of Mata Tu'u Hotu Iti, to preserve and prevent the loss of language. With their theatre performances this group expressed their point of view with regard to their position in the Chilean national territory, thus establishing their cultural difference within the Chilean culture. Later in time, when a'amu tuai performances became part of Mahana O Te Re'o, 
Lillo Haoa faced the difficulty of explaining and translating into Spanish the meaning of texts written in old Rapanui language to students. When translating these texts into Spanish, the problem was that "many words and even parts of the story were lost because there was no translation possible, not even into modern Rapanui” (Lillo Haoa, 2014). The main issue here is the loss of Rapanui vocabulary. Each story has many versions, so the parts of the story lost can be re-constructed by investigating other accounts of the same story. However, the loss of vocabulary prevents people from speaking their own language. Theatre cannot re-construct the vocabulary lost but can help prevent further linguistic knowledge from being forgotten.

\subsubsection{The Role of the Storyteller in Māori, Samoan diasporic and Rapanui Theatre}

One concept that connects Māori, Samoan and Rapanui theatre is the role of the storyteller. Examples discussed in this chapter, such as Maui: One Man against the Gods (2007) for Māori theatre, The Eel and Sina (2015) for Samoan diasporic theatre, and Nanue Para (2014) for Rapanui theatre, show that the storyteller is still an important figure to include in a performance. Although the performance styles of these plays differ, the points of contact are that all three are representations or reinterpretations of 'traditional' stories, and that the narrative is created and guided by the storyteller.

Storytelling reminds us that in Polynesian cultures oral traditions were transmitted in different formats, such as telling or singing a story about "the heroic deeds of clan founders or important historical personages" (Latukefu, 1968, p. 135). The performer usually underlined and highlighted not only the history they were describing, but the “ways in which narratives are (re-)constructed" (Gilbert \& Tomkins, 1996, p. 129). During the narration of the story, the storyteller can assess their "performance by the reaction of the audience" (Gilbert \& Tompkins, 1996, p. 128), such as re-telling the story, adding intonations, and sometimes varying the story slightly in a way that does not change the meaning, but satisfies the particular audience. This gave the storyteller the freedom to modify the story, questioning colonially-imposed notions of 'tradition' as unalterable, and encouraging the idea "that the 'truth' if any, is in the telling" (Gilbert \& Tompkins, 1996, p. 128). 
The storyteller in Maui: One Man against the Gods $(2007)^{91}$ provides structure and guides the performance, telling the non-Māori speaking audience what is going to happen in the next scene or act. In this case the role of the storyteller could be reduced to that of a translator, but the role of the storyteller extends beyond a simple translation. Although the storyteller in this performance speaks only in English, each offering made by the storyteller falls into another time and space, making the boundaries between past, present and sometimes future, permeable (Gilbert \& Tompkins, 1996, p. 139) by capturing the audience with his tone of voice, and his calm pace of narration.

The Samoan play The Eel and Sina (2015) presents another way of utilizing the character of the storyteller. In this case, the 'traditional' story of Sina and the Eel was re-created and narrated from the perspective of the Eel. The story narrates the circumstances that lead the eel to be transformed into a coconut tree. The storyteller was the tree, narrating these circumstances, his previous life as an eel, and his relationship with Sina. The interesting aspect of this storyteller was that he changed from tree to eel and back a few times during the performance and this was illustrated through short choreographed movements. The role of the storyteller in the production of The Eel and Sina was supported by four actors who created the different spaces, characters, atmospheres and situations that the eel had to face.

In Rapanui theatre the figure of the storyteller guides the entire performance and there is a protocol that the storyteller has to follow when narrating a story. This protocol draws from the set of rules that Tapati Rapa Nui festival organisers created when a'amu tuai was first included in $2000 .{ }^{92}$. The storyteller starts the performance by greeting the audience and telling the name of the story. In 2014 the performance of Nanue Para had

\footnotetext{
${ }^{91}$ This Storyteller was used in the second version of the show. The first version was entirely performed in Te Reo and this issue raised some critics suggesting that the play should be "sub-titled or re-written into English" (Kouka, 2007, p. 242).

${ }^{92}$ The set of rules of Tapati Rapa Nui, stated the way in which the competition of A'amu Tuai should develop. Each group will have to present a single play of a maximum of 30 minutes long, which will be assessed by the theme 'Haka'ara o te Tupuna' (remembering the ancestors). It was also established that this performance is a competition with a score for each candidate. The creation is free, but must be based on Rapanui oral narratives, without changing anything from the original plot. Each group must present their work without prior introduction to anyone outside the group in competition, and the director of the play must submit the name of the play to the show commission two days before the presentation. The performance will be evaluated considering: accuracy, creativity, choreography, and expression (M. Fortin, 2010, p. 80).
} 
two storytellers, one using the Rapanui language and one speaking in Spanish. The use of both languages created an interesting intercultural collaboration. The narration in the Rapanui language resonated with and reflected the Rapa Nui pace of living, calm and slow; whereas the Spanish version was faster, with different intonations and tones of voice. The narration of the storytellers was further supported by songs which highlighted the action the performers were mimicking, and providing another storytelling element to this performance.

\subsubsection{The Influence of Shakespeare in Māori and Samoan Theatre in Aotearoa}

Different plays by Shakespeare have featured in the repertoire of Māori and Samoan theatre in Aotearoa. Romeo and Juliet, The Tempest, The Merchant of Venice, Troilus and Cressida, Othello and Hamlet have found their Māori and/or Samoan version in the twenty and twenty-first century. The "retelling" (Hyland, 2011, p. 97) of these plays within Māori and a Samoan cultural and linguistic contexts draws from the "desire to settle with Shakespeare on specific and highly localised terms" (Houlahan, 2009, p. 280).

Shakespeare's plays actively arrived to Aotearoa in the late 1840s (Houlahan, 2009, p. 280). Between the 1850s and the 1860s, New Zealand as a British colony built "Theatres Royal... in the most prosperous new towns" (Houlahan, 2009, p. 280) around the country which were visited by touring theatre groups performing Shakespeare. For the settlers reading and performing Shakespeare was seen as a "crucial part of preserving that British heritage" (Houlahan, 2009, p. 280). In Sāmoa, performances of Shakespeare's plays can be traced back to 1928 (Hereniko, 1990, p. 75), or earlier if we take into consideration that a copy of the Complete Works sailed in 1769 on Captain Cook's Endeavour to the South Pacific (Houlahan, 2002, p. 170). Therefore, the South Pacific has been “inescapably Shakespearized” (Houlahan, 2002, p. 170) for the last two hundred years.

Shakespeare is understood as 'traditional' theatre not only in the English-speaking world, but I would suggest that in the Spanish-speaking world as well. Although Shakespeare's work may be considered as examples of the "Western dramatic canon" (Hyland, 2011, p. $100)$, the retelling of these plays by Indigenous practitioners "have become some of the most provocative and popular forms of cross-cultural theatre" (Hyland, 2011, p. 100). Indigenous adaptations of plays written by Shakespeare can be seen as canonical counter- 
discourses that seek to "deconstruct significations of authority and power exercised in the canonical text... to intervene in social conditioning" (Gilbert \& Tompkins, 1996, p. 16). Canonical counter-discourses not only show how 'the other' is represented in Shakespeare's plays, but that they also make Shakespeare relevant for Indigenous communities.

Shakespeare's work has been often performed in a contemporary style keeping it relevant for younger generations. One of the most effective ways of maintaining Shakespeare's presence in contemporary life and relevant to younger generations has been through translations. Hulbert, Wetmore and York (2006) explain that the notion of "translation" not only refer to the linguistic translation of a text from one language to another. It also means to translate Shakespeare's syntax and wording into the way youth speaks today. Thus the 'traditional' language used by Shakespeare does not become a barrier, but relates to 'contemporary' forms of expression. Other strategies are "reduction" where main aspects or scenes of a play are taken to be studied of performed, and "reference" when Shakespeare's play are directly or indirectly referenced in the new performance (Hulbert, Wetmore, \& York, 2006, pp. 3-4).

These strategies are directly linked to how Shakespeare's texts have been represented by Māori and Samoan theatre groups in Aotearoa. The Māori version of Shakespeare's Troilus and Cressida is a notable example of creative collaboration between cultures, which can be framed under 'translation'. This play opened at Shakespeare's Globe Theatre in London in 2012. The troupe Ngakau Toa was invited to perform this play in Te Reo Māori during "the Globe to Globe event in which 37 countries would perform 37 of Shakespeare's play in 37 languages" (Smithies, 2013). In an interview conducted by Grant Smithies, Māori actor Rawiri Paretene explains that Ngakau Toa used physical theatre as well as kapa haka in order to highlight the subtexts during the play. The entire play was translated into the Māori language, and into the pre-colonial Māori context (Waka Huia TVNZ, 2012). This translation blended all three aspects of theatre in the creation of this performance: text, style, and culture. However distant Shakespeare's work may seem from the Māori culture, Paretene states Shakespeare as a primary inspiration, stating that he is "the reason I chose to be in this acting game" (Smithies, 2013). 
When Pacific Underground created Romeo and Tusi, they translated the 'traditional' and formal Shakespearean language into a colloquial and 'contemporary' language accessible to diverse audiences. In addition, the play was based on the main scenes and topics found in Romeo and Juliet, making direct reference to the text in scenes where the characters rehearsed Shakespeare's play for the school production. It seems that Shakespeare's texts appeal to Māori and Samoan theatre practitioners, because sentences are structured in a very similar way in which the traditional Māori and Samoan language are spoken (Byrnes, 1999, p. 48). This linguistic proximity may help Māori and Samoan theatre practitioners to understand and relate to Shakespeare's texts from a cultural perspective.

\subsection{Conclusion}

Through the analysis of different plays this chapter illustrates the historical development of Māori, Samoan diasporic and Rapanui theatre. Theatre has become a forum for Māori and Samoan theatre practitioners in Aotearoa to express and expose different issues from their points of view. Through community theatre Māori and Samoan theatre practitioners were empowered to determine what, how and where to share their stories with the wider community. Theatre is seen not only as an art form but also as a political and educational tool.

Through theatre Māori, Samoan diasporic and Rapanui theatre practitioners have explored their identity creating a distinct theatre practice by integrating in a varied ways different cultural elements, 'traditional', 'contemporary', popular and European. The plays discussed in this chapter are clear examples of how performative elements that are considered to be 'traditional' have been integrated into the dramaturgy of contemporary Māori, Samoan and Rapanui plays. The integration of old and new elements have combined created new theatre 'traditions' from which to create something new in the future.

Theatre education and training have been significant to the development of Indigenous theatre in Aotearoa. Many young Māori and Samoan theatre practitioners have studied theatre or performing arts at different institutions such as Toi Whakaari, Pacific Institute of Performing Arts (PIPA) or Whitireia. In the early stages in the development of Māori 
theatre, a significant intercultural collaboration took place, allowing Māori theatre practitioners to learn a range of community theatre pedagogies and techniques.

From my own experience as an actress and educator, through conducting theatre workshops in different Rapanui schools and the local Museum, I suggest that the notion of self-determination could help Rapanui theatre practitioners to openly determine what and how they want Rapanui performances and theatre to look like, without any pressure from the tourist market or from any other Authority. The availability of theatre training in Rapa Nui could also make a significant contribution to the Rapanui performing arts in the future.The next chapter discusses the different approaches and perspectives of theatre training in Aotearoa and Rapa Nui. 


\title{
Chapter Five
}

\section{Theatre Training in Aotearoa and Rapa Nui}

\author{
Pehe Ana Hapi ki Hakararama i te $\mathrm{A}^{6} \mathrm{amu}^{93}$
}

\author{
Tugar Tugar... Salir a Jugar ${ }^{94}$
}

\subsection{Introduction}

The previous chapter discussed how historical developments and influences have impacted upon the possibilities for the creation and performance of Māori, Samoan diasporic and Rapanui theatre. Training, whether formal or informal, has been central to developing the craft of theatre, and how 'traditional' cultural elements are combined in 'contemporary' works in these different contexts. Therefore this research now analyses the practice of theatre by exploring theatre training in Chile as well as in Rapa Nui and Aotearoa. The term theatre training refers to all aspects involved in the production of a theatre production: from devising or writing a play, acting and rehearsing, creating props and costumes, to production week, and opening night. This process of creating a new show can be learnt, either at a tertiary institution or by collaborating with a theatre company.

This chapter is divided into three parts. The first part, Theatre Training at a Tertiary Institution, will discuss the different methodologies applied in the teaching of theatre in

\footnotetext{
${ }^{93}$ How to learn to tell a story

${ }^{94}$ Tugar tugar... start playing. This saying emphasises action, and that it is time to do, no more theory but practice.
} 
Chile and Aotearoa. I include a discussion of Chile because in Rapa Nui there is no formal theatre or performing arts training, so going to Chile is the main option for a Rapanui person who seeks to continue studies, in terms of language, proximity, and financial opportunities. The variety of institutions that are teaching theatre or the performing arts in Chile and Aotearoa is quite large. In the case of Chile, I will briefly describe the state of theatre training, and discuss the main methodologies used in the teaching of theatre at tertiary institutions in the capital city, Santiago. In Aotearoa, I am particularly interested in courses that look at inter or cross-cultural methodologies; for example at Toi Whakaari: New Zealand Drama School, Pacific Institute of Performing Arts (PIPA), Whitireia Community Polytechnic, and the Bicultural Theatre course offered at the University of Otago.

Learning the craft of theatre can also be done outside of these formal learning environments, for example within a theatre company and in collaboration with communities. The second part of this chapter considers theatre training outside tertiary institutions and focuses on the methodologies used in the teaching of theatre in informal educational contexts. This chapter will explore the teaching style and methodologies of the Rapanui company Mata Tu'u Hotu Iti, the Māori company Te Rakau Hua O Te Wao Tapu, and the Samoan company Pacific Underground as examples of informal, collaborative and community based theatre learning environments. The third section of this chapter explores writers' training- another aspect of theatre training that has proven to be crucial in the development of Māori and Samoan diasporic theatre. The ability to create, develop and write theatre can generate future work; therefore, it is important to consider this aspect of theatre, as a part of theatre training.

This chapter proposes a comparative analysis of the different methodologies and approaches to the learning of theatre. It aims to shed light on theatre training and to consider the possibilities that learning and integrating different methodologies from different cultures may provide the theatre practitioner. 


\subsection{Theatre Training at different Tertiary Institutions in Chile and Aotearoa}

In Western countries, formal theatre training in tertiary institutions has tended to be dominated by methods and methodologies used by European actors and directors. This section will begin by introducing some key names in theatre education curricula, before moving on to a consideration of more contemporary and contextualized influences and collaborations in theatre training in Chile and Aotearoa. The Russian actor Konstantin Stanislavski is a practitioner whose work is often a key component of theatre education programs. Stanislavski spent much of his life experimenting with exercises developing a series of methods that would enable the actor to create a character (O'Brien, 2013, p. viii). Using a series of questions about the character's background and purpose in the play is a tool which Stanislavski developed to help actors to unpack and understand their character's behaviour. In the United States, theatre practitioner Lee Strasberg developed the American Method (Carnicke, 2009, p. 4) promoting some of Stanislavski's core ideas of psychological realism throughout the Western world. ${ }^{95}$ The Polish theatre director Jerzy Grotowski created a more physical method of character development. Grotowski's methods emphasizes the notion that "everything must come from and through the body" (Grotowski, 2002, p. 204). The crucial aspects that will define a character are the "physical reaction" (Grotowski, 2002, p. 204) that he or she has to a specific situation. Building on Grotowski's ideas, the Hungarian dance artist Rudolf Laban experimented with the "dynamics of movement in space and time" (Evans, 2015, p. 91), and the French actor Jacques Lecoq developed a training method based on movement and gesture which draws from "various styles of pantomime to commedia de'll arte and the Roman mimus" (Bradby, 2006, p. xii).

However, from a Polynesian cultural perspective, these names hold little currency, and these techniques and practices may not necessarily resonate. In response to this cultural disconnect, artists in Aotearoa have developed and applied culturally appropriate methodologies that are currently used alongside/in addition to Western methods in the different tertiary institutions which provide theatre training. The inclusion of culturallysituated practices such as Marae rituals and "Pasifika Flavor" (Pacific Institute

\footnotetext{
${ }^{95}$ Later in his career Stanislavski abandoned the focus on physiological realism and worked on physical actions (Merlin, 2004, p. 29). However his psychological realist work has been most influential on drama school training.
} 
Performing Arts, 2010) that represents the identity and cultural background of Pacific Island peoples in Aotearoa, has contributed to the integration of 'traditional' cultural elements within 'contemporary' theatre productions. Theatre training in Chile is Eurocentric, and although Chile is a multicultural country (Riedemann Fuentes, 2008, p. 173), Indigenous world views are not reflected through cultural practices and pedagogies in the theatre training provided by tertiary institutions. After discussing these institutions, this chapter offers some interesting ideas about the inclusion of Indigenous cultural practices in theatre training that may benefit Chilean tertiary institutions.

In addition, I will be looking at Toi Whakaari, the Pacific Institute of Performing Arts, Whitireia, and teachings about Bicultural Theatre processes in the Theatre Department at Otago University which have all been facilitating theatre training based on intercultural practices and epistemologies to create a unique theatrical teaching and learning experience in Aotearoa.

\subsubsection{Theatre Training in Tertiary Institutions in Chile}

The history of theatre in Chile begins with the arrival of Catholic missionaries to the country during the colonial period. The missionaries introduced the "autosacramentales (one-act religious plays)" (Hurtado, 2000, p. 150) as a way to 'educate' the population on ethical and moral issues. In the early nineteenth century, leaders campaigning for Chile's independence used theatre as a way of expanding and circulating their ideological messages. By the late nineteenth century, the topics covered in plays ceased to be about overtly political ideologies, and there was greater space for stories representing local customs to be performed (Pradenas, 2006, p. 201). Theatre, which until then was produced by Spanish and Italian travelling companies, became a popular show, and comedies which were performed to audiences in outdoor settings became increasingly popular (Hurtado, 2000, p. 150). Until then, acting and performing was not recognized as a profession or a cultural activity.

The First World War stopped the flow of European theatre companies travelling to Latin America and to Chile. This meant that Chilean writers and actors were forced to produce theatre pieces to meet public demand. They began to present plays called costumbristas depicting local customs which were highly influenced by the style of Spanish theatre of 
the nineteenth century. During the twentieth century, European artists fled to Chile due to the Spanish Civil War and/or the Second World War, influencing the theatrical production in Chile (Hurtado, 2000, p. 150).

In the 1940s Chilean theatre practitioner Pedro de la Barra formed the Teatro Experiemental which later became the Escuela de Teatro (Theatre School) of the University of Chile in 1947 (Pradenas, 2006, p. 293). Similarly Chilean theatre practitioner Pedro Mortheiru founded the Teatro de Ensayo which then became the Academia de Teatro (Theatre Academy) of the Catholic University in 1947 (Pradenas, 2006, p. 295). The main purpose for both groups was:

to experiment theatrically with visual images and languages, to follow modern trends in design, to found new professional companies in Chile, to systematically study new performance trends, and to educate theatre professionals at the universities (Hurtado, 2000, p. 150).

With the establishment of these theatre schools in Chile, theatre underwent a process of “academic institutionalization” (Pradenas, 2006, p. 299) especially in the capital city, Santiago. Under this same concept, other theatre schools were created in other regions of Chile. In the 1960s in the cities of Antofagasta, Valparaiso, Concepcion and Valdivia, theatre groups were created under the guidance of the University of Chile (Hurtado, 2000, p. 165), however several of these groups closed by 1990s due to lack of resources.

The Catholic University and the University of Chile offer Degrees in Acting. University of Chile also offers a Degree in Theatre Design, and since 1990 the Catholic University offers a post-graduate Degree in Directing. The Degree in Acting at both institutions lasts about four years. During this time the students go through four main lines of study; acting, voice, movement and dance, history and cultural theory (Hurtado, 2000, p. 165). Since 1983, a variety of private theatre schools have also been established in Santiago. These schools are run by academics who used to work at the two University theatre schools (Hurtado, 2000, p. 165). Among the most renowned of these are Club de Teatro (Theatre Club) directed by Fernando Gonzalez, the Escuela de Teatro Imagen (Image Theatre School) directed by Gustavo Meza, Teatro la Casa (House Theatre) directed by Fernando Cuadra, and Teatro Camino (Road Theatre) directed by Hector Noguera. 
For a Rapanui who wishes to study performing arts, the main option is to go to Chile. Since the establishment of these theatre schools, only two Rapanui have studied theatre. Ana Maria Atan Retamales graduated in 2002 from Club de Teatro and Vai Tiare Merino Rapu studied for one semester at Universidad Católica in 2004. Both Atan Retamales and Merino Rapu subsequently pursued further studies in other areas, law and translation respectively, because the possibilities of earning a living as an actress in Rapa Nui are scant (Merino Rapu, 2014).

Theatre training in these institutions is mostly based on the work of European theatre practitioners. According to Peirano, European theatre practitioners who have had significant influence on contemporary Latin American theatre include Bertolt Brecht, Jerzy Grotowski, Eugenio Barba, Stanislavski, Brook and Artaud (Peirano, 1988, pp. 6667). The methodologies and theories developed by these European theatre practitioners have been a great influence on theatre training not only in Chile, but throughout Latin America. The writings of Barba, who trained with Grotowski, have been translated into Spanish and have facilitated the transmission of his research and methodologies around the continent (Watson, 2002, p. 171). According to Alexei Vergara, Head of Theatre School at Catholic University, the introduction of foreign theories and methodologies to Chile was not only possible through the visit of different theatre companies like Barba's, but also through Chileans who travelled to Europe to study theatre, bringing this new information back to Chile. For example, Ramon Nuñez professor of acting at Catholic University, studied at the Drama Centre in London between 1969 and 1971. Nuñez used as a fundamental part of his acting classes the Stanislavski method, especially regarding the creation of characters (Vergara, 2014).

In Chile, European theories and methodologies have been most influential regarding theatre training. By law, Chile is a multicultural country since 1993 (Riedemann Fuentes, 2008, p. 173). However, in terms of theatre training, this multiculturalism currently exists more in theory than in practice. Of the seven Indigenous cultures that comprise Chile, none has been considered as part of a theatre training methodology in any institution. Intercultural theatre training in Chile is focused mainly on European and Western methods and cultures. The intercultural relationship between Chile and its Indigenous peoples is scant and institutions do not yet consider it necessary to include Indigenous practitioners who could teach Indigenous methodologies as part of the curriculum in 
tertiary institutions, reflecting ongoing colonial relationship between the state and the Indigenous nations.

\subsubsection{Te Kura Toi Whakaari: New Zealand Drama School}

Te Kura Toi Whakaari: New Zealand Drama School (Toi Whakaari) was founded in 1970, in its first year the school was made up of nine students and five staff members, compared to the 140 students and twenty staff members the school had in 2008 (Guest, 2010). After Nola Millar, its first director, the theatre practitioners who have been in the director's position over Toi Whakaari's history, contributed towards building “a school that is truly of this place, Aotearoa New Zealand" (Ruth, 2010, p. vii).

Toi Whakaari has had a long commitment to integrating Māori and New Zealand cultures in their curriculum, aiming to provide an intercultural learning experience for their students. The integration process began in earnest with the departure of George Webby as the Director of the school. Under Webby's leadership the school had been a "very 'Europeanised' institution, despite having Māori and Polynesian graduates" (Guest, 2010, p. 115). With the arrival of Andrew Noble as the new Head of School between 1988 and 1989, and as the intake of Māori students reached 50\% in 1998 (Guest, 2010, p. 116), the School started to "explore a more bicultural way of working" (Toi Whakaari: NZ Drama School, 2011a). Noble brought experience of teaching in a variety of multicultural settings including Miami, USA, a city with a large Hispanic population, and he prompted new challenges and ideas at Toi Whakaari. His aim was to provide educational experience that would "allow the students to learn about acting within New Zealand, rather than a European context" (Guest, 2010, p. 117). Under Noble's leadership the school started taking serious steps towards biculturalism. Rona Bailey was a member of the School's Trust Board who worked on clarifying the concept of biculturalism and its relationships to the Treaty of Waitangi. In 1989 Bailey explained that "biculturalism is based on the Treaty of Waitangi and that this contains an invitation for Pākehā to share [Aotearoa] with Māori in equal partnership” (Guest, 2010, p. 125). This definition prompted the appointment of two Māori elders as members of the Trust Board, Puoho Katene and Thelma Keepa Grabmaier, helping to ensure that the needs of Māori students were met. 
The process of becoming a bicultural theatre school was completed by appointing Christian Penny, a Māori theatre director, as the new Head of School in 2011. Former director Annie Ruth stated that the appointment of Penny clearly demonstrated "the direction in which the School [was] going” (Toi Whakaari: NZ Drama School, 2011b).

In 1989 Toi Whakaari took a step of embracing Tikanga Māori (Māori process) as an essential element in the life of the School. Over the following years the School has built, step by step, on this commitment, consistently looking for processes and structures in which we can recognise a uniquely New Zealand drama school (Penny, 2014, p. 2).

The purpose of embracing tikanga Māori as an active element in the learning process at the School was to develop more dynamic theatre practices and practitioners by looking at the world not only through a New Zealand lens, but also through a Māori point of view (Ruth, 2010, p. vi), therefore acknowledging the Treaty of Waitangi as signed by both cultures. The practice of biculturalism at this educational institution helped in the development of a sense of community, a theatre communitas connecting all participants involved. The School hoped to develop students not only as actors, but as people with "a new cultural outlook and identity" contributing to "renew[ing] a sense of nation" (Richards, 2006, p. 111) that was culturally respectful and inclusive.

For Pākehā, Māori, and Pacific Island students involved in the creative process at Toi Whakaari, learning about another culture may have given them "new or additional exposure to traditional performance forms, alongside the particular mix training in Western theatre taught in that year" (Richards, 2006, p. 110), benefiting from a range of intercultural experiences.

They experienced Māori performance forms, participated in lectures and workshops focusing on Māori language and culture, and have met, been taught by and/or studied with many of the leading figures in Māori theatre (Richards, 2006, p. 110).

Biculturalism in a theatre school context gives the opportunity for intercultural encounters to occur by "applying the fundamentals of dialogue" (Byrnes, 1999, p. 50). Students were encouraged to develop the "capacity to listen another point of view, appreciating both its strengths and weaknesses before appraising it" (Webby, 2006, p. 
219). This approach provides the possibility of understanding and appreciating not only the 'new' culture, but involved a process of reflecting on your own heritage as well.

Theatre training is an exercise that requires connection to both the self and others (Byrnes, 1999, p. 49). At Toi Whakaari, theatre training is guided by "three pou (strands)" (Penny, 2014, p. 2); craft, learning, and rongo (listening). These pillars are firmly based on "Māori frameworks and approaches" (Toi Whakaari: NZ Drama School, 2014 , p. 3), providing the students not only with the skills necessary to work in the theatre industry but also with the capacity of dialoguing within cultures, thus enriching partnerships and collaborations.

Theatre training at Toi Whakaari is divided into five main sets of skills;

- Voice: voice, speech, singing

- Movement: general movement, mime, physical theatre

- Acting: improvisation, text analysis, acting methodology or technique

- Performance for Camera: history of film, multi camera, studio technique, single camera, film performance, comedy for TV, camera audition technique

- Cultural and Theoretical Studies: History, Theory and Philosophy of Theatre, Taha Māori, world philosophies, survival skills, and professional discipline (Byrnes, 1999, p. 47).

Here, at least two cultural and conceptual worlds collide and dialogue with one another, creating a unique theatre training experience. In the process of teaching these five skill sets, a mixture of European theatre techniques developed and taught by Lecoq, Laban (Tweddle, 2007), Grotowski (Guest, 2010, p. 159), as well as Stanislavski, and forms of physical and community theatre (Richards, 2006, p. 101) are a part of Toi Whakaari theatre training. These different methods and approaches are combined with approaches and methodologies situated in Māori epistemologies. This was achieved initially by introducing a bilingual vocabulary in the educational system, where the Māori language and consequentially the concepts and worldviews embedded in that language is taught alongside the English language. The School's Prospectus clearly includes Māori concepts when outlining the Bachelor of Performing Arts degree. Māori concepts of turanga (difference), raranga (collaboration), and waewae (moving forward) are core conceptual notions that guide the student's work during the first, second, and third year respectively 
(Toi Whakaari: NZ Drama School, 2014, p. 6). Māori cultural practices such as kapa haka (dance), waiata (action song), karanga (ceremonial call of welcome to visitors), and taiaha (fighting staffs) have also been part of the learning process at Toi Whakaari (Richards, 2006, pp. 105-106).

In recent years Toi Whakaari has changed its curriculum, for example, by adding the notion of Kōiwi. Based in Tikanga Marae, Kōiwi is the School's weekly meeting place where the students and staff work together in collaboration across disciplines (Toi Whakaari: NZ Drama School, 2011). Kōiwi was developed within the school initially to discuss bi-culturalism and to question differences associated with this term. Kōiwi which literally translates as "community" or "bones" (Toi Whakaari: NZ Drama School, 2011) is a place where processes, skills, research, learning experiences and practices can be tested, applied and challenged, with other members of the school community. This methodology promotes among its participants awareness of different ways of knowing and being in theatre practice. Each session focuses on a different topic which can be explored, democratically, by a wide variety of different lenses and experiences, based on the participant's points of view (Toi Whakaari: NZ Drama School, 2011). This method shows a way in which Indigenous theatre practitioners in Aotearoa integrate different 'traditional' cultural elements not only in the creation of contemporary work, but also in theatre education, enabling them to test the creative process within an Indigenous framework.

The main aspect of Māori culture that has been included in theatre training at Toi Whakaari is the integration of rituals performed at a marae as part of the culture of the School itself. As discussed in Chapter Four, marae rituals were first introduced as part of theatre practice by Jim Moriarty and Rangimoana Taylor outside of a tertiary training context, and have had a "significant effect on theatrical performance within the New Zealand context" (Ruth, 2013, p. 69). The marae is the space where a formal encounter between people and the ancestors occurs which include many different elements. It begins with a pōwhiri, which is a formal welcome to the visiting group or person, and ends with a poroporoaki, a formal farewell (Ruth, 2013, p. 69). The pōwhiri itself has structured elements which mark the different stages of the welcoming ceremony. It opens with the karanga, which is followed the whaikōrero (speech), and the ritual finishes with the hākari, sharing a meal or feast (Ruth, 2013, p. 73) to solidify the connection and relationship between people who were previously strangers to one another. These 
elements have been used to frame not only rehearsals, but the pōwhiri has also been included in Toi Whakaari's theatre processes through active collaborations with Māori elders, seeking the expertise, advice, and support of a "kaumatua and kai karanga - male and female elders with the requisite tribal and spiritual standing to authorize the school's ritual activities" (Richards, 2006, p. 106).

One example of these collaborations being validated by representatives from Māori communities is the production of Pakiwaitara (2008) which was devised by Jade Erikson and Teina Moetara. This performance reflected the structure of the pōwhiri, opening with a song at the beginning of the performance that functioned to call the audience "into the space" (Ruth, 2013, p. 112). This performance referenced the use of the karanga at a marae as a way of opening a relationship between people, but contextualized, "adapted and focused on the situation and place of the performance" (Ruth, 2013, p. 112).

The notion of whaikōrero has also been applied to theatre training at Toi Whakaari. The whaikōrero, the formal speech, the art of oratory in the Māori world view, demonstrates a "mastery of language, rhetoric and dramatic presentation" (University of Otago, 2010). Understanding this concept may help students to integrate and perform a character that has a "convoluted, seemingly alienating text, that reeked of 'the Other"' (Byrnes, 1999, p. 47). In 1998 Vanessa Byrnes, a former acting teacher at Toi Whakaari, rehearsed a scene between Hamlet and Ophelia with two first year students of Māori and Samoan heritage. The methodology she used to overcome the student's reticence to performing in Shakespeare's English language was varied. Firstly, they experimented with theatre techniques based on European traditions such as "physical ways of telling the story, experimenting with gesture, action, textual methodology and combat metaphor work that aimed to be non-culture-specific" (Byrnes, 1999, p. 48). Byrnes explains that processes that explored the use of language were a way of "opening up the emotional resonance between the two actors" by creating a "dialogue, or meeting, between the actor and Shakespeare's text” (Byrnes, 1999, p. 48):

We paraphrased the scene firstly into a general English language rendition, then into each actor's individual colloquial speech or street parlance, then parts of the text into Samoan or Māori. What we discovered was that Shakespeare's language employs metaphor and syntax in a very similar way to traditional Samoan and Māori (Byrnes, 1999, p. 48). 
This example shows not only how the notion of a 'traditional' cultural element, such as the whaikōrero, may improve the understanding of a character, their culture and worldview. It also shows how an intercultural approach to theatre training enables students to use and "discover their own cultural or historical frames of reference to the situation" (Byrnes, 1999, p. 48) applying their own worldview and language to understanding characters.

Another Māori cultural element that has been used in theatre training is the karakia. A karakia is a "formula of words which was chanted to obtain benefit or avert trouble" (Buck, 1950, p. 489). A production of Troilus \& Cressida (2003) was directed by Annie Ruth at Toi Whakaari, who worked alongside kaumatua Rangimoana Taylor. During the rehearsal process, a karakia was used to begin the work. In the case of the rehearsal, the karakia could take different forms which contained more or less overt symbolism and structure. For example the karakia consisted of elements including a

movement sequence that Rangimoana developed to reflect the Māori cosmos, sometimes a call on the elements from pre-European karakia, sometimes just some thoughts offered by one of the cast (Ruth, 2013, p. 125).

Again, this Māori cultural element was adapted into the theatre training context, providing a more meaningful experience for its participants. Ruth states that the "karakia brings an acknowledgement of purpose in the wider world and sets up an expectation that performance, role and listening all have weight" (Ruth, 2013, p. 113). Karakia prepares the environment and everybody that is involved in the rehearsal of the play, in the theatre training, to work.

The hui (gathering) is another Māori cultural element that has been incorporated into the theatre training at Toi Whakaari. In Māori culture the purpose of a hui may vary from meeting to explore "contentious issues around land settlements or political issues, to celebrations, to tangi to mourn the dead" (Ruth, 2013, p. 69). The timing of the hui depends on the needs of the gathering and the people involved, and may last "a day, three days, a week - whatever is needed to address the purpose" (Ruth, 2013, p. 69) of the meeting. The incorporation of the hui within theatre training focuses on creating a space in which to address any issues arising during the rehearsal and production of the play. A hui creates a equal and democratic space where issues about decisions made regarding the play can openly be discussed by all members involved "from the actors in lead roles 
to the assistant lighting operator" (Ruth, 2013, p. 228). In Troilus \& Cressida the hui helped performers to reach a group agreement about Shakespeare's play that is reminiscent of the relationship between Māori and European after the Treaty of Waitangi in 1840, because the play was set in the time when early British settlers and Māori peoples were in conflict over ownership of land (Ruth, 2013, p. 118).

During the production of Marat/Sade (2010) directed by Ruth, a hui was called when "not all collaborators [were] happy with the choices made, where a sense of purpose [was] lacking or unclear" (Ruth, 2013, p. 228). It allowed people involved to voice concerns about scenes which were "followed by experimentation on the floor" (Ruth, 2013, p. 233) until an agreement about the purpose of the scene in question and/or the play were reached by cast and crew working together. The hui highlights the collaborative aspect of theatre training, where decisions are reached not by the director alone, but through dialogue with the entire group involved in the process.

Theatre training becomes locally relevant and culturally pertinent because of the use of cultural elements which not only Māori students can identify with, but also due to the overarching atmosphere of cultural safety that has been created at Toi Whakaari, Pacific Island students seem also to be able to relate to these methodologies and pedagogies. The inclusion of Māori rituals in some of the plays produced as part of the theatre learning experience at Toi Whakaari, teach students to adapt and integrate cultural elements that are considered 'traditional' within their contemporary work. The incorporation of Māori cultural elements has become the 'traditional' way in which Toi Whakaari teaches theatre in Aotearoa.

It seems likely that Toi Whakaari will continue to adapt and incorporate different cultural elements, whether European, New Zealand and/or Māori world views, into the theatre training it offers. The school's staff are bicultural. In fact, some of its former students subsequently became tutors and have been invited to direct a play for one of the acting levels. This is the case for Toi Whakaari graduates Fiona Samuel, Rangimoana Taylor, Karl Kite Rangi, Miranda Harcourt, Hone Kouka, Jane Waddell, Rawiri Paratene, David O’Donnell, and Sally Richards (Guest, 2010). The intercultural background of these tutors shows the privilege students have to learn a collaborative art form by collaborating with tutors from other cultures in a theatre production. 
Toi Whakaari has worked steadily on the inclusion of Māori cultural elements in the teaching and practice of theatre. This inclusion has not only facilitated an enhanced experience of teaching and learning experience for staff and students at Toi Whakaari, but has also managed to create a dialogue between cultures. Through the use of culturally-situated theatre pedagogy and process, an intercultural dialogue occurs on a daily basis.

The incorporation of tikanga Māori, Māori values and practices, as part of the teaching methodologies used in theatre training at Toi Whakaari succeeds in creating an enhanced sense of belonging to one another. Toi Whakaari's students gain a local and site-specific perspective of their environment through approaches to theatre education which are respectful and inclusive of Māori ways of knowledge and being. Through the inclusion of Māori cultural elements such as the karanga, karakia and hui, students gain a unique perspective from which to do theatre, as well as bringing Māori students closer to the theatre learning experience. All students benefit from the fact that different epistemologies are able not only to co-exist and to be accorded equal space and respect in terms of practice and pedagogy, but these different knowledge forms and worldviews are also able to engage in ongoing, meaningful dialogue with one another.

\subsubsection{Pacific Institute for Performing Arts (PIPA) and Whitireia}

Performing arts has helped Pacific Islanders to express their beliefs and socio-cultural identities "helping them situate themselves in relation to one another and the wider universe" (UNESCO, 2002, p. 11), becoming an active agent in the construction of Pacific Island societies (UNESCO, 2002, p. 11). Performing arts, whether "religious, artistic, educational or... commercial" have a social function, which is "to unite people in a shared experience" (Nichols, 1956, p. 179). The inclusion of culturally diverse performing arts within the learning environment enables students to broaden their world views allowing them to understand and respond to people of another culture in a more inclusive way (Black, 1999, pp. 332-333).

The Pacific Institute for Performing Arts (PIPA) and Whitireia mostly, though not exclusively, attract Pacific Island and Māori students. Both institutions have different perspectives on the teaching and purpose of theatre training. The performing arts programmes at both institutions offer curriculum foundation courses which serves as a 
bridge for students in the final year of high school to gain the requirements to continue higher education. PIPA offers a Certificate in Screen and Performing Arts. This course is specifically designed for students between " 16 to 17 years old who want to keep learning” (Pacific Institute Performing Arts, 2014, p. 14), and seeks to include students "who are not sure of which direction they wish to pursue" (Pacific Institute Performing Arts, 2014, p. 2). Whitireia offers a comparable Certificate in Work Skills, which targets students that "although having the capacities and passion for performing arts, they don't have the confidence to pursue higher education" (Te Ua, 2015). Both institutions use theatre training and the creative arts as a way to foster a sense of purpose in students who otherwise would not continue with higher education. Through the performing arts, these institutions provide the student with confidence, self-esteem and discipline to pursue further studies.

\subsubsection{Pacific Institute for Performing Arts (PIPA)}

Established in 2003, PIPA is one of the six schools that are a part of the BEST Pacific Institute of Education (NZQA New Zealand Qualifications Authority, 2015, p. 5). Olivia Taouma was the Head of Dance at PIPA in 2010; she explained that the reason for setting up PIPA was that

there was no place for a lot of students who were at high school doing Polyfest ${ }^{96}$, Bring It $\mathrm{On}^{97} \ldots$ and then where did they go to... all this dance, acting and talent... (Pacific Beat St, 2010).

Taouma explains that the main purpose was to create "a school that studied Pacific Studies, Pacific music, Pacific dance... as well as Western forms of acting and dance" (Pacific Beat St, 2010). PIPA aimed to combine "contemporary teaching practice with a genuine Pasifika flavour” (Pacific Institute Performing Arts, 2010).

During my fieldwork in early October 2014, I visited PIPA and had the opportunity to observe rehearsals for the foundation course. The course was directed by Samoan theatre practitioner Anapela Polataivao. As a teacher she makes all her experience as a graduate

\footnotetext{
${ }^{96}$ Secondary Schools Māori and Pacific Islands Cultural Festival

${ }^{97}$ Bring It On is a Secondary Schools dance competition which started in 2003 in Auckland. It is mostly focused on Hip Hop dancing though can also include other dance styles and genres (Bring It On Auckland, 2012).
} 
from Toi Whakaari and as the co-founder of Kila Kokonut Krew available to her students, guiding them in the collective creation of a play. During class it was decided that the students would prepare a children's play to be performed at the end of the month. The first task for the students was to create a story roughly based on a legend from the Pacific. Once the story was ready the next step was to divide the group of students into small groups. Each group had to do a presentation about how they would produce the play. In this presentation the students were encouraged to consider elements including costumes, characters, props, lights, music, length, message, and the style of the play. Polataivao explained that the idea of making this presentation was to enable students to

know and learn from the beginning of the process everything that is entailed in the production of a play, which is not only acting, but to consider everything from the costumes to how long the play will be (Polataivao, 2014).

This style of theatre training is very much about learning through experience. PIPA tutors' focus is to provide students with skills that can potentially become the basis for future employment. Taouma explains that "in 2009 from 14 students 11 got jobs in the industry" (Pacific Beat St, 2010). Therefore one of the purposes of this foundation course is to learn how to fully create a play "from scratch to opening night" (Polataivao, 2014).

Vela Manusaute, a Toi Whakaari graduate and member of Kila Kokonut Krew, also works at PIPA as a tutor. During various rehearsals Manusaute guides the work, collaborating and offering students ideas to make the work progress. For Manusaute the first thing to be established in the production of a play is:

how are we going to tell this story... this 'how' should be included in the dramaturgy of the play, because it is through the 'how' that we are going to transmit message of the play, therefore it must not be arbitrary (Manusaute, 2014).

The methodology used in the in the process of creating the play The Journey of Queen Pele and Her Daughter Hina answers the research questions which focuses on how Indigenous theatre practitioners in Aotearoa have integrated different 'traditional' cultural elements with European theatre techniques in their contemporary work. Firstly, the group decided that the play would have music and dance. Now that the 'how' was clear, those elements had to be created to serve the purpose of the play. By trying 
different tunes and movements out, the group decided that the most suitable tune for the play was the melody of Latin American song La Bamba. The song was adapted to the representation in terms of rhythm and lyrics, and awarded to specific characters, so that every time these characters appeared on stage the music started to play. The foundation course, as Taouma explained, encourages students to "tell their stories in any way that they can express" (Pacific Beat St, 2010), using "all the tools available" (Polataivao, 2014). This is a common creative strategy in popular music in the contemporary Pacific, with popular tunes being used as the base for new creations often featuring lyrics in Pacific languages that explore Pacific-centred themes. This example illustrates the same process of creative adaptation brought to theatre practice.

With all these decisions made, rehearsal started. Polataivao used the Western technique of dividing the story into scenes, giving each a title summarizing the main action to be executed during each scene. The structure of the play and the action that will take place within each scene are ready; however the texts, that is what each character is going to say and when, have to be created by the students. Through a series of improvisations of the different scenes, ideas for the texts were tried out. During this process, Polataivao wrote down what was being said by the students on stage. In this way the creation of the text was organic and spontaneous, decisions about what to include were based on the reactions of the students towards different characters and the actions portrayed in the play. A rap appeared spontaneously when one of the students struggled with one of the texts that had been created. By giving the text a rhythm the student was able to 'sing' the text giving new dimensions to her character.

The texts and movements that worked on stage were blocked, and became part of the play. When one scene was blocked it was rehearsed and repeated from the beginning, adding at the end another scene in the process of creation. This process continues until the entire play has been put on stage. The idea of having to learn a long text by heart is almost non-existent, because the text is being created by the students in the doing, their personalities as performers are engraved on the action and the physicality of the scene. This methodology used in the production of this play seems quite straight forward. In two days the whole structure of the play was complete, including songs, movements, and text. By the time I left PIPA the students had two more weeks to rehearse, polish and prepare the entire play. The students still had to create the costumes and props; however, the play was already running on stage. 


\subsubsection{Whitireia Community Polytechnic}

With just over twenty-five years of history, Whitireia has become one of "New Zealand's leading polytechnics" (D. Campbell, 2012, p. 4). At its beginning in 1986 it was called Parumoana Community College. Later, in 1989, this changed to Te Kura Matatini o Whitireia, meaning the school of many faces of Whitireia. Whitireia means "source of light" (Methven, 2012, p. 24). The new name of this institution denotes the many facets of New Zealand's cultural environment as well as representing the ethnic diversity of staff and students at Whitireia (D. Campbell, 2012, p. 4). Whitireia originally built a campus in Porirua; this project was supported by the Ngati Toa iwi (tribe), who agreed to the construction of an educational institution on their land. Whitireia's Kaumatua, Taku Parai (Ngati Toa), recalls that at that time Porirua depended on the manufacturing industry as a source of employment that supported the livelihood of families. When the industry began to decline, Whitireia offered the option of increasing people's "ability to find stable work by reskilling or upskilling through education" hoping that "the benefits would come back to the community as a whole" (Methven, 2012, pp. 6-7).

Bicultural commitments can be seen reflected in Whitireia's goals and values. All their policies are

consistent with the Treaty of Waitangi and ensure the opportunity for Māori people to achieve their social and economic potential as an equal partner to the Treaty (Methven, 2012, p. 17).

However, Whitireia also has a multicultural nature that can be traced back to its origins. Turoa Royal, of Ngati Toa and Ngati Raukawa iwi descent, was appointed as the institution's principal between 1986 and 1996. Tino Meleisea, subsequently appointed in 1986 "was the first Pacific Island chair of any tertiary sector council in New Zealand" (Methven, 2012, p. 9). Both appointments express the willingness of the institution to represent not only the tangata whenua (people of the land) and Māori culture, but also to represent the Pacific Island cultures increasingly migrating to New Zealand and particularly prevalent in the Porirua area. Turoa Royal states that 
[s]tarting a new tertiary institution in a multicultural society was great opportunity to make that institution express the multicultural nature of that community (Methven, 2012, p. 14).

For example, in the Bachelor of Applied Arts (Performing Arts) program at Whitireia students develop an extensive knowledge of dance genres and artistic expressions in Māori, Samoan, Cook Island, and New Zealand contemporary dance. In addition, this degree allows students to "develop careers as performers and choreographers within the dance and cultural tourism industries" (Whitireia, 2012a).

Within this multicultural context, one of the main objectives, according to Royal, was to ensure that students who missed out first time around had opportunities for second- chance education... So we started foundation courses for all those who wanted to do tertiary (Methven, 2012, p. 14).

The Certificate in Work Skills, a foundation course at Whitireia, gives the opportunity to the students to study Haka Theatre (Whitireia, 2015, p. 38) which is an art form that combines kapa haka, dance, and theatre. Through this course the students get involved in the teaching/learning experience of kapa haka, mau rakau which is the use of Māori weaponry (Matamua, 2013, p. 1), contemporary Māori movement, and taonga pūoro, the use of Māori musical instruments (Flintoff, 2014, p. 1), Hip Hop, Te Reo Māori, and Māori Theatre (Whitireia, 2012).

In my interviews, Kereama Te Ua, a Kapa Haka performer and tutor of the Work Skills course explained that "Haka Theatre is a bridging course into the degree programs and attracts students that didn't do too great at school... but are performers" (Te Ua, 2015). He explains that for some Māori students, the idea of a tertiary institution is quite intimidating and they do not have the confidence to succeed in an academic environment. Therefore he works with these students, helping them to realise that "there is no big difference between the other students, 'the brainy' ones and themselves" (Te Ua, 2015). According to Te Ua, the main point of difference between Māori and some students of other cultures is that the latter may have "a bit more structure and may be better at planning and that is what is missing in some of our Māori students" (Te Ua, 2015). 
This course is about discovering the student's abilities, working and developing confidence and academic discipline through the performing arts. Te Ua explains that the methodology that has proven successful is to "work on their passion first... develop it, nurture it... the academic part will come later on" (Te Ua, 2015). This methodology draws from his experience working with Polynesian students "if they are not passionate about it, there is no way they will show up to class" (Te Ua, 2015). The main aspect for Te Ua is to getting the students to campus, "participating in the program and making them realise that actually they can do well and succeed within an academic environment through Performing Arts" (Te Ua, 2015).

Te Ua's students are from a range of different cultural backgrounds including Māori, Samoan, I-Kiribati, and Somalian students, however tikanga Māori is the main methodology used in class. Te Ua explains that a kaupapa Māori perspective also relates to Pacific Island students, because Māori protocols are similar to protocols from other Pacific Island cultures, rather than Western protocols. Tikanga Māori seems to relate quite well even to "our African student who has found some interesting similarities between African and Māori cultures" (Te Ua, 2015). The use of a karakia at the beginning of each class is one key element that helps the students in "focusing the energy in the job at hand and leaving any outside energy behind" (Te Ua, 2015), preparing the students and creating an appropriate atmosphere in which to work.

Through the Haka Theatre bridging course offered by Whitireia, two Māori students "who had no chance to enter to University or any Polytechnic" (Te Ua, 2015) were able to enrol at Whitireia in 2015. One student is in the Performing Arts Degree and the other is doing the Stage and Screen Degree. Te Ua emphasises the importance of performing arts, especially Haka Theatre to foster, nurture, and develop sets of performance skills, as well as confidence and discipline in students that "are not really academics, they are performers" (Te Ua, 2015).

Both establishments, PIPA and Whitireia, use theatre as a tool to promote educational development in young people. With different styles of teaching, students who attend these courses acquire through the use of culturally sensitive and appropriate theatre methodologies, the confidence and discipline to continue on to higher education. The methodology used in the course I observed during my fieldwork at PIPA focuses on the production of a play, for which students perform a series of exercises which shape and 
structure the play. During the process, students are encouraged to use as expressive means all possible tools, from 'traditional' stories, to music from other cultures, combining elements that could be considered 'traditional' with elements of the popular culture in which their lives are immersed, thus creating a play that they understand as clearly a 'contemporary' work.

In the case of Whitireia, the teaching pedagogy is centered on tikanga Māori and marae rituals. The course has a strong 'traditional' Māori base, since the course is Haka Theatre. Students learn the different 'traditional' Māori performing arts, which are then rearranged in a contemporary narrative. In this course, students are also encouraged to use all available tools and technical elements in the production and creation of the work, thus acknowledging culture and tradition as constantly fluid and evolving. Each element chosen, whether from the Māori performing arts or from elements of European theatre, must be in harmony with the whole work, and above all with Māori values, because those values are what ultimately will sustain and support the work on stage.

\subsubsection{Bicultural Theatre Course at Otago University}

Hilary Halba and Rua McCallum (Ngai Tahu) have conducted the undergraduate course Bicultural Theatre THEA 253/353 in Theatre Studies at the University of Otago for several years. Its main purpose is:

to investigate methods of scholarly delivery, to apply ideas in a practical context and to teach in ways that both mirror and illustrate the significant tropes of postcolonial theory and bicultural discourse that the course itself analyses (Halba, 2010, p. 22).

The significance of this paper is that is the only university course of this type in Aotearoa. Halba explains that students learn about and understand different ways of gaining knowledge and doing research through using a bicultural pedagogy. This paper supports students to explore issues such as:

who we are, from where and in what context we speak, what point of similarity and difference could be found between and within personal identities, and hence what similarities, differences, ruptures and transformations might be found within and between cultural identities (Halba, 2010, p. 29). 
Through utilising this reflective process, the bicultural pedagogy becomes a dialogue between cultures, a true cultural encounter where it does not "matter who the partner in that dialogue" (Halba, 2010, p. 33) may be. This pedagogy provides a creative tool for working in intercultural contexts, leading to deep and long-lasting learning experience, because these take place on two different levels, engaging learners in both the theory and the practice of bicultural theatre (Halba, 2010, pp. 28-34).

Halba and McCallum framed the course with a kaupapa Māori pedagogical approach, in which key principles drawn from marae rituals are introduced in the first lessons of the course (Halba, 2010, p. 26). McCallum states that "the first rule of the marae, the first tikanga, is to do with manaakitanga, to embrace and care for all, and there's no discrimination" (Halba, 2010, p. 34). Another one of these key principles involves acknowledging relationships between people, ancestors, and land, and is illustrated by each member of the group offering a mihimihi on the first day of the course as a way of building relationship and understanding amongst the group. The mihimihi "is a statement of where you are from, and how you can be related to these other people and the land, in both the past and the present" (Bishop, 1998, p. 203). McCallum explains that the mihimihi positions the person in relation to the ancestors, which is why each person's proper name is given at the end, following the line of descent (Halba, 2010, p. 26).

In addition to kaupapa (process) pedagogy, McCallum explains another Māori methodology of teaching which she sees as an appropriate methodology to be used in the Bicultural Theatre course. This methodology is called Tu Taha Ke Ai. In this methodology, the learning experience is "re-imagined as a collective activity" (Halba, 2009 , p. 195) where both student and master travel together to deeper layers of learning with each journey (Halba, 2010, pp. 22-23). This approach recognises that both teachers and students hold valuable knowledge which can be shared and contributed in the learning space. Tu Taha Ke Ai is founded on dialogue and interaction between teachers and students and both parties are conceptualised as active members in the learning experience. The result of this methodology is that theory is embodied by the learner, it becomes a life experience and therefore the knowledge of this person "is the sum result of the ancestors and landscapes that come before him or her" (Halba, McCallum, \& Holmes, 2011, p. 70). According to this description of Tu Taha Ke Ai, it is clear that a learning experience involving a Māori point of view can take place in any environment, not only in the classroom or at the marae, but in landscapes or seascapes as well. This 
learning environment could be referred to as a "lived space" which is "infused with symbolic meanings - personal/biographical and collective/cultural" (Middleton \& McKinley, 2009, p. 9).

Halba argues that in the creation and/or production of a bicultural play in Aotearoa/New Zealand, the notions of partnership, consultation, active protection, and reciprocity are fundamental. Although these qualities are difficult to measure or to quantify, Halba proposes a means whereby they are acknowledged in teaching bicultural theatre. This method hinges on valuing and adhering to tikanga Māori, Māori protocols, the correct way to do things in Māori context, and kaupapa Māori- a Māori platform of philosophyalongside aspects of theatre praxis and theory (Halba, 2010, p. 24). For example, the course is designed so that students get the opportunity to collaborate with Māori theatre practitioners from local communities, applying to this partnership the Tu Taha Ke Ai methodology. To achieve this, a period of "whakawhanaungatanga" (Halba, 2010, p. 28) meaning establishing a relationship, has to take place, in order to form a partnership with the person or group the student is collaborating with. This whakawhanaungatanga allows an engagement "and therefore, an unspoken but implicit commitment to other people" (Halba, 2010, p. 28).

In the Bicultural Theatre paper at Otago University, Boal's Image Theatre (Boal, 2002, p. 175) technique is also used as one of the methodologies applied during the process of creating a play as part of the course requirements. Boal discovered the power of images when working with communities in Latin America that spoke different languages. Through images, Boal could see what culturally diverse people understood for different concepts, for example the concepts of family, mother, and country (Boal, 2002, p. 175). In its early stages the images were static, but later on they started adding movement and even words to each image (Boal, 2002, p. 175). This technique allows students to corporeally investigate ideas, evidencing that there are "multiple lenses through which a situation may be viewed" (Halba, 2010, p. 27), as well as collectively creating, "with their bodies, static group images that represent their stories" (Linds \& Vettraino, 2008, p. $3)$.

Another methodology used relates to the incorporation of five objects that students are asked to bring to rehearsal as a means of provoking creative responses from them. These objects are 
a piece of writing, a piece of music, an image and an object that they could speak to about their 'home', and an item that signified something about their identity (in whatever way they interpreted these provocations) (Halba, 2010, p. 30).

The devising process then begins, inspired by all the stories, ideas, and situations that arose when working with the objects through improvisation. Halba explains that items were selected for improvisation by choosing "three random numbers between one and 100 , and the list was counted through until the item corresponding to that number was reached" (Halba, 2010, p. 30). During the improvisation process a long list of all the key aspects was written down and students were able to identify different topics including identity and home, using this new information. The final step of this process involved students visualising the shape and the structure of the show, not only taking into consideration the set on stage, but also how the show would look like it was physically enacted (Halba, 2010, p. 30). The play Take only Photos was performed on a stage that signified the road but also the passing of time where the scenes moved in one direction. In fourteen scenes, a series of visits to "Auntie's Tavern" (Halba, 2010, p. 30) were performed where Aunty was depicted as the archetypical mother figure.

The Bicultural Theatre course combines methods and processes from different cultures. Through Boal's Image Theatre in collaboration with Māori protocols, the theatre teaching/learning experience becomes not only a bicultural dialogue, but more of a constant intercultural dialogue. The Māori rite of the mihimihi at the beginning of each session contributes to the creation of a meeting space where the involved group learns to appreciate the concept of working collectively. Teamwork and a sense of belonging become fundamental elements through which the teaching and learning experience of theatre is achieved. Manaakitanga, as well as the concepts of partnership and reciprocity, are fundamental elements of the Tu Taha Ke Ai methodology. This methodology establishes equal partnerships between the parties during work, where learning is acquired through the experience of collaboration. Thus, protocols that are understood as 'traditional' elements of Māori culture are introduced into theatre training in a 'contemporary' context. 


\subsubsection{Indigenous Theatre Education: Synergies and Possibilities across Contexts}

In Chile and Aotearoa it is possible to find theatre institutions that teach theatre training theories and methods developed by European theatre practitioners. The main difference between the theatre training approaches in these sites is that in Aotearoa some institutions have also incorporated Māori rituals and protocols as part of their theatre training methodologies. The application of Māori rituals and protocols varies across institutions. Halba and McCallum at Otago University use the Tu Taha Ke Ai methodology to guide the entire work. More than a methodology, it is a philosophy that supports processes of creativity and collaboration between teachers and students. During this process, key concepts of partnership and reciprocity are acknowledged, relating this methodology directly to the principles embedded in the Treaty of Waitangi.

In Chile, the inclusion of Indigenous methodologies is at the moment difficult to conceive within theatre training at tertiary institutions because of ongoing colonialism and accompanying mentalities. In addition, currently there is no theatre training institution in Rapa Nui. Rapanui historian, Christian Moreno Pakarati states that a 'traditional' Rapanui value was umaya, which refers to collaborations between people. He states that currently umana is scarce: "individualism came to Rapa Nui, but it would be interesting to see if through theatre umaya can be brought back to society" (Moreno Pakarati, 2014). The Tu Taha Ke Ai methodology represents one example of the application, in theatre training context, of Māori values and behaviours that are similar to the Rapanui concept of umana. This illustrates the potential and possibilities inherent in using Indigenous worldviews and epistemologies as part of culturally-situated, reflective, and respectful pedagogies.

Toi Whakaari not only integrates different Māori protocols and methodologies in theatre training, they also incorporate them as part of theatre productions created in class. For example the karakia, a Māori incantation, spell or prayer (Reed, 2012), is used at the beginning of the class in order to focus communal energy on the work at hand. It is also used as a culturally-situated tool that helps to build community and to prepare people to work together at Whitireia in the Haka Theatre Foundation course, and by Halba and McCallum in the Bicultural Theatre paper at Otago University. In Rapa Nui, prayers are usually used before a performance, asking the ancestors for guidance and for a good 
outcome. There are also other rites that are performed at the beginning and at the end of any type of major job, for example the opening night of a festival, or the construction of a house. These rites are called umu tahu and umu hatu respectively, and refer to the preparation of two different earth ovens for collective feast. Umu tahu is performed at the beginning of any major task to seek guidance and to hope for a good result. Once the task is completed an umu hatu is performed as a way to thank the ancestors for the good result and outcome. At Toi Whakaari, we saw how marae rituals were adapted to serve the purpose of theatre, giving to the performance a cultural pertinence relating to both performer and audience. With the help and guidance of a Rapanui kaumatua, umu tahu and umu hatu could be adapted to the theatre practice, bringing theatre and Rapanui culture closer together.

Toi Whakaari has theatrically adapted the karanga (welcoming call) into some of their plays such as Pakiwaitara (2008), produced as part of theatre training experience. The incorporation of this 'traditional' cultural element gave this work a local and unique character. Thus the play opens by acknowledging different cultural sensitivities with which several of the performers and audience members can identify.

Virginia Haoa Cardinali, a member of the Rapanui Language Academy, explained in our talanoa that in the Rapanui society of the 1950s, karaya was a common part of everyday social interactions. Unlike the Māori karanga which is a call from the host inviting in visitors, in Rapa Nui the karanga was performed from the visitor's side as a type of called-out mihimihi. Haoa Cardinali explains that in Rapa Nui, every time someone visited another person, a karanga was recited where the visitor told the host who he/she was, and where he/she came before entering the host's property. "This rite is almost lost in contemporary Rapa Nui, no one practices it anymore... it was very nice to hear the recitation" (Haoa Cardinali, 2014). Through theatre practice, this 'traditional' Rapanui ritual could be re-established in contemporary Rapa Nui.

The use of the whaikōrero as a tool for textual analysis, even if the students are not $100 \%$ fluent in their Indigenous languages, is a great example of how Toi Whakaari incorporated 'traditional' elements of Māori culture as an integral part of contemporary theatre training. Working in two languages, creates a cultural bond, Māori and English, that the student can relate to, because, the person is not only working at a linguistic level but at a cognitive level as well. To change from one language to another involves not 
only translating concepts literally, but involves also the interpretation of a particular concept from one worldview to another. In this regard, the use of whaikōrero not only helps us to understand linguistically what the texts says, but will also give the text an intercultural dimension. From my experience of speaking three languages, I argue that this dimension is achieved because the linguistic concepts are being interpreted from another world view without changing their original meaning. The transferring of the original meaning into another world view, expressed by language, could help the student to understand not only linguistically but cognitively any text they need to analyse and/or perform.

Theatre training can serve a variety of social needs. Usually theatre training is associated with the formation of actors and the productions of plays. However, PIPA and Whitireia use theatre to foster self-esteem by acknowledging the student's abilities and capacities (Te Ua, 2015; Polataivao, 2014). From PIPA and Whitireia experiences it can be inferred that some Māori and Pacific Island students struggle with the idea of pursuing tertiary education (Thompson, 2014, p. 21). In these cases theatre is used to encourage students to continue into higher education. In Rapa Nui the scenario for many high school students is quite similar. Students who finish high school face the decision of leaving the island and going to Santiago to study, or staying and working. Theatre, through training and the production of Rapanui plays, could encourage students to remain in education and continue with their studies in any subject they choose, or it could through apprenticeships build capacities and theatre skills for the students to continue their own path in Rapanui performing arts. As discussed in Chapter Two, in 2010 Rapanui pianist Mahani Teave created Toki a school for music and the arts in Rapa Nui. To date, this is the only educational institution focussing on arts training, and even though at the moment is teaching music, this school could in the future open to other performing arts (Teave, 2014), creating arts training opportunities for Rapanui performers without leaving the island.

\subsection{Theatre Training Outside Tertiary Institutions}

Learning the craft of theatre is not only achieved through formal education in theatre schools. From a European point of view, theatre companies date back to Italy in the 1560s where groups improvised comedies (Russell Brown, 1995, p. 125). In the Pacific, 
the actors of faleaitu in Sāmoa were "informally trained by an older, more experienced comedian" (Sinavaiana, 1992, p. 202) who composed and directed the piece. In both cases actors were trained on the job; the craft of theatre was passed down from someone with experience to a novice member of the troupe.

This research investigates the integration of 'traditional' cultural elements in 'contemporary' theatre. The work of some theatre companies in Aotearoa and Rapa Nui has been very important in the transmission of knowledge and methodologies. In this section I will discuss the work of Mata Tu'u Hotu Iti, Te Rakau Hua o Te Wao Tapu, and Pacific Underground in order to explore Rapanui, Māori and Samoan diasporic theatre respectively. These companies have been influential not only in the production of plays, but they have also been able to train other practitioners in the art of theatre.

\subsubsection{Mata Tu'u Hotu Iti}

Mata Tu'u Hotu Iti (MTHI) was founded in 1975, setting the framework for the ways in which theatre in Rapa Nui is practiced today. The group's performances focussed on recovering their history and the maintenance of their language. Therefore they took special care in terms of storytelling, and the characterisation of the main character in each performance. Although its participants did not have any formal training regarding theatre practice - among the participants were fishermen, farmers and builders- the whole troupe put all their abilities and experiences into producing performances (Paloma Huke, 1995, p. 44).

MTHI had a well-structured system of rehearsing and preparing for shows. Paloma Huke (1995) describes the group's methodology in her book Mata Tu 'u Hotu Iti: Revelando Misterios. Generally the group met once or twice a week. The creative process started with the elders narrating and then commenting on the story to be performed. Then the characters were cast. This was done through a process of group consultation regarding what performer was most qualified to represent the main characters. The desicion was made based on three main aspects: the physicality, the personality and his or her capacity to perform a specific character.

Next, according to the plot of the story, the location for its representation was chosen. After that MTHI rehearsed songs related to the performance that a group of singers or 
koro at the back of the stage would be singing. A few days before the performance the whole troupe went camping at the venue selected for the event. To the location the group took stage props, costumes, torches, food, tents and everything they needed to live there. Finally, they had a general rehearsal in the performance location where each member took part in the dances and the execution of a dramatic scene (Paloma Huke, 1995, p. 47). During rehearsal days it was possible to hear old songs and recitations while the rest of the group was getting organised for the presentation. Everyone was fully involved with the performance, including the making of costumes and the creation of new songs related to the story (Paloma Huke, 1995, p. 46).

Performances lasted between twenty and forty minutes. There was no fixed or written script; rather the performance contained many elements of improvisation. The songs were accompanied only by the percussion of stones called maea poro. The costumes were handmade of a bark cloth called mahute, which was adorned with feathers, shells and seeds. As discussed in Chapter Three these costumes believed to be 'traditionally' from Rapa Nui are reinterpretations and adaptation of Tahitian and Chilean influences (M. Fortin, 2010, p. 127). The natural stage chosen for the occasion was lit by torches (Paloma Huke, 1995, p. 47). The way in which each character moved during the representation happened spontaneously, and performers enacted their role with passion, while the historic narration was delivered to the audience (Paloma Huke, 1995, p. 55). Through apprenticeships, Rapanui artists learnt MTHIs methods and style of producing theatre. This apprenticeship was done on the job, through performing other plays around the island.

This methodology has been passed around the Rapanui artistic community, creating a theatre training 'tradition' in Rapa Nui. Nowadays this methodology is still used, but in a condensed and 'contemporary' version. Usually performers of a'amu tuai at Tapati meet the same day, or the day before the performance, to coordinate what the group plans to do on stage. They go through the story just to clarify some points and to make sure that everybody is working from the same version of the story. They mark the main points of the story, the ones the group identifies as essential to perform, and the rest is improvised. Carlos Lillo Haoa, theatre tutor at Aldea Educativa high school prepares the performances for Mahana O Te Re`o (Language Day) following the same methodology, adapted from MTHI's work. 
In Spanish, when using the word improvisación, the understanding of this concept is as doing something without preparation, leaving it to fate. This conceptualisation is unlike the definition of improvisation in theatre practice, which requires from the performer "a communicative connection" (Lockford \& Pelia, 2004, p. 434) with other performers. During improvisation performers need to be alert in order to adapt "to emerging circumstances," listening to what is happening during improvisation to "adjust their thinking and behavior accordingly" (Lockford \& Pelia, 2004, p. 434). The use of the literal, Spanish understanding of the term improvisation, not as a theatrical tool to devise a play or to develop a character, is key in the way Rapanui performances have been carried out. This is possible because Rapanui theatre is based on stories that are wellknown by the community, so rehearsal seems unnecessary.

The main difference between MTHI's 'traditional' methodology and its 'contemporary' version is that MTHI rehearsed more than just one day or a couple of hours, as is the case of a'amu tuai in Tapati. In addition, the purpose and the urgency to perform in 1975, compared to the context in which a'amu tuai is performed nowadays is completely different. In 1975, the purpose was to express their discontent with the Chilean authorities, highlighting through theatre 'traditional' Rapanui practices. Nowadays theatre is performed twice a year, at Tapati and Mahana o Te Reo. The former frames

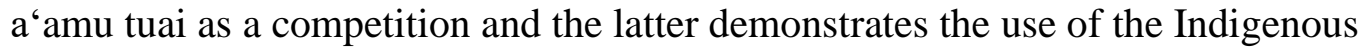
language within the school context. Many groups adopted the methods and aesthetic of MTHI, in terms of the use of costumes, and the idea of evoking the past; however none of the other groups have reached the degree of depth involved in MTHI's work (Paloma Huke, 1995, p. 46). It would be very interesting to see this Rapanui 'traditional' methodology serving as a guide for its 'contemporary' version, filling a'amu tuai's structure with deep Rapanui meaning.

Mata Tu'u Hotu Iti was formed with the purpose of representing old Rapanui stories through theatre. The group developed a methodology that allowed them to have the structure of a play in a short time, which in addition gave them time to rehearse and prepare costumes, props, and create songs for the play. MTHI, without intending it, trained a great number of Rapanui artists throughout its history. In time some of its members formed other groups, performing independently from MTHI, and passing on their knowledge and this methodology on to other Rapanui artists. Currently, the main structure of MTHI's method is still in use, creating a 'contemporary' version of this 
methodology and pedagogy. In 1975 MTHI developed a 'contemporary' style through which to present and explore 'traditional' Rapanui stories in and through the Indigenous language. This process and pedagogy, and the style of performance that it produces, has proved to be highly successful in terms of reflecting a Rapanui world view. It has been so successful that now this style is now accepted as reflecting 'traditional' ways of knowing and being, and it has become one of the foundations in terms of the ways in which performing arts are taught, practiced and understood in contemporary Rapa Nui.

\subsubsection{Te Rakau Hua O Te Wao Tapu}

During the 1990 International Festival of Arts in Wellington, Māori theatre practitioners Jim Moriarty and Rangimoana Taylor presented a marae theatre program that included dance and storytelling. From this experience, Jim Moriarty formed Te Rakau Hua O Te Wao Tapu. Moriarty refused the idea of Māori theatre being under the control of Pākehā mainstream theatre, so he created Te Rakau to in Moriarty's words, “ do my own thing with like-minded people... to create our own standalone venture" (Maunder, 2013, p. 94). After the festival, Te Rakau toured at schools, marae, and in theatres throughout Aotearoa, as well as in "the international arena" (Maunder, 2013, p. 95).

Te Rakau's community performances, included performances to audiences in prison, for example the Arohata Women's Prison whose population of Māori heritage was $50 \%$ in 2014 (Cowlishaw, 2014). In 1996 Moriarty was approached by the prison's manager to do further collaborative work with inmates and Moriarty decided to do a residency, where he developed a "fully-fledged community-based theatre model" (Maunder, 2013, p. 95). Theatre productions created as a result of these collaborations were then presented to an audience who had to go into a prison to watch the show (Scott, 2006). The group went on to work with young people at risk of social exclusion, using theatre as well as other therapeutic techniques to help them overcome their traumatic past life experiences (Scott, 2006). Due to the fact that Te Rakau participants are not performing a play, but telling and sharing their own life stories, Scott describes the theatre of Te Rakau as a "distinctive brand of a theatre of cruelty" (Scott, 2006). Theatre of cruelty was conceptualised by French theatre practitioner Antonin Artaud in which the term cruelty referred to "an appetite for life, a cosmic rigor and implacable necessity" (Artaud, 1970, p. 80) to create, in the notion that "being alive always means the death of someone else" 
(Artaud, 1970, p. 80). Through the different performances Te Rakau conducted in prison, participants enabled their past life to 'die' in the process of performing their stories, to be re-born after the play was finished as a new person. It could be said that Te Rakau embraced theatre of cruelty in their confessional productions, because they produced a theatre that was "difficult and cruel" (Artaud, 1970, p. 60) for the participants in the first place, where "the lost and the damned reveal the pain of lives lived in a manner most of us can hardly comprehend" (Scott, 2006).

Moriarty explains that wherever they went with the company, they always conducted a pōwhiri, because "[w]hat it always created was a special pitch of listening, because some sort of ritual had happened before a show" (Maunder, 2013, p. 95). Theatre practitioner, playwright and member of Te Rakau, Helen Pearse-Otene, explained that key aspects of the process in the work of Te Rakau are supported by tikanga Māori. She states that:

We base our day on the cornerstones of manaakitanga, which is hospitality and generosity, and aroha, which is respect and love, and whanaungatanga, which is relationships. So those are the cornerstones of our work. We stop as soon as there's trouble and we'll all sit down as the group and talk about it.... We are all collectively responsible for looking after each other. We need to ensure that everyone leaves the room with their mana intact - everyone (Ruth, 2013, pp. 228-229).

Te Rakau applies these concepts not only during the rehearsal process, but also during the performance. At the end of the performance Te Rakau offers a poroporoaki, encouraging the audience members to talk and ask questions of the actors before going back home (Scott, 2006), allowing apprehensions, misunderstandings and questions from the audience to be resolved.

Scott and Maunder describe the process and techniques used by Moriarty in the development of a performance at Te Rakau. The model described was used when working at both women's and men's prison in Christchurch, and it was later adapted for use when working with the different Child, Youth and Family Service (CYFS) residential centres in the country. Scott states that Te Rakau is a "self-consciously and uncompromisingly marae theatre" (Scott, 2006). But the group draws on both European and Māori traditions producing a bicultural theatre experience. Māori elements that were taught as a part of the daily work helping the performers to focus were, for example, 
waiata-ā-ringa, haka or taiaha. European elements of theatre used by Te Rakau, included Brecht's ensemble style, community theatre, and techniques and processes from Boal's theatre of the oppressed (Scott, 2006). Through community theatre, young people "identified as at-risk" (Maunder, 2013, p. 95), could share their experiences, in many cases painful, with other participants and their families. In this way, community theatre allowed these youngsters to be "immersed in devising and performing theatre for change" (Baskerville, 2009, p. 463).

The process developed by Moriarty involved two main parts. The first part included exercises and games of trust, as used by Boal. After that the participants were involved in a whakapapa exercise; during this exercise the participants were set up in pairs where each participant had to exchange past experiences, then the person was introduced to the group by the partner. Then the participants had to symbolically represent their whakapapa finding a physical shape and a sound. Consequently the participants would learn the others' whakapapa shapes and sounds to construct a piece of physical theatre. At some point during these exercises, Maunder explains that the participants had to list the qualities, good and bad, they inherited from their parents (Maunder, 2013, pp. 9697).

In the second part of the creation process, Moriarty used five questions to creatively provoke the work of the group. The participants were asked to write an answer, and then for each question they were asked to physically embody the answer through a gesture. Maunder outlines the five questions:

1) The Promise: What were you entitled to when you were born?

2) The Promise Broken: What did you actually receive? For this question, participants were asked to write and physicalize "the first-hurt memory, then the worst-hurt memory, then the one that was still with them".

3) What behaviours did you develop in order to survive?

4.1) If working in prison the question was: Where has this behaviour got you?

4.2) If working with young people the question was: Where will it get you if you continue?

5) What do you want from the future? How will you achieve this? And what behaviour change is necessary? For this last question, participants had to answer with dance, song or poem (Maunder, 2013, pp. 96-97). 
After these exercises were conducted, all the material gathered would become a script for the final performance, which would be rehearsed and presented to an audience. During the event, since the stories were quite powerful, a transitional piece would be performed, based on a waiata-ā-ringa, haka or taiaha exercise, allowing a "breathing space" (Maunder, 2013, p. 97) before the other segments. Usually the performances started with a prologue, like a karanga or a pōwhiri. Then the main performance, the play was presented in four parts: "Freedom? - seeds of imprisonment; The Past - we are not afraid to dig deep; Survival - living with our demons; Today - this is me now" (Maunder, 2013, p. 100). The performance finished with an epilogue, in the form of a haka.

The creative process used in prison by Te Rakau proved successful in terms of building confidence, due to the fact that participants were performing their own stories supported by the group. Acting skills were also developed in the process for example vocal strength through the use of Māori songs and dances, stage presence and improvisation with the aid of the different provocation Moriarty gave the participants. In time other institutions requested the group's services, including residential centres for young people. Moriarty took this model and started working with different iwi (tribes), specifically working with young people. "Te Rakau had, in essence, developed a specialist practice and Moriarty found 'a huge market out there for process work"' (Maunder, 2013, p. 99). In addition, Moriarty took with him participants from previous projects as apprentices for the next iwi-based project (Maunder, 2013, p. 103). In this way Te Rakau is not only passing on knowledge to the next generation, but also building capacities that people involved in Te Rakau's production could use later on in life. For example, the two women who had worked on two performances while imprisoned at Arohata joined the company on their release and were a part of the performance Watea (Good for Something) in 1998. Other youth projects include Te Waka Toi O Ngati Toa (2002), Purotu, the Magic Within (2000), and Te Ahika O Te Manatu Rangatahi (2001). Another example of theatre training carrying on into different work is the production of The White Guitar (2015) in which Samoan Matthias Luafutu, a former member of Te Rakau, performed with his father and brother in an autobiographical play about redemption and forgiveness. The White Guitar shows performers taking responsibility for their past actions, driven by an ethos in which "seeking forgiveness from those you hurt, including yourself, will set you free" (J. Smythe, 2015). 
Maunder explains that Te Rakau has changed in recent years, becoming "a fulltime service provider for CYFS, offering a selected group of youth at risk fulltime care for a year" (Maunder, 2013, p. 104). This change in the work of Te Rakau has several consequences. Firstly, it means that Te Rakau can establish itself in a specific place. Secondly, it has a positive economic impact by securing annual funding for staff. It also means that Te Rakau has moved away from community-based theatre to the performance of text-based plays (Maunder, 2013, p. 105). The Battalion, Ka Mate, Ka Ora, and The Ragged, all of them written by Helen Pearse-Otene, are examples of this new era in Te Rakau's work.

Te Rakau has more than twenty years of experience in teaching theatre to people in different social contexts in Aotearoa, and of using theatre as a form of social activism and praxis. Through community theatre, the use of verbal provocations, physical theatre, and working in prisons and with youth at risk, Te Rakau has helped in the healing process, enabling members to put together plays based on their own experiences.

The work of Te Rakau is all supported and based on strong tikanga Māori, creating a safe space in which participants can work and share stories. In this space concepts of generosity, respect, and partnership are privileged as core foundations for any work undertaken. In addition, the performances integrate Māori performing arts, reinforcing the sense of belonging and the Māori tikanga that infuses all Te Rakau's work.

The main feature of Te Rakau's work is the transmission of knowledge. Through these workshops, Te Rakau is teaching the craft of theatre by creating, producing and performing theatre. Theatre skills are achieved through experience, and learnt on the job. These apprenticeships give participants the opportunity to develop their capacities, therefore enhancing their self-esteem. This way of working in theatre is closely related to what Whitireia and PIPA promote with their foundation courses. Through theatre students are encouraged to recognize and acknowledge their capacities, and theatre-based processes help them to develop self-esteem and discipline to continue further studies. 


\subsubsection{Pacific Underground}

The Whakarite Theatre Company was formed in Christchurch between the late 1980s and the early 1990s. This government-funded education initiative was linked to the PuawaiPolynesian Performing Arts School (Puawai School), who provided theatre training for Māori and Pacific Island youth. The main reason for the establishment of Whakarite Theatre Company was the lack of opportunities Māori and Pacific Island students faced when leaving Puawai School (Fülöp, 2012, p. 79). Whakarite was established to fill this gap by further training young people in the performing arts. However, some Pacific Island performers lamented that the only way "Pacific Island actors could gain [professional] experience was by playing Māori roles” (Fülöp, 2012, p. 80). Therefore Puawai’s Samoan students including Mishelle Muagututi‘a, Erolia Ifopo, and Oscar Kightley formed Pacific Underground (PU) in 1992, in order to tell "our own stories, have Pacific Island roles” (T. Muagututi ‘a, 2014). This theatre company later became crucial in the production of Samoan theatre in Aotearoa.

PU was basically composed of a group of friends (Fülöp, 2012, p. 82) who came together and began writing and performing their own plays (Mallon, 2002, p. 143). Most of the participants at PU were not trained actors. Pacific Underground member Mishelle Muagututi'a as a dancer, and in my interview with her, recalled that the theatre training she had with PU was "pretty much hands on... we basically were thrown to the sharks.... You want to perform .... Up you go... on stage!” (M. Muagututi ‘a, 2014). Muagututi'a explains that sometimes they did participate in voice workshops "to learn how to use the voice properly in theatre" (M. Muagututi'a, 2014), and later they participated in a movement workshop. So instances of training were available, although for most members, the performance itself was their theatre training.

The plays PU performed were based on texts written by different company members. Oscar Kightley, the most prominent playwright of PU trained as a journalist (Mallon, 2002, p. 148), however he learned the craft as an actor and playwright through his participation in PU. During the production of Fresh Off The Boat (1993) by Oscar Kightley and Simon Small, which was described by The Press as "a milestone in New Zealand theatre"(Kightley \& Small, 2005, p. vii), the group spent time researching different characters in the play, where Ifopo acted as a mentor, guiding the work of the group (M. Muagututi'a, 2014). Muagututi'a states that during rehearsals the group "tried 
to follow the text out of pure respect to the person who wrote it... but there was always space to improvise" (M. Muagututi'a, 2014). From these statements, it seems that there was no pressure in having to produce something, the process seemed more important; they "liked to try things out, to experiment and to give the opportunity to other group members to direct, to write, to dance and act (M. Muagututi`a, 2014).

The theatre training methodology used by PU was an 'on the job' style. PU was involved in tours run by the Theatre and Education Trust. The group wrote and rehearsed short plays for children of different ages, to be performed at different schools around Christchurch, helping to build audiences for Samoan theatre in Aotearoa. These performances frequently talked about issues that were related to the school environment, for example "bullying, ethnic tensions and career choices" (Fülöp, 2012, p. 83).

Mishelle Muagututi'a explains that "sometimes we had two or three performances in one day, so we had to be creative in all respects, even in the props we used" (M. Muagututi'a, 2014). So in order to suit different age groups, possibly on the same day, PU made "minor changes" (Fülöp, 2012, pp. 83-84) to the play. This method of working in theatre developed their ability "to improvise, to make quick decisions, and to partake in any of the production stages involved in the play” (M. Muagututi ‘a, 2014). In my interviews Tanya Muagututi'a, the manager of Pacific Underground, explained that the short plays "helped with paying the bills while producing the big play" (T. Muagututi 'a, 2014). Later in time, when the group was fully established and more experienced, they could integrate school children who had seen PU performances at school and who wanted to do theatre into the collective. The new members were then given the responsibility for school performances going through the same training the older members of the company went through (T. Muagututi ‘a, 2014). Through this form of apprenticeship, another generation of Pacific Island people were trained in theatre. An example is Joy Vaele, who trained with Pacific Underground as an actress and a playwright. In 2015 Vaele co-devised the play Rangi and Mau's Amazing Race which was further development of a whole series of Rangi and Mau plays performed over a number of years by PU. The humorous and educational play tells the story of two boys, a Samoan and a Māori who need to complete their school assignment about Matariki. Through a series of challenges, situations and the help of a genie, the boys explore significant historical events in Aotearoa, which allows them to discover similarities in each other's cultures (N. Smythe, 2015) . Vaele featured as an original cast in Frangipani Perfume (1998) by Makerita Urale, and Erolia Ifopo 
was the initial director of this play. This indicates that PU training enabled both to take on roles and work outside of the PU context, creating significant and enduring repercussions in those involved, but also on the broader national context of Pacific Island theatre development in Aotearoa.

Pacific Underground was created from a sense of urgency about the need to tell stories from a Samoan perspective, and to create roles for Pacific Islanders in Aotearoa. Although not all of them were performers, they developed a methodology that not only trained them as actors, but gave them experience in all areas involved in the production of a play. Their training space was the rehearsal process and the performance itself. This methodology taught them to work flexibly and to always be ready to change, to adapt and transform the play according to the needs of the audience, to improvise and to be creative in the use of their resources. Through short school performances, members of PU wrote, directed, performed and tried different stories that were relevant to the school environment. Learning on the job provided the group with invaluable theatre experiences.

\subsubsection{Theatre Training: Learning on the Job}

Each of the theatre companies mentioned above has developed their own methodology according to their needs. Most of these methodologies have roots in community theatre practice. The establishment of each of these groups reveals a need for expression and a hope to impact the communities in which they performed. Te Rakau and Pacific Underground formed in order to tell their own stories in their own way. Te Rakau's director Jim Moriarty did not want to do theatre that was controlled by a Pākehā worldview. Likewise Pacific Underground wanted to tell stories through Samoan characters instead of performing Māori or New Zealand characters. Mata Tu'u Hotu Iti felt the need to revitalize the use of the Rapanui language as well as preserving 'traditional' practices. Each group, in its style and motivation met the needs that they felt their own community had.

Community theatre invites and enables people from the community to share their own stories through theatre. In most cases community theatre is achieved through members of the community working in collaboration with trained artists. In the case of Te Rakau, the 
trained artist is Jim Moriarty, although he has brought in other trained artists such as Lynda Chanwai-Earle, and Helen Pearse-Otene. Moriarty decided to work firstly with people in prison and then with youth at-risk who were able to share their own life experiences through theatre. Te Rakau integrated 'traditional' marae rituals into theatre practice, becoming part of the 'contemporary' actor's life. Māori 'traditional' customs, rituals, and protocols are the base for theatre training from which to create a new performance.

In the case of Pacific Underground Erolia Ifopo was the trained artist who guided the onthe-job theatre training. PU members learnt performing in different schools in Christchurch, presenting short plays with issues of importance to them. They created plays that resonated with the Samoan communities living in Aotearoa, where intercultural relations, especially between Māori and Samoan people would be part of the issues addressed in some of their plays, as well as issues related to migration, and the loss of Indigenous languages. PU integrated Samoan cultural aspects with popular culture in their works, presenting stories through their unique point of view as Samoan living in Aotearoa and attracting a younger audience to the theatre. Theatre becomes a useful and effective tool for representation and communication, enabling community and cultural expression, and also creating a sustainable source of income for Samoan artists living in Aotearoa

Mata Tu'u Hotu Iti's theatre style created almost anthropological works. This naturalistic performance style was learnt on the job. Their training and practice involved a sense of urgency in terms of the need to revitalise Rapanui culture. The first members of MTHI did not have the guidance of a trained actor, so their development was mostly intuitive. Later on, when new members were accepted, they could learn methodology already developed from experienced members, influencing an entire generation of Rapanui artists, including dancers and musicians who have used and adapted the process, pedagogy and aesthetics of MTHI in their performances.

Through the work of these different companies and methods, participants have had the opportunity to learn the art of theatre in a holistic and embodied manner -on the job. Members of the companies have taken part not only in the performance of their characters but they have also participated in all the other aspects required in the creation of a play, such as production, set design, the creation of costumes, and songs. Working in 
a theatre company creates a strong 'we' feeling, a cohesive group that works in collaboration, where teamwork, respect, harmony, and generosity are key aspects in the creative process.

Touring plays in different schools has been part of the methodological process used by Te Rakau and Pacific Underground, enabling young people to see different plays that were created from an Indigenous worldview, and that reflected shared customs and languages. Through theatre apprenticeships students interested in participating gain valuable experiences and relationships with more experienced mentors offering continuous opportunities for young people with an interest in being involved in theatre based activity.

\subsection{Writers Training}

The theatre histories that I have explored in this research demonstrate that the creation of written texts has been of great importance in the development of Māori and Samoan diasporic theatre. It is therefore essential to discuss the creation and writing of plays as a means of fully developing theatre practice. This section will discuss the writing workshops that have been conducted in Rapa Nui, and the influence of the writing workshop Writer's Block on the development of Māori and Pacific Island theatre in Aotearoa. Although in Rapa Nui there is nothing comparable to Writer's Block, there have been instances, especially at high school, where the students experience a creative writing process. These examples will demonstrate how the creation of a text may contribute to the theatre practice in both Rapa Nui and Aotearoa.

It is important to clarify that not every written text has the opportunity to be put on stage. Forster and Plumb (2013) explain that, for a text to become a theatre piece:

the writing process must be subject to a second process of production and performance [where] the reader turns into a hearer and a viewer, the senses are multiplied, and the audience take their seats together in a specially prepared place at a specially arranged time" (Forster \& Plumb, 2013, p. 12)

The written text then becomes the medium through which performers connect and interact with an audience, not only through the words, but also through the actions performed on stage. In addition the creation of a text may generate new performance 
spaces. This research has seen how Māori and Samoan theatre practitioners generated work and performance opportunities for actors from their communities through the creation of theatre texts which reflected their cultures, histories, and experiences. The creation of new texts provides a "cultural wealth" (Forster \& Plumb, 2013, p. 11) in the sense that different voices, world views, perspectives, and cultures are being presented in the public sphere. This is a significant contribution which needs to be acknowledged. The 'wealth' of Māori and Samoan playwriting includes the fruitful blending of 'traditional' and 'contemporary' elements; for example the plays Waiora by Māori Hone Kouka, and Frangipani Perfume by Samoan Makerita Urale.

\subsubsection{Writers Workshop in Rapa Nui}

The creative writing workshops conducted in Rapa Nui to date have not been long term, and have rarely lasted longer than a month. One example of a long term writing workshop was conducted in the late 1990s by Ana Maria Arredondo, the former head of Aldea Educativa high school. This creative writing workshop involved both staff and students. The methodology was to go out to the countryside, and to use the natural landscape as a source of inspiration for writing. Arredondo explains that the purpose was to write as freely as possible, to create either short stories or poems, in Spanish or in Rapanui language (Arredondo, 2014). In 2006, the Chilean Journalist Patricia Iturbe who was living in Rapa Nui at that time also conducted a creative writing workshop at Aldea Educativa. She taught a group of fifteen participants' different literary genres, and the students created different short stories and poems in the Spanish and Rapanui language. At that time Iturbe was working with Rapanui elder Felipe Pakarati, who went with Iturbe to the creative writing workshops. Pakarati, as a Rapanui kaumatua, told the students 'traditional' stories that could be used as inspiration. Due to a lack of financial resources the workshop could not be conducted in 2007 (Iturbe, 2015).

The Chilean Spanish teacher Isabel Vilches conducted several creative writing workshops between 2008 and 2010 at the Catholic School in Rapa Nui. This workshop was part of the Spanish program developed by the Ministry of Education. Vilches adapted the program to the Rapanui context as the program was oriented towards the realities of continental Chile. Vilches used different methods to guide the students in their writing. For example, she gave them specific subjects to write about, and images 
that the students should describe not only visually, but emotionally as well. Vilches also used Rapanui stories as a starting point for the creation of a new story (Vilches, 2015), her work encouraged students to integrate elements considered as 'traditional' in their ‘contemporary' process of creation.

Another example of teaching creative writing in Rapa Nui took place in 2011 when Annette Zamora Rapu, who teaches Rapanui language at the Catholic School, invited me to co-facilitate a workshop that lasted for the entire school year and included students of between fourteen and sixteen years of age. One of our main purposes of the workshop was to assist in the learning of Rapanui language using theatre as the medium. In addition our purpose was that students felt able to experiment with language as much as possible, for example in the creation of a character, in the creation of the story, in the use of the body and the voice, all within the secure boundaries that a theatrical structure can provide.

We chose to represent a particular episode of the Rapanui history, when the Williamson Balfour Company was established on the island between 1895 -1953. We asked the students to investigate and interview their grandparents and parents on the subject. Some of these interviews were conducted in pairs so that the students with Chilean heritage could be included in the task of interviewing a Rapanui elder. Students were given a deadline to accomplish this task; meanwhile we showed them photographs from that time and asked them to choose no more than ten that attracted their attention. Once the photographs were chosen and discussed by the group, we asked them to write about the photos. The idea was not to describe the photo, but to create the story behind the photo. Initially we asked students to answer questions including: Who are they? What are their names? Is it Summer/Winter? Why are they dressed like that? How old do you think they are?

Once established the basic coordinates of the characters in the photo, we asked them to continue writing and gave them another set of questions including: Why are they there? How did they get there? What happened before they got to that place? Why do you think that happened? At this stage the students began to establish relationships between the characters that appeared in the photos, and in some cases dialogues and specific traits for each character started to appear. When they had the story more or less ready, we asked them to share the history they had created with the class. 
When the interviewing task was over, interview material was shared with the group and this time we asked students to see the possibility of integrating some of the interviews into the stories created around the photographs they had selected. Some days we did fieldtrips to the local museum to review books written about that period of Rapanui history. Then we asked students to include some of this research in their stories. The information gathered at the museum also contributed to processes of designing the set and the costumes. When the stories were ready, we did a dramatised reading of the stories written by the students. It was only then the students fully realized what they had created in class.

Then we conducted a similar process, but this time physically. Students started by adopting the physical position of the photos previously selected, remembering the name and age they gave to each character. From this physical position, we asked students to explore the 'character', discovering how he/she looked, the features in his/her face, hands, posture, and to identify the body weight. After that, we asked students to explore how the character moved and sound, finding his/her tone and voice. Once we had worked on the physical exploration, and each character was more or less 'present', we went back to the text they wrote and we asked students to incorporate the text to this newly discovered character. Then they reorganised the various scenes or stories and gave them an order. We chose the storyteller, and actors to play the other characters, and began assembling this short play entitled Por Los Ojos De (Through the Eyes of) written and performed by the students (Zamora Rapu \& Fortin, 2011).

Creative writing workshops in Rapa Nui have been varied in their methodologies, although all these workshops focused on the creation of short stories. Arredondo used the landscape as a source of inspiration. Vilches used different methods, from specific topic to images, and using 'traditional' Rapanui stories to create new work. Iturbe worked with Rapanui kaumatua Felipe Pakarati, to develop a bilingual writing workshop. Iturbe's and Vilches' workshops did not have a specific purpose in terms of creating a tangible outcome or product, such as the publication of the narratives created, holding a public reading so that the community could attend to and listen to the different stories, or creating a forum or an exhibition that highlighted the work of literary creation.

The methodology used in the theatre workshop conducted by Rapu Zamora and myself was designed with the purpose of performing a play at the end of the year. After each 
session with the students, Zamora Rapu and I met to discuss and evaluate the process. According to these meetings we modified and adjusted the content and methods to be used the next sessions in order to fulfil our purpose. In this way the task of creating something new did not seem too foreign because it was supported by the work students had to do for school. In addition the task of interviewing their grandparents connected the worlds of home and school, bringing history to life and giving the students a sense of pride through featuring their grandparents' stories in a school project. The students knew from the beginning that the main purpose of conducting this workshop was to create a short play that they could perform, so all efforts were focused towards that goal. All the information gathered during the workshop was used in some way, either in the text, or through contributions to the set and costumes (Zamora Rapu \& Fortin, 2011). Interviews, pictures, and scholarly texts as well as the creative writing of the students allowed us to put together a short play at the end of 2011. The play was performed for an audience composed by parents, school staff and students. The response from the audience was very positive, encouraging us to continue working with this methodology.

\subsubsection{Writer's Block Workshop}

The work and dedication of the Māori and Samoan playwrights has made a great contribution to the theatre scene in Aotearoa. Writers from these communities created texts for Māori and Samoan diasporic theatre, providing new performance spaces and allowing culturally different perspectives and ideas to be seen on stage. In 2001 Hone Kouka decided to help other writers to develop their creative works through providing teaching in writing plays. Kouka started the Writer's Block workshop with Māori and a few Pacific Island participants. This workshop aimed to help young Māori and Pacific Island writers in the creation of new work, and to attract new audiences, changing the ways in which audiences related to Māori and Pacific Island drama. In 2001the mission and purpose of the workshop was established:

To create new full length play scripts by Māori and Pacific Island writers, with the potential to produce as stand-alone productions or by Taki Rua Productions.

To nurture and develop new Māori and Pacific Island writing. 
To expand and build the body of Māori and Pacific Island writing (O’Donnell, 2011a).

The methodology used by Writer's Block is based on the notion that the ideas can come from any source of inspiration. Initially newspaper articles were used as catalyst for writing exercises, but eventually Kouka realized that there is a "powerful connection between physicality and writing" (O’Donnell, 2011a). Kouka saw "the playing of sport as an effective way of communicating" (O’Donnell, 2011a). Working together, for example practicing a sport resonates with communal and collaborative social aspects that are core parts of Pacific cultures. Practicing a sport as a methodology used in Writer's Block workshop is reflective of social structures in Polynesian society which are ordered and often quite tightly structured, where, as in team sports, everyone knows their role and how it relates to and supports those around them. Taking into account that in the Writer's Block sessions participants would work on "characterization, structure, dialogue, construction,[and] character development" (O’Donnell, 2011a) among other things, practicing a team sport such as cricket facilitates the development of these areas.

Kouka explained that team sports can be used to create small societies, where situations in which quick decisions are made, where conflicts may arise, and in which a variety of dialogues can occur. In addition, team mates can become a source of inspiration in the creation of new characters and or situations. This strategy of playing sports and then “translating this into writing” (O’Donnell, 2011a) proved successful in the workshop for several reasons. It eliminates the pressure of having to begin with words, and to sit down to write and create ideas out of thin air. It also promotes observation, a very important feature for every theatre practitioner. Exercising observation also allows the writer to add specific details to each character and/or situation, differentiating one text from another.

Miria George, a Māori/Cook Islands playwright and actress participated in Writer's Block workshops for around nine years (2005-2013). She explains that "to get the writing muscle working" (George, 2015) Kouka would give them a task or a subject to write about. The exercise consisted of writing for five or ten minutes about that subject, and then reading the piece out loud. In this way the pressure of having to produce a good piece right away was reduced. On the contrary "sometimes those short pieces were really inspirational for the writer to keep developing the story" (George, 2015). Another method used in the workshops, was that works were read out loud and shared with fellow 
workshop's writers. Kouka explains that this exercise enabled participants to learn how to constructively criticize each other's work, beginning "with the positive" (O'Donnell, 2011a), "offering a solution" (George, 2015) and noting that "different tones are necessary for different people" (O’Donnell, 2011a). The collaborative atmosphere in which Writer's Block worked may have been part of the reason why this initiative lasted for such a long period of time. Another reason for its success can be placed on the requirements for the participants, which was a long-term commitment to the workshop.

Writer's Block stopped offering workshops in 2013. The reasons why are not documented, however it could be possible to think that because more Māori and Pacific Islanders in Aotearoa are regularly writing plays, the workshops may have seemed unnecessary in terms of creating capabilities. During the years that Writer's Block functioned writing skills were already formed. Nevertheless, Kouka created, as Tawata Productions, the Matariki Development Festival (2010), held each June at Circa Theatre where many of the works created at Writer's Block were read or performed, giving continuity to the writing process. In 2014 Hikoi by Nancy Brunning developed at Writer's Block was performed at Matariki Festival in 2013. In addition, three other plays, 2080 by Māori actress Aroha White, Bless the Child by Hone Kouka and Ships by Moana Ete of Samoan heritage, as well as a variety of monologues were part of this festival.

In 2013 Miria George conducted a writing workshop in Rarotonga which was based on her experience at Writer's Block. In my interviews George explained that she worked with a "mixed local group from thirteen to sixty years old who [all] wanted to tell a story... they just didn't know how to do it" (George, 2015). In this workshop George transferred methodologies acquired through experience at the Writer's Block to the Rarotongan context. The workshop lasted for two and a half weeks, and during this time the group met for three to four hours at a time "two nights in a row and three nights off and then two nights in a row again" (George, 2015).

George decided to use a variety of creative forms including short stories, poetry, short films, and monologues to identify forms that the writers could approach and identify with. She showed practical examples, for instance a short film script written by Hone Kouka called Fade Away. In this story about basketball Kouka integrates 'traditional' Māori concepts. This example inspired the youngest member of the workshop to create a short story based on one character from Kouka's script. For the older members of the 
workshop, this example opened up a door in terms of exemplifying the possibilities of blending “'traditional' knowledge with our 'contemporary' world and how we may be able to do that" (George, 2015). Another method George selected to use was to get participants to read their work out loud so that participants could hear it, and learn how to give and receive feedback. She did not want this to be a destructive process so she waited four sessions until relationships between people were established before asking participants to give feedback to one another. This is an example of a practitioner becoming a teacher, transforming her students' worlds by passing on skills that she herself had learnt from Writer's Block. By sharing these new skills, George, through the Writing workshop in Rarotonga became a political agent for transformation, since she "shows the means of carrying out that transformation" (Boal, 2000, p. xiii).

Writer's Block was an initiative founded due to the lack of stories and characters written for Māori and Pacific Island theatre practitioners. The primary objective was for Māori and Pacific Islanders to acquire the skills and the discipline that a writer requires, so that new works could be produced. During the twelve years the workshops lasted, a variety of different methodologies were implemented.

Through these workshops different texts emerged. The aim was also to develop these texts to be performed on stage. To do so, some of the texts produced in the workshop were read aloud during the Matariki Development Festival which provided continuity to the theatre writing process. To the plays read, audience members gave feedback allowing the writers to adjust and modify some aspects of their writing, polishing it for a future staging of their plays. The methods developed by Writer's Block served as a model for a subsequent writer's workshop conducted by Miria George in Rarotonga who adapted these methods for use in this new socio-cultural context.

\subsubsection{Creative Writing Approaches across Contexts}

Writer's Block was created due to the lack of stories and characters that reflected the point of view of Māori and Pacific Island actors in Aotearoa. A similar need to reflect Indigenous ways of knowing and being motivated workshops using creative writing in Rapanui context, as no dramatic texts or Rapanui characters have been yet developed to tell contemporary Rapanui stories. The 'traditional' stories that have been performed until today are the only Rapanui 'texts'. In terms of creating 'contemporary' texts the 
creative writing workshops conducted in Rapa Nui have made a small contribution to what must be a much wider process.

Writer's Block had a clear and precise objective, which was to support, encourage and nurture emerging Māori and Pacific Island playwrights. Writer's Block led by Kouka demanded commitment from its participants. It was crucial that this commitment was maintained over time so that participants could see results. The use of physical activity as a way of learning how to describe situations, characters, as well as to sharpen the sense of observation is a very interesting method as it also provides writing material to develop during the workshop.

In the case of Rapa Nui, creative writing workshops to date have had less tangible outcomes, and have not resulted in publications of works created. The workshop conducted by Zamora Rapu and myself was successful, because we incorporated to the process the collaboration of family members and we showcased the work at the end of the process. In the future, rather than creating written text as in Western processes, it could be possible to design creative processes which write a text at the end, beginning with more culturally and relational processes that later on will be translated into a written text, breaking up the challenges associated with reading and writing. Arredondo's workshop used the land as a source of inspiration for writing which would engage the imagination of Rapanui peoples intimately connected to the land.

Vilches, like Kouka gave the participants specific topics to write about. Iturbe collaborated with a Rapanui kaumatua who encouraged participants to write and express themselves in their own language. George in her workshop in Rarotonga showed participants how it would be possible to integrate the 'traditional' knowledge with the 'contemporary' world through writing. In terms of their methodology, Writer's Block and the creative writing workshops in Rapa Nui have much in common. However, the success of Writer's Block could be placed in the expectation of showing new work in progress. Miria George explains that as a group "we put warm pressure to each other... with the expectations that at some point you would be bringing new work" (George, 2015). This new work in progress would be read aloud by another person, giving life to the text, and showing the possible ways and forms in which this text could be improved and possibly transformed into a play. 
I think it would be important, especially for participants of creative writing workshops in Rapa Nui to have a presentation of their work, whether in progress or finished. Through public reading of these texts, the work would be released, would be present in the memory of the school community, filling participants with pride and a sense of achievement through having their work acknowledged.

\subsection{Conclusion}

This chapter demonstrates some of the ways in which cultural integration is learnt during theatre training. It also shows that theatre in education in Aotearoa relates not only to learn theatre skills but also to promote social change, self-esteem, and a particular point of view regarding the integration of traditional' and 'contemporary' cultural elements in theatre.

In Aotearoa different protocols and rituals from Māori culture have been adapted to theatre training around the country as one of the methodologies used in formal and informal education settings such as universities and institutes as well as in theatre companies in Aotearoa. The integration of Māori cultural protocols as part of their working methods reveal theatre training in Aotearoa as having developed an openness to a range of cultural and aesthetic possibilities and culturally different interpretations. Māori rituals have also been integrated in plays created by students as part of their theatre training process. Pacific Island students have also been exposed to this culturally reflective pedagogy, which in turn enables them to reflect on how they might integrate 'traditional' elements from their own cultures into their 'contemporary' work. For Pākehā students, bicultural theatre methodologies can support the emergence of new perspectives and insights as actors supporting respect and empathy for different cultural practices and different ways of knowing and being in the world.

Theatre education in Chile reflects on the development of theatre in Rapa Nui. Contemporary Rapa Nui remains significantly influenced and interconnected with developments in education happening in Chile, therefore an exploration of this cultural context can enhance understandings of cultural influences and developments affecting theatre education and performance in Rapa Nui. In Chile, tertiary institutions that offer theatre training have a strong European influence and it seems unlikely that Indigenous 
methodologies will be integrated as part of the theatre training in these institutions. I argue however that theatre training in Chile could benefit from culturally inclusive processes and pedagogies such as those implemented in Aotearoa. In Rapa Nui, the work of Mata Tu'u Hotu Iti has made a great contribution to theatre training. This group used theatre as a means of expressing a Rapanui point of view, integrating 'traditional' elements in their 'contemporary' work. While today this methodology continues, but in a condensed form in Rapa Nui, the methodology exists and could be revitalized.

Creating written plays is an important part of developing cultures, performances and theatre education. Through their work playwrights can create opportunities for new representation. The benefits of having a strong group of Indigenous playwrights are significant. Creating your own play allows theatre practitioners to express their own voice and perspectives about issues and histories that otherwise are not told. In Rapa Nui currently no new texts are being written by Rapanui artists, only the 'traditional' stories are being performed. Self-determination has been crucial in the development of Māori and Samoan theatre in Aotearoa. Part of this self-determination has been the creation of new written work. 
ค咱

1

La Cosecha

\section{Harvest}

\section{'Ahune}




\title{
Chapter Six
}

\section{Findings and Conclusion}

\author{
Ko Mau A
}

\section{Atender y Entender para Aprender}

\subsection{Introduction}

This research has explored two central questions: Firstly, what are some of the ways in which notions of 'traditional' and 'contemporary' theatre are conceptualised by artists and performers in contemporary Aotearoa and Rapa Nui? Secondly, how have these different attitudes shaped and influenced the production of culturally reflective 'contemporary' theatre practices in these comparative contexts?

To answer these questions, this thesis focuses on how Māori and Samoan theatre practitioners in Aotearoa have integrated different 'traditional' cultural elements with European theatre techniques in their 'contemporary' work, to see if the experiences of Maori and Samoans theatre practitioners in Aotearoa can be used as a source of inspiration for the further development of theatre practice in Rapa Nui. During the talanoa sessions I conducted in Rapa Nui during my field work, the Rapanui community recognised that there is a lack of professionalism in contemporary theatre practice (Araki, 2014; Araki Pont, 2014; Hotus, 2014; Hotus Pate, 2014; Lillo Haoa, 2014; Rapu Drago, 2014). This thesis is presents itself as an opportunity to reflect on the theatre practice in Rapa Nui in comparison to the Indigenous theatre practice in Aotearoa. 
This thesis describes the multiple benefits of practicing theatre for Indigenous Pacific communities. Theatre has served as a tool to promote educational development in young people, to foster intercultural collaborations between community members and trained artists, to assist in the transmission of knowledge to other potential practitioners, and to foster social activism. The notion of self-determination is crucial, enabling Indigenous practitioners to dominate and determine the way in which they want to practice theatre. All these possibilities result from and contribute to the productive interplay of 'traditional' and 'contemporary' elements in Indigenous theatre.

This thesis has investigated the history, development and influences of Māori, Samoan diasporic and Rapanui theatre, and explored the different methods used in theatre education in Aotearoa, Rapa Nui, and Chile to understand the different journeys and developments of Indigenous theatre in these contexts. Māori theatre has combined elements of tikanga Māori with European theatre techniques, creating unique blends of 'traditional' and 'contemporary' cultural elements through theatre. Māori theatre has also been a significant influence upon theatre created by the Samoan community in Aotearoa, who have been integrating European theatre techniques and elements from popular culture with Samoan 'traditional' customs and forms of expression to create 'contemporary' works. This integration of cultural forms has been possible in Aotearoa through the creation of theatre training which uses methodologies and pedagogies which are embedded in and respectful of Indigenous cultural worldviews.

In Rapa Nui there is currently no institution in which to study theatre, and the development of intercultural theatre training in educational institutions in Chile is extremely important given the variety of Indigenous cultures living in the country. However, there is little possibility for exploring relationships between theatre and Indigenous epistemologies in Chile, reflecting fundamentally differences in the sociopolitical systems that are not so easy to contrast against each other. In addition, at present there are no Indigenous students or teachers who could take leading roles in implementing Indigenous protocols and rituals in relationship to theatre education.

This thesis has explored the different motivations of Māori, Samoan, and Rapanui theatre practitioners in developing culturally situated theatre forms and practices. In contemporary Rapa Nui, as in the early stages of Māori and Samoan theatre, the motivation for creativity has been primarily linked to cultural revitalisation and to 
preventing further loss of the Indigenous language. In contrast, Chapter Four showed that one of the main motivations for Māori and Samoan theatre practitioners was to create greater opportunities for Indigenous actors, who were under-represented in the New Zealand arts and media scene. The lack of stories and characters reflecting Māori and Samoan worldviews in Aotearoa also prompted the creation of 'contemporary' texts, and inspired a new generation of Indigenous writers.

The creation and production of new Indigenous plays had been crucial to the development of Māori and Samoan theatre in Aotearoa. The work of Writer's Block discussed in Chapter Five is an example of a group committed to the production of new plays written by people of Māori and Pacific Island descent. The idea of the group was not only to write new plays but also to stage them, thus generating new opportunities for both theatre practitioners and audiences from Māori and Pacific Island communities to get involved in theatre.

At present Rapanui theatre practitioners are not writing new stories. The focus so far has been on performing stories which have been orally transmitted across generations. These stories are understood to reflect worldviews of 'traditional' Rapanui society, and 'contemporary' Rapanui audiences relate to and value these stories. The Rapanui teacher Annette Zamora Rapu questions the use of the term a'amu tuai which translates as "telling old stories," as a description for Rapanui theatre because "it leaves out all possibility of creating a'amu api” meaning new stories (Zamora Rapu, 2014). Possibilities for new developments in the creative arts from where to explore the blending of 'traditional' and 'contemporary' cultural elements exist in Rapa Nui. As shown in Chapter Two, ONG Toki has been integrating classical musical instruments, such as piano, cello and violin with the Rapanui musical repertoire. However this combination has not yet been carried out in Rapanui theatre.

Indigenous theatre in Aotearoa is grounded in cultural ways of knowing and being, where theatre practitioners can express, explore, and discuss different issues related to contemporary life. The blending of formal and informal arts education, Indigenous rituals and epistemologies, politics and the performing arts in Aotearoa has created a rich, confident, and outspoken Indigenous theatre community, which not only explores and extends artistic aesthetics and possibilities, but also raises awareness and works towards social change through portraying Indigenous histories and experiences. 
Rapanui theatre faces significant challenges in terms of developing theatre forms and 'traditions' in a geographically isolated location which is still under colonial rule. Ongoing colonial understandings of the need to preserve 'traditional' forms combined with the ever-present demands of the tourist industry, means that the reproduction of 'traditional' styles and stories dominates creativity and performances in contemporary Rapanui society. Chapter Three showed that in Aotearoa tourist performances and aesthetic performance are quite separate, targeting a completely different audience. However in Rapa Nui the 'traditional' cultural elements that are created and re-created to satisfy the tourist industry has become a "straitjacket" (Wendt, 1978, p. 109) for most Rapanui artists. Rather than attempting to work outside of the demands of the tourist industry, Rapanui performances could use the tourist market as a platform through which to express their culture and views about contemporary issues, thus creating 'contemporary' works reflecting a distinct Rapanui worldview.

\subsection{Different Approaches and Conceptualisations: 'Traditional' and 'Contemporary' Theatre}

There is an agreement between scholars (Handler, 1984; Jolly, 1992; Mallon, 2012; Turner, 1997; Wendt, 1982; Watson, 2002) that notions of 'tradition' are not fixed or static. On the contrary, the maintenance of 'tradition' involves a constant recreation of the past in the present. Rather than being binaries or opposites, ideas of what is 'traditional' and 'contemporary' are intimately interconnected; these terms in fact define and construct one another.

Theatre is an art form which cannot be fixed in time. Each performance is ever-evolving, changing from day to day (Balme, 1998, p. 54). The re-creation of 'tradition' in the present (Handler \& Linnekin, 1984, p. 275) inevitably leads to the creation of 'contemporary' work, even though the artist's intentions might be to reproduce or adhere to notions of 'tradition.' 'Tradition' defines the space from which the artist faces and creates something new; enabling creative possibilities in the present which reference the past. This research illustrates that 'contemporary' work is defined in relation to how ideas about 'tradition' were constructed in particular cultural contexts and communities.

Inspired by the work of Albert Wendt this thesis has argued that no culture is static; and therefore there is no "state of cultural purity" (Wendt, 1982, p.206) to which artists and 
performers can return. Because notions of 'tradition' are always assessed through the values of the present, Wendt states that "there are no true interpreters or sacred guardians of any culture" (Wendt, 1982, p. 208). However, discourses in contemporary Rapanui culture do not regard culture and 'tradition' in this way. 'Contemporary' creativity involves claims about the 'purity' of culture, and this is linked to artists feeling the need to create 'authentic' representations of 'traditional' stories. Rapanui peoples who are involved in the performing arts tend to conceptualise themselves as "guardians of tradition" (Santa Coloma, 2006). This is in spite of all the changes that Rapanui society has gone through in modern times; for example aeroplanes reaching the island on a daily basis, and having access to the latest communication technologies such as the internet, modern phones, and the influence of tourism (Arthur De La Maza, 2009, p. 66).

In 2004 Van den Berg questioned whether Rapanui performing arts could adapt and survive, or if in the future they would become performances solely for tourist audiences. Her question retains its relevance more than ten years on. 'Contemporary' performances of Rapanui culture are an integral part of the tourist industry, leading to paid employment for many artists and performers. The economic sustainability that participating in 'traditional' Rapanui performances for the tourist market provides to Rapanui performers is a significant factor contributing to the cultural fixation on the representation and recreation of 'tradition.' This focus on 'tradition' prevents the development of theatre practices which seek to re-create or re-interpret histories and cultures through performances which blend 'traditional' themes and practices with components which are considered more 'contemporary' in style and subject matter. 'Traditional' Rapanui performances do not reflect or represent contemporary issues, adaptations, and realities. Instead they function to recreate European colonial notions of Rapa Nui as an unchanging 'paradise' somehow trapped in times past, and as a 'lost' island in the middle of the Pacific (Hotus, 2014). These performances use pre-colonial costumes that are seen as 'traditional' by the Rapanui community, however as discussed in Chapter Three these clothes are in fact reinterpretations of Tahitian and Chilean clothing (M. Fortin, 2010, p. 127). Ironically, by reinterpreting pre-colonial Rapanui clothing and blending it with Tahitian and Chilean clothing, Rapanui peoples are creating 'new traditions' in terms of how they visually represent themselves in the present to the wider Pacific, and to Chile. This demonstrates that even when the intention may be to represent 'tradition,' 'contemporary' elements almost inevitably creep in. As soon as aesthetic decisions have 
to be made by designers or artists, elements of 'contemporary' experience become implicated in the process.

\subsection{Intercultural Collaborations through Theatre}

Cultural encounters from a theatrical perspective which consider different understandings and approaches have been developed and used in different forms of intercultural theatre. Indigenous Plays produced within this 'intercultural' environment can be understood as forms of negotiation or collaboration, where different cultural heritage, and understandings intersect with and influence one another (Pavis, 1996, p. 4).

The work of theatre companies from across the globe continues to influence both Māori and Samoan diasporic theatre. This thesis has considered how international and intercultural collaborations have played an important part in developing theatre practices among these communities. In the 1980s Māori theatre practitioner Roma Potiki worked and collaborated with the Philippine community theatre company PETA. Later in 1990 Potiki adapted the teachings of PETA to her practice, developing the play Whatungarongaro (1990) with the Māori community theatre group He Ara Hou. The collaboration between Pacific Underground and the Australian theatre company ZEAL in 1996, the Māori version of Shakespeare's Troilus and Cressida (2012) presented at London's Globe Theatre, and The White Guitar (2015) which was a collaboration between Pasifika theatre company The Conch and Māori director Jim Moriarty, demonstrate that dialogue and negotiation between different cultural sensibilities, result in the creation and development of new Indigenous theatre forms, allowing people from different cultures to connect with and to learn from each other's cultural worldviews.

While collaboration with other theatre companies has been an important element in the development of Māori and Samoan theatre in Aotearoa, such collaborations have been scarce in Rapa Nui to date. Chilean theatre companies have performed in Rapa Nui between 2005 and 2011, and many of these groups have also conducted theatre workshops. However, these workshops have usually been designed as an extracurricular activity targeting children. These workshops have not developed theatre skills or collaborated with adults involved in the production of a'amu tuai. 
This represents an opportunity for future theatre workshops in Rapa Nui. These workshops, however, will need to be underlined by self-determination and therefore driven by Rapanui artists. In this way Rapanui artists will be able to determine how these intercultural collaborations and exchanges should take place, creating an opportunity in terms of ideational, intercultural exchange, and dialogue with other perspectives and practices in contemporary Rapanui society. Rapanui theatre has many 'traditional' performative elements from were to build upon and devolp 'contemporary' theatre practices, and these intercultural exganges will facilitate dialogue among different cultural sensibilities, inspiring one another, and from where more exchanges can be organised.

\subsection{Community Theatre and the Development of Māori and Samoan Diasporic Theatre}

The collaborative notion that involves community theatre is very appealing to Māori and Pacific Island theatre practitioners in Aotearoa (Samasoni, 1986, p. 15), where the foundation of Indigenous theatre has been driven by and for the Māori and Pacific Island communities, and based on feeding and teaching each other theatre skills. In my interviews, Hone Kouka stated that taking care of the cast members in any work produced by Tawata Productions is a priority allowing "the entire group to come together and feel comfortable with everybody during rehearsals" (Kouka, 2015), fostering a sense of belonging.

Community theatre involves community members working together, fostering a sense of belonging, and collaborating with artists who have been trained in theatre processes (Maunder, 2013, p. 21). In the early stages of Māori and Samoan diasporic theatre, community theatre was an important tool which helped communities share their stories and experiences with the wider community. Lo \& Gilbert (2014) describe community theatre as a form of "social engagement," where the relationship with audiences is crucial; not only to deliver the story to someone, but also because the aesthetics of the play are influenced by the audience's perspectives and backgrounds (Lo and Gilbert, 2002, p.14).

The inclusion of community theatre practices in Māori and Samoan theatre in Aotearoa has contributed to closing the gap between audiences and theatre. The fact that 
performances are often based on stories that are well known to Indigenous communities, that they relate to the life experiences of audiences, and are usually performed in Indigenous languages facilitates the participation of Indigenous peoples as audiences. This introduces them to an experience of theatre which represents their realities, perspectives, and concerns.

An example of how audiences have been developed through the work of community theatre companies can be found in the work of Samoan Pacific Underground and Māori He Ara Hou. Through including community theatre practices in their work, for example in Romeo and Tusi (2013) and Whatungarongaro (1990), respectively, these groups supported their own communities to understand and accept 'contemporary' Indigenous theatre as a valid form of social and cultural expression. Their work involved developing 'contemporary' stories written by Indigenous peoples, which reflect Indigenous worldviews and experiences. Through community theatre practices both Pacific Underground and $\mathrm{He}$ Ara Hou inspired and influenced members of their own communities in Aotearoa to become active audience members, and to become involved in the art of theatre.

'Contemporary' art in Rapa Nui is understood by many artists as a rupture with 'tradition,' where ancestral ways of knowing and being are not sufficiently acknowledged, showing that in Rapa Nui there is somewhat of a resistance to embracing syncretism. Community theatre principles, as they did for Māori practitioners in the 1980s, could support and inspire people from the Rapanui community to create and write scripts which reflect their culture, and how it intersects with their contemporary experiences. Exposing members of the community to theatre performed by Rapanui actors may inspire others to write and produce contemporary Rapanui theatre that will resonate with Indigenous Rapanui audiences and epistemologies. 


\subsection{Self-determination through Indigenous Theatre}

Colonial histories have undoubtedly effected the development of Māori, Samoan diasporic, and Rapanui theatre. Indigenous theatre across these locations arose as a response to social and political issues that were happening in each historical context. Māori theatre practitioner Roma Potiki explained that she understands theatre practice as a space from which to re-establish cultural identity, which involves Indigenous peoples producing their own stories. This understanding of Māori theatre has been described as a practice of self-determination (Durie, 1995, p. 46) or "Tino Rangatiratanga in action" (Potiki, 1991a, p. 57). This control that Māori people have claimed over their theatre creations relates to the right that Māori theatre practitioners have to determine what to perform, and how to present these performances to Māori and non-Māori audiences.

The notion of self-determination has also inspired the production of Samoan theatre in Aotearoa, in which texts, characters, and performances reflecting Samoan points of view have been produced. In the case of Rapanui theatre, the work of Mata Tu'u Hotu Iti in the 1970s acted as an agent for self-determination through theatre. The group determined what Rapanui performances should look and sound like and what stories they should tell, breaking new ground, and excluding Chilean forms of expression that were dominant at the time.

The inclusion of Indigenous languages in theatre has been a significant marker of selfdetermination. Although not everybody participating in Māori, Samoan and Rapanui theatre speaks their own Indigenous languages, including them in their theatre practice has supported the revitalisation of Indigenous languages on a larger scale. One example of this is Te Reo Season which was developed by Taki Rua in the 1990s and contributed to the development of Māori audiences. This was achieved not only by performing Māori stories in Māori language, but also by touring these productions to different Māori language schools, thus contributing to the overall development of Māori theatre in Aotearoa. 


\subsection{Intercultural Theatre Training: The Integration of 'Traditional' Cultural Elements with European Theatre Techniques}

Theatre training has played a key role in the integration of 'traditional' cultural elements and in some cases in the integration of elements from popular culture with European theatre techniques. Different theatre training techniques that have been developed and used by Māori and Samoan theatre practitioners in Aotearoa which are grounded in culturally respectful and reflective Indigenous processes, worldviews, stories, and ways of knowing and being in the contemporary world. Many Māori theatre practitioners use 'traditional' Māori rituals such as the pōwhiri, karanga, and karakia as part of theatre training methodologies that emphasise reciprocity and collaboration as fundamental principles. Examples of this practice can be seen in the theatre training offered by the New Zealand Drama School Toi Whakaari, the Bicultural Theatre paper conducted by Hilary Halba and Rua McCallum at Otago University, as well as in the Māori theatre company Te Rakau Hua O Te Wao Tapu directed by Jim Moriarty.

Training can be taught through professional training, or by professional artists leading non-professionals who will gain craft skills on-the-job, by participating and performing in a theatre company. Pacific Underground used school performances as a form of theatre training, and as tools to gain experiences in theatre practice. This approach has been a part of their methodology since the early stages of the group's formation. Through these school performances PU had the opportunity to share moments from Samoan history with young people from the community, many of whom were born in Aotearoa and may not ever have been to Sāmoa. These school performances also led to workshops with audience members that resulted in new company members being recruited. Theatre companies in Aotearoa and Rapa Nui have taught theatre skills through apprenticeship, where its participants have later on created their own theatre companies and passing on knowledge to others. For example, Miria George and her creative writing workshop in Rarotonga where she taught skills learnt at the Writers Block workshop in Aotearoa. In an interview with Christopher Balme, Roma Potiki stated "[i]t is political if it can be passed on" (Balme, 1996b), acknowledging the importance of learning new skills and transmiting knowledge among Indigenous practitioners to develop culturally reflective 'contemporary' theatre. This political act becomes an agent of change by demonstrating and developing the skills that will help the "transformation" (Boal, 2000, p. xiii) of 
society. An example of theatre training as an agent for social transformation can be found at Whitireia and PIPA in Aotearoa. Both institutions offer curriculum foundation courses in performing arts, through which to build confidence, self-esteem, a sense of purpose, and discipline encouraging young people into further education.

Learning the craft of theatre is essential to performing stories on stage to an audience. One of the biggest criticisms that the creative community in Rapa Nui make about a'amu tuai, Rapanui's Indigenous theatre form, is the lack of preparation and rehearsal that is often evident in the plays performed during Tapati Rapa Nui. Despite the efforts of many people involved in Rapanui theatre, the absence of theatre training opportunities in Rapa Nui means that the skills and support needed to theatrically embed local content in performances are often missing. Sometimes this can lead to confusion for people who are not part of the Indigenous community and are not familiar with the stories being presented. Clarity is crucial in any theatre production, if the message or the story does not reach the audience, the experience of theatre is not happening. Boal states that:

[T]he most important characteristic of the theatre that addresses itself to the people must be its permanent clarity, its ability to reach the spectator - appealing to his intelligence and sensitivity (Boal, 2000, p. 72).

Rapanui artists Carlos Lillo Haoa and Tiare Iti Araki Pont claim that Rapanui theatre is lacking in clarity and the ability to reach out to audiences. A 'amu tuai performances were suspended from the Tapati Rapa Nui Festival between 2012 and 2014 due to a series of performances which were critiqued for lacking clarity and preparation (Araki Pont, 2014). If this continues it seems likely that a'amu tuai will be at risk of suspension again, and as one of the major annual forums for theatre performances, this will have significant and ongoing consequences for the production of Rapanui theatre.

The development of theatre training that is grounded in culture and Indigenous epistemologies has positively influenced the integration of 'traditional' cultural elements in the production of 'contemporary' Māori and Samoan theatre in Aotearoa. Māori theatre practitioners have developed a myriad of ways to integrate 'traditional' practices with European theatre techniques in the production of 'contemporary' Māori theatre. Māori performing arts such as the haka and the use of the poi, as well as rituals such as the karanga, and the pōwhiri have been de-constructed, de-contextualised, and reintegrated into theatre rehearsal processes and productions as new elements with new 
meanings and functions. Examples of these contemporary uses of Māori performing arts can be found in Hone Kouka's plays $T \bar{U}$ (2012), and The Beautiful Ones (2013). In the former he deconstructs the haka and the poi, giving these performance forms new meaning within the context of the play. In the latter he created a contemporary aesthetic for the pōwhiri that was performed at the beginning of the play.

Samoan diasporic theatre practitioners also integrate 'traditional' cultural elements with European theatre techniques in their 'contemporary' work. Some Samoan theatre practitioners in Aotearoa also combine elements from popular culture in their theatre productions, reflecting the new contexts in which they live, and the range of different influences upon their creativity. Samoan theatre practitioners in Aotearoa encourage the use of all possible tools available in order to tell a story. The possibilities for the style and content of creativity among the Samoan theatre community are wide open, and have undoubtedly been influenced by the ground-breaking work of Māori theatre practitioners. Through combining 'traditional' and popular elements, such as using music by Christina Aguilera and Beyoncé in plays such as The Eel and Sina (2015) or through incorporating Kung Fu movements, as is the case in Frangipani Perfume (1998), Samoan diasporic theatre connects with and relates to younger audiences. The use of these different tools has also allowed Samoan theatre to share significant episodes from Samoan history with the New Zealand-born Samoan community who may not be fully familiar with Samoan history, customs, and language.

The role that has been given to elders in Māori and Samoan theatre practices in Aotearoa is reflective of their roles in the wider Indigenous community. Elders have been significant to the integration of 'traditional' cultural practices into the 'contemporary' works. Following the work of Annie Ruth (2013), I argue that working with elders who represent communities and traditions contributes to the application of "the principles beneath these cultural practices, rather than appropriate[ing] their original form into a theatrical context" (Ruth, 2013, p. 14). The ethics, values and principles underpinning 'traditional' Rapanui practices such as the karana, umu tahu, and umu hatu could also be explored and applied to 'contemporary' Rapanui theatre productions, leading to a revitalisation of 'traditional' rituals that some participants in this research have argued are at risk of being forgotten (Haoa Cardinali, 2014). As suggested by Rapanui historian Moreno Pakarati in Chapter Five, the integration of these practices could be framed by the concept of umana, meaning mutual collaboration. This concept involves values of 
reciprocity and partnership that are also central to the theatre practices which have been developed and that seek to reflect a Māori worldview. According to Moreno Pakarati, many people in contemporary Rapanui society seem to have forgotten the concept of umana due to aspects of modern life such as individualism (Moreno Pakarati, 2014). Using the concepts of umana to inform and inspire theatre training could lead to a reconsideration and dialogue around the relevance of the concept in the wider 'contemporary' Rapanui community.

\subsection{Theatre: A Liminal Space}

This thesis has conceptualised theatre practices as creating a liminal space, drawing on two understandings of this concept. Firstly, following the work of Janinka Greenwood (1999) and Homi Bhabha (2012), theatre practice has been understood as a third space in which different cultures can intersect. Secondly, theatre practice has been understood as a liminal space where 'traditional' and 'contemporary' practices intersect.

Balme (1999) and Kouka (2007) described Māori theatre as syncretic and hybrid respectively, because they combine Indigenous and Western theatre epistemologies. Notions of syncretism and hybridity can be applied to Māori, Samoan diasporic and Rapanui theatre because they are constantly blending 'traditional' and 'contemporary' cultural elements in their theatre productions; thus creating a liminal space. The existence of this liminal space enables Indigenous theatre practitioners to use and adapt 'traditional' practices and ceremonies to the new context of 'contemporary' theatre, conferring new meanings on these 'traditional' practices. For example integrating 'traditional' Rapanui practices such as karanga and umaya with contemporary forms of expression.

This research has sought an inclusive conceptualisation of knowledge by advocating for the use of both Western and Indigenous methodologies in the creation of theatre. The combination of three different languages used throughout this research, demonstrates an approach which values and includes a range of different perspectives embedded in language, but which also affirms the possibility of translation and understandings across linguistic worlds. The communicative and relational qualities of theatre mean that theatre is a place which can facilitate dialogue between cultures. In Chapter Two and Four I have documented how Indigenous peoples in Aotearoa and Rapa Nui have engaged in forms 
of dialogue with their colonial counterparts through theatre. Theatre productions based on historical episodes and facts from an Indigenous perspective have allowed audiences to learn from other versions of history. These theatre productions have contributed to dialogue across cultures, adding silenced and marginalised accounts of history to the stories we tell which make up 'history,' and helping to close the gap between cultures.

\subsection{Policy Implications and Possibilities for Theatre Practice in Rapa Nui}

Reflecting on the experiences that Māori and Samoan theatre practitioners have had in the production of theatre throughout history, I argue that there are five main aspects that could influence the development of Rapanui theatre. The availability of theatre training which will allow Rapanui theatre practitioners to learn the craft of theatre is crucial to the development of new works and directions. Writer's training is another aspect which has been crucial to the development of Māori and Samoan Diasporic Theatre in Aotearoa/New Zealand. Intercultural collaborations through theatre practice in Aotearoa has produced a variety of performances, learning environments and opportunities for discussion with the wider community. The assessment of creative processes under Kōiwi has enabled students and staff at Toi Whakaari Drama School in Aotearoa to work in collaboration, creating and producing theatre which is based on Indigenous ways of knowing and being. Finally, I have argued that theatre is an art that needs regular practice to ensure that a performer's skills are maintained and developed over time. Performing regularly at different schools, in the same way in which PU used to do, could provide a space in which to practice and develop theatre skills.

Aldea Educativa Honga'a O Te Mana is the Rapa Nui school that has produced the most theatre to date. At this school Carlos Lillo Haoa has produced various different plays since 2008, presenting them mainly in November at Manaha o Te Re'o the Rapa Nui Language Day celebrations. An interesting aspect of this school is that it focusses on technical education, enabling students in their final years of education to finish High School with certificates in Agriculture and Tourism. 
I suggest that this school would be a good place to offer a certificate in Rapa Nui performing arts and/or theatre, where it would be possible to incorporate and develop some of the methods and ideas proposed in this research. Such a programme teach Rapa Nui 'traditional' performing arts such as kaikai (string figures), takona (body painting), patau'u ta'u (recitations), ori (dance) and old songs such as riu and ute. It could also explore ways in which to reflect upon these 'traditional' forms, through incorporating aspects of popular culture and using European theatre techniques to create 'contemporary' forms of Rapa Nui theatre. Students could also explore new forms of expression, for example, playwriting, producing new work, and collaborating in the development of Rapa Nui 'contemporary' theatre.

For Māori and Samoan Diasporic Theatre in Aotearoa, the development of a theoretical and conceptual foundation based on Indigenous cultural world views has been crucial, in which the guidance of elders and kaumatua has been important to developing culturally respectful protocols in Aotearoa. To create a performing arts and theatre qualification, Rapa Nui will need to develop such theoretical and conceptual foundation based on a Rapa Nui Indigenous cultural worldviews. Rapa Nui values then would be at the core of all theatre practice, and as the basis of working together, writing and rehearsing. At this point in my research, I am not sure who could develop such a conceptual work in Rapa Nui, certainly it will have to be a group of people including elders, teachers, Rapa Nui performers and curriculum planners. This is an important issue to be acknowledged as a limitation in my recommendation for policy and development. The next steps of this ongoing research will be gathering practitioners in Rapa Nui together to discuss about how Rapa Nui cultural processes and understandings could be used to ground the design of a new programme in theatre and performing arts which is unique to Rapa Nui, and then designing it which will be a challenging task.

The incorporation of a certificate in performing arts and theatre as part of the school's curriculum could be beneficial for students for several reasons. Firstly, through this certificate, students could professionalize their performing arts practice. Secondly, education about 'contemporary' theatre practices and techniques could lead to these being attributed greater value within the school context. Thirdly, the integration of 'traditional' Rapa Nui cultural elements with popular culture and European theatre techniques could be achieved as part of the learning process. Locating theatre education in school rather than hoping that these developments will happen within the wider 
community of performers in Rapa Nui is more realistic given the ongoing and significant pressures of the tourist market. Although tourism is the main driver for the performing arts in Rapa Nui, the industry significantly limits creative possibilities by demanding the creation and production of profitable performances, hat adhere to ideas of 'traditional' culture, and satisfy the tourist gaze.

This research has demonstrated that performing arts education in Aotearoa has served as a tool to encourage students who might otherwise leave formal education to continue on into higher education, and I argue that this might also be a possible outcome for the Rapa Nui context. Tertiary Institutions such as Whitireia and the Pacific Institute of Performing Arts (PIPA) offer foundation courses in performing arts. These courses are designed to enhance the student's abilities, self-esteem, and to encourage them to continue on into higher education in the performing arts. By implementing a certificate in Rapa Nui performing arts and theatre, the same could be achieved in Rapa Nui. The Aldea Educativa Honga'a o Te Mana High School could enhance performance skills, and design a programme which seeks to develop self-esteem amongst students through culturally reflective and culturally situated theatre practice. Using theatre education in schools as a basis for developing a wider interest in the performing arts could inspire Rapa Nui students to go to Chile or somewhere else to further their studies. This thesis has shown that inter-cultural collaborations and exchanges in theatre practice have been important to the development of Maori and Samoan Disporic Theatre in Aotearoa, and students who choose to study theatre and performance outside Rapa Nui could potentially engage in rich intercultural collaborations, where they can contribute a distinct Rapa Nui perspective on the process of creating and producing theatre, and also learn new techniques and methodologies which could then be incorporated into 'contemporary' theatre practices in Rapa Nui. The feasibility and viability in the implementation of these processes will be explored in the future in collaboration with the Rapanui community.

\subsection{Original Contribution to Knowledge and Conclusion}

Many articles and some books have been written about the development and influences of Māori and Pacific Island theatre in Aotearoa and in Oceania, however very little has been written about 'contemporary' Rapanui theatre practices. For example, the book Pacific Performances (2007) by Christopher Balme does not mention the production of 
theatre in Rapa Nui. Remaking the Pacific Pasts: History, Memory and Identity in Contemporary Theatre from Oceania (2014) by Diana Looser, only briefly mentions the cultural festival Tapati Rapa Nui. This thesis addresses this gap in scholarly analysis of theatre practice in Oceania. Since the year 2000 I have been researching Rapanui theatre from a practitioner's perspective, focusing on the craft of theatre, through performing, recording and analysing the development of Rapanui theatre.

This is the first research which compares Māori, Samoan and Rapanui perspectives on theatre practice. Using a combination of qualitative research methods including talanoa, and understanding my positionality through the lens of a Multi Perceptive Culturally Responsive (MPCR) researcher (Clery et al., 2015), I have engaged in original research with artists and performers in Aotearoa and Rapa Nui, generating new knowledge about blends of 'contemporary' and 'traditional' cultural practices in the theatre that have been produced by three different Pacific Island cultures.

Attitudes towards the concepts of 'traditional' and 'contemporary' vary among Māori, Samoan, and Rapanui theatre practitioners. Māori and Samoan theatre practitioners in Aotearoa generally understand 'tradition' as a platform for 'contemporary' creation. For example, this sentiment is shared by both the Māori theatre practitioner Hone Kouka (2015), and the Samoan actor Iaheto Ah Hi (2014). These artists see 'tradition' as an important reference point for contemporary creativity. In fact, in my interviews kapa haka performer Kereama Te Ua stated that "if my ancestors had lights and music they would've used them ... and now we would call them traditional" (Te Ua, 2015). This statement proves that Indigenous theatre practitioners in Aotearoa conceptualised 'tradition' as evolving and able to adapt to change, allowing an open re-interpretation and re-creation of 'tradition' in the present, thereby creating 'new' traditions.

The understanding of both terms as inextricably interconnected has enabled Māori and Samoan theatre practitioners in Aotearoa to incorporate 'traditional' and 'contemporary' cultural elements in their theatre works. Doing so, these Indigenous theatre practitioners made the boundaries between 'traditional' and 'contemporary' more permeable, challenging the idea that these terms 'traditional' and 'contemporary' are binary and opposites. The blending of 'traditional' cultural elements with 'contemporary' practices in Māori and Samoan theatre in Aotearoa is part of a continuum through which notions of what is 'traditional' are continuously defined and re-interpreted in the present. What is 
considered to be 'contemporary' today may become the 'tradition' that will influence Indigenous cultural practices and forms of creativity in the future.

In Rapa Nui, 'tradition' is a notion which is more stringently upheld, and there seems to be a general reluctance to deviate from 'tradition' in the contemporary performing arts. 'Traditional' cultural practices are favoured over 'contemporary' work. As stated by Julio Hotus (2014) in Chapter Three, 'contemporary' theatre is understood as something that comes from the outside, and this is seen as something that should be resisted. Mirroring the focus and concerns of artists in the early stages of Māori theatre, Rapanui theatre practitioners are seeking to reclaim their stories, language, cultures and traditions as a response to the ongoing history of colonialism in the nation. In Rapa Nui 'contemporary' creativity is not understood as the constant and fluid interaction of worlds and values, both past and present. Cultural heritage is seen as something which needs to be preserved, and the re-creation of stories and creative forms that are considered to be 'traditional' is the focus of much 'contemporary' creativity.

Another original contribution of this research is that it brings together a wide range of critical literature, across multiple languages. One barrier for Rapanui peoples to communicate with other Polynesian peoples is the language of colonisation, because they are Hispanophones. Literature about historical developments and influences of theatre in Polynesia has mostly been written in English. This research has also been written in English; however it will be translated into Spanish before being submitted to the William Mulloy Library in Rapa Nui. The translation of this research into Spanish, and my own practice using material learned in the process of this research in the theatre education community in Rapa Nui will act as an extension of the talanoa sessions initiated with this research that seeks to put New Zealand's Indigenous theatre in dialogue with that of Rapa Nui. Other ways of addressing accessibility for broader Rapanui community to this research is to publish articles about this research in the Rapanui open access journal Moe Varua. In this way, the Rapanui community will be able to access material about the historical development of Māori and Samoan theatre in Aotearoa that would otherwise be inaccessible because it is written in English.

The conceptual framework guiding this research is based on dialogue and intercultural collaboration which is an original contribution of this research to the field of Theatre Studies. This framework argues that theatre practice can support different ways of seeing 
and understanding creating an intercultural dialogue. The Spanish title of this chapter acknowledges this conceptual framework. The proverb "Atender y Entender para Aprender" translates as "Pay Attention and Understand to Learn." The proverb refers to the process of gaining knowledge, in which paying attention to what is being said, shown and done are key aspects in gaining new knowledge. The second factor involves the act of understanding. There are significant aspects in the concept to 'understand,' including empathising with what is being said or shown. Theatre's ability to increase empathy between people is very strong, allowing us to experience and to imagine a day in the life of someone whose daily realities and culture may be very different from our own. Different opinions and ideas can be shared, enabling us to learn in collaboration with others and to reflect upon our own context and see how our cultural situations and understandings shape our realities and perspectives.

This research guided me through a journey where I learnt and experienced Indigenous forms of producing theatre within a Polynesian context that I will share with Rapanui theatre practitioners on my return to Rapa Nui. As a member of the Rapanui community I have been involved in Rapanui performing arts and theatre for over ten years. It is my intention to continue to be involved in theatre production in Rapa Nui, either by producing and directing plays, or by facilitating theatre workshops where I will apply the findings of this research as part of my methodology.

This research is my way of giving back to a community that has been generous enough to accept my family and myself. On my return to Rapa Nui, I will present the findings of this to the Rapanui community, in the same way I did as part of the process of fieldwork. I hope that this presentation will open a dialogue about the Rapanui theatre production in the present, and contribute to the discussion of the possible ways in which 'contemporary' Rapanui theatre might go in the future. 


\section{Bibliography}

Ah Hi, I. (2014, March 1). Interview/Talanoa with Moira Fortin in Wellington.

Alfaro, L., \& Sura, C. (2007). Teatro Comunitario como Proceso de Transformación Social. Sistematización de Tres Experiencias en Chile: Un desafío para el Trabajo Social Comunitario. (Dissertation). Universidad Tecnologica Mtropolitana, Santiago Chile.

Alvarado, R. (2006). El Teatro Chileno Bajo la Dictadura. Escenario de Resistencia. Archivo Chile. Historia Politico Social - Movimiento Popular.

Anae, M. (2002). Palagi Redefined: Toward a New Zealand-Born Samoan Identity. In P. Spickard, J. L. Rondilla, \& De. H. Wright (Eds.), Pacific Diaspora. Island Peoples in the United States and Across the Pacific (pp. 150-168). Honolulu, Hawaii: University of Hawaii Press.

Andrade, P. (2004). Artifices del Imaginario. La Puesta en Escena, una Aproximacion a la Construccion de Identidad Rapa Nui. Universidad Academia del Humanismo Cristiano, Santiago Chile.

Anuanua Dance Troupe. (2013). Anuanua Dance Troupe. Retrieved March 11, 2015, from http://www.anuanuadance.com/

Araki Pont, T. I. (2014, July 17). Interview/Talanoa with Moira Fortin in Rapa Nui.

Ariyoshi, R. (2003). All the Spirit of the Islands. Laie, Hawaii: Polynesian Cultural Center of the Church of Jesus Christ of Latter-Day Saints.

Arredondo, A. M. (2009). Rapa Nui: Takona Tatu. Rapanui Press.

Arredondo, A. M. (2012). Historia de la Educacion en Isla de Pascua: Primera Parte 1864 - 1956. Apuntes Del Museo, 1, 53-81. 
Arredondo, A. M. (2013). Historia de la Educacion en Isla de Pascua. Segunda Parte 1956-1997. Apuntes de Museo, 2, 117-138.

Arredondo, A. M. (2014, July 28). Interview/Talanoa with Moira Fortin in Rapa Nui. Artaud, A. (1970). The Theater and Its Double. (V. Corti, Trans.). London: Calder and Boyars Ltd.

Arthur De La Maza, J. (2009). Hakari o te Rapa Nui. Representacion del Mito en Rapa Nui: de Ritual Ancestral a Performance Postmoderna. Catedra de Artes, 7, 65-92. Ashley, L. (2013, February 27). Mixed Nuts 3 - Mythical - Show Puts Put a Smile on Your Heart. Retrieved September 27, 2015, from http://www.theatreview.org.nz/reviews/review.php?id=5579

Atkinson, L. (1997, December 18). Three Sisters Prove Highly Entertaining. The Evening Post.

Atkinson, L. (2010, November 17). The Ragged. Retrieved September 22, 2015, from http://www.theatreview.org.nz/reviews/production.php?id=1867

Atkinson, L. (2014, September 30). Actors and Acting. Retrieved February 20, 2015, from http://www.teara.govt.nz/en/actors-and-acting

Balme, C. (1989). New Māori Theatre in New Zealand. Australasian Drama Studies, $15 / 16,149-166$.

Balme, C. (1996a). Between Separation and Integration: Intercultural Strategies in Contemporary Māori Theatre. In P. Pavis (Ed.), The Intercultural Performance Reader (pp. 179-187). London: Routledge.

Balme, C. (1996b). It is Political if it can be Passed On: An Interview with Roma Potiki. In P. Pavis (Ed.), The Intercultural Performance Reader (pp. 172-178). London: Routledge. 
Balme, C. (1998). Staging the Pacific: Framing Authenticity in Performances for Tourists at the Polynesian Cultural Center. Theatre Journal, 50(1), 53-70.

Balme, C. (1999). Decolonizing the Stage: Theatrical Syncretism and Post-colonial Drama. Oxford University Press.

Balme, C. (2007). Pacific Performances: Theatricality and Cross-Cultural Encounter in the South Seas. New York: Palgrave Macmillan.

Balme, C., \& Carstensen, A. (2001). Home Fires: Creating a Pacific Theatre in the Diaspora. Theatre Research International, 26(1), 35-46.

Barba, E. (2002). The Essence of Theatre. TDR/The Drama Review, 46(3), 12-30.

Barthel, T. (1962). Masken und Theaterwessen in der Alten Kultur der Oster Insel. Sonderdruck aus Akten des Internationales Amerikanistenkongresses, (34), 653661.

Baskerville, D. (2009). Navigating the Unfamiliar in a Quest Towards Culturally Responsive Pedagogy in the Classroom. Teaching and Teacher Education, 25(3), $461-467$

Beckwith, M. W. (1970). Hawaiian Mythology. United Staes of America: University of Hawaii Press.

Belich, J. (2007). Making Peoples. A History of the New Zealanders: from Polynesian Settlement to the end of the Nineteenth Century (2nd ed.). North Shore, N.Z.: Penguin Group New Zealand.

Bendrups, D. (2000). The Liminal Researcher in Ethnomusicology: An Approach to the Study of Latin American Migrant Music. Context: Journal of Music Research, (20), 35 .

Bendrups, D. (2005). Continuity in Adaptation: A History of Rapa Nui Music (PhD). Macquire University, Sydney Australia. 
Bendrups, D. (2006). War in Rapanui Music: A History of Cultural Representation. Yearbook for Traditional Music, 38, 19-33.

Bendrups, D. (2008). Pacific Festivals as Dynamic Contact Zones. Shima: The International Journal of Research onto Island Cultures, 2(1), 14-28.

Berthold, M. (1991). History of World Theater: From the Beginnings to the Baroque. New York: Bloomsbury Academic.

Betz, A. (2003). Die Inszenierung der Südsee: Untersuchung zur Konstruktion von Authentizität im Theater. Munich, Germany: Herbert Utz Verlag.

Bhabha, H. K. (1990). Nation and Narration. Psychology Press.

Bhabha, H. K. (2012). The Location of Culture. New York: Routledge.

Bhattacharjee, J. (2015). Constructivist Approach to Learning - An Effective Approach of Teaching Learning. International Research Journal of Interdisciplinary \& Multidisciplinary Studies (IRJIMS), I(VI), 65-74.

Bishop, R. (1998). Freeing Ourselves from Neo-Colonial Domination in Research: A Māori Approach to Creating Knowledge. Qualitative Studies in Education, 11(2), 199-219.

Black, S. (1999). Using Polynesian Legends and Folktales To Encourage Culture Vision and Creativity. Childhood Education, 75(6), 332-36.

Boal, A. (2000). Theater of the Oppressed (2nd ed.). London: Pluto Press.

Boal, A. (2002). Games for Actors and Non-Actors (2nd ed.). New York: Routledge.

Boersema, J. J. (2015). The Survival of Easter Island. Dwindling Resources and Cultural Resilience. (D. Webb, Trans.). New York: Cambridge University Press.

Bradby, D. (Ed.). (2006). Editor's Introduction. In J. Lecoq, Theatre of Movement and Gesture. New York: Routledge. 
Bring It On Auckland. (2012, February 26). Bring It On Auckland. Retrieved July 29, 2015, from https://www.facebook.com/pages/Bring-It-OnAuckland/273729789364618?sk=info

Brooking, T. (2004). The History of New Zealand. Westport: Greenwood Press.

Buck, P. (1950). The Coming of the Māori. Wellington, NZ: Whitcombe \& Tombs.

Budd, S. (1997, December 19). Sweet-scented Memories. The Domion.

Bustamante Diaz, P., Viguie Juan, P., Andoue Lelandais, M., \& Tuki Tepano, R. (2008, Enero). Rapa Iti como Candidata a ser Identificada como Hiva, Tierra de Origen del Pueblo Rapa Nui. Retrieved September 24, 2015, from http://www.rupestreweb.info/rapa.html

Byrnes, V. (1999). Constructing the Stuff that Dreams are made on: "Bi-Cultural" Processes of Investigation and Training at Toi Whakaari: New Zealand Drama School. In Industrial Relations. A Conference Exploring the Links between Theatre Scholarship and Professional Theatre Practice. Queensland University of Technology.

Calman, R. (2013, June 20). Māori Education - Mātauranga. Retrieved February 20, 2015, from http://www.teara.govt.nz/en/maori-education-matauranga Campbell, D. (2012). Foreword. In P. Methven, 25 Years Leading and Illuminating. Whitireia New Zealand. Wellington, NZ: Steele Roberrts Publishers.

Campbell, I. C. (2001). Island Kingdom: Tonga Ancient and Modern. Canterbury University Press.

Carnicke, S. M. (2009). Stanislavsky in Focus (2nd ed.). London: Routledge Taylor \& Francis Group.

Carter, A. (2002). Taking Centre Stage: Pacific Theatre in New Zealand. In S. Mallon \& P. F. Pereire (Eds.), Pacific Art Niu Sila: The Pacific Dimension of Contemporary 
New Zealand Arts (pp. 147-159). Wellington: Te Papa Press, Museum of New Zealand.

Castro, N. (1996). Misioneros y Milenaristas: Isla de Pascua 1864-1914 (Dissertation). Universidad de Valparaiso, Valparaiso Chile.

Chapman, T. M. (1982). Niue: A History of the Island. Alofi, Niue: Institute of Pacific Studies.

Clery, T. N. (2013). The Art of Peace: Performative and Arts-based Peace Practices in Contemporary Fiji (PhD). Otago University, Dunedin New Zealand.

Clery, T. N. (2014). Extending Talanoa: Weaving Pacific and Performative Methods for Peace Research in Contemporary Fiji. In P. Fairbairn-Dulop \& E. Coxon (Eds.), Talanoa. Building a Pasifika Research Culture. Auckland, NZ: Dunmore Publishing Ltd.

Clery, T. N., Cochise, A. D., \& Metcalfe, R. (2015). Research is Relational: Exploring Researcher Identities and Colonial Echoes in Pacific and Indigenous Studies. Pacific Studies, 38(3), 303-326.

Clifford, J. (1994). Diasporas. Cultural Anthropology, 9(3), 302-338.

CNCA. (2003). Quiénes Somos. Retrieved from http://www.cultura.gob.cl/institucion/quienes-somos/

Cocke, D., Newman, H., \& Salmons-Rue, J. (Eds.). (1993). From the Ground Up: Grassroots Theater in Historical and Contemporary Perspective. Ithaca, NY: Community Based Arts Project, Cornell University.

Cohen, N. (2013, February 17). Black Faggot. Retrieved April 28, 2015, from http://www.theatreview.org.nz/reviews/review.php?id=5491

Coleman, E. (2012, March 3). TU - Life in the Raw after the War. Retrieved September 22, 2015, from http://www.theatreview.org.nz/reviews/review.php?id=4610 
Cook, V., \& Bassetti, B. (Eds.). (2011). Language and Bilingual Cognition. New York: Psychology Press.

Cowlishaw, S. (2014, January 25). Inside Arohata Women's Prison. Stuff.co.nz.

Retrieved from http://www.stuff.co.nz/dominion-

post/news/wellington/9649950/Inside-Arohata-Womens-Prison

Craig, R. D. (2004). Handbook of Polynesian Mythology. Santa Barbara: ABC-CLIO.

Crompton, J. L., \& McKay, S. L. (1997). Motives of Visitors Attending Festival Events. Annals of Tourism Research, 24(2), 425-439.

Dahlberg, T. R. M. (1996). Māori Representation in Parliament and Tino Rangatiratanga. He Pukenga Korero, 2(1), 62-72.

Dansey, H. R., \& Dansey, T. R. D. (2013, June 7). Dansey, Harry Delamere Barter. Retrieved June 21, 2015, from http://www.teara.govt.nz/en/biographies/5d3/dansey-harry-delamere-barter

De Toro, A. (1991). Los Caminos del Teatro Actual: Hacia la Plurimedialidad Espectacular Postmoderna o el Fin del Teatro Mimetico Referencial? (pp. 21-72). Presented at the Ibero-Amerikanisches Forshungsseminar, Leipzig, Germany. Delilkan, S. (2011, August 14). Review: The Factory (Kila Kokonut Krew). Killer Kreation Knocks yer Socks off. Retrieved June 30, 2015, from http://www.theatrescenes.co.nz/review-the-factory-kila-kokonut-krew/

Delsing, R. (2004). Colonialism and Resistance in Rapa Nui. Rapa Nui Journal, 18(1), $24-30$

Derby, M., \& Grace-Smith, B. (2014, May 13). Māori Theatre - Te Whare Tapere Hōu. Retrieved May 20, 2014, from http://www.teara.govt.nz/en/maori-theatre-tewhare-tapere-hou/page-1 
Desmond, J. (1999). Staging Tourism: Bodies on Display from Waikiki to Sea World. University of Chicago Press.

Downes, P. (1975). Shadow on the Stage: Theatre in New Zealand - The First 70 Years. Dunedin: J. McIndoe.

Dubatti, J. (2011). Introduccion a los Estudios Teatrales. Mexico: LIbros de Godot.

Durie, M. H. (1989). The Treaty of Waitangi Perspectives for Social Policy. In I. H. Kawharu, Waitangi: Māori \& Pākehā Perspectives of the Treaty of Waitangi. Auckland, NZ: Oxford University Press.

Durie, M. H. (1995). Tino Rangatiratanga: Māori Self-determination. He Pukenga Korero - A Journal of Māori Studies, 1(1), 44-53.

During, S. (1991). Waiting for the Post: Some Relations between Modernity, Colonization and Writing. In I. Adam \& H. Tiffin (Eds.), Past and the Last Post: Theorizing Post-Colonialism and Post-Modernism. California: Harvester Wheatsheaf.

Education Review Office. (2012). Improving Education Outcomes for Pacific Learners. Education Review Office Te Tari Arotake Matauranga. Retrieved from http://www.ero.govt.nz/National-Reports/Improving-Education-Outcomes-forPacific-Learners-May-2012/Introduction/The-Pasifika-Education-Plan-2009-2012 El Mercurio. (1995, April 16). En Isla de Pascua Polinesicos se Reuniran tras Un Milenio de Separacion. El Mercurio.

Englert, S. (1980). Leyendas de Isla de Pascua. Santiago Chile: Ediciones de la Universidad de Chile.

Englert, S. (2007). La Tierra de Hotu Matu'a: Historia y Etnología de la Isla de Pascua. 1948. (2nd ed.). Rapa Nui: Rapanui Press. 
Ete, M. (2013, March 11). Te Rau O Te Rangi - The Love, the Hardship, the Journey. Retrieved September 22, 2015, from http://www.theatreview.org.nz/reviews/review.php?id=5677

Evans, M. (2015). The Actor Training Reader. New York: Routledge.

Fagg, W. (1973). The African Artist. In D. P. Biebuyck (Ed.), Tradition and Creativity in Tribal Art (pp. 42-57). Berkeley: University of California Press.

Farrell, B. (1979). Tourism's Human Conflicts: Cases from the Pacific. Annals of Tourism Research, 6(2), 122-136.

Farrell, B. (Ed.). (1980). Pacific Tourism, as Islanders See it. Suva, Fiji: University of the South Pacific.

Fischer, H. (1998). Schatten auf der Osterinsel: Plädoyer für ein Vergessenes Volk. Oldenburg: Bis, Bibliotheks- und Informationssystem der Universität Oldenburg.

Fischer, S. R. (2005). Island at the End of the World: The Turbulent History of Easter Island. London: Reaktion Books.

Flintoff, B. (2014, October 23). Māori Musical Instruments - Taonga Puoro. Retrieved August 3, 2015, from http://www.teara.govt.nz/en/maori-musical-instrumentstaonga-puoro

Forster, M., \& Plumb, V. (2013). Twenty New Zealand Playwrights. Wellington NZ: Playmarket.

Fortin, M. (2009). Takona: Body Painting in Rapa Nui Performing Arts. Australasian Drama Studies, (55), 150.

Fortin, M. (2010). The Development of Theatre in Easter Island: Hakararama i te A'amu Tuai o Rapa Nui (MA). Otago University, Dunedin New Zealand.

Fortin, P. (2014, September 22). Interview/Talanoa with Moira Fortin in Vina del Mar. 
Freire, P. (2013). Pedagogia del Oprimido (6th ed.). Buenos Aires, Argentina: Siglo Veintiuno Editores.

Fresh TV. (2011). The Factory by Kila Kokonut Krew Brown and Around. Auckland, NZ. Retrieved from https://www.youtube.com/watch?v=Yxd7vCddsEI

Fuentes, M. (2013a). Entre el Colapso Rapa Nui y la Lucha por los Derechos Civiles: Contextualizacion Historica del Ciclo Ganadero en Isla de Pascua (1862 - 1966). In M. Fuentes (Ed.), Rapa Nui y la Compañia Explotadora (pp. 19-75). Rapa Nui: Rapa Nui Press.

Fuentes, M. (Ed.). (2013b). Rapa Nui y la Compañia Explotadora. Rapa Nui: Rapanui Press.

Fülöp, K. (2012). Reverse Chameleon in the Kiwi Jungle: Identity Construction of Pasifika Theatre Makers. (PhD). University of Canterbury, Christchurch, NZ. Gaudry, A. J. P. (2011). Insurgent Research. Wicazo Sa Review, 26(1), 113-136.

George, M. (2015, February 27). Interview/Talanoa with Moira Fortin in Wellington.

Getty, G. A. (2010). The Journey between Western and Indigenous Research Paradigms. Journal of Transcultural Nursing, 21(1), 5-14.

Gibb, S., \& Lualua, T. (2015, May 26). Programme Measina Festival 2015. Jandals Inc and Le Moana.

Gilbert, H., \& Tompkins, J. (1996). Post-Colonial Drama: Theory, Practice, Politics. London: Routledge.

Gilson, R. (1980). The Cook Islands, 1820-1950. (R. G. Crocombe, Ed.). Wellington, N.Z.: Victoria University Press in association with the Institute of Pacific Studies of the University of the South Pacific.

Gostand, R. (1980). Verbal and Non-Verbal Communication: Drama as Translation. In O. Zuber (Ed.), The Languages of Theatre (pp. 1-9). Amsterdam: Pergamon. 
Grace-Smith, B. (1999). Purapurawhetu. Wellington, N.Z.: Huia Publishers.

Grant, R. S., \& Wallace, J. (2014). Annual Report. Purongo A Tau. Creative New Zealand.

Greenwood, D. J. (1972). Tourism as an Agent of Change: A Spanish Basque Case. Ethnology, 11(1), 80-91.

Greenwood, J. (1999). Journeys into a Third Space. A Study of how Theatre Enables us to Interpret the Emergent Space between Cultures (PhD). Griffith University.

Greenwood, J. (2002). History of a Bicultural Theatre: Mapping the Terrain.

Christchurch, NZ: Christchurch College of Education.

Greenwood, J., \& Plum, V. (2002). Purapurawhetu and The Pohutukawa Tree: The Bicultural Landscape \& Māori Theatre. Te Kete Ipurangi. Retrieved from www.tki.org.nz/r/arts/drama/purapurawhetu

Grotowski, J. (2002). Towards a Poor Theatre. In E. Barba (Ed.), Towards a Poor Theatre. Jerzy Grotowski. New York: Routledge.

Guest, B. (2010). Transitions: Four Decades of Toi Whakaari New Zealand Drama School. Wellington, N.Z.: Victoria University Press.

Guevara Brenes, J. E. (2012, December). Fundamentos del Etnoturismo y su Aporte en la Promocion Turistica Sostenible de Costa Rica. Universidad para la Cooperacion Internacional, San Jose, Costa Rica.

Halba, H. (2009). Creating Images and Telling Stories: Decolonising Performing Arts and Image-based Research in Aotearoa/New Zealand. About Performance, (9), 193.

Halba, H. (2010). Performing Identity: Teaching Bicultural Theatre in Aotearoa. Australasian Drama Studies, (57), 22. 
Halba, H., McCallum, R., \& Holmes, H. (2011). Tu Taha, Tu Kaha: Transcultural Dialogues. Australasian Drama Studies, (59), 69.

Handler, R., \& Linnekin, J. (1984). Tradition, Genuine or Spurious. The Journal of American Folklore, 97(385), 273-290.

Haoa Cardinali, V. (2014, August 23). Interview/Talanoa with Moira Fortin in Rapa Nui. Harcourt, P. (1978). A Dramatic Appearance. New Zealand Theatre 1920- 1970. Wellington, NZ: Methuen Publications New Zealand Ltd.

Harrison, D. (2003). Themes in Pacific Island Tourism. In D. Harrison (Ed.), Pacific Island Tourism (pp. 1-23). New York: Cognizant Communication Corporation.

Hau'ofa, E. (2008). We Are the Ocean: Selected Works. Honolulu, Hawaii: University of Hawaii Press.

Hayward, J. (2012, July 13). Principles of the Treaty of Waitangi - Ngā Mātāpono o te Tiriti. Retrieved November 20, 2015, from http://www.teara.govt.nz/en/principles-of-the-treaty-of-waitangi-nga-matapono-ote-tiriti/page-1

Hebdige, D. (1988). Hiding in the Light: On Images and Things. London: Routledge. Hereniko, V. (1990). Polynesian Clowns and Satirical Comedies (PhD). University of the South Pacific, Suva, Fiji.

Hereniko, V. (1993). Pacific Clowning. In V. Hereniko \& T. Teaiwa, Last Virgin in Paradise: A Serious Comedy. Suva: Mana Publications.

Hereniko, V. (1994). Clowning as Political Commentary: Polynesia, Then and Now. The Contemporary Pacific, 6(1), 1-28.

Hereniko, V. (1999). Representations of Cultural Identities. In V. Hereniko \& R. Wilson (Eds.), Inside Out: Literature, Cultural Politics, and Identity in the New Pacific. United States of America: Rowman \& Littlefield. 
Herrick, L. (2007, November 15). Powerhouse of Drama All Ready to Go. New Zealand Herald. Retrieved from http://www.nzherald.co.nz/entertainment/news/article.cfm?c_id=1501119\&object $\mathrm{id}=10476080$

Hills, G. (2004, November). Communicating Your Art. Case Study: Extreme Copywriting Makeover Pacifc Underground. Retrieved April 29, 2014, from http://www.creativenz.govt.nz/assets/paperclip/publication_documents/document s/101/original/extreme-copywriting-makeover-pacificunderground.pdf?1322079829

Hobsbawm, E., \& Ranger, T. (2012). The Invention of Tradition. Cambridge: Cambridge University Press.

Hotus, J. (2014, August 19). Interview/Talanoa with Moira Fortin in Rapa Nui. Hotus Tuki, M. (2014, July 24). Interview/Talanoa with Moira Fortin in Rapa Nui. Houlahan, M. (2002). “Think About Shakespeare”: King Lear on Pacific Cliffs. In P. Holland (Ed.), Shakespeare Survey: Volume 55, King Lear and Its Afterlife: An Annual Survey of Shakespeare Studies and Production. Cambridge: Cambridge University Press.

Houlahan, M. (2009). Romeo and Tusi: An Eclectically Musical Samoan/Māori Romeo and Juliet from Aotearoa/New Zealand. Contemporary Theatre Review, 19(3), 279-288.

Huke, K. (2011, December 20). Interview/Talanoa with Moira Fortin in Rapa Nui. Huke, P. (1995). Mata Tu’u Hotu Iti: Revelando Misterios. Santiago Chile: Editorial TiempoNuevo.

Huke, P. (2009, January 20). Interview/Talanoa with Moira Fortin in Rapa Nui. 
Hulbert, J., Wetmore, K. J., \& York, R. L. (2006). Shakespeare and Youth Culture. New York: Palgrave Macmillan.

Huria, J. (Ed.). (1999). Introduction. In B. Grace-Smith, Purapurawhetu. Wellington, NZ: Huia Publishers.

Hurtado, M. de la L. (2000). Chile. In D. Rubin \& C. Solorzano (Eds.), World Encyclopedia of Contemporary Theatre: The Americas (Vol. 2, pp. 149-167). New York: Routledge.

Hyland, N. (2011). Wherefore Art thou Bro'? Youth, Hybridity and Cross-Cultural Retellings of Romeo and Juliet (PhD). University of Melbourne, Melbourne. Hyland, N. (2015, February 3). Interview/Talanoa with Moira Fortin in Wellington. Ika, V., \& De Arruda, R. (2013). Te Ra'ai. Retrieved March 11, 2015, from http://www.teraai.com/en/about-us/

Instituto Nacional de Estadisticas INE. (2012). Isla de Pascua - Reportes Estadisticos Comunales. Retrieved September 24, 2015, from http://reportescomunales.bcn.cl/2012/index.php/Isla_de_Pascua

Iturbe, P. (2015, July 21). Interview/Talanoa with Moira Fortin on Skype.

Jolly, M. (1992). Specters of Inauthenticity. The Contemporary Pacific, 4(1), 49-72.

Jolly, M., \& Thomas, N. (1992). The Politics of Tradition in the Pacific. Oceania, 62(4), $241-248$.

Kahutoi, T. K. (2014, October 15). Māori Weaving and Tukutuku - Te Raranga me te Whatu. Retrieved June 24, 2015, from http://www.teara.govt.nz/en/maoriweaving-and-tukutuku-te-raranga-me-te-whatu/page-3

Kamu, L. (1996). The Samoan Culture and the Christian Gospel. Apia: Methodist Printing Press. 
Keane, B. (2012, December 4). Te Rāngai Mahi - Māori in the Workforce. Retrieved February 20, 2015, from http://www.teara.govt.nz/en/te-rangai-mahi-maori-inthe-workforce

Keown, M. (2007). Pacific Islands Writing: The Postcolonial Literatures of Aotearoa/New Zealand and Oceania. Oxford: Oxford University Press.

Kightley, O., \& Small, S. (2005). Fresh Off the Boat. Wellington, N.Z.: The Play Press. Kila Kokonut Krew. (2009). Kila Kokonut Krew. Retrieved April 28, 2015, from https://www.facebook.com/pages/Kila-KokonutKrew/92837192322?sk=info\&tab=page_info

King, M. (2003). The Penguin History of New Zealand. Auckland, N.Z: Penguin Books.

Kouka, H. (1994). Ngā Tāngata Toa. Wellington, N.Z.: Victoria University Press.

Kouka, H. (1997). Waiora: Te Ūkaipo. Wellington, N.Z.: Huia Publishers.

Kouka, H. (Ed.). (1999). Ta Matou Mangai. Three Plays of the 1990s. Wellington, N.Z.: Victoria University Press.

Kouka, H. (2007). Re-Colonising the Natives: The State of Contemporary Māori Theatre. In M. Maufort \& D. O’Donnell (Eds.), Performing Aotearoa: New Zealand Theatre and Drama in an Age of Transition (pp. 237-245). New York: Peter Lang.

Kouka, H. (2012). Tu. Wellington, N.Z.: Playmarket.

Kouka, H. (2015, May 1). Interview/Talanoa with Moira Fortin in Wellington.

Kouka, H., \& McNaughton, H. (1999). Ta Matou Mangai/Our Own Voice: A Discussion. In H. Gilbert (Ed.), (Post) Colonial Stages. Critical \& Creative Views on Drama, Theatre \& Performance. London: Dangaroo Press. 
Kreifels, S. (1999a, June 14). Rapa Nui. The Loneliest Island. Star Bulletin. Honolulu, Hawaii. Retrieved from http://archives.starbulletin.com/1999/06/14/hokulea/index.html

Kreifels, S. (1999b, October 8). Landfall! Star Bulletin. Honolulu, Hawaii. Retrieved from http://archives.starbulletin.com/1999/10/08/news/story1.html

La Estrella. (1995, March 3). Polinesicos se Reunen en Pascua. La Estrella. Valparaiso Chile.

Labbe, F., Carrasco, E., \& Mathews, S. (2012, June 30). Resultados Preliminares Censo de Poblacion y Vivienda 2012. Instituto Nacional de Estadisticas. Retrieved from http://www.ine.cl/canales/chile_estadistico/censos_poblacion_vivienda/censo_po bl_vivi.php

Latukefu, S. (1968). Oral Traditions: An Appraisal of their Value in Historical Research in Tonga. The Journal of Pacific History, 3, 135-143.

Lee, M. (2015, April 5). Balancing Act. Retrieved from http://ngaitahu.iwi.nz/our_stories/balancing-act/

Lichtenberg, S. (2011). Experiencing Samoa Through Stories: Myths and Legends of a People and Place. Independent Study Project (ISP) Collection. Paper 1057. Retrieved from http://digitalcollections.sit.edu/isp_collection/1057/?utm_source=digitalcollection s.sit.edu\%2Fisp_collection\%2F1057\&utm_medium=PDF\&utm_campaign=PDF CoverPages

Lillo Haoa, C. (2014, July 29). Interview/Talanoa with Moira Fortin in Rapa Nui. Lilomaiava-Doktor, S. 'iliemanu. (2009). Beyond "Migration”: Samoan Population Movement (Malaga) and the Geography of Social Space (Va). The Contemporary Pacific, 21(1). 
Linds, W., \& Vettraino, E. (2008). Collective Imagining: Collaborative Story Telling through Image Theatre. FQS Forum: Qualitative Social Research, 9(2 (Art. 56)).

Lo, J., \& Gilbert, H. (2002). Toward a Topography of Cross-Cultural Theatre Praxis. TDR/The Drama Review, 46(3), 31-53.

Locke, E. (1992). Two Peoples One Land. A History of Aotearoa/New Zealand. Wellington, N.Z.: GP Publications LTD.

Lockford, L., \& Pelia, R. J. (2004). Bodily Poeticizing in Theatrical Improvisation: A Typology of Performative Knowledge. Theatre Topics, 14(2).

Looser, D. (2012). Moving Islands: Mapping the Samoan Diaspora in Contemporary Transnational Theatre from the South Pacific. Contemporary Theatre Review, 22(4), 451-466.

Looser, D. (2014). Remaking Pacific Pasts: History, Memory, and Identity in Contemporary Theater from Oceania. Honolulu, Hawaii: University of Hawaii Press.

MacCannell, D. (1973). Staged Authenticity: Arrangements of Social Space in Tourist Settings. American Journal of Sociology, 79(3), 589-603.

Macnaught, T. J. (1982). Mass Tourism and the Dilemmas of Modernization in Pacific Island Communities. Annals of Tourism Research, 9(3), 359-381.

Macpherson, C. (2004). Transnationalism and Transformation in Samoan Society. In V. S. Lockwood (Ed.), Globalization and Culture Change in the Pacific Islands. Pearson/Prentice Hall.

Madariaga Paoa, C. (2009, February 28). Interview/Talanoa with Moira Fortin in Rapa Nui.

Mallon, S. (2002). Samoan Art and Artists. Honolulu, Hawaii: University of Hawaii Press. 
Mallon, S. (2010). Against Tradition. The Contemporary Pacific, 22(2), 362-381.

Mallor, E., Gonzalez-Gallarza Granizo, M., \& Fayos Gardo, T. (2013). Que es y Como se Mide el Turismo Cultural? Un Estudio Longitudinal con Series Temporales para el Caso Español. Pasos-Revista de Turismo Y Patrimonio Cultural, 11(2), 269284.

Manusaute, V. (2012). Introduction. In Playmarket, Urbanesia. Four Pasifika Plays. Wellington, NZ: Playmarket.

Manusaute, V. (2014, October 2). Interview/Talanoa with Moira Fortin in Auckland. Mata O Te Rapa Nui. (2005). Ure a Oho Vehi. A'amu Tuai in Tapati Rapa Nui [Performance]. Rapa Nui.

Matamua, R. (2013, August 14). Mau Rākau - Māori use of Weaponry. Retrieved August 3, 2015, from http://www.teara.govt.nz/en/mau-rakau-maori-use-ofweaponry/page-1

Maude, H. E. (1981). Slavers in Paradise: The Peruvian Labour Trade in Polynesia, 1862-1864. Canberra: Australian National University Press.

Maufort, M., \& O’Donnell, D. (2007). Performing Aotearoa: New Zealand Theatre and Drama in an Age of Transition. New York: Peter Lang.

Maunder, P. (2013). Rebellious Mirror: Community-based Theatre in Aotearoa/New Zealand. Christchurch, N.Z.: Canterbury University Press.

Mazer, S. (2011). Performance: Ethnographer/Tourist/Cannibal. Australasian Drama Studies, (59), 104.

McGrath, J. (1996). A Good Night Out: Popular Theatre: Audience, Class, and Form. London: Nick Hern Books.

McIntosh, T., \& Mulholland, M. (Eds.). (2011). Māori and Social Issues. (1st ed.). Wellington, N.Z.: Huia Publishers. 
McQuarrie, P. (2007). Tokelau: People, Atolls and History. Wellington, N.Z: Peter McQuarrie.

Mein Smith, P. (2007). A Concise History of New Zealand. Melbourne: Cambridge University Press.

Meleisea, M., \& Schoeffel Meleisea, P. (Eds.). (1987). Lagaga: A Short History of Western Samoa. Apia, Western Samoan: Samoa Extension Centre of the University of the South Pacific.

Meleisea, M., Schoeffel Meleisea, P., Sio, G. P. S., \& Suafole, I. 'iga. (1987). German Samoa 1900-1914. In M. Meleisea \& P. Schoeffel Meleisea (Eds.), Lagaga: A Short History of Western Samoa. Apia, Western Samoan: Samoa Extension Centre of the University of the South Pacific.

Mendoza Uriarte, O. (2011). Chile, un País Colonialista: El Caso del Pueblo Rapanui: El Estado Chileno y el Territorio de Te Pito o Te Henua. España: Editorial Academica Española.

Merino Rapu, V. T. (2014, August 22). Interview/Talanoa with Moira Fortin in Rapa Nui.

Merlin, B. (2004). Konstantin Stanislavsky. London: Routledge.

Methven, P. (2012). 25 Years Leading and Illuminating. Whitireia New Zealand. Wellington, NZ: Steele Roberrts Publishers.

Métraux, A. (1971). Ethnology of Easter Island. Honolulu, Hawaii: Bernice P. Bishop Museum.

Middleton, S., \& McKinley, E. (2009). The Gown and the Korowai: Māori Doctoral Students and the Spatial Organisation of Academic Knowledge. Presented at the British Educational Research Association Annual Conference, University of Manchester: Education-Line. 
Mieder, W. (1990). International Proverb Scholarship. An Annotated Bibliography. New York: Garland Publishing Inc.

Morales Gonzalez, M. (2008). Etnoturismo o Turismo Indigena? Teoria Y Praxis, 5 , $123-136$.

Morande, P. (1990). El Teatro como Encuentro en la Tradicion Oral y Re-Dramatizacion de la Vida. Revista Apuntes de Teatro, (100), 99-101.

Moreno, S. (2012). Tesoros Humanos Vivos. Federico Pate Tuki [DVD]. Rapa Nui: Consejo Nacional de la Cultura y las Artes.

Moreno Pakarati, C. (2011). Rebelion, Sumision y Mediacion en Rapa Nui: 1898 - 1915. In C. Cristino \& M. Fuentes (Eds.), La Compañia Explotadora de Isla de Pascua. Patrimonio, Memoria e Identidad en Rapa Nui. Concepcion: Ediciones Escaparate.

Moreno Pakarati, C. (2013). La Importancia de la Arqueologia Historica en Rapa Nui: El caso de la Explotacion Ovejera y la Domesticacion del Poder Colonial. In M. Fuentes (Ed.), Rapa Nui y la Compañia Explotadora. Rapa Nui: Rapanui Press. Moreno Pakarati, C. (2014, August 8). Interview/Talanoa with Moira Fortin in Rapa Nui. Mosavel, M., Ahmed, R., Daniels, D., \& Simon, C. (2011). Community Researchers Conducting Health Disparities Research: Ethical and other Insights from Fieldwork Journaling. Social Science \& Medicine (1982), 73(1), 145-152. http://doi.org/10.1016/j.socscimed.2011.04.029

Muagututi'a, M. (2014, April 11). Interview/Talanoa with Moira Fortin in Wellington. Muagututi'a, T. (2014, October 1). Interview/Talanoa with Moira Fortin in Auckland. Multinesia. (2014, April 26). Black Faggot. Retrieved from https://multinesia.wordpress.com/tag/black-faggot/ 
Museo Antropologico Padre Sebastian Englert. (2008). Haka Ara. Expofotos. Rapanui 1864-1993. Rapa Nui: Rapa Nui Press.

New Zealand Government. (2014, August 5). New Zealand Ministry of Foreign Affarirs and Trade. Retrieved from http://www.mfat.govt.nz/Countries/Pacific.php

Nga Taonga Sound \& Vision - TVNZ Collection. (1998). Frangipani Perfume Footage. Queer Nation Series 2 Programme 13. Accessed 1 May 2015 [VHS].

Nichols, D. (1956). Theatre, Society, Education. Educational Theatre Journal, 8(3), 179184.

Nixon, M. (2007, May 14). Maui - One Man Against The Gods - A Wonderfully Engaging and Creative Spectacle. Retrieved June 25, 2015, from http://www.theatreview.org.nz/reviews/review.php?id=761

NZ on Screen. (2011). Nathaniel Lees. Retrieved May 11, 2015, from http://www.nzonscreen.com/person/nathaniel-lees/biography

NZ on Screen. (2012). Lani Tupu. Retrieved November 23, 2015, from http://www.nzonscreen.com/person/lani-tupu/biography

NZPA. (1997, December 16). Pacific Play Cuts into Stereotypes. Media Search.

NZQA New Zealand Qualifications Authority. (2015). Report of External Evaluation and Review. BEST Pacific Institute of Education Limited. (No. C16567). Auckland, NZ: NZQA New Zealand Qualifications Authority.

O’Brien, N. (2013). Preface to the Bloomsbury Revelations Edition. In C. Stanislavski, Building a Character. London: Bloomsbury Academic.

O’Donnell, D. (2003). "Whakarongo ki te Tangi Hotuhotu Mokemoke e: Listen to the One who Cries to be Heard" Recent Theatre in Aotearoa/New Zealand. In A.-R. Glaap \& M. Maufort (Eds.), Keying in to Postcolonial Cultures: Contemporary Stage Plays in English (pp. 3-20). Germany: WVT. 
O’Donnell, D. (2004a). Introduction. In M. Urale \& D. Fuemana, Frangipani Perfume. Mapaki. Wellington, N.Z.: The Play Press.

O’Donnell, D. (2004b). Issues in PI Women's Theatre: Vula and Frangipani Perfume. Illusions: New Zealand Moving Image and Performing Arts Critism, 36, 32-35. O’Donnell, D. (2007). Everything is Family. David O’Donnell Interviews Nathaniel Lees. In M. Maufort \& D. O’Donnell (Eds.), Performing Aotearoa: New Zealand Theatre and Drama in an Age of Transition (pp. 331-347). New York: Peter Lang.

O’Donnell, D. (2007). The Immigrant Family in Samoan Drama. In M. Maufort \& D. O’Donnell (Eds.), Performing Aotearoa: New Zealand Theatre and Drama in an Age of Transition. New York: Peter Lang.

O’Donnell, D. (2007). “Whaddarya?" Questioning National Identity in New Zealand Drama. In M. Maufort \& D. O’Donnell (Eds.), Performing Aotearoa: New Zealand Theatre and Drama in an Age of Transition (pp. 17-25). New York: Peter Lang.

O'Donnell, D. (2009). Politics of Place and Extended Family in Taki Rua Productions' 25th Year: "Strange Resting Places” and "Te Karakia.” Australasian Drama Studies, (55), 10.

O'Donnell, D. (2011a). A Place of Safety: The Influence of Writer's Block on Contemporary Māori Theatre. Presented at the SPACIALS Conference, Te Herenga Waka Marae Victoria University.

O’Donnell, D. (2011b). Quoting the "Other": Intertextuality and Indigeneity in Pacific Theatre. In D. M. Figueira \& M. Maufort (Eds.), Theatres in the Round (pp. 109132). Brussels: P.I.E. Peter Lang. 
O’Donnell, D. (2012). Foreword. In Playmarket (Ed.), Urbanesia. Four Pasifika Plays. Wellington, NZ: Playmarket.

O’Donnell, D., \& Tweddle, B. (2003). Toa Fraser: Shifting Boundaries in Pacific Island Comedy. Australasian Drama Studies, (42), 123.

O’Leary, C. (2008). Interview with Sima Urale. NZ On Screen. Retrieved from http://screentalk.nzonscreen.com/interviews/interview-with-sima-urale

Oñate, M. (2014, July 18). Interview/Talanoa with Moira Fortin in Rapa Nui.

Orbell, M. (1995). The Illustrated Encyclopedia of Māori Myth and Legend. Chrsitchurch: Canterbury University Press.

Oreglia, G. (1968). The Commedia dell'Arte. (L. F. Edwards, Trans.). New York: Methuen and Co Ltd.

Orenstein, C. (1998). Festive Revolutions: The Politics of Popular Theater and the San Francisco Mime Troupe. United Staes of America: University Press of Mississippi.

Oxford University Press. (2014). Oxford Dicionary. Retrieved May 16, 2014, from https://www.google.co.nz/search?q=oxford+dicionary\&ie=utf- $8 \& o e=u t f-$ $8 \& a q=t \& r l s=$ org.mozilla:en-US:official\&client=firefoxa\&channel=sb\&gfe_rd=cr\&ei=RWp1U7nsJ-bC8geyk4CYDQ

Pacific Beat St. (2010). Ep 190 - Pacific Institute of Performing Arts [TV Show]. Auckland, NZ. Retrieved from https://www.youtube.com/watch?v=EQqomQ9x7wg

Pacific Institute Performing Arts. (2010). Pacific Institute Performing Arts. Retrieved July 19, 2015, from http://www.pipa.ac.nz/

Pacific Institute Performing Arts. (2014). Prospectus. Auckland, NZ. 
Pacific Underground. (1995). Fresh Off the Boat [VHS]. Downstage Theatre, Wellington.

Pakarati, F. (2009, February 15). Interview/Talanoa with Moira Fortin in Rapa Nui.

Pakarati, F. (2011). Destruyendo Mitos en torno a la Williamson \& Balfour. In C.

Cristino \& M. Fuentes (Eds.), La Compañia Explotadora de Isla de Pascua.

Patrimonio, Memoria e Identidad en Rapa Nui. Concepcion: Ediciones

Escaparate.

Pakarati Gula, M. (2014, August 6). Interview/Talanoa with Moira Fortin in Rapa Nui.

Paoa, R., Aranda, M., \& Sandia, L. (1983). La Recreacion en Isla de Pascua

(Dissertation). Academia Superior de Ciencias Pedagogicas de Valparaiso, Valparaiso Chile.

Paoa Aguila, S. (2014). Turismo en Rapa Nui y Proyecciones. Servicio Nacional del Turismo SERNATUR.

Pavis, P. (Ed.). (1996). The Intercultural Performance Reader. London: Routledge.

Peirano, L. (1988). Notas sobre la Creacion Teatral en America Latina. Desde la Perspectiva de la Puesta en Escena. In Proyecto Regional de Patrimonio Cultural y Desarrollo PNUD / UNESCO (Ed.), Dramaturgia y Puesta en Escena en el Teatro Latinoamericano y Caribeño Contemporaneo. (pp. 61-74). Lima, Peru: UNESCO.

Penny, C. (2014). Director's Welcome. In Toi Whakaari: NZ Drama School, Prospectus. Wellington NZ: Toi Whakaari New Zealand Drama School.

Pinfield, G. (2011). Part 1: Maui. Retrieved June 25, 2015, from https://vimeo.com/20031974

PIPA. (2010). Pacific Institute Performing Arts. Retrieved May 11, 2015, from http://pipa.ac.nz/about.html 
Playmarket News. (2008, November 5). Matariki Forum: Where is Māori Theatre now? Retrieved October 16, 2015, from http://www.thebigidea.co.nz/news/industrynews/2008/nov/31395-matariki-forum-where-is-maori-theatre-now

Polataivao, A. (2014, October 3). Interview/Talanoa with Moira Fortin in Auckland.

Pont Chamorro, A. (2014, August 4). Interview/Talanoa with Moira Fortin in Rapa Nui. Pool, I. (2012, July 13). Death Rates and Life Expectancy - Effects of Colonisation on Māori. Retrieved September 22, 2015, from http://www.teara.govt.nz/en/deathrates-and-life-expectancy/page-4

Porteous, J. D. (1981). The Modernization of Easter Island. Victoria B.C.: Dept. of Geography, University of Victoria.

Potiki, R. (1991a). A Māori Point of View: The Journey from Anxiety to Confidence. Australasian Drama Studies, 18, 57-63.

Potiki, R. (1991b). Introduction. In S. Garrett, He Reo Hou. 5 Plays by Māori Playwrights. Wellington, NZ: Playmarket.

Potiki, R. (1992). Confirming Identity and Telling the Stories: A Woman's Perspective on Māori Theatre. In R. D. Plessis \& P. Bunkle (Eds.), Feminist Voices: Women's Studies Texts for Aotearoa/New Zealand (pp. 153-163). Auckland, N.Z.: Oxford University Press.

Potiki, R., \& Anderson, J. (1990). Whatungarongaro [VHS]. He Ara Hou.

Potiki-Bryant, L., \& Royal, T. A. C. (2010). Te Karohirohi: The Light Dances [Video]. Waimangō, Wharekawa, Hauraki. Retrieved from http://www.orotokare.org.nz/Default.aspx ?page $=3247$

Pradenas, L. (2006). Teatro en Chile: Huellas y Trayectorias, Siglos XVI-XX. Santiago Chile: Lom Ediciones.

Quiroga, C. (2009, July 23). Interview/Talanoa with Moira Fortin in Blenheim. 
Rapu, B. (2013). Maori Tupuna 2013 [DVD]. Mata O Te Rapa Nui.

Rapu Drago, V. a H. (2014, July 18). Interview/Talanoa with Moira Fortin in Rapa Nui.

Rapu Tuki, L. (2009, January 25). Interview/Talanoa with Moira Fortin in Rapa Nui.

Reed, A. W. (2012). The Raupo Concise Māori Dictionary. UK: Penguin Books.

Reilly, M. P. J. (2011). Māori Studies, Past and Present: A Review. The Contemporary Pacific, 23(2), 340-369.

Richards, A. (2006). Bicultural Bodies: The Production of Nation at the NZ Drama School. In H. McNaughton \& A. Lam (Eds.), The Reinvention of Everyday Life: Culture in the Twenty-first Century. Christchurch, N.Z.: Canterbury University Press.

Riedemann Fuentes, A. (2008). La Educacion Intercultural Bilingue en Chile: Ampliacion de Oportunidades para Alumnos Indigenas? INDIANA, 25, 169-193. Ringeling, K. (2014, August 1). Interview/Talanoa with Moira Fortin in Rapa Nui. Romney, P. (2005). The Art of Dialogue. In P. Korza, B. S. Bacon, \& A. Assaf (Eds.), Civic Dialogue Arts \& Culture (pp. 57-74). Washington DC: Americans for the Arts.

Routledge, K. (1920). The Mystery of Easter Island. London: Hazell, Watson and Viney: Sifton Praed.

Royal, J., \& Campbell, R. (1987). The Filipino Workshop Tour and the Māori Theatre Network. Hakas \& Jasmine. Illusions: New Zealand Moving Image and Performing Arts Critism, 9-15.

Royal, T. A. C. (1998). Te Whare Tapere: Towards a Model for Māori Performance Art (PhD). Victoria University of Wellington.

Royal, T. A. C. (2007). Orotokare: Towards a new Model for Indigenous Theatre and Performing Arts. In M. Maufort \& D. O’Donnell (Eds.), Performing Aotearoa: 
New Zealand Theatre and Drama in an Age of Transition (pp. 193-208). New York: Peter Lang.

Rushdie, S. (1991). Imaginary Homelands: Essays and Criticism 1981-1991. London: Granta.

Russell Brown, J. (1995). The Oxford Illustrated History of Theatre. Oxford: Oxford University Press.

Ruth, A. (2010). Preface. In B. Guest, Transitions. Four Decades of Toi Whakaari: New Zealand Drama School. Wellington, NZ: Victoria University Press.

Ruth, A. (2013). Kanohi ki te Kanohi: Face to Face. Frameworks from Tikanga Māori meet Viewpoints Improvisations, Shocking the Theatrical Encounter into Alive-liness (PhD). Victoria University of Wellington, Wellington NZ.

Salesa, D. I. (2011). Racial Crossings: Race, Intermarriage, and the Victorian British Empire. New York: Oxford University Press.

Samant, S. (2010, June 19). Purapurawhetu. Retrieved June 24, 2015, from http://lumiere.net.nz/index.php/purapurawhetu/

Samasoni, S. (1986). Māori and Pacific Island Theatre in New Zealand - Past and Future. Act, 2(2), 15-16.

Sanitoa, L. (2012). 10th Festival of Pacific Arts. American Samoa - July 20-August 2, 2008. American Samoa: John Newton - Souvenir program.

Santa Coloma, M. E. (2006). Rapa Nui: Guardianes de la Tradicion. Mestizaje y Conflicto en la sociedad Rapanui. Rapa Nui: Rapanui Press.

Schechner, R. (2013). Performance Studies: An Introduction (3rd ed.). London: Routledge.

Schechter, J. (Ed.). (2002). Popular Theatre: A Sourcebook. New York: Routledge. 
Scheyvens, R., \& Russell, M. (2009). Tourism and Poverty Reduction in the South Pacific. Wellington, NZ: Massey University.

Sciascia, G. (2011). Haka Theatre. DANZ Quarterly, (Summer), 10.

Scott, A. (2006). The Theatre of Te Rakau Hua O Te Wao Tapu and the Politics of Change. E-Journal Research in New Zealand Performing Arts - Nga Mahi a Rehia No Aotearoa, Edition 1. Retrieved from http://www.drama.org.nz/thetheatre-of-te-rakau-hua-o-te-wao-tapu-and-the-politics-of-change/

Selasi, T. (2015). Don't Ask Where I'm From, Ask Where I'm Local. Presented at the TED Talks, Technology, Entertainment and Design. Retrieved from https://www.youtube.com/watch?v=LYCKzpXEW6E

Sharpley, R. (1994). Tourism, Tourist \& Society. Huntington, Cambridgeshire: ELM. Shepardson, B. (2013). Moai. A New Look at Old Faces. Rapa Nui: Rapanui Press.

Sinavaiana, C. (1992). Comic Theatre in Samoa as Indigenous Media. Pacific Studies, 15(4), 199-209.

Sinavaiana, C. (1998). Music and Theatre: Samoa. In A. L. Kaeppler \& J. W. Love (Eds.), The Garland Encyclopedia of World Music. Australia and the Pacific Islands (Vol. 9). New York: Garland Publishing Inc.

Smith, L. T. (1999). Decolonizing Methodologies: Research and Indigenous Peoples. London: Zed Books.

Smith, V. (2014, October 20). Kapa Haka - Māori Performing Arts. Retrieved September 22, 2015, from http://www.teara.govt.nz/en/kapa-haka-maori-performingarts/page-3

Smithies, G. (2013, April 21). Globe Trotter. Sunday Star Times, p. E 32.

Smythe, J. (2006, March 8). The Battalion - Full-on to a Fault. Retrieved September 22, 2015, from http://www.theatreview.org.nz/reviews/review.php?id=16 
Smythe, J. (2007, May 10). Maui - One Man Against The Gods - Defies Gravity in Every Sense. Retrieved June 25, 2015, from http://www.theatreview.org.nz/reviews/review.php?id=719

Smythe, J. (2015, September 5). The White Guitar - Brave, Generous and Unconditional. Retrieved October 25, 2015, from http://www.theatreview.org.nz/reviews/review.php?id=8421

Smythe, N. (2015, July 12). Rangi and Mau's Amazing Race - Funny, Fast-paced, Educational Entertainment. Retrieved October 25, 2015, from http://www.theatreview.org.nz/reviews/review.php?id=8313

Soo-Choon, J. (2015). The Eel and Sina [Performance]. Measina Festival.

Soto, L., \& Delgado, A. (2015). Arte InVisible. La Memoria de los Artistas Ejecutados y Detenidos Desaparecidos en Chile. Santiago Chile: Ventana Abierta.

Spoonley, P. (2012, July 13). Ethnic and Religious Intolerance. Retrieved May 8, 2015, from http://www.teara.govt.nz/en/ethnic-and-religious-intolerance/page-4

Spradley, J. P. (1979). Participant Observation. New York: Holt, Rinehart and Winston. Sprinchorn, E. (1968). Introduction. In G. Oreglia, The Commedia dell' Arte. New York: Methuen and Co Ltd.

Stam, R. (1988). Mikhail Bakhtin and Critical Left Pedagogy. In A. Kaplan (Ed.), Postmodernism and its Discontents. New York: Verso.

Statistics New Zealand. (2014). 2013 Census Ethnic Group Profiles. Statistics New Zealand. Retrieved from http://www.stats.govt.nz/Census/2013-census/profileand-summary-reports/ethnic-profiles.aspx

Stevenson, K. (2008). The Frangipani is Dead: Contemporary Pacific Art in New Zealand, 1985-2000. Wellington, N.Z.: Huia Publishers. 
Stevenson, K. (2012). The Festival of Pacific Arts Celebrating 40 Years. Suva, Fiji: SPC Secretariat of the Pacific Community.

Stross, B. (1999). The Hybrid Metaphor: From Biology to Culture. The Journal of American Folklore, 112(445), 254-267.

Sulivan, A. (2012, July 13). Tōrangapū - Māori and Political Parties - The Emergence of the Party System. Retrieved September 22, 2015, from http://www.teara.govt.nz/en/torangapu-maori-and-political-parties/page-2

Tahana, N., \& Oppermann, M. (1998). Māori Cultural Performances and Tourism. Tourism Recreation Research, 23(1), 23-30.

Tapati Rapa Nui. (2009). Uho Te Uka [Performance Recorded by Moira Fortin]. Rapa Nui.

Te Ua, K. (2015, July 25). Interview/Talanoa with Moira Fortin in Wellington.

Teave, M. (2014, August 19). Interview/Talanoa with Moira Fortin in Rapa Nui.

Tennent Brown, G. (2015, March). ASB Polyfest. Retrieved May 11, 2015, from http://www.asbpolyfest.com/

The New Zealand Herald. (2002, June 4). Helen Clark's Apology to Samoa. New Zealand Herald. Retrieved from http://www.nzherald.co.nz/nz/news/article.cfm?c_id=1\&objectid=2044857

Thomas, N. (1995). Oceanic Art. London: Thames and Hudson.

Thompson, K. (2014). Helping Māori and Pasifika Learners Build Their Skills In The Workplace. Auckland, NZ: The University of Auckland and Competenz Skils for Industry. Retrieved from https://www.competenz.org.nz/assets/Downloads/Helping-Maori-and-Pasifikalearners-build-their-skills-in-the-workplace2.pdf

Thomson, W. J. (2007). Te Pito Te Henua or Easter Island. Rapa Nui: Rapanui Press. 
Toi Whakaari: NZ Drama School. (2011). Context \& Practice. Retrieved June 28, 2016, from http://toiwhakaari.ac.nz/study-at-toi-whakaari/context-practice/

Toi Whakaari: NZ Drama School. (2011). History. Retrieved July 16, 2015, from http://www.toiwhakaari.ac.nz/about-us/history/

Toi Whakaari: NZ Drama School. (2011, February 22). New Toi Whakaari Director. Retrieved July 16, 2015, from http://www.thebigidea.co.nz/news/industrynews/2011/feb/81664-new-toi-whakaari-director

Toi Whakaari: NZ Drama School. (2014). Prospectus. Wellington, NZ: Toi Whakaari New Zealand Drama School.

Tuki Pate, B. (2014, July 28). Interview/Talanoa with Moira Fortin in Rapa Nui.

Turner, S. (2002). Quiet Revolution in Aotearoa New Zealand. ARENA Journal, (20).

Turner, V. (1988). The Anthropology of Performance. New York: Performing Arts Journal Publications.

Tweddle, B. (2007). Where Lecoq and Grotowski meet. Training at Toi Whakaari: New Zealand Drama School. In M. Maufort \& D. O’Donnell (Eds.), Performing Aotearoa: New Zealand Theatre and Drama in an Age of Transition (pp. 69-85). New York: Peter Lang.

UNESCO. (2002, November 25). For Education in the Arts and Creativity in Primary and Secondary Schools. Arts Education in the Pacific Region: Heritage and Creativity. Document based on the conclusions of the Regional Conference on Arts Education. Nadi, Fiji. Retrieved from http://portal.unesco.org/culture/en/files/40394/12653845103booklet.pdf/booklet.p df

University of Otago. (2010). Māori at Otago - Māori ki Otago. Pōwhiri. Retrieved July 17, 2015, from http://maori.otago.ac.nz/reo-tikanga-treaty/tikanga/powhiri 
Urale, M. (2015, April 22). Interview/Talanoa with Moira Fortin in Wellington.

Urale, M., \& Fuemana, D. (2004). Frangipani Perfume. Wellington, N.Z.: Play Press.

Urry, J. (1979). Beyond the Frontier: European Influence, Aborigines and the Concept of “Traditional” Culture. Journal of Australian Studies, 5(2), 16.

Vaioleti, T. M. (2006). Talanoa Research Methodology: A Developing Position on Pacific Research. Waikato Journal of Education, 12.

Van den Berg, D. (2004). Performing Arts on Easter Island: Will they Survive or Transform into a Tourist Attraction? In Island of the World 8th International Conference (pp. 1188-1202). Kinmen Island Taiwan.

van Erven, E. (2001). Community Theatre: Global Perspectives. United Staes of America: Routledge.

Ven Gennep, A. (1965). The Rites of Passage (2nd ed.). London: Routledge \& Kegan Paul.

Vergara, A. (2014, September 11). Interview/Talanoa with Moira Fortin in Santiago.

Vilches, I. (2015, July 25). Interview/Talanoa with Moira Fortin on Skype.

Waka Huia TVNZ. (2012). The Mãori Adaption of the Shakespeare's “Troilus \& Cressida.” Retrieved from https://www.youtube.com/watch?v=88kZQWsPazE Walker, R. (2004). Ka Whawhai Tonu Matou: Struggle Without End. Auckland, NZ: Penguin Books.

Watson, I. (2002). Negotiating Cultures: Eugenio Barba and the Intercultural Debate. Manchester: Manchester University Press.

Webb, T. (1994). Highly Structured Tourist Art: Form and Meaning of the Polynesian Cultural Center. The Contemporary Pacific, 6(1), 59-85.

Webby, G. (2006). Just Who Does He Think He Is? George Webby - That's Who! Wellington, NZ: Steele Roberts. 
Welch, D. (1998, January 24). Heaven Scent. The Listener, p. 44.

Wendt, A. (1978). The Artist and the Reefs Breaking Open. Mana, A South Pacific Journal of Language and Literature, 3(1), 107-121.

Wendt, A. (1982). Towards a New Oceania. In G. Amirthanayagam \& E.-W. C. Institute (Eds.), Writers in East-West Encounter: New Cultural Bearings (pp. 202-215). London: Macmillan.

Wendt, A. (1999). Afterword: Tatauing the Post-Colonial Body. In V. Hereniko \& R. Wilson (Eds.), Inside Out: Literature, Cultural Politics and Identity in the New Pacific. Rowman \& Littlefield.

Werry, M. (2011). The Tourist State: Performing Leisure, Liberalism, and Race in New Zealand. Minneapolis: University of Minnesota Press.

West Turner, J. (1997). Continuity and Constraint: Reconstructing the Concept of Tradition from a Pacific Perspective. The Contemporary Pacific, 9(2), 345.

Whimp, G. (2010). A Search for the New Oceania. The Contemporary Pacific, 22(2), $382-388$.

Whitireia. (2012). Bachelor of Applied Arts (Performing Arts). Retrieved July 20, 2015, from http://whitireia.ac.nz/courses/Pages/BachelorofAppliedArts(PerformingArts).aspx ?return=/AreasOfInterest/Performing-Arts

Whitireia. (2012). Certificate in Work Skills - Haka Theatre or Music. Retrieved July 20, 2015 , from http://whitireia.ac.nz/courses/Pages/CertificateinWorkSkills.aspx?return=/AreasO fInterest/Performing-Arts 
Whitireia. (2012). Whakatauākī and Values, Mission and Purpose, Success and identity. Retrieved May 11, 2015, from http://www.whitireia.ac.nz/about/Pages/WhakataukiandValues.aspx Whitireia. (2015). Prospectus. New Zealand: Whitireia.

Wilke, S. (2010). Staging Culture - Staging Nature: Polynesian Performance as Nature and Nature as Performance in Hawaii. Critical Studies, 33, 131-140,237.

Willis, E. (2014). Lost in Our Own Land: Re-Enacting Colonial Violence. In Theatricality, Dark Tourism and Ethical Spectatorship: Absent Others (pp. 161187). Basingstoke, Hampshire: Palgrave Macmillan.

Wilson, C. (2001). Decolonizing Methodologies: Research and Indigenous Peoples. Social Policy Journal of New Zealand, (7), 214-217.

Zamora Rapu, A. (2014, August 14). Interview/Talanoa with Moira Fortin in Rapa Nui. Zamora Rapu, A., \& Fortin, M. (2011). Por los Ojos de [DVD]. Rapa Nui. 


\section{Appendix}

\section{List of Interviewees/Talanoa}

Ah Hi, Iaheto. Actor of Samoan heritage, performer in Black Faggot by Victor Rodger. Interview/Talanoa with Moira Fortin in Wellington. March 01, 2014.

Alfaro Bittner, Marlene. Chilean theatre practitioner who did her honours dissertation on Rapanui performing arts. Interview/Talanoa with Moira Fortin in Viña del Mar. September 12, 2014.

Amenábar, Magdalena. Chilean actress, singer and lecturer in Theatre Studies at Universidad Católica. Interview/Talanoa with Moira Fortin in Santiago. September 04, 2014

Araki Pont, Tiare Iti. Rapanui dancer and member of Tapati Rapa Nui Festival organizing committee. Interview/Talanoa with Moira Fortin in Rapa Nui. July 17, 2014.

Araki Tuki, Marisol. Rapanui dance instructor at Kari Kari Cultural Ballet. Interview/Talanoa with Moira Fortin in Rapa Nui. August 05, 2014.

Arredondo, Ana Maria. Chilean Historian former head of High School Aldea Educativa in Rapa Nui. Interview/Talanoa with Moira Fortin in Rapa Nui. July 28, 2014.

Barriga Mejias, Barbara. Chilean citizen former member of the Rapanui community who now lives in Papeete, Tahiti. Interview/Talanoa with Moira Fortin in Rapa Nui. August 16, 2014.

Coyle, Sean. New Zealander former Head of School at Pacific Institute of Performing Arts (PIPA). Interview/Talanoa with Moira Fortin in Auckland. October 02, 2014.

Fortin Martinez, Pablo. Chilean journalist member of Consejo Nacional de la Cultura y las Arts (CNCA). Interview with Moira Fortin in Viña del Mar. September 22, 2014.

Fuentealba, Victoria. Chilean citizen member of the Rapanui community for more than 30 years and former librarian at Aldea Educativa high school. Interview/Talanoa with Moira Fortin in Rapa Nui. August 16, 2014.

George, Miria. Māori/ Cook Island playwright and actress. Interview/Talanoa with Moira Fortin in Wellington. February 27, 2015.

Halba, Hilary. New Zealander theatre practitioner and lecturer in Theatre Studies at Otago University. Interview/Talanoa with Moira Fortin in Dunedin. April 23, 2014. 
Haoa Cardinali, Virginia. Rapanui teacher and member of the Rapanui Language Academy. Interview/Talanoa with Moira Fortin in Rapa Nui. August 23, 2014.

Hotus Pate, Puaru. Rapanui singer and theatre practitioner. Interview/Talanoa with Moira Fortin in Rapa Nui. August 07, 2014.

Hotus Salinas, Julio. Rapanui musician and member of Consejo Nacional de la Cultura y las Artes (CNCA). Interview/Talanoa with Moira Fortin in Rapa Nui. August 19, 2014.

Hotus Tuki, Marta. Former Governor of Rapa Nui. Interview/Talanoa with Moira Fortin in Rapa Nui. July 24, 2014.

Huke, Karlo. Rapanui artist, sculptor and former member of Mata Tu'u Hotu Iti theatre group. Interview/Talanoa with Moira Fortin in Rapa Nui. December 20, 2011.

Huke, Pamela. Rapanui artist and former member of Mata Tu'u Hotu Iti theatre group. Interview/Talanoa with Moira Fortin in Rapa Nui. January 20, 2009.

Hyland, Nicola. Māori actress and lecturer in Theatre Studies at Victoria University. Interview/Talanoa with Moira Fortin in Wellington. February 03, 2015.

Iturbe, Patricia. Chilean journalist and creative writing teacher at Aldea Educativa high school. Interview/Talanoa with Moira Fortin on Skype. July 21, 2015.

Kouka, Hone. Māori playwright, actor, director and producer of Tawata Productions. Interview/Talanoa with Moira Fortin in Wellington. May 01, 2015

Lillo Haoa, Carlos. Rapanui musician, theatre practitioner and theatre tutor at Aldea Educativa high school. Interview/Talanoa with Moira Fortin in Rapa Nui. July 29, 2014.

Lualua, Tupe. Samoan dancer and theatre practitioner. Interview/Talanoa with Moira Fortin in Wellington. April 08, 2014.

Madariaga Paoa, Cristian. Rapanui teacher and member of the Rapanui Language Academy. Interview/Talanoa with Moira Fortin in Rapa Nui. February 28, 2009.

Manusaute, Vela. Niuean/Samoan actor and playwright, founder of Kila Kokonut Krew theatre company. Interview/Talanoa with Moira Fortin in Auckland. October 02, 2014.

McCallum, Rua. Māori theatre practitioner teacher of the bicultural theatre paper at Otago University. Interview/Talanoa with Moira Fortin in Dunedin. April 24, 2014.

Merino Rapu, Vai Tiare. Rapanui dancer, former theatre student at Universidad Católica. Interview/Talanoa with Moira Fortin in Rapa Nui. August 22, 2014.

Moreno Pakarati, Cristian. Rapanui historian, scholar and tour guide in Rapa Nui. Interview/Talanoa with Moira Fortin in Rapa Nui. August 08, 2014.

Muagututi ‘a, Mishelle. Samoan dancer, actress and member of Pacific Underground. Interview/Talanoa with Moira Fortin in Wellington. April 11, 2014. 
Muagututi'a, Tanya. Samoan actress and manager of Pacific Underground.

Interview/Talanoa with Moira Fortin in Auckland. October 01, 2014.

Oñate, Macarena. Chilean citizen member of the Rapanui community and director at the CNCA liaison office in Rapa Nui. Interview/Talanoa with Moira Fortin in Rapa Nui. July $18,2014$.

Pakarati, Felipe. Rapanui elder and storyteller. Interview/Talanoa with Moira Fortin in Rapa Nui. February 15, 2009.

Pakarati Gula, Miriam. Rapanui dancer. Interview/Talanoa with Moira Fortin in Rapa Nui. August 06, 2014.

Pate Tuki, Tuvalu. Rapanui dancer. Interview/Talanoa with Moira Fortin in Rapa Nui. August 13, 2014.

Peleasa, Taofia. Actor of Tokelauan heritage, performing in Black Faggot by Victor Rodger. Interview/Talanoa with Moira Fortin in Wellington. March 01, 2014.

Polataivao, Anapela. Samoan actor, director, producer and founder of Kila Kokonut Krew theatre company. Interview/Talanoa with Moira Fortin in Auckland. October 03, 2014.

Pont Chamorro, Angie. Rapanui dancer and administrator of Servicio Nacional del Turismo (SERNATUR) in Rapa Nui. Interview/Talanoa with Moira Fortin in Rapa Nui. August 04, 2014.

Quiroga Saavedra, Claudia. Chilean citizen former member of the Rapanui community. Interview/Talanoa with Moira Fortin in Blenheim. July 23, 2009.

Rapu Drago, Vai a Heva. Rapanui dancer and instructor at Dance Academy Ori Rapa Nui. Interview/Talanoa with Moira Fortin in Rapa Nui. July 31, 2014.

Rapu Tuki, Lynn. Rapanui artists and head of Kari Kari Cultural Ballet. Interview/Talanoa with Moira Fortin in Rapa Nui. January 25, 2009.

Ringeling, Katherine. Chilean citizen member of the Rapanui community and head of Aldea Educativa high school. Interview/Talanoa with Moira Fortin in Rapa Nui. August 01, 2014.

Taylor, Rangimoana. Māori actor and kaukmatua. Interview/Talanoa with Moira Fortin in Wellington. May 02, 2014.

Te Ua, Kereama. Māori performer and tutor of Kapa Theatre at Whitireia. Interview/Talanoa with Moira Fortin in Wellington. July 25, 2015.

Teave, Mahani. Rapanui pianist, director of Toki music school. Interview/Talanoa with Moira Fortin in Rapa Nui. August 19, 2014. 
Tramon, Barbara. Chilean citizen member of the Rapanui community and psychologist at Colegio Católico in Rapa Nui. Interview/Talanoa with Moira Fortin in Rapa Nui. August 12, 2014.

Tramon, Gabriel. Chilean citizen member of the Rapanui community and former camera man at the local TV Chanel Mata O Te Rapa Nui. Interview/Talanoa with Moira Fortin in Rapa Nui. August 12, 2014.

Tuki Pate, Benedicto. Rapanui sculptor. Interview/Talanoa with Moira Fortin in Rapa Nui. July 28, 2014.

Ubal, Andrea. Chilean actress and lecturer in Theatre Studies at Universidad Católica. Interview/Talanoa with Moira Fortin in Santiago. September 08, 2014.

Urale, Makerita. Samoan producer and playwright. Interview/Talanoa with Moira Fortin in Wellington. April 22, 2014.

Vergara, Alexei. Chilean actor and head of school of Theatre Studies at Universidad Católica. Interview/Talanoa with Moira Fortin in Santiago. September 11, 2014.

Vilches, Isabel. Chilean Spanish teacher who facilitated creative writing workshops at Colegio Católico in Rapa Nui. Interview/Talanoa with Moira Fortin on Skype. July 25, 2015.

Villanueva Tuki, Mario. Rapanui musician. Interview/Talanoa with Moira Fortin in Rapa Nui. August 04, 2014.

Zamora Rapu, Annette. Rapanui teacher and head of primary school Liceo Lorenzo Baeza Vega in Rapa Nui. Interview/Talanoa with Moira Fortin in Rapa Nui. August 14, 2014. 